\title{
False positives or hidden dimensions : the definition and measurement of child poverty
}

Citation for published version (APA):

Roelen, K. C. H. (2010). False positives or hidden dimensions : the definition and measurement of child poverty. [Doctoral Thesis, Maastricht University]. Boekenplan. https://doi.org/10.26481/dis.20100709kr

Document status and date:

Published: 01/01/2010

DOI:

10.26481/dis.20100709kr

Document Version:

Publisher's PDF, also known as Version of record

\section{Please check the document version of this publication:}

- A submitted manuscript is the version of the article upon submission and before peer-review. There can be important differences between the submitted version and the official published version of record.

People interested in the research are advised to contact the author for the final version of the publication, or visit the DOI to the publisher's website.

- The final author version and the galley proof are versions of the publication after peer review.

- The final published version features the final layout of the paper including the volume, issue and page numbers.

Link to publication

\footnotetext{
General rights rights.

- You may freely distribute the URL identifying the publication in the public portal. please follow below link for the End User Agreement:

www.umlib.nl/taverne-license

Take down policy

If you believe that this document breaches copyright please contact us at:

repository@maastrichtuniversity.nl

providing details and we will investigate your claim.
}

Copyright and moral rights for the publications made accessible in the public portal are retained by the authors and/or other copyright owners and it is a condition of accessing publications that users recognise and abide by the legal requirements associated with these

- Users may download and print one copy of any publication from the public portal for the purpose of private study or research.

- You may not further distribute the material or use it for any profit-making activity or commercial gain

If the publication is distributed under the terms of Article $25 \mathrm{fa}$ of the Dutch Copyright Act, indicated by the "Taverne" license above, 


\section{FALSE POSITIVES OR HIDDEN DIMENSIONS}

The Definition and Measurement of Child Poverty 


\section{(C) 2010 Keetie Roelen}

Published by Boekenplan, Maastricht

\section{ISBN 9789086661541}

All rights reserved. No part of this publication may be reproduced, stored on a retrieval system, or transmitted in any form, or by any means, electronic, mechanical, photocopying, recording or otherwise, without the prior permission in writing, from the author. 


\title{
False Positives or Hidden Dimensions the definition and measurement of child poverty
}

\author{
DISSERTATION
}

to obtain the degree of Doctor at the Maastricht University, on the authority of the Rector Magnificus, Prof. dr. G. P. M. F. Mols,

in accordance with the decision of the Board of Deans, to be defended in public on Friday 9 July 2010, at 10:00 hours

by Keetie Catharina Huberdina Roelen 
Supervisor: $\quad$ Prof. dr. Chris. de Neubourg

Co-supervisor: Dr. Franziska Gassmann

Assessment Committee: Prof. dr. Luc Soete (chairman)

Dr. Kristof Bosmans

Prof. dr. Jane Falkingham, University of Southampton

Dr. Chris Leonards

Prof. dr. Jan Vranken, University of Antwerp 


\section{ACKNOWLEDGMENTS}

This dissertation has my name on its cover but its completion wouldn't have been possible without the support of many. I am happy to have the opportunity here to acknowledge those that have made this happen.

First of all, I would like to extent my gratitude to my supervisors, Chris and Franziska. Thank you for your perseverance and finally convincing me that $\mathrm{PhD}$ research does not have to be pursued in solitude behind a computer in a university office. And thank you even more for creating the possibilities to live up to that premise. My cooperation with you during my $\mathrm{PhD}$ will be remembered by the many work- as well as non work-related activities. Chris, I am grateful for the freedom you gave me to try out different tasks at the School and your full support throughout the years in pursuing those. Also, biking through the hutongs of Beijing and enjoying great food in Florence will belong to the memorable non-work activities! Franziska, thank you for all your valuable advice concerning research and project work and for including me in all those interesting opportunities. Cruising Halong Bay in Vietnam and drinking macchiato's in Kosovo are amongst my many fond memories of our trips together, which I hope will not end with the finalization of this dissertation!

I am also grateful to UNICEF Vietnam; not only for making this research possible but also for making it such an interesting and enjoyable experience. Van Anh, Dan, Geeta, Paul, Ngoc, Tam and other colleagues at the Social Policy section, thank you for your cooperation and introduction to Vietnam and its people (and food!). I look back at a very pleasant time spent in your section and numerous return visits and hope to come back again in the future! I would also like to thank MOLISA and GSO for the fruitful cooperation and support throughout the whole project. Two other persons also deserve special mention in this book, as they played an important role in shaping the research by providing comments and feedback. Geranda and Martin Evans, thank you for reading draft papers and improving my work!

Although I am happy I got to spend a lot of time out and about, I am also very grateful for the great atmosphere when I was at the School. The many morning coffees with the "downstairs ladies" were always a good start of the day and chats with all $\mathrm{PhD}$ fellows during seminar lunches and cake sessions or at the copy machine presented a welcome break from work. Lina, Robert, Metka and Renée, it was great sharing offices with you. Martin and Floor, well before we made it to "corridor-mates", we already moved beyond being just colleagues. And that made being in the same corridor even more fun! Sepideh, your courage and your passion for a better world is admirable and an example for many. Maha, your stories and laughter can turn any bad day into a good one and I'm grateful I got to enjoy your company in and outside of the School in these last years! Finally, a special mention goes out to Charlotte and Esther. Finding such true friends and "Himmel Schwestern" is more than I could have wished for when I started working at the School.

A gross shortcoming of my own research in this dissertation is that I fail to discuss the importance of family and friends for one's well-being. Let me correct myself here 
and state that they are not only an important dimension but rather a key to wellbeing. Thank you to my family and friends for being in my life. Riny, Ger, Marjolein and Robert Jan, it's great to be part of the Rienties-family now as well! Annemarie, Esther, David, Emmy, Katrien, Kim, Nicolle and Valerie, you have shared happy and some more difficult times with me in these last few years, most of which had nothing to do with this dissertation but were still far more important. I am grateful to have you around and hope to have this pleasure for many more years to come!

En als laatste een dankwoord aan degenen zonder wie dit proefschrift er echt nooit was gekomen. Papa, mama en Ruud, dankjewel voor jullie steun en vertrouwen in alles wat ik wilde doen; in Maastricht studeren, ver weg naar Afrika en daarna ook nog eens aan een proefschrift beginnen. Zonder die steun en vertrouwen had ik het nooit tot hier gebracht! En zo ook niet zonder mijn man: de stoere motormuis, harde fietser, ambitieuze onderzoeker, geboren komiek en positieve denker. Maar vooral mijn Meneer Bart. Samen met jou is geen berg te hoog en is de beklimming ervan nog een groot plezier ook! Samen sterk en samen voor elkaar. 


\section{LIST OF PUBLICATIONS}

\section{Peer-reviewed journal and book publications}

Roelen, Keetie and Franziska Gassmann (20xx) Multidimensional Child Poverty in Vietnam - a case study in A. Minujin (Eds) Child Poverty: A global perspective, Policy Press, forthcoming

Roelen, Keetie (2010) Child poverty - what's in a word? in Vandenhole, W., Vranken, J. and K. De Boyser (Eds) Children's Rights and Poverty, Intersentia Publishing, forthcoming

Roelen, Keetie (2010) Social Welfare in Vietnam - a curse or a blessing for poor children?, Asian Social Work and Policy Review, forthcoming

Roelen, Keetie, Franziska Gassmann (2009) Equal Opportunities for all children in Vietnam - Assessing the distribution of child poverty from a monetary and multidimensional perspective, Journal of Income Distribution 18(3-4) 206-231

Neubourg, Chris de, Keetie Roelen and Franziska Gassmann (2009) Making Poverty Analyses Richer - Multidimensional poverty research for policy design in Boyser, K., C. Dewilde, D. Dierckx and J. Friedrichs (Eds) Between the Social and the Spatial Exploring Multiple Dimensions of Poverty and Social Exclusion, Ashgate Publishing, pp 35-56

Roelen, Keetie, Franziska Gassmann and Chris de Neubourg (2009) Child Poverty in Vietnam - providing insights using a country-specific and multidimensional model, Social Indicators Research, DOI: 10.1007/s11205-009-9522-X

Roelen, Keetie, Franziska Gassmann and Chris de Neubourg (2009) The Importance of Choice and Definition for the Measurement of Child Poverty-the case of Vietnam, Child Indicators Research, 2(3) 245-263

\section{Working Papers}

Roelen, Keetie, Franziska Gassmann and Chris de Neubourg (2009) False Positives or Hidden Dimensions- What can monetary and multidimensional measurement tell us about child poverty?, MGSoG WP 2009/015, Maastricht

Roelen, Keetie, Franziska Gassmann and Chris de Neubourg (2009) Child Poverty in Vietnam - providing insights using an country-specific and multidimensional model, MGSoG WP 2009/001, Maastricht

Roelen, Keetie, Franziska Gassmann and Chris de Neubourg (2008) A global measurement approach versus a country-specific measurement approach - Do they draw the same picture of child poverty? The case of Vietnam, Maastricht Graduate School of Governance Working Paper, MGSoG WP 2008/005, Maastricht

Roelen, Keetie and Franziska Gassmann (2008) Measuring Child Poverty and WellBeing: a literature review, Maastricht Graduate School of Governance Working Paper, MGSoG WP 2008/001, Maastricht

Neubourg, C. de, Castonguay, J. and K. Roelen (2007) Social Safety Nets and Targeted Social Assistance: Lessons from the European Experience, SP Discussion Paper, No 0718, World Bank, Washington DC 


\section{Reports}

Roelen, K. and F. Gassmann (2009), Impact of Social Assistance Cash Benefit Scheme on Children in Kosovo - a report to UNICEF Kosovo, UNICEF Kosovo, Pristina

Roelen K., F. Gassmann and C. de Neubourg (2008), Children in Viet Nam - Who and Where are the poor? The development and application of a multidimensional approach to child poverty, UNICEF Vietnam, Hanoi. 


\section{CONTENTS}

Chapter 1 INTRODUCTION

1.1 INTRODUCTION 2

1.2 WHY MEASURE CHILD POVERTY?

1.3 AN ACCOUNT OF THE EXISTING APPROACHES FOR CHILD POVERTY

MEASUREMENT

1.4 RESEARCH QUESTIONS $\quad 6$

1.5 STRUCTURE 8

Chapter 2 THE IMPORTANCE OF CHOICE AND DEFINITION FOR THE

MEASUREMENT OF CHILD POVERTY - THE CASE OF VIETNAM 9

2.1 INTRODUCTION 10

2.2 Generic Construction Process 11

2.3 CHOICE AND DEFINITION IN EXISTING CHILD POVERTY APPROACHES 14

2.4 METHODOLOGY AND DATA 16

2.5 DEVELOPMENT OF A VIETNAM-SPECIFIC APPROACH 16

2.5.1 Choice one - Rationale and Purpose 16

2.5.2 Choice two - Concept 17

2.5.3 Choice three - Domains 18

2.5.4 Choice four - Indicators 19

2.5.5 Choice five - Outcome Products 21

2.6 EMPIRICAL RESULTS $\quad 23$

$\begin{array}{ll}2.7 \text { CONCLUSION } & 27\end{array}$

Chapter 3 CHILD POVERTY IN VIETNAM - PROVIDING INSIGHTS USING A COUNTRY-SPECIFIC AND MULTIDIMENSIONAL MODEL 29

$\begin{array}{ll}3.1 \text { INTRODUCTION } & 30\end{array}$

3.2 CONCEPTUAL FRAMEWORK 31

3.3 IDENTIFICATION AND AGgREgATION 32

$\begin{array}{ll}3.4 \text { DATA } & 36\end{array}$

3.5 Child Poverty Incidence, Depth And SEverity 36

3.6 GROUPS OF CHILD POVERTY $\quad 44$

3.7 CONCLUSION 46

$\begin{array}{ll}3.8 \text { ANNEXES } & 47\end{array}$

3.8.1 Annex 1 Exact definitions individual child poverty indicators as
based on MICS

Chapter 4 EQUAL OPPORTUNITIES FOR ALL CHILDREN IN VIETNAM? -ASSESSING THE DISTRIBUTION OF CHILD POVERTY FROM A MONETARY AND

\section{MULTIDIMENSIONAL PERSPECTIVE}

4.1 INTRODUCTION 52

4.2 MONETARY AND MULTIDIMENSIONAL CHILD POVERTY 53

4.3 INDIVIDUAL AND HOUSEHOLD CHARACTERISTICS

4.4 METhODOLOGY AND Data $\quad 57$

4.4.1 VHLSS $2006 \quad 57$ 
4.4.2 Methodology 58

4.5 UNCONDITIONAL POVERTY PROFILE

$\begin{array}{ll}4.6 & \text { CONDITIONAL POVERTY PROFILE }\end{array}$

$\begin{array}{ll}4.7 \text { CONCLUSION } & 70\end{array}$

$\begin{array}{ll}4.8 \text { ANNEXES } & 72\end{array}$

4.8.1 Annex 1 Domains and indicators multidimensional child poverty

$\begin{array}{ll}\text { approach as based on VHLSS } & 72\end{array}$

Chapter 5 MAKING POVERTY ANALYSES RICHER - MULTIDIMENSIONAL POVERTY RESEARCH FOR POLICY DESIGN

$\begin{array}{ll}5.1 \text { INTRODUCTION } & 76\end{array}$

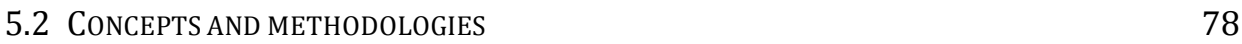

5.3 MONETARY POVERTY AND DOMAIN POVERTY RATES FOR CHILDREN IN VIETNAM 79

5.4 MONETARY POVERTY AND DOMAIN POVERTY RATES FOR ADULTS IN CONGO 83

5.5 MAKING POVERTY ANALYSES RICHER BY PROVIDING MORE DETAILED INFORMATION TO POLICY DESIGNERS $\quad 84$

$\begin{array}{ll}5.6 \text { CONCLUSION } & 91\end{array}$

Chapter 6 FALSE POSITIVES OR HIDDEN DIMENSIONS - WHAT CAN MONETARY AND MULTIDIMENSIONAL MEASUREMENT TELL US ABOUT CHILD POVERTY? 93

6.1 INTRODUCTION 94

6.2 Monetary ANd Multidimensional Child POVERTy 95

6.3 Data AND METHODOLOGY 97

6.3.1 VHLSS $2006 \quad 97$

6.3.2 Methods of Analysis 98

6.4 Comparing Monetary and Multidimensional Poverty MEasurement 101

6.5 GROUPS OF POVERTY 107

6.6 DRIVERS OF POVERTY MiSMATCH 111

6.7 CONCLUSION 119

Chapter 7 SOCIAL WELFARE IN VIETNAM - A CURSE OR BLESSING FOR POOR CHILDREN?

\section{3}

$\begin{array}{ll}7.1 \text { INTRODUCTION } & 124\end{array}$

7.2 SOCIAL TRANSFERS IN VIETNAM $\quad 125$

7.3 DATA AND METHODS OF ANALYSIS 126

$\begin{array}{ll}\text { 7.3.1 VHLSS } 2006 & 126\end{array}$

$\begin{array}{ll}\text { 7.3.2 Methods of Analysis } & 127\end{array}$

$\begin{array}{ll}7.4 \text { CHILD POVERTY IN VIETNAM } & 128\end{array}$

7.5 COVERAGE AND INCLUSION ERRORS OF SOCIAL WELFARE 130

7.6 SOCIAL WELFARE AND ITS IMPACT ON CHILD POVERTY 139

$\begin{array}{ll}7.7 \text { CONCLUSION } & 140\end{array}$

$\begin{array}{ll}\text { Chapter } 8 \text { CONCLUSION } & 143\end{array}$

8.1 UNDER WHAT CONDITIONS CAN CHILD POVERTY APPROACHES BE DEVELOPED
AND USED?

8.2 WHAT IS THE STATE OF CHILD POVERTY IN VIETNAM? 145

8.3 TO WHAT EXTENT DO MONETARY AND MULTIDIMENSIONAL APPROACHES OF CHILD POVERTY DIFFER WITH RESPECT TO CONCEPTUAL AND EMPIRICAL OUTCOMES? 
False Positives or Hidden Dimensions | xi

8.3.1 Monetary versus multidimensional child poverty - implications for poverty analysis

8.3.2 Monetary versus multidimensional child poverty - what does it mean for policy analysis?

8.4 FUTURE RESEARCH

9 References

151

10 Samenvatting

161

11 Biography

165

12 MGSoG Dissertation Series

166 


\section{LIST OF TABLES}

TABLE 2.1 SELECTED DOMAINS

TABLE 2.2 INDICATORS OF THE VIETNAM CHILD POVERTY APPROACH BASED ON MICS 2006 DATA

TABLE 2.3 CHILD VULNERABILITY TO POVERTY RATES

TABLE 2.4 REGIONAL RANKINGS (= BASED ON INDICATOR DISTANCE FROM 0\% AS REFERENCE VALUE)

TABLE 3.1 INDICATORS OF THE VIETNAM CHILD POVERTY APPROACH

TABLE 3.2 INDICATOR POVERTY INCIDENCE RATES BY DEMOGRAPHIC GROUP FOR EDUCATION, HEALTH AND SHELTER

TABLE 3.3 INDICATOR POVERTY INCIDENCE RATES BY DEMOGRAPHIC GROUP FOR WATER AND SANITATION, WORK, LEISURE, SOCIAL INCLUSION

TABLE 3.4 CHILD DEPRIVATION AND POVERTY INCIDENCE RATES BY DEMOGRAPHIC GROUPS

TABLE 3.5 OVERLAP DOMAIN POVERTY AND CORRELATION MATRIX

TABLE 3.6 CHILD POVERTY DEPTH AND SEVERITY

TABLE 3.7 POVERTY GROUPS AND THEIR DEGREE OF POVERTY

TABLE 3.8 DISTRIBUTION OF POVERTY AND DOMAIN POVERTY RATES IN THE POOREST QUINTILE

TABLE A3.1 EXACT DEFINITIONS SELECTED INDICATORS BASED ON MICS DATA

TABLE 4.1 DOMAINS AND INDICATORS OF THE MULTIDIMENSIONAL CHILD POVERTY

TABLE 4.2 UNCONDITIONAL CHILD POVERTY PROFILE FOR INDIVIDUAL CHARACTERISTICS

TABLE 4.3 DOMAIN POVERTY FOR CHILDREN IN URBAN AND RURAL AREAS

TABLE 4.4 UNCONDITIONAL CHILD POVERTY PROFILE FOR HOUSEHOLD CHARACTERISTICS

TABLE 4.5 CONDITIONAL POVERTY PROFILE - MARGINAL EFFECTS OF INDIVIDUAL AND HOUSEHOLD CHARACTERISTICS

TABLE 4.6 DOMAIN POVERTY RATES FOR SELECTED DEMOGRAPHIC GROUPS

TABLE A4.1 EXACT DEFINITIONS SELECTED INDICATORS BASED ON VHLSS DATA

TABLE 5.1 MONETARY AND DOMAIN CHILD POVERTY RATES FOR VIETNAM

TABLE 5.2 CORRELATION BETWEEN MONETARY AND MULTIDIMENSIONAL POVERTY,

TABLE 5.3 POVERTY INCIDENCE PER DOMAIN: CONGO 2005.

TABLE 5.4: ADULT WOMEN AND MEN SIMULTANEOUSLY MONETARY POOR AND DEPRIVED IN ONE OF SIX DOMAINS, CONGO 2005

TABLE 5.5 PROPORTIONS OF CHILDREN EXPERIENCING POVERTY IN TWO DOMAINS, VIETNAM 2006

TABLE 5.6 PROPORTIONS OF CHILDREN EXPERIENCING POVERTY IN TWO DOMAINS, CONGO 2005

TABLE 5.7 PROPORTIONS OF ADULT WOMEN EXPERIENCING POVERTY IN TWO DOMAINS: CONGO 2005

TABLE 5.8 PROPORTIONS OF ADULT MEN EXPERIENCING POVERTY IN TWO DOMAINS: CONGO 2005 
TABLE 6.1 MONETARY AND MULTIDIMENSIONAL POVERTY

TABLE 6.2 ADJUSTED MONETARY AND MULTIDIMENSIONAL POVERTY BY DEMOGRAPHIC GROUPS

TABLE 6.3 CORRELATION MONETARY AND MULTIDIMENSIONAL POVERTY

TABLE 6.4 CROSS TABULATIONS OF MULTIDIMENSIONAL

TABLE 6.5 POVERTY RATES FOR DEMOGRAPHIC CHARACTERISTICS AS A PROPORTION OF CHILDREN IN SPECIFIC POVERTY GROUP

TABLE 6.6 DOMAIN POVERTY RATES BY POVERTY GROUP

TABLE 6.7 MULTINOMIAL REGRESSION POVERTY GROUPS

TABLE 7.1 POVERTY IN VIETNAM

TABLE 7.2 CHILD POVERTY IN VIETNAM

TABLE 7.3 COVERAGE OF INFORMAL TRANSFERS, SOCIAL INSURANCE AND SOCIAL WELFARE

TABLE 7.4 DISTRIBUTION OF SOCIAL WELFARE AND POVERTY OVER DEMOGRAPHIC GROUPS OF CHILDREN

TABLE 7.5 INCLUSION ERROR OF SOCIAL WELFARE

TABLE 7.6 DISTRIBUTION OF SOCIAL WELFARE

TABLE 7.7 MULTINOMIAL REGRESSION RESULTS CHILD POVERTY AND SOCIAL WELFARE 


\section{LIST OF FIGURES}

FIGURE 2.1 GENERIC CONSTRUCTION PROCESS OF CHILD POVERTY APPROACHES

FIGURE 3.1 SENSITIVITY PLOT POVERTY RATES FOR DIFFERENT CUT-OFF POINTS

FIGURE 5.1 NORMALIZED PER CAPITA EXPENDITURES FOR ALL CHILDREN AND CHILDREN DEPRIVED IN THE HEALTH DOMAIN, VIETNAM 2006

FIGURE 5.2: NORMALIZED PER CAPITA EXPENDITURES FOR MONETARY POOR CHILDREN AND CHILDREN DEPRIVED IN THE HEALTH DOMAIN, VIETNAM 2006

FIGURE 5.3 PROPORTION OF HEALTH DEPRIVED CHILDREN BY INCOME QUINTILE, VIETNAM 2006

FIGURE 5.4 OVERLAP BETWEEN THE MONETARY, EDUCATION AND CHILD LABOUR POVERTY, CHILDREN CONGO 2005

FIGURE 6.1 DISTRIBUTION OF NORMALIZED INCOME FOR MULTIDIMENSIONALLY POOR AND NON-POOR

FIGURE 6.2 PROPORTION OF MULTIDIMENSIONALLY POOR CHILDREN BYINCOME QUINTILE

FIGURE 6.3 ROC CURVE FOR MONETARY POVERTY AS A TEST FOR MULTIDIMENSIONAL POVERTY

FIGURE 6.4 VENN DIAGRAM OVERLAP MULTIDIMENSIONAL AND MONETARY POVERTY

FIGURE 6.5 INCOME DISTRIBUTION POVERTY GROUPS A AND C

FIGURE 6.6 INCOME DISTRIBUTION POVERTY GROUPS B AND AB

FIGURE 6.7 MONETARY AND MULTIDIMENSIONAL POVERTY DEPTH BY POVERTY GROUP

FIGURE 7.1 COVERAGE, EXCLUSION AND INCLUSION OF SOCIAL WELFARE IN TERMS

FIGURE 7.2 COVERAGE, EXCLUSION AND INCLUSION OF SOCIAL WELFARE IN TERMS OF MULTIDIMENSIONAL POVERTY 
False Positives or Hidden Dimensions $\mid \mathbf{1}$

Chapter 1 INTRODUCTION 


\subsection{Introduction}

Despite the wide acknowledgement that no child should grow up in poverty, many children around the world live in poor households and miserable conditions. Research efforts to translate children's specific situation into appropriate concepts and estimates are limited and relatively new; efforts to incorporate these concepts and estimates in policy design, policy monitoring and policy evaluation are even rarer. As a result, the living conditions of many children are ill-documented and the related problems go unnoticed or underestimated by analysts and politicians alike. This study fills this gap by developing, applying and studying the use of a multidimensional approach to child poverty that is analytically sound, relatively easy to understand and delivering relevant information for policy design and evaluation. It addresses the need for more adequate information, which helps to understand the nature of child poverty and assists policy designers to formulate effective policy responses. Inherent to the production of more information is the tension between different approaches to define and measure the issue of child poverty and to document who is poor and who is not. There are various reasons for choosing one versus the other poverty approach; these reasons are discussed at length later in this study. The main argument, however, is important in the light of this introduction and is summarized by the questions: Are those children identified as poor by one of those approaches "false positives" in terms of other definitions of poverty? Or does their situation suffer from "hidden dimensions" that are not revealed or incorporated by other poverty definitions?

The study addresses a number of gaps in the literature by providing an in-depth discussion of theoretical issues inherent to (child) poverty measurement and an applied analysis using Vietnam as a primary country case study. It intends to answer not merely questions concerning the magnitude and pattern of child poverty and the mismatch of information provided by different poverty approaches, but also to explore the various conditions under which children in Vietnam live and in which domains children are deprived of decent living conditions. The study discusses the various approaches to child poverty from a theoretical perspective, analyses the data for Vietnam empirically and links the outcomes of both parts to the policy debate. It has been the ambition to go beyond the mere academic interest of the theoretical and empirical debates and to provide useful instruments and analyses for practitioners and policy makers. It is only through policy that this academic study can actually contribute to making the world for children a better place to live in.

This book is a collection of (published) articles; this implies that each chapter is can be read as a stand-alone piece of work. However, it also means that some overlap between the chapters is inevitable. To guide the reader, sections that show considerable overlap with sections in previous chapters are clearly signposted by means of footnotes.

\subsection{Why measure child poverty?}

Poverty is an undesirable and, to many, an unacceptable phenomenon. An extensive body of research has shown that the hardship of poverty is even more undesirable when it concerns children due to its far-reaching short-term and long-run negative implications (see e.g. Haveman and Wolfe, 1995; Brooks-Gunn and Duncan, 


\section{False Positives or Hidden Dimensions | $\mathbf{3}$}

1997; Duncan and Brooks-Gunn, 1997; Esping-Andersen and Sarasa, 2002). Children growing up in a poor or low-income family are more likely to receive poorer health care (Duncan and Brooks-Gunn, 1997), to obtain lower educational outcomes (Haveman and Wolfe, 1995; Brooks-Gunn and Duncan 1997; Esping-Andersen, 2002) and to reach lower levels of attainment in the labour market (Haveman and Wolfe, 1995; Esping-Andersen and Sarasa, 2002). Children living in poverty are also more likely to grow up to become poor adults (Esping-Andersen and Sarasa, 2002; Corak, 2006a). Effects are more pronounced for those children that experience persistent poverty and live in poor and vulnerable conditions for a number of consecutive years (Brooks-Gunn and Duncan, 1997; Duncan and Brooks-Gunn, 1997). The importance of tackling the issue of child poverty is further underlined by the fact that it does not only have a negative impact on children themselves but also on the society as a whole (Esping-Andersen and Sarasa, 2002). As a result, there is increasing acknowledgment that children deserve particular attention when designing, implementing and evaluating efforts to reduce poverty (Ben-Arieh, 2000).

In order to adequately analyze and investigate the issue of child poverty, childfocused approaches are required. Several reasons can be put forward for the need to define and analyze child poverty in a different form from general or adult poverty (Minujin, Delamonica, Gonzalez and Davidziuk, 2005). A first reason is that children are largely dependent on their direct environment for the provision of their basic needs. Since they are not independent economic actors themselves, they rely on the distribution of resources by their parents, household or community members. Childfocused poverty measures are crucial to account for the within-household distribution and poverty at the child-specific level (e.g. White, Leavy and Masters, 2002). Secondly, children are affected differently by poverty than adults since their basic human needs are different. Children have different dietary requirements, for example, and the role of education is vital during their stage of life (e.g. Brooks-Gunn and Duncan, 1997; Waddington, 2004). A child-specific approach can incorporate those special needs and consequently reflect on and emphasize them. A third reason can be found within the discourse on child rights. The development of the children's right concept instigated the development of child poverty approaches that are geared to reflect the premise that children should be treated as an autonomous group and in their own right as individual human beings (Ben-Arieh, 2000; Redmond 2008). Finally, a generally accepted and workable definition and measurement method of child poverty is an important tool for both academics and policy makers. It does not merely offer the opportunity to gain an insight into children's poverty status but also gives the possibility to formulate and monitor sound poverty reduction objectives, strategies and policies (e.g. Ben-Arieh, 2000; Minujn et al. 2005; Corak, 2006). In sum, there is a strong case to advance the field of and extend the body of research on poverty definitions and measures that are specifically geared towards children, thereby acknowledging the far-reaching negative implications of child poverty and taking into account their specific needs and characteristics. 


\subsection{An account of the existing approaches for child poverty measurement ${ }^{1}$}

In the last decade, the body of research concerning child-focused poverty approaches has experienced an, albeit limited, increase in both scope and depth. This section aims to provide an account of the various approaches that have been developed in recent years to gain insight into the range and scope of approaches available and their different characteristics. Taking stock of the existing range of literature and its various characteristics provides valuable and crucial information for further development of this field of expertise. The existing approaches for the measurement of child poverty can be considered to vary along a number of aspects, which include objective, concept, resource base and poverty measure.

The objective of a given child poverty measure has strong implications for the way in which child poverty is consequently conceptualized, defined and measured (Laderchi, Saith and Stewart, 2003; Roelen, Gassmann and de Neubourg, 2009a). A review of literature indicates that objectives can differ along the dimensions of space (cross-country versus within-country) and time (longitudinal versus static), which has its reflection on the operationalization of poverty approaches (Ravallion, 1994; Alkire, $2002,2008)$. In terms of space, there is a range of approaches that aim to analyze child poverty in a cross-comparative context whilst others focus on single countries. Crosscountry studies of child poverty include those by Bradbury and Jäntti (2001), Gordon, Nandy, Patazis, Pemberton and Townsend (2003a, 2003b), Bradshaw, Hoelscher and Richardson (2006), Save the Children (2008) and Richardson, Hoelscher and Bradshaw (2008). Whilst Gordon et al. (2003a, 2003b) focus on developing countries, Bradshaw et al. (2006) focus on countries in the EU and Richardson et al. (2008) on the CEE/CIS countries. Save the Children (2008) takes a global perspective, incorporating countries from around the world. Taking such a cross-country comparative focus implies that data on the same set of issues has to be available for all countries, the choice of domains and indicators has to present an adequate reflection of child poverty in all countries and that thresholds have to be defined meaningfully for all countries under consideration. Studies aiming to capture and explain withincountry variation of child poverty are not bound by these considerations and can rely on country-specific data, reflecting issues that are relevant in the national context. A few examples of studies focused on measuring child poverty in a specific country include the work by Noble, Wright and Cluver (2006) and Barnes, Wright, Noble and Dawes (2007) in South Africa and Land, Lamb and Mustillo (2001) in the United States. With respect to the time dimension, the majority of studies do not have the special objective of capturing the dynamics of poverty. Although they might end up tracking child poverty over time, they were not designed with that special purpose in mind. The studies by Land et al. (2001) and Land (2005) present an exception as they aim to capture the trends of child well-being in the US. The child well-being approach was developed with the specific objective to monitor changes in child and youth wellbeing in the US benchmarked against the base year 1975 (Land et al., 2001; Land,

1 This section is based on the literature review of child poverty approaches by Roelen and Gassmann (2008). 


\section{False Positives or Hidden Dimensions | 5}

2005). This specific objective is clearly reflected in the concurrent choice of methodology and poverty measures.

The conceptualization of child poverty is an aspect that also has far-reaching implications for the design and operationalization of poverty approaches. The debate on how to conceptualize the issue of child poverty is long-standing and on-going and can be characterized by two schools of thought, namely child well-being and child well-becoming (see Ben-Arieh, 2000; White, 2002). Whilst those focusing on child well-becoming support the notion that children should be prepared for the future and adult life, the proponents of child well-being advocate the idea that childhood is a state in and of itself (see Ben-Arieh 2000). As discussed in section 1.2, there is widespread agreement that poverty during childhood has life-long adversary effects and damages the development of a child (see e.g. Haveman and Wolfe, 1995; BrooksGunn and Duncan, 1997; Duncan and Brooks-Gunn, 1997; Esping-Andersen and Sarasa, 2002). A denial of child well-being in the present thus hampers a child's wellbecoming in the future. The focus on child well-being in the present is not merely justifiable on the basis of its implications for the future but also because of its importance here and now (Ben-Arieh, 2000; Qvortrup, 1997). Qvortrup (1999) expresses the fear that a sole focus on child well-becoming "[...] justifies any type of life for children, provided the end result - that is, the adult person - exhibits positive values on a set of success criteria". The intrinsic importance of child well-being also follows the concept of children's rights (Ben-Arieh 2000) as stipulated in the Convention of the Rights of the Child (UNHCHR 1989). Despite the strong differentiation between the two theoretical concepts, they are used interchangeably or as complements in the majority of child poverty approaches. The approaches' conceptual frameworks attempt to make an implicit or explicit link between the interlinked issues of well-being, fulfilment of rights and development of children (see Gordon et al. 2003a, 2003b; Bradshaw et al., 2006; Noble et al. 2006; Richardson et al. 2008; Save the Children, 2008). The combination of the two schools of thought is not merely a result of conceptual reasoning but often also of pragmatic considerations. The available data frequently does not allow for the operationalization of child poverty approaches along the dichotic lines of either the theory of well-being or wellbecoming, culminating in a conceptual mixture.

The choice for the resource base to measure child poverty is a third aspect along which existing child poverty approaches differ. It refers to those aspects of children's lives that are deemed capable of reflecting their poverty status or level of well-being and can include monetary, basic-needs as well as subjective aspects. The choice for a specific resource base is highly normative and subject to value judgements (Ravallion, 1994; Alkire 2002, 2008; Corak 2006b) and differs from one child poverty approach to the other. Thinking of the range of resource bases along a continuum of dimensionality facilitates the discussion for the variety of existing child poverty approaches. The resource base can range from uni-dimensional to more multidimensional, basing the identification solely on the aspect of one dimension on the one hand or on multiple dimensions on the other hand. Child poverty approaches on the uni-dimensional end of the continuum are primarily represented by monetarybased poverty approaches (see Bradbury and Jäntti, 2001; Corak, 2006) whilst the majority of child poverty approaches have a more multidimensional focus (e.g. Land et al., 2001; Gordon et al., 2003a, 2003b; Bradshaw et al., 2006; Noble et al. 2006; Richardson et al. 2008; Save the Children, 2008). Examples of aspects included in the 
resources bases of these approaches include education, health, shelter, food, sanitation and social networks. The choice for the resource base can be considered a direct result of the defined objectives and concept of child poverty as the resource base aims to be a reflection of those aspects. In addition, the choice for resource base is also dependent on theoretical and methodological considerations.

The final aspect that differentiates the variety of child poverty approaches from each other is the way in which poor children are counted and the detailed-level information is aggregated into a composite number. The review of the existing child poverty approaches shows that they can roughly be divided in count and index measures on the basis of the aggregation methods used. The child poverty count measures are based on micro-data and "count" the number of poor children on the basis of the assessment of their individual resource bases. Examples of child poverty approaches taking such a micro-perspective include the studies by Bradbury and Jäntti (2001), Gordon et al. (2003a, 2003b) and Corak (2006b). Poverty measures on the basis of "count" methodologies and employed in these studies include the poverty headcount or incidence, poverty gap or depth and poverty severity measures. Child poverty index measures are primarily based on macro data at group level (for example, administrative data at region or country-level), allowing for the use of data from different sources at different levels of aggregation. These measures culminate in an aggregate figure that enables one to compare the performance of various groups with respect to child poverty (Moore et al., 2007). Examples of studies taking such a macro-perspective include Land et al. (2001), Bradshaw et al. (2006), Noble et al. (2006), Richardson et al. (2008), Save the Children (2008). Whilst Land et al. (2001) focus on the comparison between various socio-economic and demographic groups in the US, Noble et al. (2006) and Barnes et al. (2007) focus on comparing municipalities and provinces in South Africa and Bradshaw et al. (2006), Richardson et al. (2008) and Save the Children (2008) aim to explain differences between countries. A range of methods is available for the construction of index measures and inherent to this construction are decisions on the normalization, weighting and aggregation techniques (Nardo et al. 2005). Generally, child poverty index measures culminate in an index score, which allows for the comparison between groups but does not have an intuitive meaning of its own. As such, the choice for a poverty measure is related to the aforementioned objective of the child poverty approach.

\subsection{Research questions}

The review of literature shows that despite the field of child poverty being rather novel, it already contains a range of studies with different objectives, concepts, resources bases and measures. Nevertheless, the account of existing approaches leaves considerable scope for extending the current research on child poverty definition and measurement. Three main research questions are addressed within the collection of chapters in this book. The questions are both conceptual and empirical in nature and are considered in one or more chapters in this book. This section introduces those three research questions.

The review of existing literature on child poverty measurement reveals that many of the approaches used are developed in an implicit and unclear manner with 


\section{False Positives or Hidden Dimensions $\mid 7$}

lack of transparency concerning decisions on concepts, resource bases and poverty measures. The concurrent analysis of child poverty on the basis of such approaches is susceptible to misinterpretations and misunderstandings, possibly leading to unjust conclusions and policy recommendations. This finding from the existing body of research on child poverty measurement calls for further investigation into the issue of:

\section{1) The importance of choice and definition for the measurement of child poverty.}

In order to investigate and exemplify the specific conditions under which clear and transparent child poverty approaches can be developed, a generic construction process is derived from the review of existing literature. The assessment of practical implications of the development and use of a child poverty approach is illustrated by the case study of Vietnam.

The range of previous child poverty assessments in a specific country using a tailor-made and multidimensional approach is limited. The majority of approaches focus on cross-country comparisons, rather than investigating child poverty in a specific space and time. To investigate the development and use of an in-depth and context-specific poverty approach, Vietnam is used as a country case study. Findings for the first research question are used to address the following issue:

\section{2) Child poverty in Vietnam: who and where are the poor?}

This research topic is both conceptual and empirical in nature as it requires the development of a country-specific and multidimensional child poverty approach geared to capture the situation in Vietnam as well as the empirical investigation of child poverty in both monetary and multidimensional terms. More specifically, it considers the domains in which children are most deprived, the determinants of poverty, the existence of horizontal inequalities and the link between child poverty and social welfare. The extensive and in-depth empirical profile of children in Vietnam resulting from this assessment also fills a knowledge gap in Vietnam as information about the situation of children in Vietnam was limited at the time the research was commenced.

A common division in the body of literature on poverty measurement is that between monetary (uni-dimensional) and multidimensional approaches. This division is based on conceptual and ideological underpinnings as well as empirical and analytical outcomes. Comparisons of the use and outcomes of these methods in existing studies have shown that they predominantly provide different pictures of poverty in terms of figures of overall levels of poverty as well as groups of poor individuals. Studies have not yet been undertaken with a special consideration of children and with a more in-depth deliberation of factors underlying the degree of overlap or mismatch, raising the question:

3) To what extent do monetary and multidimensional approaches of child poverty differ with respect to conceptual and empirical outcomes? 
This research question investigates the conceptual underpinnings for the use of either one or both of the approaches and the empirical implications. The empirical investigation is based on the country case of Vietnam and the outcomes for monetary and multidimensional child poverty as found by answering the second research question. More specifically, it considers the extent to which different groups of children are captured by the two approaches, the characteristics of these groups and the underlying factors explaining variation amongst these groups. The empirical implications are assessed in terms of poverty analysis and policy analysis.

\subsection{Structure}

The remainder of the book is structured as follows: The second chapter in this book addresses the normative development of child poverty approaches by distilling a generic construction process from a review of existing approaches. This process is applied to the case of Vietnam to illustrate its practical use. It thereby aims to answer the first research question put forward in this book. The third chapter presents an empirical extension of the child poverty approach for Vietnam. As such, it tests the practical use and robustness when employed for in-depth child poverty profiling. A distributional analysis of child poverty in Vietnam is undertaken in the fourth chapter, thereby moving beyond a mere child poverty profile towards an empirical investigation of inequality amongst different groups of children in Vietnam. Together, chapters 3 and 4 address this book's second research question. The tension between monetary and multidimensional approaches to poverty is elaborated upon in the fifth chapter. It explores the mismatch between the identification of poverty on the basis of these approaches in Vietnam and Congo and discusses the implications for policy design. A more detailed and in-depth investigation into the issue misidentification by different child poverty approaches is provided in the sixth chapter. This chapter builds on the case of Vietnam to address these questions. It investigates the degree of overlap or mismatch using monetary versus multidimensional approaches for the measurement of child poverty, the extent to which one approach can serve as a proxy for the other and the factors underlying misidentification. Finally, the practical use of monetary and multidimensional child poverty approaches for policy evaluation is considered in the seventh chapter, which presents an evaluation of the social welfare scheme in Vietnam in terms of child poverty. The performance of the social welfare scheme is considered with respect to coverage as well as poverty impact. Findings in chapters 5, 6 and 7 contribute to answering the third research question. The policy analysis in chapter 7 also extends the answer to the second research question concerning the child poverty profile in Vietnam. The main findings and conclusions from all chapters are combined in the concluding chapter along the lines of the research questions. 


\section{Chapter 2}

\section{THE IMPORTANCE OF CHOICE AND DEFINITION FOR THE MEASUREMENT OF CHILD POVERTY - THE CASE OF VIETNAM 2}

Increased attention to children's' special position within poverty measurement resulted in the development of various child poverty approaches in the last decade. Analysis shows that their development processes involve a similar set of steps and decisions, predominantly taken in the same sequence. However, it also becomes apparent that many of these decisions are made implicitly rather than explicitly, resulting in unclear and non-transparent underlying constructs. Consequently, child poverty approaches often lack a solid and robust foundation and are misinterpreted and misunderstood when used for analytical and policy purposes. This paper distils a generic construction process from the analysis of existing child poverty approaches, presenting a tool for clear and transparent development of such approaches. It is then applied to the case of Vietnam, using household survey data, to illustrate its practical use and develop a Vietnam-specific child poverty approach. Findings suggest that 37 percent of all children are poor, whilst observing a large rural-urban divide but no significant differences between boys and girls.

2 Published as:

Roelen, Keetie, Franziska Gassmann and Chris de Neubourg (2009) The Importance of Choice and Definition for the Measurement of Child Poverty-the case of Vietnam, Child Indicators Research, 2(3): 245-263. 


\subsection{Introduction}

In the last decade(s), it has been widely recognized that children deserve a child focused perspective in the development and poverty reduction process (e.g. CHIP 2004; Gordon et al. 2003a, 2003b; Minujin et al. 2005) and the need to treat them "[...] in their own right as individuals" (Redmond 2008 p. 63, White 2002). ${ }^{3}$ Several reasons can be put forward for the importance of such a child-focused approach towards poverty (e.g. Gordon et al. 2003a, 2003b; Minujin et al. 2005; Waddington 2004). The dependence on parents, household and community for the distribution of basic needs puts children at a higher risk of poverty and makes their situation less transparent (e.g. White, Leavy and Masters 2003). Further, poverty often manifests itself as a vicious circle, causing children to be trapped in poverty from birth onwards (e.g. Corak 2006a; DWP 2002). Moreover, children have different basic needs than adults do (e.g. Waddington 2004). Child-focused poverty approaches are crucial to account for these issues and provide detailed information at the level of the individual child. A generally accepted definition and measurement method of child poverty is an important tool for both academics and policy makers. It does not only offer the opportunity to get an insight into the poverty status of children but also gives the possibility to formulate and monitor sound poverty reduction objectives, strategies and policies (e.g. Ben-Arieh 2000; Corak 2006b).

A number of approaches have been developed for the measurement and analysis of child poverty, each one of them tackling the issue from a different angle. Every poverty approach is the result of theoretical considerations and value judgments (Ravallion 1994), culminating into approaches that are different in concept, definition and method (Laderchi et al. 2003). An analysis of poverty approaches, and in specific child poverty approaches, suggests that their processes of development involve a similar set of steps and decisions, predominantly taken in the same sequence. However, it also becomes apparent that many of these decisions are made in an implicit rather than explicit manner. As a result, poverty approaches suffer from a lack of distinction between the different elements of the approaches (Noble, Wright and Cluver 2006) and the underlying constructs and considerations are not transparent (Laderchi et al. 2003). Consequently, poverty approaches lack a solid and robust base for poverty comparisons (Ravallion 1994) and the identification of a specific individual or group as being poor is misinterpreted or misunderstood (Alkire 2008, Laderchi et al. 2003). Clear and explicit discussion of purposes, concepts and decisions underlying the development of a poverty approach is necessary to avoid these pitfalls and to ensure robust poverty analysis (Ravallion 1994; Laderchi 1997; Laderchi et al. 2003). A review of child poverty approaches suggests that the majority of these approaches suffer from one or more of these weaknesses. This paper distils a generic construction process from the analysis of child poverty approaches, presenting a useful tool to guide and ensure a clear and transparent development of such approaches. For the purposes of a practical illustration, the generic construction process is applied to the case of Vietnam.

\footnotetext{
${ }^{3}$ This paragraph shows overlap with section 1.2; readers having read that section are advised to continue with the next paragraph.
} 


\section{False Positives or Hidden Dimensions | 11}

Vietnam has experienced a period of outstanding rapid economic growth after the Doi Moi (renovation) reform policies came into place in the late 1980's, accompanied by a large reduction of poverty. Central planning made way for free-market oriented economic policies, bringing about great changes in the agricultural sector, private business and employment development, foreign trade and social sector policies, creating business and entrepreneurial opportunities for Vietnamese as well as foreigners. The reforms proved to be greatly beneficial for Vietnam's economic performance, with average economic growth rates of 6.9 percent from 1988 to 1994 and 7.4 percent from 1994 to 2000 (Glewwe 2004). Furthermore, monetary poverty was also reduced notably; from 58 percent in 1993 to 19.5 percent in 2004 (VASS 2006). These poverty figures can be decomposed by various demographic groups and are often presented by region, gender and ethnicity. However, representation per age group is less common and, as a consequence, little is known about the state of child poverty. Until now, there have not been any comprehensive poverty analyses in Vietnam for children, presenting a gap in crucial knowledge required by policy makers and analysts. Applying the generic construction process to the case of Vietnam serves, on the one hand, to illustrate its use and, on the other hand, to fill the knowledge gap with respect to child poverty in Vietnam.

The paper is structured as follows: we firstly discuss the distilled generic construction process. Second, a selection of child poverty approaches is analyzed in terms of this process. Next, the methodology and data are shortly discussed. The generic construction process is then applied to the case of Vietnam, explicitly discussing the decision making processes at hand. Finally, we present empirical results on the basis of household survey data and draw a picture of child poverty in Vietnam.

\subsection{Generic Construction Process}

The generic construction process presented here is deduced from literature on a range of different child poverty approaches, that have either explicitly discussed or implicitly suggested their process of construction. The list of approaches included in the literature review was by no means exhaustive but does provide an insight into previous work and a valuable basis for discussion ${ }^{4}$. Further, for reasons mentioned in the introduction, we have chosen to focus on child poverty in particular. However, many of the elements discussed in this study also hold for general poverty measurement. Naturally, we also incorporate insights from general poverty measurement into our analysis.

The review of child poverty approaches suggests that all approaches generally follow the same steps towards their development, using the same building blocks. The various steps and their particular sequence are depicted in Figure 2.1. Every step and building block is subject to a decision-making process and builds upon the choices made in the previous step. As a result, different choices made at each stage of the process culminate in different outcome products.

\footnotetext{
${ }^{4}$ For the literature review of child poverty approaches, see section 1.3 and Roelen and Gassmann (2008).
} 
Figure 2.1 Generic Construction Process of child poverty approaches

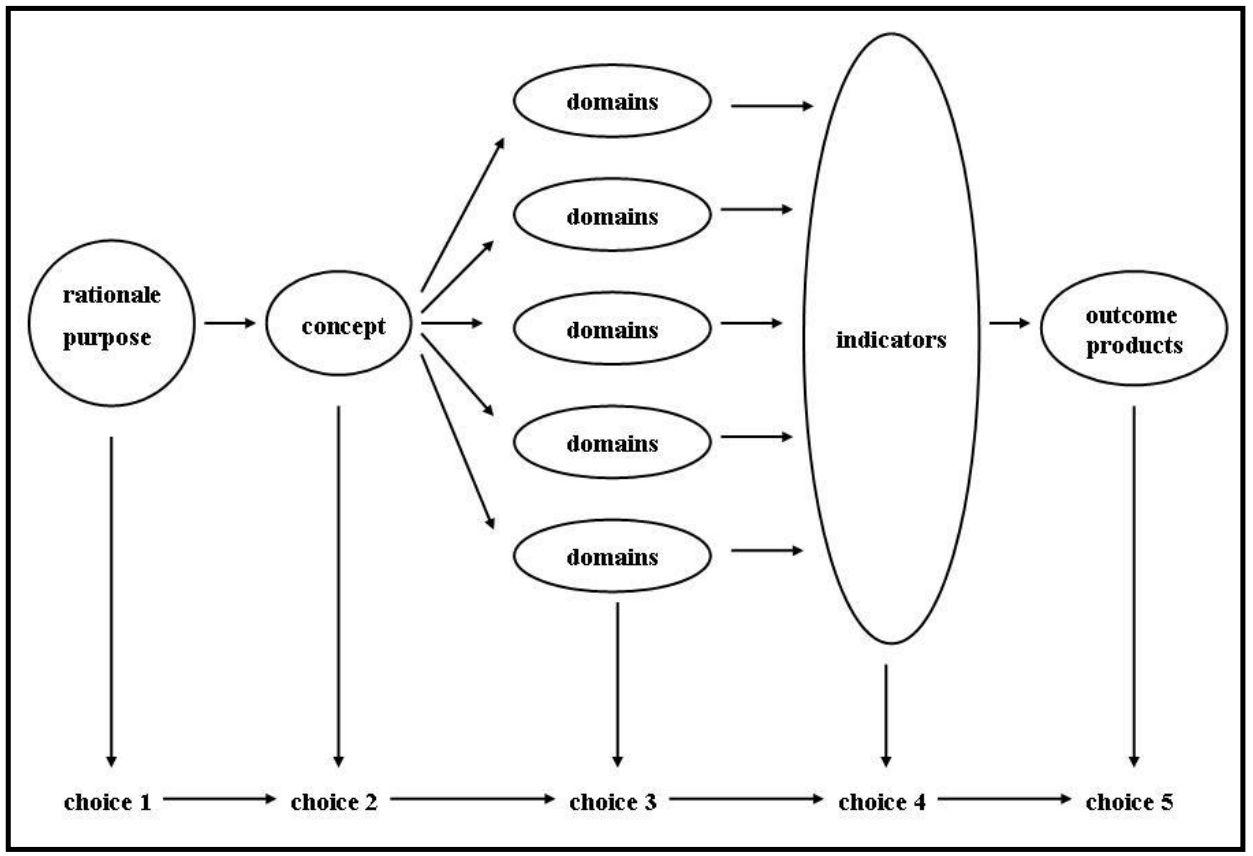

The identification of the underlying rationale and specific purposes of the child poverty approach presents the first choice in the overall process. A clarification of the rationale explains the underlying reasoning for the development of the approach. This is of great importance as it informs the values attached to such approaches, having farreaching impact on the actual operationalization (Alkire 2008, 2002; Ravallion 1994). Robeyns (2005) provides an illustration of this importance in terms of the capabilities approach by arguing that the role attached to capabilities within the developed approach is crucial for the choice of the final set of capabilities. An explicit discussion of the approach's purpose clarifies what the approach will be used for. Ravallion (1994) was one of the many scholars to emphasize the importance of clarifying the poverty approach's purpose to be able to make solid poverty comparisons.

The second choice concerns the formulation of an overall concept, encompassing a definition of child poverty. Thorbecke (2008, pp4) states that "[...] Poverty has to be defined, or at least grasped conceptually, before it can be measured", illustrating the importance of this building block in the generic construction process. Laderchi et al. (2003) reflect on a number of aspects that one encounters when formulating a concept of poverty, including the universality of the approach (should the approach fit multiple contexts or be tailor-made to a specific group?), the objectivity versus subjectivity of the approach (how to deal with value judgments?), the unit of analysis (should the focus be on households or individuals?) and dimensionality (choosing for a single or multidimensional method?). Logically, the choices with respect to these issues are in part a result of the rationale and purposes defined in the first building block of the process and have implications for the remaining choices. 
The choices for domains and indicators are referred to as choices three and four in the generic process. The domains represent the different areas of development but also correspond with policy areas to enhance the approach's usefulness for policymakers. Indicators are chosen to give a comprehensive representation of the development within the respective domains. Alkire (2002, pp182) argues that a "[...] fundamental reason for a serious account of dimensions is to give secure epistemological and empirical footing to the multidimensional objective of human development". Further, the choice of domains and indicators is subject to assumptions and value judgments, which are to be made as explicit as possible (Alkire 2002, 2008; Robeyns 2005; Laderchi et al. 2003).

The final choice within the construction process refers to the approach's outcome products or actual poverty figures. The choice with respect to this building block further underlines the interdependency of the various steps within the process. Different purposes require different types of outcome products and in part guide the construction of the child poverty approach (Vandivere and McPhee 2008). While an advocacy purpose calls for an easily interpretable single summary measure (Moore et al. 2007), a policy input purpose requires more disaggregated and in-depth information (Ben-Arieh 2000). The choice with respect to concept will have great consequences for the method of aggregation in terms of single versus multidimensionality and unit of analysis.

The discussion of the various steps within the generic construction process shows that many poverty scholars have emphasized, in different contexts and forms, of clarifying different underlying elements of poverty approaches to arrive at sound poverty analysis. Analysis of child poverty literature, however, suggests that the majority of child poverty approaches does not explicitly discuss or thoroughly explain choices made throughout their process of development. One the one hand, this could result in overlooking other, possibly more suitable, options and opportunities for the approach at hand. On the other hand, it creates confusion about why a specific group of children is identified as poor or not. Vandivere and McPhee $(2008$, pp10) point out that "[...] there is no reason to expect findings based on different index calculation methods to correspond, as each has been designed to address different questions about child well-being". In their study on child well-being in the US, Vandivere and McPhee (2008) conclude that different types of approaches applied to the same data provide different results. They emphasize that these should be interpreted in reference to the approaches' purposes and concepts to be meaningful (Vandivere and McPhee 2008). The generic construction process guides an explicit discussion of the specific questions a child poverty approach aims to tackle and the decision-making processes for answering them. It strengthens the approach under development and creates awareness about underlying choices, making the identification of specific groups of children as poor more transparent and understandable. 


\subsection{Choice and definition in existing child poverty approaches}

This section briefly explores the development processes and use of a small selection of existing child poverty approaches. It illustrates the caveats and possible implications for some approaches and provides some good practices for others.

The monetary approach is the most widely used poverty approach worldwide (Laderchi et al. 2003; Redmond 2008) but often done so with little consideration of underlying choices and definition. The approach conceptualizes child poverty as children living in low income ${ }^{5}$ households (Vandivere and McPhee 2008). It is a onedimensional poverty measure, incorporating income as the single indicator of wellbeing (Thorbecke 2008). The outcome products include incidence rates, counting the number of children in households with an income below a pre-defined threshold (Ravallion 2004), which are often extended to the poverty gap and severity measure (Ravallion 2004). Its fundamental underlying concept is based on the assumption that individuals seek to maximize utility given the budget they have and income is able to measure that utility (Laderchi et al. 2003). However, the use of monetary measures, with regards to child poverty as well as general poverty, is often due to other reasons than the belief that income is the most appropriate method for capturing poverty. Income is often invoked because of the assumption that it appropriately proxies other aspects of poverty and well-being (Redmond 2008, Laderchi et al.2003) in order to benefit from the strengths of the monetary approach, including the long-standing tradition (Redmond 2008) but also its intuition and easy interpretation. In terms of the generic construction process, this suggests that child poverty approaches based on the monetary method often suffer from implicit and tacit decision-making, especially with respect to purpose and concept. A comparative study of child poverty in industrialized country by Bradbury and Jäntti (2001), for example, shortly justifies the choice of a money-metric measure by claiming that "[...] money matters" (Bradbury and Jäntti 2001, pp5). Another study by Bradshaw (2000), placing child poverty in Britain in perspective to other countries, employs relative monetary measures without an explanation of why this would be the most appropriate measure. Failing to place the choice for approaches in context of the studies' purpose and rationale, leaves the reader to guess about issues such as multidimensionality, absolute versus relative poverty and the unit of analysis. These are cross-cutting considerations in the development process of any (child) poverty approach (Vandivere and McPhee 2008) and vital for an understanding of the studies' outcomes.

In contrast to these examples, Corak (2006b) does provide an explicit and clear line of reasoning to explain the use of a de facto monetary method for the measurement of child poverty in rich countries. Corak's study uses the Convention of the Rights of the Child (CRC) as a starting point, thereby acknowledging that child poverty is a multifaceted problem. Six guiding principles, emphasizing feasibility aspects and practical constraints, however form the approach's broad basis 6 .

\footnotetext{
${ }^{5}$ With the term income, we interchangeably mean monetary indicators including consumption and expenditures.

${ }^{6}$ The six principles of Corak's practical approach include the avoidance of unnecessary complexities, the use of a limited number of complementary indicators to income measures,
} 
Consequently, the approach, its concept and choice of indicators are predominantly guided by data availability and practical operationalization and child poverty is defined as the proportion of children with equivalent incomes below the threshold of $50 \%$ of national median equivalent income (Corak 2006b). Hence, despite the approach being multidimensional in concept, it is one-dimensional in implementation (Roelen and Gassmann 2008). The explicit discussion of the choices at hand benefits the credibility of the study and enhances understanding and meaningful interpretation of the figures. It rightfully informs further analytical work, academic discussion but also practitioners and policy makers.

Another illustration of the importance to clarify rationale and purpose before developing and using a child poverty approach is the US Child and Youth Well-being Index (US CWI) by Land et al. (2001). The US CWI was designed for the purpose of considering changes in child well-being over time (Land et al. 2001, Vandivere and McPhee 2008). The construction of the index is based on the quality of life concept, including both objective as well as subjective measures of well-being in seven different domains ${ }^{7}$. Percentage changes from the base year are averaged over all indicators per domain and consequently domain indices are averaged to obtain the composite index score (Land et al. 2001). One of the great disadvantages of the US CWI measure is its limited provision of information as it only presents figures in reference to a base year, unable to provide insights into absolute or individual performance. Hence, it proves only useful for tracking the average performance of specific groups over time in reference to a base year. However, the main purpose of the development of this approach was exactly to answer this question and provide insight into these dynamics over time. In reference to the generic construction process, it can be said that Land et al. (2001) made a conscious decision for the first building block concerning rationale and purpose and consequently followed up on it throughout the remainder of the process. And by clearly postulating that standpoint throughout the development of the approach, the authors manage to take away concerns about the approach's limited use and answer exactly those questions they have set out to tackle.

Other child poverty approaches that follow the line of reasoning of the generic construction process in their development, albeit explicit or more implicit, are the Bristol deprivation approach by Gordon et al. (2003a, 2003b), the EU Child Well-being Index (EU CWI) by Bradshaw et al. (2006) and the CEE/CIS Child Well-being Index (CEE/CIS CWI) by Richardson et al. (2008). All approaches share a multidimensional nature and country-comparative focus and have described decision-making processes at different steps throughout their development in different degrees of detail. For example, while Gordon et al. (2003a, 2003b) are quite explicit in their choice for domains and indicators and their specific cut-offs, using the "continuum of deprivation", this discussion is limited with respect to the CEE/CIS CWI of Richardson et al. (2008). Using the generic construction process would assist those developing a child poverty approach to avoid any caveats in their discussion on concepts and

the inclusion of social norms in the drawing of poverty lines, regular updating of indicators, the use of a fixed as well as moving poverty line and the building of public support for poverty reduction (Corak 2006b).

7 The seven domains included in the US CWI are material well-being, health, safety, productive activity, place in community, intimacy and emotional well-being (Land et al. 2001). 
definitions of various building blocks. With respect to these cases, the process could now assist those analyzing or applying the approaches to be aware of and fill potential gaps.

\subsection{Methodology and Data}

In the remainder of this paper, the practical use of the generic construction process is illustrated through the development of a child poverty approach for Vietnam. Decision making processes at every step of the process are explicitly discussed, ensuring a clear and transparent development of the Vietnam-specific approach. Consequently, household survey data is employed for the calculation of child poverty figures. We use the Multiple Indicator Cluster Survey (MICS) from 2006. This household survey provides child as well as household specific information for a number of indicators as specified in the theoretical framework. The Vietnam MICS is based on the standardized MICS surveys as technically supported by UNICEF. The first and second round was conducted in 1995 and 2000, while the third round was completed in 2006. The survey contains a range of questions especially focused on education, health, reproductive health, HIV/AIDS and is separated into a questionnaire for households, women of reproductive age and children under five. Regions were identified as the main sampling domains and the sample was selected in two stages, based on enumeration areas from the census (GSO 2007). The sample consists of a total number of 8.356 households with 36.573 individuals out of which 10.874 are children up to 16 years of age

\subsection{Development of a Vietnam-specific approach}

In this section, the generic construction process is applied to the case of child poverty in Vietnam. We follow the line of reasoning of the construction process, discuss each step in detail and illustrate its practical implementation.

\subsubsection{Choice one - Rationale and Purpose ${ }^{8}$}

The acknowledgement by policy makers and practitioners in Vietnam that a measurement tool is needed to provide comprehensive and clear information about child poverty in Vietnam provided the rationale for this approach. Currently, poor and vulnerable children in Vietnam are identified along different categories and overall referred to as Children under Special Circumstances. The identification of poor and vulnerable children along these categories is not meant as a monitoring and evaluation tool but rather as a means of targeting. According to the Law on Child Protection, Care and Education in Vietnam (Socialist Republic of Vietnam 2004), children under special circumstances are divided into 9 different categories for which

${ }^{8}$ The identification of the rationale and purpose of the child poverty approach in Vietnam is the result of extensive discussions and interviews with UNICEF Vietnam and the Ministry of Labour, Invalids and Social Affairs (MOLISA) in Vietnam. 
various programmes and benefit schemes are in place ${ }^{9}$. Due to policy design, targeting and evaluation taking place along the lines of this categorization, no overall definition and measurement has been used in Vietnam to capture the issue of child poverty. However, the use of this type of categorization does not draw a comprehensive picture of the current situation that children are in. For the assessment of children's outcomes, one has to take stock of the state of affairs in various domains of children's lives and focus on multiple dimensions. Currently the outcomes for children in Vietnam are not clearly visualized and a wide gap exists in the poverty profiling and information provision for policy development and evaluation.

The identified purpose of the approach in Vietnam is two-fold. On the one hand, it should serve as an advocacy tool to raise public awareness on the issue of children's well-being in Vietnam. On the other hand, the approach's outcome products should feed into the policy design and monitoring process at primarily the regional level. The two purposes require different methodologies and outcome products (Moore et al. 2007; Vandivere and McPhee 2008). Bearing in mind that these purposes are formulated for the specific case of Vietnam, the approach will also have a Vietnamspecific character, fitting the standards of that particular society. As the child poverty approach is developed within the societal and cultural context of Vietnam and as such, cannot be directly transferred to other countries.

\subsubsection{Choice two - Concept}

The identified rationale and purpose emphasize children's outcomes and a wider perspective of child poverty. The approach focuses on the outcomes rather than individual capabilities or characteristics that might lead to the increased poverty risk. Along the lines of theories of distributive justice and equality, the Vietnam child poverty approach is outcome- rather than opportunity based ${ }^{10}$ (Robeyns 2003). In other words, we focus on achievements (or non-achievements) rather than the capabilities to reach the achievements, thereby departing from Sen's multidimensional capability approach (Thorbecke 2008) or Roemer's concept of equality of opportunity (Roemer 2000). As children's capabilities are difficult to observe and the materialization of their capabilities largely dependent on others in their direct environment (White et al. 2003), a measure of capabilities of opportunities is deemed inadequate to reflect child poverty. Furthermore, the approach should go beyond the use of a single poverty dimension but rather take a multidimensional perspective to include different dimensions of poverty. In support of the multidimensional standpoint, the Vietnam approach is based on the CRC and the basic needs approach as used in Vietnam. The CRC has served as a basis and input for many legal and policy documents internationally (Redmond 2008) as well as on country-level. In Vietnam, the CRC was ratified in 1990 and influenced the Law on Protection, Care and Education of Children (Committee on the Rights of the Child

${ }^{9}$ The 9 categories of Children under Special Circumstances are orphaned children, disabled children, homeless children, drug addicted children, sexually abused children, child labourers, children that have committed crimes, poor children and HIV/AIDS affected children (Socialist Republic of Vietnam, 2004).

10 According to Robeyns (2003), Sen's capability approach can be characterized as an opportunity-based theory. 
2005). The CRC builds on four themes, being survival, protection, development and participation and identifies basic rights for children within these areas (UNHCHR 1989). The basic needs approach in Vietnam identifies eight groups of basic needs: food, shelter, clothes, health, education, water, sanitation and social exclusion ${ }^{11}$. The basic needs approach also holds firm ground in underlying rationale for policy design ${ }^{12}$. The needs defined under the basic needs approach and rights formulated under the CRC are largely overlapping and point to the same areas of development for children. Although they do not directly provide a definition or concept (Redmond 2008), they complement and reinforce each other as underlying lines of thought for child poverty. As a result, the child poverty concept underlying this approach is multidimensional, based on non-monetary measures and adjusted to Vietnam's cultural and social context. Although the term poverty is often used in reference to merely income indicators, we employ it here to have a broader meaning encompassing a more comprehensive set of deprivations. Other terms commonly found in the literature to acknowledge the use of a broader set of indicators beyond the monetary dimension, such as well-being (see Bradshaw et al. 2006; Land et al. 2001; Vandivere and McPhee 2008), are considered inappropriate to intuitively reflect the negative formulation of the approach for Vietnam. The concept used in this study focuses on what children lack rather than what they have and the term poverty is commonly associated with the lack of needs. Finally, we choose to identify children as individuals under the age of 16 years because this is the official definition according to the Law on the Protection, Care and Education of Children in Vietnam (Socialist Republic of Vietnam 2004).

\subsubsection{Choice three - Domains}

Alkire (2008) and Biggeri (2007) identified various methods for the selection of domains for multidimensional poverty measurement purposes. A first selection method is the assessment of available data. This method is a predominantly practical one as domains are selected regardless of its use and validity within the conceptual framework. Selection based on expert opinions or assumptions is a second method often employed, building upon informed guesses based on convention, theory or ideology. A third method is public consensus, including lists of issues and domains that have received legitimacy through widespread acknowledgement of the importance of these issues ${ }^{13}$. Participatory assessments are a fourth method to identify those domains and indicators that present poverty best according to the views of various stakeholders. Finally, one can base a selection on empirical evidence about people's values with respect to poverty and well-being. All these methods have advantages and disadvantages to its use and alone do not suffice as a valid selection

11 See Streeten (1984) for a discussion on the adjustment and interpretation of the basic needs approach within a specific social and cultural context.

12 The use of the basic needs concept as a basis for policy making in Vietnam became apparent from interviews and discussions with policy officers from the Ministry of Labour, Invalids and Social Affairs (MOLISA) in Vietnam.

13 Examples of consensus-based lists of domains are the Convention of the Rights of the Child, the ILO Conventions on the Minimum Age and Worst Forms of Child Labor and the Millennium Development Goals (Biggeri 2007). 
method (Alkire 2007). Robeyns (2006) proposes four procedural criteria that should be taken into account throughout the selection process to promote its objectivity. These criteria consist of explicit formulation of the selected domains and indicators, a methodological justification, the two stage ideal - feasible process and, finally, exhaustion and non-reduction. From these criteria, we deduct our own guidelines with which the chosen dimensions should comply. On the one hand, they should fit into our conceptual framework of child poverty and the societal context of Vietnam, representing child poverty in Vietnam as inclusive as possible. On the other hand, they should also be practical and feasible, thereby ensuring that the tool can be used to serve its purposes.

A combination of Alkire's (2008) and Biggeri's (2007) methods has been used in the selection process of the domains for our child poverty approach, taking into account the Robeyns' (2006) procedural criteria and own guidelines. The method of assumptions and expert opinion inspired a first set of domains and indicators, complemented by those identified on the basis of public consensus. Next, participatory processes were employed to account for the views of stakeholders and key-informants, thereby ensuring the incorporation of the Vietnamese context. A final selection mechanism at work during the identification process for domains was the assessment of existing data and data availability. The methods of assumption, expert opinion and public consensus put forward a list of domains including income, education, health, nutrition, transport, communication, subjective well-being, safety, shelter and water and sanitation, social inclusion and protection. The interviews with key-informants and an in-depth assessment of available data provided a reduced and final list of 8 domains, presented in 2.1. The income dimension was left out of consideration because it was considered a means to an end rather than an end in itself and did not fit the pre-defined purpose and concept of the approach. The issues of communication, safety and transport were not considered dimensions properly reflecting the poverty status of Vietnamese children and did not fit the country's context. The dimension referring to children's subjective well-being and nutrition had to be left out of consideration due to lack of data. .

\section{Table 2.1 Selected domains}

\begin{tabular}{l|l}
1 & Education \\
2 & Health \\
3 & Shelter \\
4 & Water and Sanitation \\
5 & Labour \\
6 & Leisure \\
7 & Social Inclusion and Protection \\
\hline
\end{tabular}

\subsubsection{Choice four - Indicators}

The selection process of indicators was conducted using a combination of the same selection methods as used for the selection of domains. The criteria for indicators, however, are laid down more specifically. The two stage ideal-feasible process (Robeyns 2006) was used throughout the process of identification and selection of indicators. Ideal indicators, on the basis of assumptions, expert opinions, public 
consensus and participatory data, were immediately screened against the following feasibility criteria. Firstly, the indicators should ideally be child-specific. The importance of a child-centric analysis with respect to poverty has also been emphasized in other approaches (Bradshaw et al. 2006; Gordon et al. 2003a, 2003b; Noble et al. 2006; Richardson et al. 2008). Nevertheless, it is unavoidable to measure certain indicators related to shelter, water and sanitation at the household level as data is only collected at the household level (Gordon et al. 2003a, 2003b). Secondly, indicators should be easily observable and thereby measurable (Moore et al. 2004). This implies that indicators about quality of services, for example, are difficult to include in our list of indicators unless we can formulate a clearly measurable standard for such quality. Thirdly, indicators should be easily interpretable. The indicators serve the goal to provide information about a certain aspect of child poverty and to feed into the policy making and monitoring process. To be able to use indicators to this end, they should be easily interpretable in an unambiguous way (Moore et al. 2004). Fourthly, indicators should be factual. Hence, they should measure facts rather than subjective opinions and have the same meaning over time as well as different groups within the overall reference population (Gordon et al 2003b). Fifthly, the indicators should adhere to the values and norms of the specific society in order to be meaningful (Thorbecke 2008). Thus, the indicators chosen should fit the Vietnamese context and are as such culture and society-specific. Finally, the indicators should be decomposable by gender, age, location and ethnicity (Noble et al. 2004). Based on these criteria as well as the selection mechanisms by Alkire (2008) and Biggeri (2007), one or more suitable indicators were selected for the case of Vietnam, presented in Table 2.2.

Table 2.2 Indicators of the Vietnam child poverty approach based on MICS 2006 data

\begin{tabular}{|c|c|}
\hline \multicolumn{2}{|c|}{ 1. Education } \\
\hline $1 \mathrm{a}$ & children in age 5 not attending pre-school as a percentage of all children in age 5 \\
\hline $1 \mathrm{~b}$ & $\begin{array}{l}\text { children in age 6-10 not attending primary school as a percentage of all children in } \\
\text { age } 6-10\end{array}$ \\
\hline $1 \mathrm{c}$ & $\begin{array}{l}\text { children in age 11-15 not attending lower secondary school as a percentage of all } \\
\text { children in age 11-15 }\end{array}$ \\
\hline 2 & $\begin{array}{l}\text { children in age } 11-15 \text { that have not completed primary education as a percentage of } \\
\text { all children } 11-15\end{array}$ \\
\hline \multicolumn{2}{|r|}{ 2. Health } \\
\hline 1 & $\begin{array}{l}\text { children in age } 2-4 \text { that have not received full immunization as a percentage of all } \\
\text { children in age } 2-4\end{array}$ \\
\hline \multicolumn{2}{|r|}{ 3. Shelter } \\
\hline 1 & $\begin{array}{l}\text { children living in a dwelling without electricity as a percentage of all children in age } \\
0-15\end{array}$ \\
\hline 2 & $\begin{array}{l}\text { children living in a dwelling without a proper roof as a percentage of all children in } \\
\text { age } 0-15\end{array}$ \\
\hline 3 & $\begin{array}{l}\text { children living in a dwelling without a proper floor as a percentage of all children age } \\
0-15\end{array}$ \\
\hline \multicolumn{2}{|r|}{ 4. Water and Sanitation } \\
\hline 1 & $\begin{array}{l}\text { children living in a dwelling without a hygienic sanitation facility as a percentage of } \\
\text { all children in age } 0-15\end{array}$ \\
\hline 2 & children not drinking safe drinking water as a percentage of all children in age $0-15$ \\
\hline
\end{tabular}


children age 5-14 having worked for an employer, in household production or selfemployer in the last 12 months as a percentage of all children in age 5-14

\begin{tabular}{l|l}
\hline \multicolumn{2}{l}{ 6. Leisure } \\
\hline 1 & $\begin{array}{l}\text { children in age } 0-4 \text { not having store-bought or home-made toys worth as a } \\
\text { percentage of all children age 0-4 }\end{array}$ \\
\hline 2 & $\begin{array}{l}\text { children in age 0-4 not having at least one children's or picture book as a percentage } \\
\text { of all children age 0-4 }\end{array}$ \\
\hline 7. Social Inclusion and Protection \\
\hline 1 & $\begin{array}{l}\text { children in age 0-4 not having a birth registration as a percentage of all children age } \\
0-4\end{array}$ \\
\hline
\end{tabular}

With respect to education, ideal outcome indicators at the individual level would have been numeracy or literacy rates. However, these are difficult to observe and not available from current data. We use the net enrolment rate per level of schooling and primary school completion rates as a proxy instead. Immunization rates are considered appropriate indicators of access to and provision of health care, measured at the level of the individual child. Due to limited data, no more indicators could be added in this domain. Three indicators were defined within the shelter domain, which are thought to adequately reflect the living conditions of Vietnamese children. Another indicator that was considered within this domain was the number of people sharing a bedroom. However, this was deemed not to be appropriate within the Vietnamese context as it is customary to share bedrooms. The shelter indicators, as well as the water and sanitation indicators, are measured at the household level. The categories of safe drinking water and hygienic sanitation facilities were informed by international and national standards on water and sanitation issues. The formulation of the child labour indicator was primarily based on the national Law on Protection, Care and Education of Children, stipulating that children under 16 are not allowed to work. Other indicators referring to working conditions or number of hours worked were considered superfluous in this context. The choice of indicators within leisure and social inclusion and protection domains were mainly guided by data availability. Little information was available and the chosen indicators are considered a proxy at the individual level of the dimensions they try to shed light on. Birth registration, for example, is an important pre-condition in Vietnam for access to social services for children such as education and participation in social programs. The overall set of indicators is considered an adequate and appropriate to represent child poverty in Vietnam ${ }^{14}$. They do not adhere to all criteria but as Richardson et al. (2008, pp3) indicate "[...] in indicator development the perfect is too often the enemy of the good".

\subsubsection{Choice five - Outcome Products}

As previously indicated, the outcome products of this approach are to serve the advocacy and policy input purposes. An outcome product that is suitable for the advocacy purpose, that complies with the feasibility criteria and can serve as a communication vehicle is a child poverty incidence rate. An incidence rate makes child poverty visible in an understandable manner and is accessible for the general public

${ }^{14}$ For a more elaborate discussion of each individual indicator, please refer to Roelen, Gassmann and de Neubourg (2006). 
due to its intuitive strength. It is an aggregate of the individual indicator and thus is genuinely child-specific and adjusted to the societal context. Further, at a lower level of aggregation and decomposition ${ }^{15}$, the individual indicators can be used for detailed policy design and analysis. Further, a regional composite child poverty index can be constructed to complement the child poverty rate and serve the purpose of policy input. Such an index can be formed by combining indicators into domain indices and single-number indices across regions. Vandivere and McPhee (2008) refer to this method as the standard score method. The method can be used for relative regional comparisons by the ranking of regions. A disadvantage of a composite index is its lack of intuitive explanatory power. The index score is a result of statistical calculations and transformations and does not represent a cardinal value that can be intuitively explained (Micklewright 2001). However, when used in combination with the child poverty rate, the two methods can complement information and provide more detailed insights. Ranking on the basis of index scores might encourage policy makers in relatively poor performing regions to give the issue of child poverty greater emphasis. To avoid confusion with widely used terms such as poverty and deprivation, the terminology of the various measures and outcome products developed within the child poverty approach for Vietnam refer to vulnerability and vulnerability to poverty.

Inherent to the choice of outcome products is the choice of a methodology for the operationalization of the defined concept (Noble et al. 2006). The individual indicators used for the Vietnam-specific child poverty approach are dichotomous, indicating whether a child is below or above a pre-determined threshold. We refer to the percentage of children falling below the specified threshold per indicator as the indicator vulnerability rate. Domain vulnerability is in turn determined by the rate of children that do not meet the specified threshold of one or more indicators within that domain. The construction of the aggregate child poverty figure is based on the dual intersection cut-off point, identifying a child as poor when it is vulnerable in at least two domains (Alkire and Foster 2008). This type of poverty line proved robust and prevented the poverty rate to be inflated by single indicators, as is the case when using the union approach (Alkire and Foster 2008). This dual cut-off identification strategy is also employed by Gordon et al. (2003a, 2003b) in the Bristol deprivation approach and referred to as the absolute poverty. In this study, we refer to the Child Vulnerability to Poverty Rate (CVPR) ${ }^{16}$.

The second outcome product is referred to as the Child Vulnerability to Poverty Index (CVPI), which can also be considered a squared domain severity index. All individual indicators are included in the calculation of the overall index, thereby incorporating all those issues identified as valid and important for the measurement of child poverty in Vietnam. Domain scores are calculated by averaging the indicator vulnerability rates. Using squared domain scores as a subsequent weighting scheme gives the index a "severity" element as higher vulnerability scores are given a larger weight. It was deemed appropriate to apply a scheme that would highlight worse situations for children and give those greater weights rather than assigning weights

${ }^{15}$ Lower levels of aggregation refer to individual and domain indicators, while lower levels of decomposition refer to indicators per demographic group.

$16 \mathrm{~A}$ formal notation of the CVPR can be found in chapter 6 , where it is referred to as Child Poverty. 


\section{False Positives or Hidden Dimensions $\mid 23$}

on the basis of a prioritization of domains, which would be subject to a large degree of subjectivity and value judgment. Applying the "severity" scheme to domain scores rather than indicator scores implies full compensability within domains but not between domains. Within one domain, a bad performance on one indicator can be offset with a good performance on another indicator. Full compensability between domains is abandoned when using squared domain scores. A high poverty rate in, for example, health can not be offset by a low poverty rate in water and sanitation. This is thought to properly reflect the actual situation of children as poverty in one domain can not just simply be compensated by affluence in another. The overall index is then calculated by averaging the weighted domain scores. The normalization of indicators on the basis of a target reference value of 0 percent provides an overall index score that assesses the regional performance towards an absolute, desirable level that is stable over time. The regional index scores and consequent ranking is not dependent on the relative performance of regions in comparison to the best-performing region or average regional performance, which are not a stable reference point over time. Further, applying this scheme to domain scores rather than indicator scores implies full compensability within domains but not between domains. Within one domain, a bad performance on one indicator can be offset with a good performance on another indicator. Full compensability between domains is abandoned when using squared domain scores, meaning that a high vulnerability rate in, for example, health cannot be offset by a low vulnerability rate in water and sanitation. This is thought to properly reflect the actual situation of children as vulnerability in one domain cannot just simply be compensated by affluence in another. Index scores are calculated for the eight regions of Vietnam for the purposes of geographical comparisons.

\subsection{Empirical results}

This section presents the child poverty estimates for Vietnam on the basis of the Child Vulnerability to Poverty methodology and MICS data. Table 2.3 shows the incidence rates decomposed by gender, area (urban versus rural areas), region and age group. Findings suggest that child vulnerability to poverty rate is 36 percent. There is no significant difference between boys and girls but we can observe a great urban-rural divide. Approximately one out of ten children living in urban areas are identified as being vulnerable to poverty, while this figure is four times higher for children living in rural areas. Further, the poverty figures display great differences between regions. Vulnerability to poverty is lowest in the Red River Delta and South East regions, ranging from 11 to 21 percent, and highest in the North East and North West regions with figures ranging from 58 to 77 percent ${ }^{17}$. With respect to age groups, we observe high rates of vulnerability for the youngest children, in age brackets $0-2$ and 3-4, and the oldest children at age 15 . These results, however, should be interpreted with caution. Not all indicators are observable for all children. For example, 7 indicators are observable for children in age bracket 6-10 while 9

\footnotetext{
${ }^{17}$ The Red River Delta and South East regions respectively include the capital Hanoi and Ho Chi Minh City. The North West and North East regions are mountainous regions in the north of Vietnam.
} 
indicators are observable for those in age bracket 3-4. Hence, the latter group by definition has more chance to be included in the vulnerability figures.

Table 2.3 Child Vulnerability to Poverty Rates

\begin{tabular}{|c|c|}
\hline & MICS, n=10874 \\
\hline & $\begin{array}{l}\text { Child Vulnerability to } \\
\text { Poverty Rate }\end{array}$ \\
\hline Total & 36.65 \\
\hline Male & 36.86 \\
\hline \multirow[t]{2}{*}{ Female } & 35.42 \\
\hline & $* * *$ \\
\hline Urban & 12.04 \\
\hline \multirow[t]{2}{*}{ Rural } & 43.40 \\
\hline & $* * *$ \\
\hline Red River Delta & 11.26 \\
\hline North East & 58.76 \\
\hline North West & 77.65 \\
\hline North Central Coast & 30.95 \\
\hline South Central Coast & 28.79 \\
\hline Central Highlands & 40.53 \\
\hline South East & 22.63 \\
\hline \multirow[t]{2}{*}{ Mekong River Delta } & 59.95 \\
\hline & $* * *$ \\
\hline $0-2$ & 51.12 \\
\hline $3-4$ & 52.04 \\
\hline 5 & 28.08 \\
\hline $6-10$ & 27.30 \\
\hline $11-14$ & 35.05 \\
\hline 15 & 36.14 \\
\hline
\end{tabular}

Source: Authors' calculations from MICS 2006 Note: ${ }^{* * *}<0.001$, significance level chi-squared group equality of means

The results for the composite CVPI and the underlying domain indices are presented in Table 2.4, providing detailed information about regional performances. Table 2.4 presents the composite CVPI score as well as rankings based on the overall CVPI and domain scores. Regional rankings for the good performing regions, Red River Delta and South East, and poor performing rankings, North East and North West prove to be rather consistent over the range of domains. In accordance with the domain rankings, the ranking positions of these regions for the CVPI are respectively the first and second place and the seventh and eighth place. The middle rankings, however, vary depending on the domain. The North Central Coast region, for example, holds rankings positions 2 to 7 depending on the specific domain. With respect to the composite CVPI, it holds the fourth position. Further, when comparing regional rankings on the basis of the CVPI with the CVPR results in Table 2.3, it can be observed that rankings are similar among the higher ranks but different among the lower ranks. While the Mekong River Delta ranks one but last using the CVPR method, it holds ranking position 5 for the CVPI. The Central Highlands and North East hold a lower 
False Positives or Hidden Dimensions $\mid 25$

rank when using CVPI compared to CVPR, further indicating that the choice of methodology can have strong implications for the final poverty estimates. 


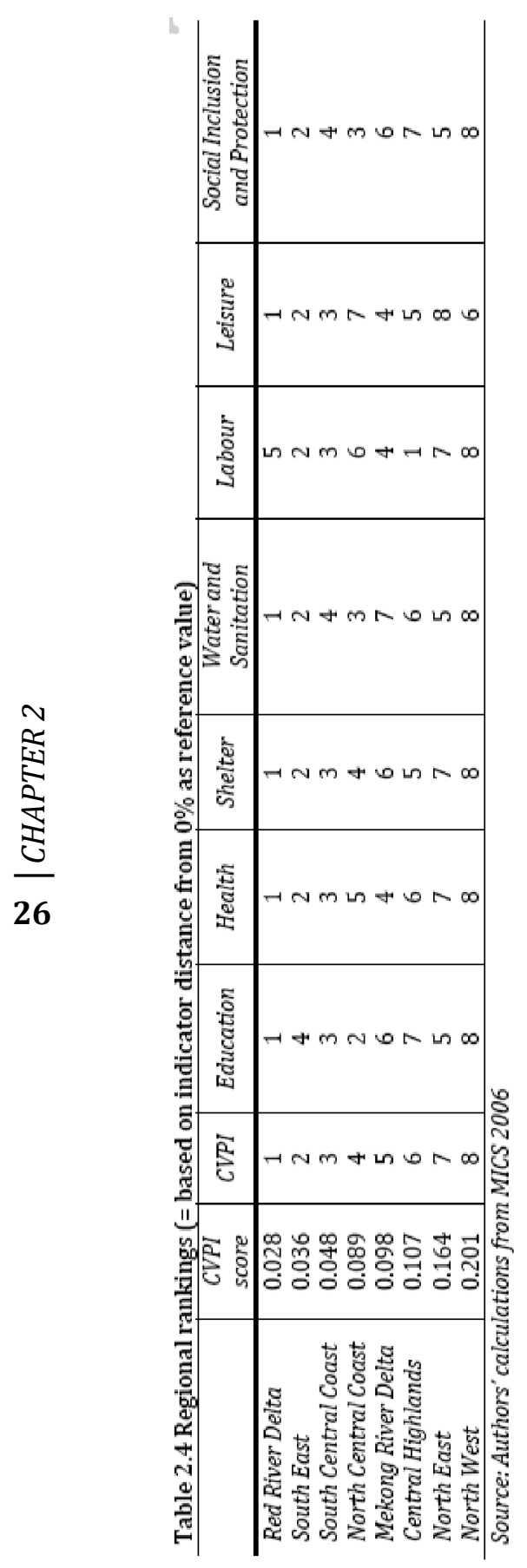


The empirical findings from both the CVPR as well as CVPI are valuable for advocacy and policy input in Vietnam. Due to the intuitive nature of the CVPR and its recognition of issues relevant for children in Vietnam, it is an appealing tool to create awareness about child poverty in the country. The outcomes are understandable and meaningful for the general public as well as for more informed stakeholders. Further, due to the explicit discussion of underlying concepts and constructs, the findings can be presented with full transparency and information. The same holds for the CVPI. In combination with the CVPR, the index estimates provide valuable input for especially policy makers at the regional level. The CVPI provides an insight into regional performance while the CVPR can complement this with detailed information at the individual level of the child. The opportunities and limitations of both tools are clear due to the structured development guided by the generic construction process. This clarity ensures that the tools are adequately used for the appropriate purposes in the proper context.

\subsection{Conclusion}

This paper argues and illustrates the importance of making conscious and explicit choices and decisions when developing or using a child poverty approach. Many scholars have voiced, in different contexts and forms, the strong links between different underlying elements of poverty approaches and the importance of acknowledging them to arrive at sound poverty analysis. Nevertheless, many child poverty studies, either focusing on the development or application of a child poverty approach, fail to explicitly discuss definitions and concepts. As a result, approaches might overlook other, possibly more suitable, options and opportunities in their development or create confusion about why a specific group of children is identified as poor or not. This paper proposes a generic construction process that serves as guide for those wishing to develop or apply any child poverty approach, responding to researchers that call for more transparency and acknowledgement of underlying concepts. The process contributes to unambiguous and solid foundations of child poverty approaches and avoids misunderstandings and -interpretations when used for analytical or policy purposes.

The application to the case of Vietnam illustrates that the generic construction process ensures a consistent and structured development of a child poverty approach as it guides you through the various steps in a logical sequence. As each step builds on the previous, one is forced to be explicit in each one of them and to make a solid decision. This does not only benefit the actual development of the approach but also the consequent use in analytical or policy terms. The clear and transparent discussion assists scholars, practitioners and policy makers in choosing the appropriate approach for their intentions and to adequately interpret the results and findings. In Vietnam, one can now benefit from child poverty estimations that are geared to the specific cultural and social context, multidimensional and child-focused to create awareness about the issue of child poverty and inform policies towards the reduction of child poverty.

This study focuses primarily on child poverty measurement but further research is required to explore the use of the generic construction process in other contexts. For 
the time being, we strongly encourage the development and implementation of any type of poverty approach to take place in an explicit and transparent manner. 


\section{Chapter 3}

\section{CHILD POVERTY IN VIETNAM - PROVIDING INSIGHTS USING A COUNTRY-SPECIFIC AND MULTIDIMENSIONAL MODEL 18}

In the last two decades, the issue of child poverty has received increasing attention worldwide. The acknowledgement in Vietnam that child-specific poverty measurement is crucial for poverty efforts directed towards children, and the current lack thereof, instigated the development of a Vietnam child poverty approach. In this paper, we develop a country-specific, multidimensional and outcome-based child poverty approach, taking into account policymakers' perspectives and current advances in child poverty measurement. The approach is applied to household survey data from 2006 to obtain an in-depth child poverty profile. Findings suggest that 37 percent of all children in Vietnam live in poverty, with the most pressing areas of deprivation being water, sanitation and leisure. Further, we do not find evidence for a gender bias but do observe a large urban-rural divide, regional disparities and large ethnic inequalities. We argue that this tailor-made approach is a valuable new tool for policy makers and analysts in Vietnam as it enables identification and analysis of poor children, their characteristics and most pressing areas of deprivation within the country's specific social and cultural context.

18 Based upon:

Roelen, Keetie, Franziska Gassmann and Chris de Neubourg (2009) Child Poverty in Vietnam - providing insights using a country-specific and multidimensional model, Social Indicators Research, DOI: 10.1007/s11205-009-9522-x and Roelen, Keetie and Franziska Gassmann (20xx) Multidimensional Child Poverty in Vietnam - a case study in A. Minujin (Eds) Child Poverty: A global perspective, Policy Press, forthcoming. 


\subsection{Introduction}

The need for a child focused perspective in the development and poverty reduction process has been widely recognized over the last decade (e.g. CHIP 2004, Gordon et al. 2003a, 2003b, Minujin et al. 2005) ${ }^{19}$. Several reasons can be put forward for the importance of such a child-focused approach towards poverty (see e.g. Boyden 2006, Gordon et al. 2003a, 2003b, Minujin et al. 2005, Young Lives 2001; Waddington 2004). High dependency on the direct environment for the distribution of basic needs puts children at a higher risk of poverty and makes their situation less transparent (e.g. White, Leavy and Masters 2002). Further, poverty often manifests itself as a vicious circle, causing children to be trapped in poverty from birth onwards (e.g. Corak 2006a; DWP 2002). Moreover, children have different basic needs than adults do (e.g. Waddington 2004) and childhood deprivation can have life-long adversary effects (Duncan and Brooks-Gunn 1997). Child-focused poverty approaches are crucial to account for these issues and provide detailed information at the level of the individual child. A generally accepted definition and measurement method of child poverty is an important tool for both academics and policy makers. It does not merely offer the opportunity to get an insight into the poverty status of children but also provides the possibility to formulate and monitor sound poverty reduction objectives, strategies and policies (e.g. Ben-Arieh 2000; Corak 2006).

The country of Vietnam has experienced a period of outstanding rapid economic growth, after the Doi Moi (renovation) reform policies that came into place in the late 1980's. Central planning made way for free-market oriented economic policies, bringing about great changes in the agricultural sector, private business and employment development, foreign trade and social sector policies, creating business and entrepreneurial opportunities for Vietnamese as well as foreigners. The reforms proved to be greatly beneficial for Vietnam's economic performance, with average economic growth rates of 6.9 percent from 1988 to 1994 and 7.4 percent from 1994 to 2000 (Glewwe 2004). Furthermore, monetary poverty was also reduced notably; from 58 percent in 1993 to 19.5 percent in 2004 (VASS 2006). The demographic decomposition of these poverty figures in terms of region, gender and ethnicity are widely available and studies of specific groups well-documented (see e.g. Baulch et al. 2007, Minot 2000, Minot and Baulch 2004, Nguyen 2007). Analysis of various age groups, however, is less common and as a consequence little is known about children and their situation in Vietnam. Until now, there have not been any comprehensive poverty analyses in Vietnam for children, presenting a knowledge gap for policy makers and analysts in their efforts to design, implement and evaluate policies directed towards children.

This paper presents a tailor-made approach for measuring child poverty in Vietnam and analyzes its empirical outcomes on the basis of data from the 2006 Multiple Indicator Cluster Survey (MICS). The remainder of this paper is structured as follows: firstly, the concepts and underlying theories of the multidimensional versus monetary poverty are discussed. Secondly, the processes of identification and aggregation are described, leading to the set of domains and indicators. Next, the data

19 This paragraph shows overlap with section 1.2; readers having read that section are advised to continue with the next paragraph. 
and its opportunities and limitations are outlined. The conceptual framework is then extended to a practical construction and findings for multidimensional child poverty incidence, depth and severity are presented and discussed. Finally, we draw conclusions about the value and use of the approach put forward in this paper in both academic and policy terms.

\subsection{Conceptual Framework}

Different scholars have emphasized the importance of having a clear understanding of the underlying rationale and concept of a poverty approach to be able to adequately and appropriately use it (e.g. Ravallion 1994, Roelen et al. 2009a, Laderchi et al. 2003, Vandivere and McPhee 2008) and the lack thereof in many poverty debates (Noble et al. 2006). Avoiding this fallacy, we firstly outline the conceptual framework of our child poverty approach before turning to other definitional and methodological choices inherent to the development of a (child) poverty approach.

The approach's conceptual framework is a result of extensive discussions and deliberations with policymakers (including line ministries, UN agencies and other international organizations ${ }^{20}$ ) and a careful assessment of current advances in child poverty measurement. A first step in the conceptual framework is to consider a monetary versus multidimensional focus, a division that is commonly made within the area of poverty measurement. While monetary definitions refer to the measurement of poverty on the basis of income or expenditures, multidimensional measurement incorporate a larger range of attributes that are assumed to reflect the state of poverty. Money-metric poverty measurement was and remains the most widely used method for poverty analysis world-wide (Redmond 2008, Laderchi et al. 2003), based on the rationale that individuals with a certain degree of purchasing power are able to fulfil their basic needs (Thorbecke 2008, Tsui 2002). However, an increasing number of scholars reject the conceptual notion that monetary measures adequately reflect the state of human development (Wagle 2009). Moreover, there are a number of drawbacks of the monetary approach, also in terms of child poverty measurement. Its underlying rationale assumes that all attributes for the fulfilment of basic needs can be purchased on markets and expressed in monetary terms. However, in many instances those markets do not exist or function imperfectly (Thorbecke 2008, Bourguignon and Chakravarty 2003, Tsui 2002) and monetary values can not be assigned to specific attributes ${ }^{21}$ (Thorbecke 2008, Hulme and McKay 2008). Further, when individuals or households have sufficient income for the purchase of a basic basket of goods, it does not directly imply that it is also spent on this basket of goods (Thorbecke 2008). Also, income is predominantly measured at the household level, not capturing intra-household distribution (Hulme and McKay 2008). Finally, children are not economic agents and therefore not able to generate income to sustain their

20 The first identification of the rationale and purpose of the child poverty approach in Vietnam was primarily the result of extensive discussions and interviews with UNICEF Vietnam and the Ministry of Labour, Invalids and Social Affairs (MOLISA) in Vietnam.

21 Consider attributes such as literacy, numeracy, life expectancy, social participation and information. 
own livelihood, making monetary indicators inadequate tools for capturing child poverty (White, Leavy and Masters 2002). Against the backdrop of these conceptual and technical drawbacks of the money-metric poverty approach, we deem it more suitable to develop a multidimensional approach for the measurement of child poverty in Vietnam, including other aspects than income that are considered to more adequately reflect the state of poverty.

A second consideration within the approach's conceptual framework concerns opportunity versus outcome-based measurement. Amartya Sen's work $(1976,1979,1985)$ on poverty and the capability approach was groundbreaking for the topic of multidimensional poverty measurement, focusing on individuals' capabilities to reach an improved standard of living that is not merely reflected by income. Capabilities can also be referred to as a "[...] persons freedom to promote or achieve valuable functionings." (Alkire 2002). In other words, the capabilities approach can thus be classified as an opportunity-based theory as opposed to an outcome-based one (Robeyns 2003) or ex-ante rather than ex-post method (Thorbecke 2008). We choose to focus on an outcome-based rather than opportunitybased approach for two reasons. Firstly, capabilities and opportunities are very hard to define and observe, making it difficult to operationalize Sen's approach (Alkire 2002). Secondly, children might not have the power to fully utilize their set of capabilities. They are dependent on their direct environment, including parents, family and community, to turn capabilities into positive outcomes. Therefore, it is preferable to focus on outcomes to learn about children's actual state of living (Thorbecke 2008).

Furthermore, the approach presented here is child-specific, measuring child poverty at the level of the individual child. Focusing on the individual child as unit of analysis ensures that the actual situation of that child is considered and there is no need for assumptions about the distribution of resources within the household (White et al. 2002). The importance of a child-centric analysis with respect to poverty is also emphasized within the deprivation approach (Gordon et al. 2003a, 2003b) and a model of child poverty for South Africa (Noble, Wright and Cluver 2006).

Finally, the proposed approach is tailored to fit the social and cultural context of Vietnam, including issues that are deemed to adequately reflect child poverty. Along the lines of the consistency versus specificity trade-off (Thorbecke 2008), we have chosen to be specific at the national level to enable consistent intra-country comparisons. Employing a country-specific approach also provides the opportunity to incorporate country-specific thoughts and processes on child well-being such as the Law on the Protection, Care and Education of Children (Socialist Republic of Vietnam 2004) and ensures the usefulness of this approach for its intended purposes, namely policy advocacy, design and evaluation in Vietnam.

\subsection{Identification and Aggregation}

On the basis of these premises, a number of choices have to be made in the actual construction of the child poverty approach. Sen (1976) referred to a two-step process in poverty measurement, namely identification and aggregation. Identification can be said to refer to the selection of domains and indicators, thresholds within each domain, weights and the multidimensional poverty line (Alkire and Foster 2008). 
Aggregation concerns the summary of individual level information to an aggregate statistic.

By definition, a multidimensional approach is comprised of a set of domains, reflecting different aspects that are considered to constitute poverty. Indicators are selected to give a comprehensive representation of the development within the respective domains. An elaborate discussion on the choice of domains and indicators is important as it is subject to value judgments, which should be made as explicit as possible, and should be firmly grounded in the academic and policy arena (Alkire 2002). While some scholars, such as Nussbaum $(2000,1992)$, suggest the use of a universal list of domains and indicators, others advocate for a context-specific set (Alkire 2008). Sen (1993) proposes that a set of domains or indicators "[...] has to be related to the underlying concerns and values" (Sen 1993, p. 32). Therefore we select domains and indicators that are specific to the situation for children in Vietnam, thereby ensuring its relevance for national analysts and policy makers. Alkire (2008) and Biggeri (2007) identified various methods for the selection of domains for multidimensional poverty measurement purposes. These selection methods include the assessment of available data, expert opinions or assumptions, public consensus, participatory assessments and empirical evidence about people's values with respect to poverty and well-being (Alkire 2008, Biggeri 2007). All these methods have advantages and disadvantages to its use and alone do not suffice as a valid selection method (Alkire 2008). Robeyns (2006) further describes an ideal-feasible choice process as one of the several procedural criteria in the selection of domains and indicators.

A combination of Alkire (2008) and Biggeri's (2007) selection methods against the backdrop of Robeyns' (2006) ideal-feasible process was used for the selection of domains and indicators. Ideal indicators, on the basis of assumptions, expert opinions, public consensus and participatory data, were immediately screened against indicator characteristics that followed from the approach's conceptual framework. Firstly, the indicators should ideally be child-specific. Nevertheless, it is inevitable to measure certain indicators related to shelter, water and sanitation at the household level as such data is only available at the household level (Gordon et al. 2003a, 2003b). Secondly, indicators should be easily observable and thereby measurable (Moore, Lippmann and Brown 2004), implying that indicators about quality of services, for example, are difficult to include in our list of indicators. Thirdly, indicators should be easily interpretable. To be able to use indicators for the provision of information about a certain aspect of child poverty and to feed into the policy making and monitoring process, they should be easily interpretable in an unambiguous way (Moore, Lippmann and Brown 2004). Fourthly, indicators should be factual. Hence, they should measure facts rather than subjective opinions and have the same meaning over time as well as different groups within the overall reference population (Gordon et al 2003b). Finally, the indicators should adhere to the values and norms of the specific society in order to be meaningful (Thorbecke 2008). In this study, the chosen indicators should fit the Vietnamese context and are as such culture and societyspecific.

The method of assumptions and expert opinion inspired a first set of domains and indicators, complemented by those identified on the basis of public consensus. Next, participatory processes were employed to account for the views of stakeholders and 
key-informants, thereby ensuring the incorporation of the Vietnamese context. A final selection mechanism at work during the identification process for domains was the assessment of existing data and data availability. The ideal list of domains included income, education, health, nutrition, transport, communication, subjective well-being, safety, shelter and water and sanitation, social inclusion and protection. Keyinformants interviews, an in-depth assessment of available data and consistency check with the conceptual framework provided a reduced and final feasible list of seven domains and twelve indicators, see Table 3.1. The income dimension was left out of consideration because it was considered a means to an end rather than an end in itself and did not fit the pre-defined purpose and outcome-based concept of the approach. The issues of communication, safety and transport were not considered dimensions properly reflecting the poverty status of Vietnamese children and did not fit the country's context. The dimension referring to children's nutrition had to be left out of consideration due to data constraints. Lack of data also restricted the inclusion of more indicators with respect to social protection and inclusion.

Table 3.1 Indicators of the Vietnam child poverty approach 22

\begin{tabular}{l|l}
\hline Domain & Indicators \\
\hline \multirow{2}{*}{ 1. Education poverty } & \% of children not enrolled at the appropriate level \\
\cline { 2 - 2 } & $\%$ of children not having completed primary school \\
\hline 2. Health poverty & $\%$ of children not fully immunized \\
\hline \multirow{2}{*}{. Shelter poverty } & $\%$ of children living in dwellings without electricity \\
\cline { 2 - 2 } & $\%$ of children living in dwellings without proper roofing \\
\cline { 2 - 2 } & $\%$ of children living in dwellings without proper flooring \\
\hline \multirow{2}{*}{ p. Water and Sanitation } & $\%$ of children living in dwellings without hygienic sanitation \\
\cline { 2 - 2 } 5.Child work & $\%$ of children living in dwellings without safe drinking water \\
\hline 6. Leisure poverty & $\%$ of children working \\
& $\%$ of children not having toys \\
\cline { 2 - 2 } 7. Social inclusion and & $\%$ of children not having at least one book \\
protection poverty & $\%$ of children not having their birth registered \\
\hline
\end{tabular}

After having identified the set of domains and indicators, one has to consider the question of how to weigh these different elements in constructing the composite measure (Alkire and Foster 2008). Regardless of the weighting scheme chosen, it is subject to value judgments and remains a debatable issue. Existing (child) poverty approaches have opted for different schemes, some applying equal weighting (e.g. Gordon et al. 2003, Bradshaw et al. 2006, Land 2001) while others have used statistical inference methods such as principal component analysis (e.g. Tanton et al. 2006) or stated preference methods (e.g. Kruijk and Rutte 2007, Watson et al. 2008). The choices for these methods are inspired by practical and feasibility considerations, conceptual motivations and technical reasons. With respect to the child poverty approach in Vietnam, we opt for an equal weighting strategy. Conceptual considerations have not resulted in compelling reasons to assign greater weight to certain domains over others. Moreover, applying factor analysis did not provide results in support of differential weights for different indicators or domains. Finally,

22 Please refer to 3.8.1 Annex 1 for the exact definition of indicators and cut-off points. 
Hagerty and Land (2007) argue that the use of an equal-weighting strategy is justified in case stated preferences are unknown.

The multidimensional poverty line of our approach for calculating the poverty headcount is based on a dual cut-off identification strategy (Alkire and Foster 2008) as opposed to other options such as the union and intersection approach (Atkinson 2003). The dual cut-off identification strategy implies that a child is identified as being poor when he/she is vulnerable in at least two domains. In turn, domain poverty is constituted by not meeting the poverty line for at least one of the indicators within that domain. Poverty in at least one domain constitutes poverty in terms of the union approach and poverty in all domains constitutes poverty along the definition of the intersection approach (Atkinson 2003). While the intersection approach is generally considered to be too constricting, excluding too many from the definition of poverty, the union approach is widely thought to be too inclusive and leads to overestimations of poverty (Alkire and Foster 2008). The dual cut-off identification strategy is an alternative measure, which satisfies a number of important properties such as decomposability, symmetry and dimensional monotonicity (Alkire and Foster 2008) 23. This type of aggregation of the poor, defining a poverty limit for each attribute and aggregating over attributes per individual rather than aggregating over individuals per attribute, was pioneered by Bourguignon and Chakravarty (2003) and influenced concurrent development of multidimensional (child) poverty approaches (see Gordon et al. 2003, Alkire and Foster 2008).

In addition to the poverty headcount, we also consider the depth and severity of child poverty in terms of a child poverty gap and severity measure. A simple count of deprivations would not suffice for these purposes and provide biased results as not all indicator deprivations are observable for children of all ages ${ }^{24}$. In response to this issue, we calculate the normalized child poverty gap, dividing the total number of observed deprivations by the maximum number of observable deprivations per individual child. The child poverty gap ratio indicates the average poverty gap of the total population as a percentage of the maximum number of observable deprivations. Child poverty severity is consequently calculated by taking the square value of the normalized poverty gap, thereby assigning greater weight to those children with a larger poverty gap. The calculation of the child poverty depth and severity in this manner is in line with the calculation of the monetary poverty indicators and can be used parallel in a comprehensive poverty analysis. To our knowledge, the only previous attempt to measure the depth and severity of child poverty was undertaken

23 The technical notation of the calculation of child poverty figures can be found in chapter 6 .

${ }^{24}$ For example, indicators with respect to education are only collected for children from 5 years and upwards while information with respect to leisure and social inclusion and protection is only available for children below the age of 5 years. A total count of deprivations would thus bias the results in terms of child depth and severity towards children for whom more deprivations are observable. The fact that not all indicators are observable for children of all ages creates difficulties in terms of measurement and direct comparisons but makes sense in conceptual terms. Whilst the observation of child immunization (which is only observed for children 2-4 in the current data) would be meaningful for a 8-year old child, it is not conceptually meaningful to have an observation with respect to education or child labour for a 2-year old child. 
by Delamonica and Minujin (2007). However, rather than focusing on the individual child, they focused on the household as the unit of analysis.

\subsection{Data}

The data used for our study is the Multiple Indicator Cluster Survey (MICS) from 200625. The Vietnam MICS is based on the standardized MICS surveys as technically supported by UNICEF. The first and second round was conducted in 1995 and 2000, while the third round was completed in 2006. The survey contains a range of questions especially focused on education, health, accommodation,

HIV/AIDS and is separated into a questionnaire for households, women of reproductive age and children under five. Regions were identified as the main sampling domains and the sample was selected in two stages, based on enumeration areas from the census (GSO 2007). The sample consists of a total number of 8.356 households with 36.573 individuals out of which 10.874 are children up to 16 years of age. Household surveys like the MICS provide micro-data at the level of the individual child, allowing for the possibility to derive all deprivations back to the individual child. A number of limitations are also inherent to the use of the MICS. Micro-data from the survey is not collected for all children of all age groups, data on nutrition is not available at the time of writing and the sampling method of the MICS (and other household surveys in Vietnam) causes a substantial group in the society to be omitted from the sample and subsequent data. The sample for the survey is constructed on the basis of the official lists of registered households that have lived in the enumeration area for at least six months (Pincus and Sender 2006, 2008). This implies that households or individuals that have recently migrated are not included in the sampling frame (Edmond and Turk 2004). Furthermore, due to the strict household registration system, or ho khau system, many households and individuals do not satisfy the necessary criteria to newly register and thus stay unregistered (Pincus and Sender 2006, 2008). The omission of this group in society is not only an important issue to point out because of its suspected significant size but even more so because of the denial of social and public services they experience due to their status. The structural exclusion of this group from the data will most likely result in underestimations for child poverty.

\subsection{Child Poverty Incidence, Depth and Severity}

In this section, we present empirical outcomes for the child poverty approach at the indicator level as well as aggregate level. Tables 3.2 and 3.3 present the indicator poverty rates that lie at the heart of the child poverty approach. They indicate the proportions of children not meeting the thresholds for individual indicators as a share of all children for whom the indicator can be observed.

25 This section is a more elaborate discussion of the MICS data than presented in chapter 2. 


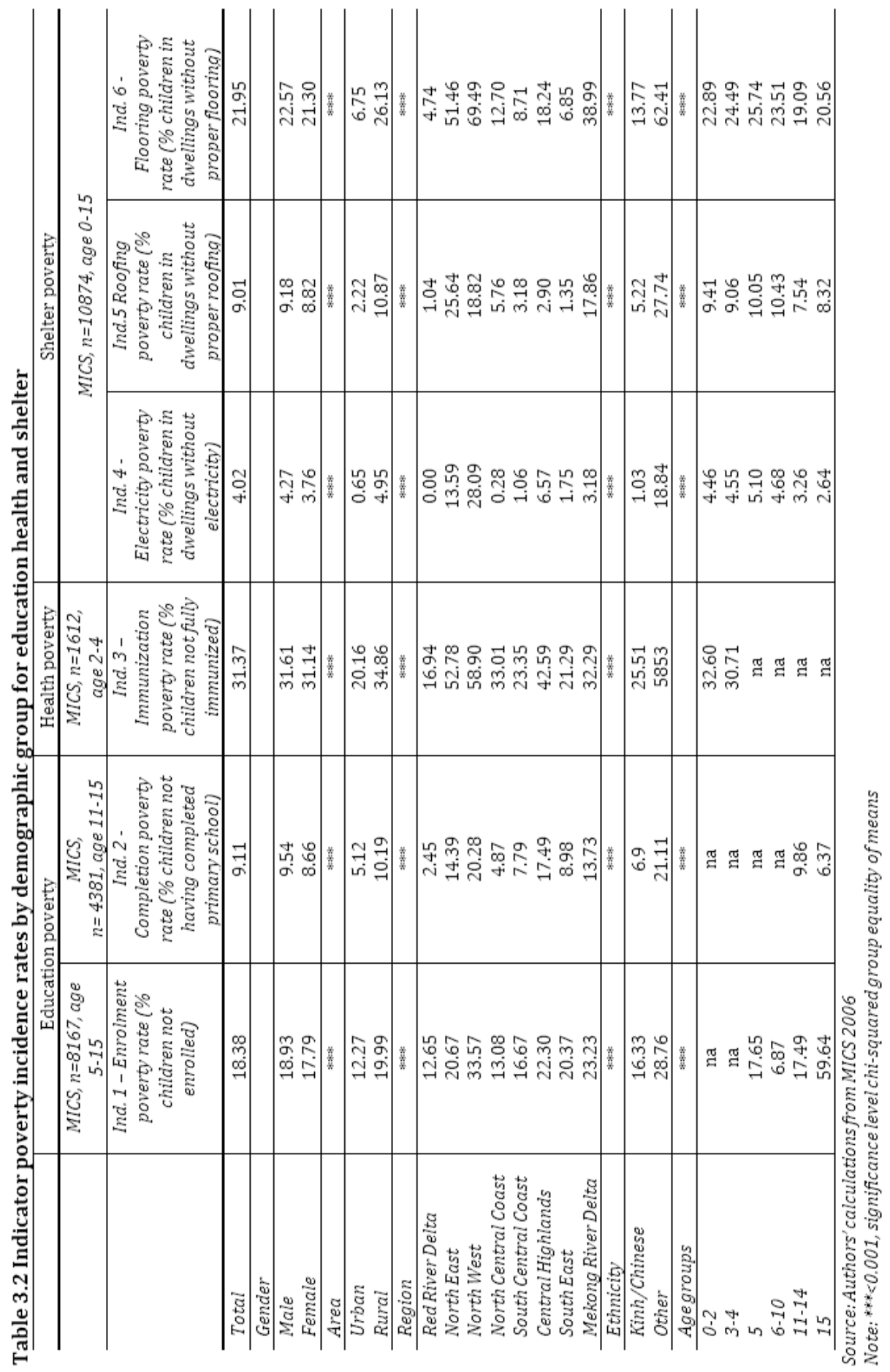




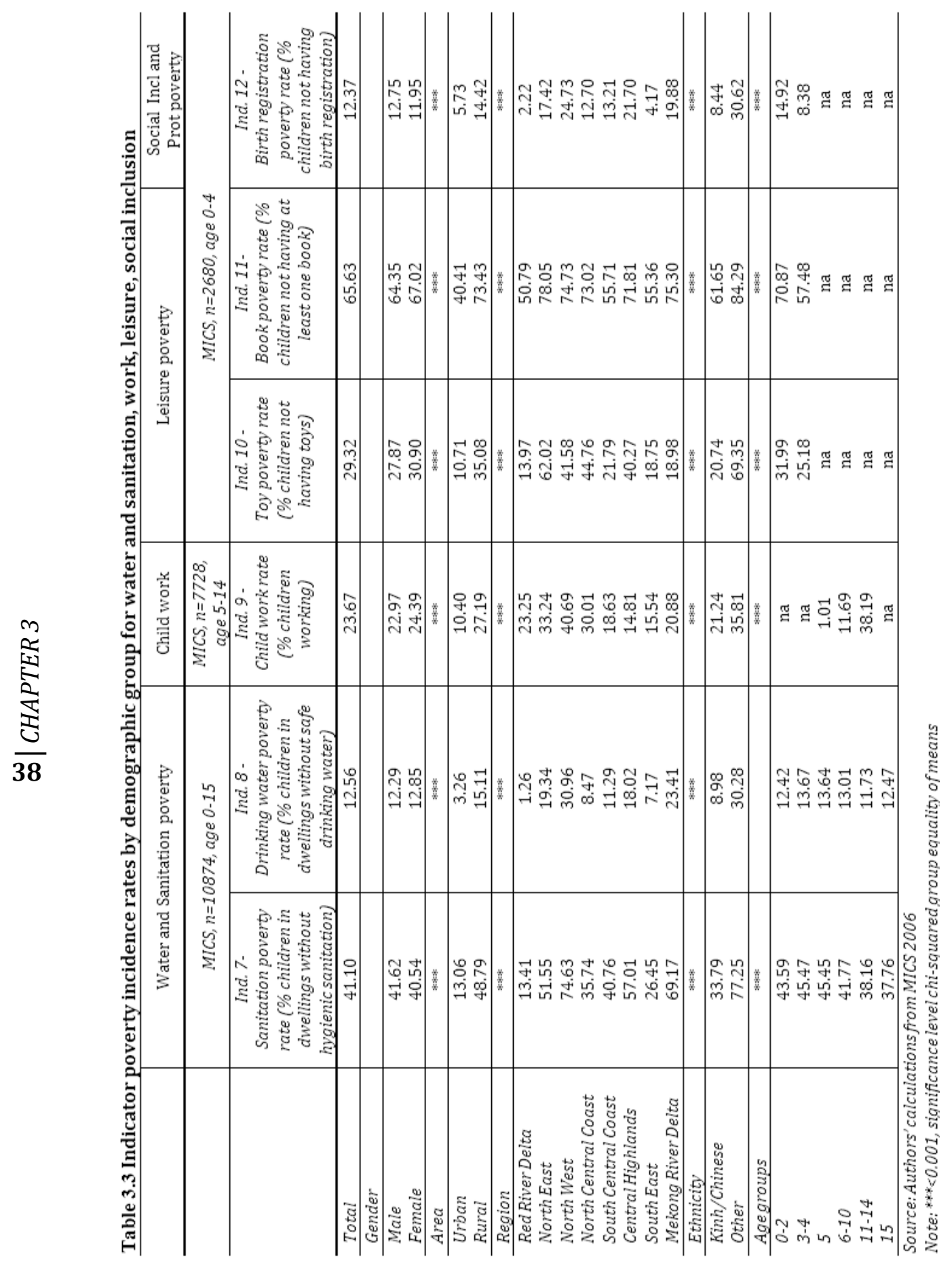


The results suggest that the most pressing areas of poverty are leisure, sanitation and health. Almost two-thirds of children up to age five do not have a children's or picture book and 41 percent of all children live in a dwelling without a hygienic sanitation facility. One out of three children aged 2 to 4 have not received the full package of vaccinations. The overall poverty incidence for the indicators referring to the availability of toys, child labour and type of flooring in the dwelling that the child resides in is between 20 and 30 percent. Almost one out of five children aged 5-15 are not net enrolled. Primary school completion, electricity and proper roofing in the child's dwelling, safe drinking water and birth registration are indicators with the lowest overall poverty rates, ranging from 4 to 13 percent. Demographic decomposition of these figures displays large disparities for some groups, which can also differ from indicator to indicator. Across the board, there is no sign of gender inequality. All indicators display fairly equal poverty rates for boys and girls. Decomposition by area, however, suggests a large urban-rural divide in Vietnam. Although significant, the rates and their differences are fairly modest with respect to the educational and social protection indicators. However, large disparities can be observed especially when considering the water and sanitation and shelter domains. Poverty incidence in terms of these indicators is four to seven times higher in rural areas than it is in urban areas. Regional results also display considerable differences with respect to indicator poverty rates. The Red River Delta region holds the smallest percentage of vulnerable children in terms of all indicators, except for child labour. The Northern mountainous North West and North East regions are always among the regions with the highest proportion of vulnerable children followed by the Mekong River Delta and Central Highlands regions. Nevertheless, the regional rankings of poverty rates differ from indicator to indicator, especially among the middle rankings. The North Central Coast region, for example, ranks second best with respect to the educational indicators while it has the second largest poverty rate when considering the leisure domain. Finally, interpretation of age group results is less straightforward as not all indicators are observed for all children. Nevertheless, the results indicate, in line with intuition, that older children are more vulnerable with respect to net enrolment while a larger proportion of younger children suffer poverty in terms of leisure and social protection and inclusion.

The poverty results for the individual indicators are further aggregated to arrive at composite poverty indicators, which are presented in Table 3.4. Along the lines of the union approach, child deprivation is constituted by deprivation in at least one domain. By the same token, the dual cut-off identification strategy implies that child poverty is based on deprivation in at least two domains.

Table 3.4 Child deprivation and poverty incidence rates by demographic groups

\begin{tabular}{l|c|c}
\hline & $\begin{array}{c}\text { Child Deprivation Rate } \\
\text { (one-domain poverty } \\
\text { line) }\end{array}$ & $\begin{array}{c}\text { Child Poverty Rate } \\
\text { (two-domain poverty } \\
\text { line) }\end{array}$ \\
\hline Total & 66.97 & 36.65 \\
\hline Gender & & 36.86 \\
\hline Male & 66.39 & 35.42 \\
\hline Female & 67.58 & $* * *$ \\
\hline Urea & $* * *$ & 12.04 \\
Rural & 38.80 & 43.40
\end{tabular}




\begin{tabular}{l|c|c}
\hline Region & $* * *$ & $* * *$ \\
\hline Red River Delta & 47.63 & 11.26 \\
North East & 80.20 & 58.76 \\
North West & 93.09 & 77.65 \\
North Central Coast & 68.49 & 30.95 \\
South Central Coast & 60.61 & 28.79 \\
Central Highlands & 74.21 & 40.53 \\
South East & 55.14 & 22.63 \\
Mekong River Delta & 83.20 & 59.95 \\
\hline Ethnicity & $* * *$ & $* * *$ \\
\hline Kinh/Chinese & 61.51 & 28.27 \\
Other & 93.96 & 78.09 \\
\hline Age group & $* * *$ & $* * *$ \\
\hline $0-2$ & 82.98 & 51.12 \\
$3-4$ & 76.50 & 52.04 \\
5 & 60.52 & 28.08 \\
$6-10$ & 56.21 & 27.30 \\
$11-14$ & 65.38 & 35.05 \\
15 & 73.59 & 36.14 \\
\hline
\end{tabular}

Source: Authors' calculations from MICS 2006

Note: ${ }^{* * *}<0.001$, significance level chi-squared group equality of means

Overall child deprivation amounts to 67 percent, while 37 percent of all children are identified to be poor. The patterns for both child deprivation and child poverty considering different demographic groups are similar to those observed for individual indicators. There is no significant difference in poverty incidence for boys and girls. Furthermore, poverty incidence is much higher in rural areas than it is in urban areas, regardless of the poverty definition used. Rural child deprivation is 74 percent compared to 39 percent in urban areas. The disparity is even greater in terms of child poverty with respective rates of 12 and 43 percent. Regional figures point towards the North West and North East regions as bad performers while the Red River Delta and South East regions hold the lowest poverty rates. Child poverty has an incidence rate of 11 percent in the Red River Delta, while this amounts to 78 percent in the North West region. These large spatial differences have also been identified in previous studies relating to monetary indicators (see e.g. Minot and Baulch 2004, Minot 2000, Nguyen 2007). With respect to age groups, we observe high rates of poverty for the youngest children, in age brackets $0-2$ and 3-4, and the oldest children of age 15 . These results, however, only present a partial picture as not all indicators are observable for all children. For example, 7 indicators are observable for children in age bracket 6-10 while 9 indicators are observable for those in age bracket 3-4. Hence, the latter group by definition has more chance to be included in the poverty figures.

The figures in Table 3.4 indicate that child deprivation is almost twice as high as child poverty, basing poverty measurement on the union approach compared to the dual cut-off identification strategy. The high headcount rate for child deprivation confirms the previously identified inclusive nature of the method, suggesting that it suffers a large inclusion error and does not discriminate well between poor and nonpoor children. This finding underlines the conceptual reasoning to employ child poverty as the most preferred method. Moreover, we tested the robustness of results. Sensitivity was checked by plotting child poverty rates against various cut-off 
points/poverty lines for children living in different regions. Figure 3.1 indicates that poverty rankings only change when using cut-off points higher than two domains, illustrating the approach's robustness.

\section{Figure 3.1 Sensitivity plot poverty rates for different cut-off points}

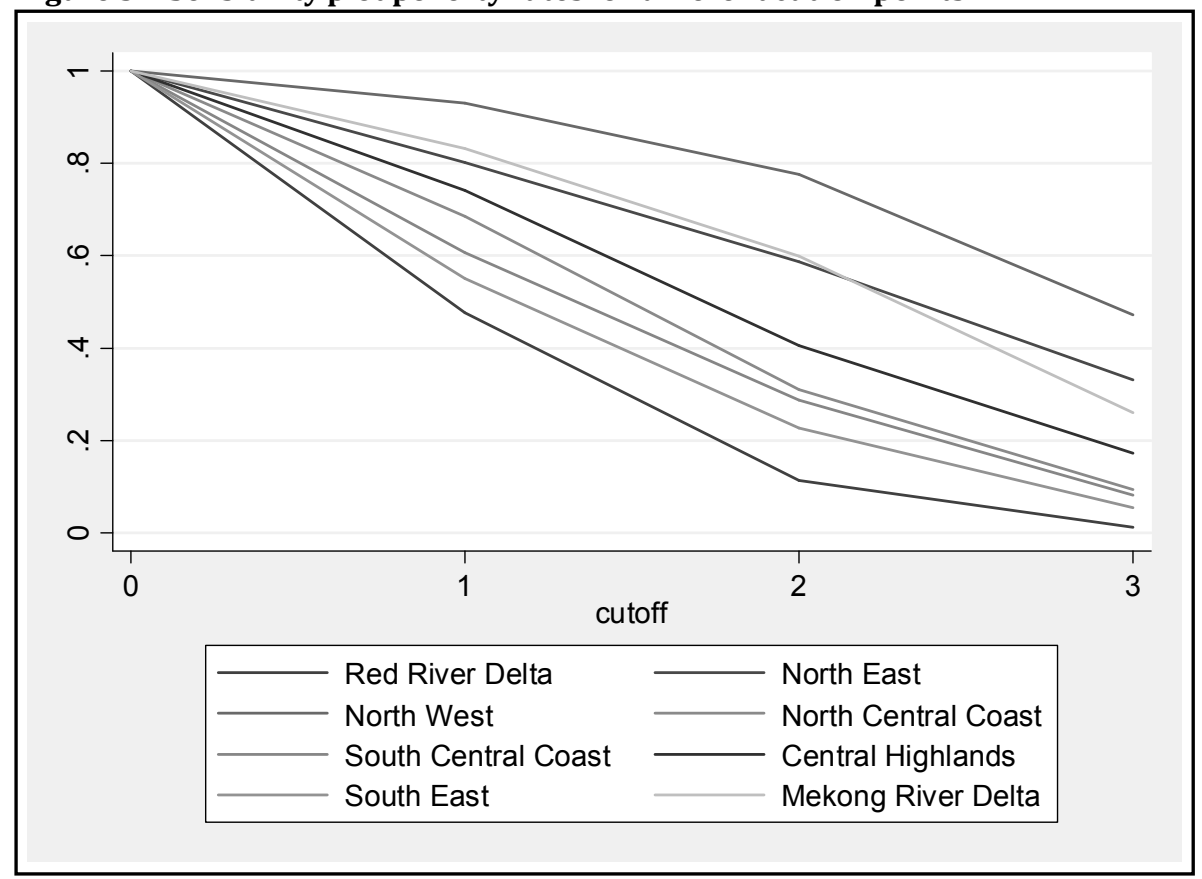

Source: Authors' calculations from MICS 2006

A more detailed picture of child poverty in Vietnam and the most common combinations of domain poverty can be obtained by considering the overlap of domain poverty. An insight into these combinations of domain poverty might provide important input into the policy formulation and design process when effectively aiming to reduce child poverty in multiple dimensions. The poverty incidence rates in Table 3.5 represent the proportion of children that are considered poor in both domains as a share of all children for whom both domains can be observed. For example, 6.7 percent of all children aged 5-15 that are deprived with respect to both education and shelter. Correlation coefficients for the corresponding combinations and their levels of significance are also reported in Table 3.5. 
Table 3.5 Overlap domain poverty and correlation matrix

\begin{tabular}{|c|c|c|c|c|c|c|c|}
\hline & education & health & shelter & $\begin{array}{l}\text { water and } \\
\text { sanitation }\end{array}$ & labour & leisure & $\begin{array}{c}\text { social } \\
\text { inclusion } \\
\text { and } \\
\text { protection } \\
\end{array}$ \\
\hline \multirow{3}{*}{ education } & $\begin{array}{c}5-15, \\
\mathrm{n}=8167\end{array}$ & \multirow{3}{*}{$\mathrm{x}$} & $\begin{array}{c}5-15, \\
\mathrm{n}=8167\end{array}$ & $5-15, n=8167$ & $\begin{array}{c}5-14, \\
\mathrm{n}=7228\end{array}$ & \multirow{3}{*}{$\mathrm{x}$} & \multirow{3}{*}{$\mathrm{x}$} \\
\hline & $187 \%$ & & $6.7 \%$ & $10.9 \%$ & $4.7 \%$ & & \\
\hline & $18.7 \%$ & & $0.1626^{*}$ & $0.1654^{*}$ & $0.1309^{*}$ & & \\
\hline \multirow{3}{*}{ health } & & $\begin{array}{c}2-4, \\
\mathrm{n}=1627\end{array}$ & $\begin{array}{c}2-4, \\
\mathrm{n}=1627\end{array}$ & $2-4, n=1627$ & \multirow{3}{*}{$\mathrm{x}$} & $\begin{array}{c}2-4 \\
\mathrm{n}=1627\end{array}$ & $2-4, n=1627$ \\
\hline & & $313 \%$ & $12.8 \%$ & $19.2 \%$ & & $23.2 \%$ & $4.2 \%$ \\
\hline & & $31.3 \%$ & $0.2745^{*}$ & $0.2209^{*}$ & & $0.2084^{*}$ & $0.2029^{*}$ \\
\hline \multirow{3}{*}{ shelter } & & & $\begin{array}{c}0-15 \\
\mathrm{n}=10874\end{array}$ & $\begin{array}{c}0-15 \\
\mathrm{n}=10874\end{array}$ & $\begin{array}{c}5-14, \\
\mathrm{n}=7228\end{array}$ & $\begin{array}{c}0-4, \\
\mathrm{n}=2707\end{array}$ & $0-4, n=2707$ \\
\hline & & & \multirow{2}{*}{$24.6 \%$} & $20.4 \%$ & $7.1 \%$ & $22.8 \%$ & $6.7 \%$ \\
\hline & & & & 0.4351* & $0.1167^{*}$ & $0.2574^{*}$ & $0.2730^{*}$ \\
\hline \multirow{3}{*}{$\begin{array}{l}\text { water and } \\
\text { sanitation }\end{array}$} & & & & $\begin{array}{c}0-15 \\
\mathrm{n}=10874\end{array}$ & $\begin{array}{c}5-14, \\
\mathrm{n}=7228\end{array}$ & $\begin{array}{c}0-4, \\
\mathrm{n}=2707\end{array}$ & $0-4, n=2707$ \\
\hline & & & & \multirow{2}{*}{$44.1 \%$} & $12.1 \%$ & $39.5 \%$ & $9.4 \%$ \\
\hline & & & & & $0.1043^{*}$ & $0.3232^{*}$ & $0.2660^{*}$ \\
\hline \multirow{2}{*}{ labour } & & & & & $\begin{array}{c}5-14, \\
\mathrm{n}=7228\end{array}$ & \multirow{2}{*}{$\mathrm{x}$} & \multirow{2}{*}{$\mathrm{x}$} \\
\hline & & & & & $23.7 \%$ & & \\
\hline \multirow{3}{*}{ leisure } & & & & & & $\begin{array}{c}0-4, \\
\mathrm{n}=2707\end{array}$ & $0-4, n=2707$ \\
\hline & & & & & & \multirow{2}{*}{$69.1 \%$} & $11.5 \%$ \\
\hline & & & & & & & $0.2257^{*}$ \\
\hline \multirow{2}{*}{$\begin{array}{l}\text { social } \\
\text { inclusion } \\
\text { and } \\
\text { protection }\end{array}$} & & & & & & & $0-4, n=2707$ \\
\hline & & & & & & & $12.4 \%$ \\
\hline
\end{tabular}

Source: Authors' calculations from MICS 2006

Notes: X indicates that no overlap could be observed due to non-corresponding age groups, ${ }^{*}<0.01$, significance level Phi correlation coefficient 


\section{False Positives or Hidden Dimensions $\mid \mathbf{4 3}$}

The most prevalent combinations of deprivation inevitably include domains with the highest poverty rates. The combined deprivation of leisure and water and sanitation is most prevalent with an incidence rate of 40 percent for children aged 0-4. In other words, 4 out of 10 children in Vietnam aged 0-4 suffer deprivation with respect to leisure as well as water and sanitation. Shelter and health poverty in combination with leisure poverty is suffered by respectively 23 percent of the different age groups. The domains referring to housing conditions are most strongly associated with a correlation coefficient of 0.435 . Despite high incidence rates, the correlation coefficients do not display a high degree of correlation between domain deprivations. These low coefficients are largely due to taking the whole child population in Vietnam as reference group. The poverty incidence rate is 37 percent, meaning that 63 percent of all children do not suffer deprivation in a combination of at least two domains. The inclusion of the non-poor children in the reference group weakens the overall correlation coefficients.

In addition to assessing the magnitude of multidimensional child poverty in Vietnam, we also consider its depth and severity. The methods used for the poverty gap and severity indicators are compatible with those used for the standard monetary poverty measurement. However, instead of taking the distance to the poverty line as underlying measure, we count the total number of observed indicator deprivations per individual child. In both the monetary and multidimensional poverty case, the poverty measures can take a value between 0 and 1 , a value of 0 representing no poverty gap or severity and higher values representing increasing values of poverty. Poverty gap and severity results for children of different demographic groups are presented in Table 3.6.

Table 3.6 Child poverty depth and severity

\begin{tabular}{l|c|c}
\hline Total & Child poverty gap ratio & $\begin{array}{c}\text { Child poverty severity } \\
\text { index }\end{array}$ \\
\hline Gender & 0.21 & 0.09 \\
\hline Male & 0.21 & 0.09 \\
Female & 0.21 & 0.09 \\
\hline Area & $* * *$ & $* * *$ \\
\hline Urban & 0.07 & 0.02 \\
Rural & 0.25 & 0.11 \\
\hline Region & $* * *$ & $* * *$ \\
\hline Red River Delta & 0.08 & 0.02 \\
North East & 0.31 & 0.16 \\
North West & 0.40 & 0.22 \\
North Central Coast & 0.16 & 0.05 \\
South Central Coast & 0.14 & 0.05 \\
Central Highlands & 0.22 & 0.09 \\
South East & 0.12 & 0.03 \\
Mekong River Delta & 0.28 & 0.12 \\
\hline Ethnicity & $* * *$ & $* * *$ \\
\hline Kinh/Chinese & 0.14 & 0.04 \\
Other & 0.41 & 0.22 \\
\hline Age group & $* * *$ & $* * *$ \\
\hline 0-2 & 0.29 & 0.14 \\
3-4 & 0.27 & 0.13
\end{tabular}




\begin{tabular}{l|l|l}
5 & 0.17 & 0.06 \\
$6-10$ & 0.16 & 0.06 \\
$11-14$ & 0.20 & 0.09 \\
15 & 0.23 & 0.10 \\
\hline
\end{tabular}

Source: Authors' calculations from MICS 2006

Note: ${ }^{* * *}<0.001$, significance level chi-squared group equality of means

Estimates in Table 3.6 indicate that the average normalized child poverty gap ratio is 0.21 and depth ratio 0.09 . In line with the child poverty incidence rates, we find that children in rural areas do not only face a higher poverty risk but also deeper and more severe poverty than children living in urban areas. The Northern mountainous regions are by far the poorest regions in terms of depth and severity with poverty gap ratios that are one and a half to twice the size of the average gap ratio and depth ratios that are 8 to 10 times higher than average. In terms of ethnicity, children belonging to ethnic minorities experience deeper and more severe poverty than children belonging to the Kinh/Chinese ethnic majority. Finally, the figures suggest that poverty depth and severity for children is high for young children, decreases with age until the age of 10 but increases again for children aged 11-15. Deep and severe poverty for young children could be attributed to the immunization and leisure indicators, which displayed high rates of deprivation. By the same token, higher child depth and severity ratios for children in older age brackets could be attributed to relatively high deprivation rates in terms of net enrolment and the child work indicator.

\subsection{Groups of child poverty}

An analysis of domain poverty by quintiles on the basis of the poverty gap and severity provides further insights into the poverty characteristics of those different groups. However, the poverty gap ratio and severity index based on the current methodology for multidimensional poverty measurement do not represent a continuous variable but consist of a limited range of values due to the count of indicator deprivations. Therefore, the population cannot be separated into quintiles that represent equal shares of the population. Table 3.7 presents an approximation of the poverty quintiles, separating the child population in five poverty groups on the basis of their degree of poverty.

Table 3.7 Poverty groups and their degree of poverty

\begin{tabular}{l|c|c|c|c}
\hline & $\begin{array}{c}\text { Proportion of } \\
\text { all children }\end{array}$ & $\begin{array}{c}\text { Poverty } \\
\text { incidence }\end{array}$ & $\begin{array}{c}\text { Average } \\
\text { poverty gap } \\
\text { ratio }\end{array}$ & $\begin{array}{c}\text { Average } \\
\text { poverty } \\
\text { severity index }\end{array}$ \\
\hline Total population & 100 & 36.7 & 41.8 & 20.4 \\
\hline Poverty group 1 & 33.0 & 0 & 0 & 0 \\
Poverty group 2 & 23.8 & 0 & 12.3 & 1.5 \\
Poverty group 3 & 18.5 & 39.8 & 17.9 & 3.4 \\
Poverty group 4 & 11.0 & 87.1 & 29.9 & 9.3 \\
Poverty group 5 & 13.7 & 100 & 58.7 & 36.1 \\
\hline
\end{tabular}

Source: Authors' calculations from MICS 2006 
Poverty groups 1 and 2 consist of children that are not considered poor. Children in group 1 do not suffer from poverty with respect to any indicator, whilst children in group 2 do suffer a degree of poverty albeit below the poverty line. Groups 3 and 4 include poor and non-poor children whilst group 5 consists solely of poor children. Depth and severity of poverty within these groups increases considerable from group 2 to 5 . On average, children in group 2 suffer poverty with respect to 12 percent of the maximum observable indicators whilst this amounts to 59 percent for the children in group 5. The poverty severity index confirms that children in the poorest quintile suffer considerably more severe poverty than children in the other quintiles. Table 3.8 provides further insight into the distribution of poverty over various demographic groups and types of domain poverty suffered by the group of poorest children.

Table 3.8 Distribution of poverty and domain poverty rates in the poorest quintile

\begin{tabular}{l|c}
\hline & Share of poverty in poorest quintile \\
\hline Gender & \\
\hline Male & 53.9 \\
Female & 46.1 \\
\hline Area & \\
\hline Urban & 3.9 \\
Rural & 96.1 \\
\hline Region & \\
\hline Red River Delta & 0.3 \\
North East & 31.5 \\
North West & 11.5 \\
North Central Coast & 8.6 \\
South Central Coast & 4.7 \\
Central Highlands & 6.1 \\
South East & 4.8 \\
Mekong River Delta & 32.5 \\
\hline Ethnicity & \\
\hline Kinh/Chinese & 56.7 \\
Other & 43.3 \\
\hline Age group & \\
\hline O-2 & 24.1 \\
3-4 & 17.7 \\
5 & 2.9 \\
6-10 & 14.6 \\
11-14 & 27.6 \\
15 & 13.1 \\
\hline & Domain poverty rate in poorest quintile \\
\hline Education poverty & 37.5 \\
Health poverty & 17.1 \\
Shelter poverty & 85.6 \\
Water and Sanitation poverty & 97.4 \\
Child work & 26.0 \\
Leisure poverty & 40.7 \\
Social inclusion poverty & 15.7 \\
\hline Source:Authors'calculations from & \\
\hline & \\
\hline & \\
\hline & \\
\hline & \\
\hline
\end{tabular}

Source: Authors' calculations from MICS 2006

Estimates on the distribution of poverty illustrate the share of poverty of various demographic groups in the poorest quintile. Figures suggest that a greater share of the 
poor is male than female, which is a reflection of the demographic distribution of gender in Vietnam. The large majority of poorest children live in rural areas in Vietnam, whilst the North East and Mekong River Delta regions together hold twothirds of all poorest children. Despite the disadvantaged position of ethnic minorities, more than half of the children in the poorest group are of the Kinh/Chinese ethnic majority as this group presents a larger proportion of the overall population. Estimates by domain poverty present the proportion of children in the poorest group suffering poverty in the specific domain. Findings indicate that almost all children in this group suffer from poverty with respect to water and sanitation. Shelter poverty is suffered by almost 9 out of 10 children in this group. Deprivation in other domains is more dispersed with 4 out of 10 children suffering poverty with respect to leisure and education and 1 out of 4 with respect to child work. When interpreting these results, however, one has to keep in mind that indicators in the shelter and water and sanitation domains are observable for all children in the sample while the health indicator, for example, is only observable for a restrictive age group. This limitation of the data is likely to result in an underestimation of poverty for those indicators and domains that are only observable for a restrictive group of children.

The findings above and its concurrent analysis illustrate that the child poverty approach put forward in this paper can serve as an alternative of or complement to the monetary poverty measurement. The presentation and interpretation is similar and provides a poverty profile for different groups of children in society. However, in contrast to standard money-metric poverty measurement approaches, the multidimensional methodology also allows for a breakdown of poverty by different areas of development or well-being. This allows for a more in-depth poverty analysis that can add value to the academic debate as well as policy process.

\subsection{Conclusion}

In this paper, we propose a new approach for measuring child poverty in Vietnam, taking a multidimensional and child-specific perspective. It provides conceptual as well as empirical outcomes that add value to the debate on child poverty measurement in the academic and policy arena. The development of a child poverty approach that is multidimensional in nature combined with an outcome, child-specific and country-specific focus and including a measurement for poverty incidence, depth and severity comprises the study's contribution in conceptual terms. Empirical outcomes include a detailed multidimensional child poverty analysis for Vietnam, providing breakdowns by demographic groups as well as indicator and domain poverty.

Conceptually, this paper explores the development of a country-specific approach to capture child poverty in a multidimensional matter. It illustrates the process of development and the inherent choices and decisions that one has to make to construct a sound and solid approach. Empirical findings highlight a number of relevant issues. Child poverty incidence estimates indicate that every third child in Vietnam is multidimensionally poor. The most pressing areas for children in Vietnam are water and sanitation, leisure and shelter. Domain poverty is lowest with respect to education. The poverty profile on the basis of demographic decomposition does not display any signs of gender inequality but does point towards a large urban-rural 
divide and regional disparities in terms of poverty incidence as well as depth and severity. Infants as well as children in the oldest two age brackets are found to experience the deepest and most severe poverty. Analysis of combined domain vulnerabilities and overlap of deprivations indicate that poverty referring to shelter and water and sanitation are most closely related. Furthermore, children that are vulnerable in terms of social inclusion and protection seem to be more prone to suffering poverty in other domains whilst children performing labour are not necessarily more deprived with respect to education.

On the basis of the paper's outcomes, it can be argued that this approach has a number of advantages over the use of other approaches for the measurement of child poverty in the specific context of Vietnam. Firstly, all deprivations can be derived back to an individual child, allowing for a detailed poverty analysis down to the level of individual indicators. Secondly, the approach and its measures are child-specific, using as much information at the level of the individual child as possible for the measures of poverty incidence as well as depth and severity. It avoids using assumptions about intra-household distributions. Furthermore, the approach is tailor-made and geared towards national use for child poverty reduction efforts. Due to its fit with the country's social and cultural standards, the approach appeals to national policymakers and is feasible with respect to available data and resources. Finally, the approach put forward in this paper proposes the estimation of child poverty incidence as well as depth and severity, making the approach compatible with monetary poverty measurement in terms of poverty analysis. Against the backdrop of these advantages, it can serve as an important tool for policy-making and academic research, filling a knowledge gap in Vietnam and setting an example for the development of other country-specific child poverty approaches. It provides detailed information that is decomposable at different levels of analysis, allowing for detailed policy design and evaluation. Further research should explore the relation between multidimensional and child monetary poverty measurement using the approach put forward here.

\subsection{Annexes}

\subsubsection{Annex 1 Exact definitions individual child poverty indicators as based on MICS}

Table A3.1 Exact definitions selected indicators based on MICS data

\begin{tabular}{|c|c|c|c|}
\hline Domain & Indicators & Definition of indicator & $\begin{array}{l}\text { Definition of threshold and } \\
\text { remarks on indicator } \\
\text { definition }\end{array}$ \\
\hline \multirow[t]{2}{*}{$\begin{array}{l}\text { Education } \\
\text { poverty }\end{array}$} & \multirow[t]{2}{*}{$\begin{array}{l}\text { Enrolment } \\
\text { poverty rate }\end{array}$} & $\begin{array}{l}\text { children in age } 5 \text { not } \\
\text { attending pre-school as a } \\
\text { percentage of all children in } \\
\text { age } 5\end{array}$ & \multirow{2}{*}{$\begin{array}{l}\text { Age definition used for } \\
\text { calculating net enrolment rate } \\
\text { per level of schooling: taking } \\
\text { into account birth date and } \\
\text { start of school year. including } \\
\text { over-achieving children that } \\
\text { are in a higher level than } \\
\text { appropriate for their age }\end{array}$} \\
\hline & & $\begin{array}{l}\text { children in age } 6-10 \text { not } \\
\text { attending primary school as } \\
\text { a percentage of all children } \\
\text { in age } 6-10\end{array}$ & \\
\hline
\end{tabular}




\begin{tabular}{|c|c|c|c|}
\hline \multirow[b]{6}{*}{$\frac{m}{2}$} & & $\begin{array}{l}\text { children in age } 11-15 \text { not } \\
\text { attending lower primary } \\
\text { school as a percentage of all } \\
\text { children in age } 11-15\end{array}$ & \\
\hline & $\begin{array}{l}\text { Completion } \\
\text { poverty rate }\end{array}$ & $\begin{array}{l}\text { children in age } 11-15 \text { that } \\
\text { have not completed } \\
\text { primary education as a } \\
\text { percentage of all children } \\
11-15\end{array}$ & $\begin{array}{l}\text { All children aged } 11-15 \text { at the } \\
\text { time of interview are } \\
\text { considered poor when they } \\
\text { have not completed primary } \\
\text { school }\end{array}$ \\
\hline & $\begin{array}{l}\text { Immunization } \\
\text { poverty rate }\end{array}$ & $\begin{array}{l}\text { children in age } 2-4 \text { that } \\
\text { have not received full } \\
\text { immunization as a } \\
\text { percentage of all children } \\
\text { in age } 2-4\end{array}$ & $\begin{array}{l}\text { A full immunization package } \\
\text { includes BCG vaccination } \\
\text { against TB, three vaccinations } \\
\text { against DPT, three } \\
\text { vaccinations against polio and } \\
\text { a measles vaccination }\end{array}$ \\
\hline & $\begin{array}{l}\text { Electricity } \\
\text { poverty rate }\end{array}$ & $\begin{array}{l}\text { children living in a dwelling } \\
\text { without electricity as a } \\
\text { percentage of all children in } \\
\text { age } 0-15\end{array}$ & \\
\hline & $\begin{array}{l}\text { Roofing } \\
\text { poverty rate }\end{array}$ & $\begin{array}{l}\text { children living in a dwelling } \\
\text { with natural/grass roof as a } \\
\text { percentage of all children in } \\
\text { age } 0-15\end{array}$ & $\begin{array}{l}\text { natural roof includes thatch, } \\
\text { straw, } \\
\text { palm leaf, bamboo tree-trunk, } \\
\text { wood and other materials }\end{array}$ \\
\hline & $\begin{array}{l}\text { Flooring } \\
\text { poverty rate }\end{array}$ & $\begin{array}{l}\text { children living in a dwelling } \\
\text { with natural/mud floor as a } \\
\text { percentage of all children } \\
\text { age } 0-15\end{array}$ & $\begin{array}{l}\text { natural/improper floor } \\
\text { includes materials } \\
\text { as earth, simple bamboo, } \\
\text { palm, wood plank and other } \\
\text { materials }\end{array}$ \\
\hline $\begin{array}{l}\text { Water and } \\
\text { Sanitation } \\
\text { poverty }\end{array}$ & $\begin{array}{l}\text { Sanitation } \\
\text { poverty rate }\end{array}$ & $\begin{array}{l}\text { children living in a dwelling } \\
\text { without a hygienic } \\
\text { sanitation facility as a } \\
\text { percentage of all children in } \\
\text { age } 0-15\end{array}$ & $\begin{array}{l}\text { Hygienic sanitation facilities } \\
\text { includes flush toilets into } \\
\text { sewerage, septic tanks or pit } \\
\text { latrines, ventilated improved } \\
\text { pit latrine, pit latrine with slab } \\
\text { and composting latrines } \\
\text { (following def. improved } \\
\text { sanitation facilities - MICS) }\end{array}$ \\
\hline & $\begin{array}{l}\text { Water poverty } \\
\text { rate }\end{array}$ & $\begin{array}{l}\text { children not drinking safe } \\
\text { drinking water as a } \\
\text { percentage of all children in } \\
\text { age } 0-15\end{array}$ & $\begin{array}{l}\text { Safe drinking water sources } \\
\text { include private piped water } \\
\text { into house and house's yard, } \\
\text { public piped water, protected } \\
\text { dug well, rain water and } \\
\text { bottled water (following } \\
\text { definition of improved } \\
\text { sources - MICS) }\end{array}$ \\
\hline Child work & $\begin{array}{l}\text { Child work } \\
\text { rate }\end{array}$ & $\begin{array}{l}\text { children age } 5-14 \text { that have } \\
\text { worked for an employer, in } \\
\text { household production or } \\
\text { were self-employed in the } \\
\text { last } 12 \text { months as a } \\
\text { percentage of all children in } \\
\text { age } 5-14\end{array}$ & $\begin{array}{l}\text { Child work includes any work } \\
\text { performed (regardless of } \\
\text { number of days and hours } \\
\text { worked) for a member } \\
\text { outside of the home (paid and } \\
\text { unpaid) as well as household } \\
\text { production (on the rice field, } \\
\text { family business or begging on } \\
\text { the streets) and self- }\end{array}$ \\
\hline
\end{tabular}




\begin{tabular}{|c|c|c|c|}
\hline & & & $\begin{array}{l}\text { employment in the last } 12 \\
\text { months }\end{array}$ \\
\hline \multirow[t]{2}{*}{$\begin{array}{l}\text { Leisure } \\
\text { poverty }\end{array}$} & $\begin{array}{l}\text { Toy poverty } \\
\text { rate }\end{array}$ & $\begin{array}{l}\text { children in age } 0-4 \text { that do } \\
\text { not have store bought or } \\
\text { home-made toys as a } \\
\text { percentage of all children } \\
\text { age } 0-4\end{array}$ & - \\
\hline & $\begin{array}{l}\text { Book poverty } \\
\text { rate }\end{array}$ & $\begin{array}{l}\text { children in age } 0-4 \text { not } \\
\text { having at least one } \\
\text { children's or picture book } \\
\text { as a percentage of all } \\
\text { children age } 0-4\end{array}$ & - \\
\hline $\begin{array}{l}\text { Social } \\
\text { Inclusion } \\
\text { and } \\
\text { Protection } \\
\text { poverty }\end{array}$ & $\begin{array}{l}\text { Birth } \\
\text { registration } \\
\text { poverty rate }\end{array}$ & $\begin{array}{l}\text { children in age } 0-4 \text { not } \\
\text { having a birth registration } \\
\text { as a percentage of all } \\
\text { children age } 0-4\end{array}$ & - \\
\hline
\end{tabular}


$\frac{m}{50}$ 


\section{Chapter 4}

\section{EQUAL OPPORTUNITIES FOR ALL CHILDREN IN VIETNAM? - ASSESSING THE DISTRIBUTION OF CHILD POVERTY FROM A MONETARY AND MULTIDIMENSIONAL PERSPECTIVE}

Despite two decades of rapid economic growth in Vietnam, child poverty remains a sizeable problem. This paper investigates the distribution of child poverty and the existence of horizontal inequalities over a variety of groups in Vietnam using a multitude of poverty measures. Findings suggest that the burden of child poverty is unequally shared by demographic and socio-economic groups. Conclusions about the degree of inequality and the groups that are disproportionately affected depend on the poverty indicator used for analysis. The set of poverty indicators provides complementary information to gain an indepth understanding of the distribution of child poverty in Vietnam.

${ }^{26}$ Published as:

Roelen, Keetie, Franziska Gassmann (2009) Equal Opportunities for all children in Vietnam Assessing the distribution of child poverty from a monetary and multidimensional perspective, Journal of Income Distribution 18(3-4): 206-231 


\subsection{Introduction}

Far reaching economic reforms that were implemented in Vietnam in the late 1980's, the so-called Doi Moi policies, resulted in rapid economic growth and were accompanied by a steep decrease in poverty rates (Balisacan et al. 2004). Average economic growth rates amounted to 6.9 percent from 1988 to 1994 and 7.4 percent from 1994 to 2000 (Glewwe 2004a). Central planning made way for free-market oriented economic policies, bringing about great changes in the agricultural sector, private business and employment development, foreign trade and social sector policies, creating business and entrepreneurial opportunities for Vietnamese as well as foreigners (Glewwe 2004a). Further, it has resulted in a sharp decrease in poverty with monetary rates dropping from 29 percent in 2002 to 16 percent in 2006 (VDR 2008). However, there is ample research suggesting that the economic success and drop in poverty was not shared by all groups in society (Taylor 2004).

Vietnam suffers a considerable degree of income inequality with the wealthiest 20 percent of the population spending 6 times more than the poorest 20 percent of the population (Haughton 2001). Research by different scholars suggests that various aspects of poverty are disproportionately distributed over different demographic and socio-economic groups. Nguyen et al. (2007) find that there is a large urban-rural divide in terms of real per capita household consumption. Spatial inequality is also found at regional and lower geographic levels by Minot and Baulch (2004), suggesting that monetary poverty is concentrated in Vietnam's Northern regions. In terms of ethnicity, Baulch et al. (2007) find that ethnic minorities do not only have considerably lower real per capita expenditures compared to the majority Kinh/Chinese ethnic groups but are also disproportionately disadvantaged with respect to schooling and endowments. Malnourishment is found to be especially prevalent among children in rural areas, monetary poor households and ethnic minorities (Thang and Popkin 2003). Further, entrance rates for lower and secondary schooling are also considerably lower in rural areas, for the monetary poorest quintiles and ethnic minorities (Glewwe 2004b). These and other findings strongly support the hypothesis that the outstanding economic performance and concurrent raise in living standards did not equally benefit all in Vietnam. Inequality between social groups is referred to as horizontal inequality by Stewart (2002) and argued to be an important concern for both instrumental and direct welfare reasons. Focusing attention on disadvantaged groups may be an efficient targeting tool, increase the groups' capability to contribute to their own and society's prosperity and increasing individuals' well-being (Stewart 2002). When ignored, such horizontal inequalities can lead to far-reaching political and economic consequences (Stewart 2002). This paper aims to investigate the distributional pattern of poverty and deprivation and consider the existence of horizontal inequalities in Vietnam.

Previous research with respect to inequality in Vietnam has primarily focused on single aspects of poverty or deprivation, such as expenditures, education and nutrition, and their distribution over demographic and socio-economic groups. A comprehensive analysis using a combination of poverty indicators is missing. Furthermore, a distributional analysis for children has not yet been undertaken, despite the increased acknowledgement that children require a special focus within the poverty debate (e.g. Minujin et al. 2005). To date, little is known about the 
situation of poor children in Vietnam and the distribution of child poverty over various groups. This paper advances the discussion on the distribution of poverty in Vietnam by specifically considering child poverty using a complementary set of poverty indicators. We assess whether children in Vietnam face equal opportunities or whether children in specific demographic and socio-economic groups face higher poverty risks than others using a monetary or multidimensional poverty approach. The monetary poverty approach estimates poverty on the basis of a national poverty line at the household level, based on household expenditures. The concept of multidimensional poverty is constructed in such a way to capture a variety of deprivations that are deemed to adequately reflect the poverty status of children in Vietnam. In addition to the aggregate information with respect to multidimensional poverty, we use domain level information to draw a more detailed picture of the distribution of child poverty. In this paper, we aim to show that the use of a set of complementary poverty indicators can provide valuable insights into the distribution of poverty and guide efforts towards the reduction of inequality.

The remainder of the paper is structured as follows: Firstly, we clarify the concepts of monetary and multidimensional child poverty used for the purposes of this study. Next, the vectors of individual and characteristics are outlined. Third, we shortly explain the data and methodology used for our analysis. Results are then presented in the form of an unconditional and conditional poverty profile and consequently discussed. Finally, we draw conclusions on the distribution of child poverty over different groups in Vietnam and the use of a complementary set of poverty indicators in a distributional analysis.

\subsection{Monetary and multidimensional child poverty}

Child poverty, in monetary as well as multidimensional terms, is still persistent at considerable rates in Vietnam. In 2006, 23 percent of all children under the age of 16 were living in monetary poor households and 31 percent were poor in multidimensional terms ${ }^{27}$. As a clear understanding of the child poverty approach at hand is crucial for a sound and solid poverty analysis and interpretation of results (Ravallion 2004, Roelen et al. 2009a), this section outlines the poverty indicators used in this study in more detail.

The monetary poverty method builds on per capita expenditures ${ }^{28}$ as underlying welfare measure. The monetary poverty line in 2006 lies at 2559 VND per day, capturing the cost of a food and non-food basket (VDR 2008) ${ }^{29}$. This poverty line was established by the General Statistical Office (GSO) and the World Bank (WB) and is generally referred to as the official poverty line. The use of this monetary poverty

27 Authors' own calculations based on the Vietnam Household Living Standards Survey (VHLSS) 2006 using the national monetary poverty by the General Statistics Office (GSO) and a multidimensional measure developed for UNICEF Vietnam.

${ }^{28}$ Per capita expenditures have been calculated on the basis of equal weights for each household member, making no assumptions about economics of scale. Furthermore, potential differences in living costs are not adjusted using area or regional deflators as such information was not available.

29 The cost component of the food basket is based on a daily intake of 2100 calories per person per day (VDR 2008). 
method for the purposes of the study at hand ensures comparability and compatibility with regularly published official poverty assessments. We will use the poverty headcount rate as basic poverty measure for analysis.

The multidimensional poverty method used in this paper was especially developed to identify poverty among children in Vietnam. It is a child-specific, outcome-focused and country-specific approach, considering non-monetary aspects of deprivation that are especially relevant for children. The approach was chosen to be multidimensional and non-monetary in nature due to considerable drawbacks of the widely used monetary approach, especially in relation to child poverty measurement (see Roelen et al. 2009b, 2009c). In order to operationalize the child poverty approach, domains and indicators are identified within the overall conceptual framework. The list of domains and indicators presented in Table 4.1 are considered to adequately represent the range of issues constituting child poverty in Vietnam ${ }^{30}$.

Table 4.1 Domains and indicators of the multidimensional child poverty

\begin{tabular}{|c|c|}
\hline \multicolumn{2}{|c|}{ VHLSS 2006} \\
\hline 1 & Enrolment poverty rate \\
\hline $\begin{array}{l}\mathrm{a} \\
\mathrm{b}\end{array}$ & $\begin{array}{l}\text { children in age } 5 \text { not attending pre-school as a percentage of all children in age } 5 \\
\text { children in age } 6-10 \text { not attending primary school as a percentage of all children in } \\
\text { age } 6-10 \\
\text { children in age } 11-15 \text { not attending lower secondary school as a percentage of all } \\
\text { children in age } 11-15\end{array}$ \\
\hline c & Completion poverty rate \\
\hline 2 & $\begin{array}{l}\text { children in age 11-15 that have not completed primary education as a percentage of } \\
\text { all children } 11-15\end{array}$ \\
\hline \multicolumn{2}{|c|}{ 2. Health poverty } \\
\hline & Health visit poverty rate \\
\hline 1 & $\begin{array}{l}\text { children age } 2-4 \text { not having visited a professional health facility at least once in the } \\
\text { last } 12 \text { months as a percentage of all children in age } 2-4\end{array}$ \\
\hline \multicolumn{2}{|r|}{ 3. Shelter poverty } \\
\hline & Electricity poverty rate \\
\hline \multirow[t]{2}{*}{1} & $\begin{array}{l}\text { children living in a dwelling without electricity as a percentage of all children in age 0- } \\
15\end{array}$ \\
\hline & Housing poverty rate \\
\hline 2 & children not living in proper housing as a percentage of all children in age 0-15 \\
\hline \multicolumn{2}{|r|}{ 4. Water and Sanitation poverty } \\
\hline & Sanitation poverty rate \\
\hline \multirow[t]{2}{*}{1} & $\begin{array}{l}\text { children living in a dwelling without a hygienic sanitation facility as a percentage of } \\
\text { all children in age } 0-15\end{array}$ \\
\hline & Water poverty rate \\
\hline 2 & Children not drinking safe drinking water as a percentage of all children in age $0-15$ \\
\hline & d work \\
\hline
\end{tabular}

30 Various selection methods and criteria, as set out by Alkire (2008), Biggeri (2007) and Robeyns (2005) were used for the actual selection and formulation of domains and indicators and their thresholds. See Roelen et al. (2009a, 2009b) and chapters 2 and 3 for a more detailed discussion. The exact thresholds for each indicator can be found in 4.8.1 Annex 1 Please note that the list of indicators is slightly different from the ones in chapters 2 and 3 as these were based on the MICS database rather than the VHLSS database. 


\begin{tabular}{c|l}
\hline & Child work rate \\
\hline 1 & $\begin{array}{l}\text { children age 6-15 that have worked for an employer or in household production in } \\
\text { the last 12 months as a percentage of all children in age 6-15 }\end{array}$ \\
\hline 6. Social Inclusion and Protection poverty \\
\hline \multicolumn{2}{c}{ Caregiver poverty rate } \\
\hline 1 & $\begin{array}{l}\text { children in age 0-15 living in households with heads that do not work due to } \\
\text { disablement or old age, age 0-15 }\end{array}$ \\
\hline
\end{tabular}

In addition to analyzing the situation of children with respect to the separate domains and indicators of poverty, we also consider an aggregate measure of multidimensional poverty. The aggregation method used to arrive at a composite multidimensional poverty rate is a combination of the union approach (Atkinson 2003) and dual cut-off identification strategy (Alkire and Foster 2008). At a first level of aggregation, a child is considered poor in a specific domain when it does not meet the threshold of at least one of the indicators within that domain, thereby following the union approach. This results in the domain poverty rate, referring to the proportion of children poor in that specific domain ${ }^{31}$. At a second level of aggregation, a child is identified as overall poor when it is poor in at least two domains, which follows the dual cut-off identification strategy. This second step of aggregation results in the aggregate multidimensional poverty rate ${ }^{32}$. The choice for two domains as poverty line for the measurement of child poverty in Vietnam was found to be most robust (Roelen et al. 2009b) ${ }^{33}$ and satisfies a number of properties such as decomposability, symmetry and monotonicity (Alkire and Foster 2008). For the purposes of this study, the headcount of multidimensionally poor children (the multidimensional poverty rate) is used as the basis poverty measure. The results of the aggregate measure will be complemented by domain poverty rates to gain a more detailed understanding of the underlying domains.

\subsection{Individual and household characteristics}

The distributional analysis of child poverty is conducted for a number of demographic and socio-economic groups. These groups are formed along the lines of a vector of individual characteristics and a vector of household factors. The choice of these characteristics results from previous research on the distribution of poverty in Vietnam as well as other countries and an assessment of data availability. Individual characteristics include the child's gender, age, area and region of residence, which are common factors in unconditional and conditional poverty profiling (e.g. Alexandrova et al. 2006, Baulch and McCulloch 2002, Wodon 2000). Ethnicity is an especially important issue in Vietnam with a large number of disadvantaged ethnic minorities

31 Domain poverty rates only refer to those children for whom the indicators within that domain could actually be observed. For example, the health poverty rate only refers to children in the age group 2-4.

32 The technical notation of the indicator poverty rates, domain poverty rates and multidimensional poverty rate can be found in chapter 6 .

33 Robustness was checked by plotting child poverty rates against various cut-off points/poverty lines for different demographic groups. The plots indicated that poverty rankings changed considerably when using cut-off points of 3 domains and more. 
(Baulch et al. 2007). The inclusion of these factors enables an assessment of gender equality, the spatial distribution of poverty and disproportionate advantages or disadvantages for various age and ethnic groups. Household characteristics that are widely considered to be correlated with poverty include the number of children in the household, total number of household members, the level of educational attainment, occupational status, marital status, gender and age of the household head (other studies having included these factors are e.g. Baulch and McCulloch 2002, Grootaert 1997, Minot 2000, Luzzi et al. 2008, Silva 2008, Wodon 2000). These factors allow for a distributional analysis of child poverty on the basis of characteristics of the household that the child lives in. Previous distributional studies, in- and outside of Vietnam, provide and indication of the likely impact of the individual and household factors in distributional terms.

With respect to individual child characteristics, poverty is often ascertained to be gender biased with disproportionately high poverty incidence among women (Quisumbing et al. 2001). The gender gap in Vietnam, however, is known to be less pronounced in terms of monetary as well non-monetary indicators (Baulch and Masset 2003). Age can be considered an increasing as well as decreasing factor of poverty (Luzzi et al. 2008) with an inverse U-shape effect. Children might present a larger burden when growing older due to, for example, increasing school fees and thereby increasing the risk of poverty. Vietnam is also a highly ethnically diverse society and previous research has shown that the country is subject to large ethnic disparities (Baulch et al. 2007). The largest ethnic group, the Kinh majority, accounts for 84 percent of the population and coexists with 53 other ethnic minorities (Baulch et al. 2007). Despite the evidence that ethnic minorities are faring worse than the Kinh and Chinese ethnic groups, Minot and Baulch (2004) find that the effect of ethnicity on per capita expenditures is only slightly significant in rural areas but not in urban areas. Furthermore, poverty is spatially concentrated with poverty being more pronounced in rural than urban areas and concentrated in a number of regions (e.g. Minot and Baulch 2004, Nguyen et al. 2007). Minot and Baulch (2004) argue that the unequal spatial distribution of poverty is more persistent in Vietnam as the institutional arrangements of registration (ho khau system) form an impediment to internal migration.

Based on these findings from previous research, we expect the distributional analysis to provide little evidence for gender inequality but also to suggest that poverty is disproportionately distributed over older children compared to young children and children of ethnic minority. Furthermore, we expect to find disproportionately high concentrations of poor children in rural areas and disadvantaged regions.

In reference to household characteristics, we conclude from previous research that larger households are widely associated with higher poverty rates (Lanjouw and Ravallion 1995), especially when the household members include children and elderly. Various empirical studies confirm such a positive relation between household size, in terms of children and elderly, and poverty (e.g. Silva 2008). In a previous study on Vietnam, Minot and Baulch (2004) associate larger households with higher monetary poverty rates and find a significant negative relation between the per capita expenditures and the number of children and females in the household in rural areas. In urban areas, only a higher number of children in the household significantly increase poverty. Educational attainment of the household head has previously been 
shown to have a poverty reducing effect, regardless of the educational level or definition of poverty under consideration (e.g. Baulch and McCulloch 2002, Grootaert 1997, Luzzi et al. 2008, Silva 2008). In the case of Vietnam, Minot and Baulch (2004) found that household heads in urban areas having completed primary or lower secondary school do not significantly impact per capita expenditures when compared to having received no education at all. This is in contrast to higher educational levels, which do have a significant positive association with expenditures. In rural areas, all levels of educational attainment were found to significantly decrease the poverty risk. The occupational status of the heads of household that children live in also tends to have an important poverty impact. Previous studies found that employment in the non-agricultural sector leads to reduced poverty based on per capita consumption in comparison to employment in agricultural occupations (Wodon 2000). Also with respect to the specific case of Vietnam, Minot (2000) found that employment in the farming sector increases poverty risks while employment in the fishery sector reduces the probability to be monetary poor (Minot 2000). Furthermore, female-headed households are often associated with higher poverty incidence (Buvinic and Gupta 1997, Quisumbing et al. 2001). Minot (2000) confirmed this effect in case of Vietnam, thereby suggesting that relatively more children living in households headed by women are poor than those headed by men. The age of the household head can be expected to have a poverty reducing impact due to the inverse poverty effect as discussed for the individual characteristics.

In reference to this study, households with large numbers of children in the household, headed by individuals with low educational attainment, unemployed or agricultural workers and females are thus hypothesized to hold a disproportionate share of poor children.

\subsection{Methodology and Data}

\subsubsection{VHLSS 2006}

The data used for this study is the Vietnam Households Living Standards Survey (VHLSS) from 2006. This household survey is based on the former Vietnam Living Standards Survey (VLSS) but employs a bigger sample size and to be conducted every other year. The VLSS was conducted in 1993 and 1998 and VHLSS from 2002 onwards every second year by the Government Statistical Office (GSO), following the World Bank's Living Standards Measurement Survey (LSMS) methodology. The VHLSS survey samples from 2002 to 2010 are drawn from a master sample, which is a random sample of the 1999 Population Census enumeration areas. This sample of enumeration areas can consequently be used for multiple samples of households for different surveys or for the rotating panel that VHLSS employs. The VHLSS 2006 contains 9.189 households with 39.071 individuals, including 10.696 children under the age of 16 .

Household surveys like the VHLSS provide micro-data at the level of the individual child. This offers the possibility to derive all deprivations back to the individual child, thereby allowing for cross-tabulations and poverty profiling. The survey provides data on a range of issues related to children's well-being and poverty. Nevertheless, a number of limitations are also inherent to the use of the VHLSS. A first limitation is 
that the micro-data from the survey is not collected for all children of all ages. While information on health is only collected for children up to five years of age, educational information is only collected for children aged five and upwards. Hence, the total number and types of deprivations that a child suffers theoretically depends on the age category, making the analysis of age groups less straightforward. A second limitation at the time of writing is that data on nutrition is not available. This is a considerable drawback as nutritional indicators are important aspects of a multidimensional measurement of child poverty. Third, the sampling method of the VHLSS (and other household surveys in Vietnam) causes a substantial group in the society to be omitted from the sample and subsequent data. The sample for the survey is constructed on the basis of the official lists of registered households in communes and urban wards in Vietnam that have lived in the enumeration area for at least six months (Pincus and Sender 2006, 2008). This implies that households or individuals that have recently migrated are not included in the sampling frame (Edmond and Turk 2004). Further, due to the strict household registration system, or ho khau system, many households and individuals do not satisfy the necessary criteria to newly register and stay unregistered (Pincus and Sender 2006, 2008). The omission of this group in society is not only an important issue to point out because of its suspected significant size but even more so because of the denial of social and public services they experience due to their status. The structural exclusion of this group from the data will most likely lead to underestimations for child poverty in terms of both monetary and multidimensional poverty.

\subsubsection{Methodology}

Unconditional and conditional poverty profiling is used in this study to investigate the distribution of child poverty in Vietnam. The unconditional poverty profiles present cross tabulations of decomposed poverty figures along the vectors of individual and household characteristics. Descriptive statistics in the unconditional profile indicate the degree to which different groups are affected by child poverty. Regression modelling is used for the purpose of conditional poverty profiling, testing the effect of a set of parameters on the binary outcome being child poverty. When testing for the probability of such a binary outcome, a regression model based on ordinary least squares (OLS) causes a number of problems (Long 1997). The most prominent problem is that of its functional form. A linear regression model assumes that the level of change in the dependent variable is constant for all levels of the independent variables. However, when the dependent variable consists of a probability, it is very likely that the impact of the independent variables increases or decreases as the predicted probability approaches 0 or 1 (Long, 1997). To overcome this and other problems when estimating a regression model with a binary outcome, one can use logistic regression. This method does not assume a linear relationship between the dependent and independent variables and is therefore more appropriate. Models including alternative child poverty lines for monetary and multidimensional poverty as dependent variables are estimated to test for the robustness of regression results (see also Baulch and McCulloch 2002, Grootaert 1997). Instead of using two domains as cut-off point with respect to multidimensional poverty, we estimate the models for poverty determined by one and three domains as cut-off points. The 
alternative poverty lines for the monetary child poverty measure include a food poverty line, set at a lower level of expenditures, and an alternative poverty line at a higher level of expenditures. Results are compared with the original model, using the two-domain cut-off for the multidimensional model and the food and non-food items monetary poverty line in terms of coefficients.

\subsection{Unconditional poverty profile}

The unconditional poverty profile reports monetary and multidimensional child poverty headcount rates of the various demographic and socio-economic groups in Tables 4.2 and 4.4. Furthermore, we consider the urban-rural disparities in greater detail by analyzing domain level indicators in Table 4.3. Table 4.2 includes child poverty incidence rates along the lines of individual characteristics and Table 4.4 presents the results for the household characteristics. The analysis of differences in outcomes between the monetary and multidimensional poverty indicators will not focus on size differences as they are largely a result from the arbitrariness underlying the establishment of the poverty line. We rather focus on diverging trends and rankings with respect to both poverty indicators between socio-economic and demographic groups.

Table 4.2 Unconditional child poverty profile for individual characteristics

\begin{tabular}{l|c|c}
\hline Indicator & Monetary poverty rate & $\begin{array}{c}\text { Multidimensional } \\
\text { poverty rate }\end{array}$ \\
\hline Total & 22.62 & 30.72 \\
\hline Gender & & \\
\hline Male & 22.40 & 30.47 \\
Female & 22.85 & 30.99 \\
\hline Area & $* * *$ & $* * *$ \\
\hline Urban & 5.42 & 11.25 \\
Rural & 27.58 & 36.33 \\
\hline Region & $* * *$ & $* * *$ \\
\hline Red River Delta & 13.22 & 9.66 \\
North East & 34.05 & 36.16 \\
North West & 58.94 & 63.12 \\
North Central Coast & 37.99 & 25.75 \\
South Central Coast & 16.73 & 18.50 \\
Central Highlands & 37.16 & 39.33 \\
South East & 9.08 & 20.24 \\
Mekong River Delta & 12.59 & 56.31 \\
\hline Ethnicity & $* * *$ & $* * *$ \\
\hline Kinh/Chinese ethnicity & 14.50 & 24.08 \\
Other ethnicity & 61.25 & 62.34 \\
\hline Age group & $* * *$ & $* * *$ \\
\hline O-2 & 27.14 & 27.87 \\
3-4 & 27.50 & 41.61 \\
\end{tabular}




\begin{tabular}{l|l|l}
5 & 26.45 & 38.40 \\
$6-10$ & 25.21 & 25.76 \\
$11-14$ & 19.35 & 29.45 \\
15 & 13.46 & 40.44 \\
\hline
\end{tabular}

Source: Authors' calculations from VHLSS 2006

Note: ${ }^{* * *}<0.001$, significance level chi-squared equality of means

A first observation from Table 4.2 is that there is no indication of the existence of any gender inequality with similar child poverty incidence rates for boys and girls. However, there is a large discrepancy between urban and rural poverty figures, confirming previous findings with respect to Vietnam (Minot and Baulch 2004, Nguyen et al. 2007). Decomposition by age group indicates that children aged 3-5 are most prone to poverty according to both poverty methods. The multidimensional method, however, indicates that poverty is more prevalent for children in the oldest age bracket while the monetary method identifies this group to have the lowest poverty incidence. These results could be a result of the child work domain that is incorporated in the multidimensional approach. The multidimensional approach considers children who work to be poor, while the monetary approach does rather the opposite as child work generates income. Regional child poverty estimates display large spatial disparities across the board but also provide a clear indication that the multidimensional and monetary approaches draw a different picture of child poverty. In both cases, the Red River Delta is the region with the lowest child poverty incidence. However, results differ remarkably when considering the regions with higher child poverty rates. Especially in reference to the Mekong River Delta, it can be observed that the monetary poverty measure identifies this region as one with comparatively low child poverty incidence while the multidimensional estimates identifies it as one of the regions with most child poverty. A closer examination of the separate poverty domains can provide insight into the drivers of these differences. Domain level information for the assessment of regional differences will be considered in a later section of this paper. Finally, the findings suggest that ethnic minorities are disadvantaged groups in terms of child poverty, regardless of the poverty measure at hand.

Before proceeding with the unconditional poverty profile on the basis of household characteristics, we will use domain level information to explore the urbanrural divide in greater detail. Domain poverty rates can provide an indication of the drivers of this discrepancy in terms of multidimensional poverty. Table 4.3 presents domain poverty rates for urban and rural areas and the rural-urban poverty ratio, providing an indication of the size of the inequality. 
Table 4.3 Domain poverty for children in urban and rural areas

\begin{tabular}{l|c|c|c|c}
\hline & Total & Urban & Rural & Rural/Urban ratio \\
\hline Education poverty & 18.4 & 11.9 & 20.2 & 1.7 \\
\hline Health poverty & 47.8 & 38.1 & 50.9 & 1.3 \\
\hline Shelter poverty & 20.1 & 7.8 & 24.8 & 3.2 \\
\hline $\begin{array}{l}\text { Water and sanitation } \\
\text { poverty }\end{array}$ & 48.8 & 15.7 & 58.3 & 3.7 \\
\hline $\begin{array}{l}\text { Child work } \\
\text { Social inclusion and } \\
\text { protection poverty }\end{array}$ & 8.9 & 2.8 & 10.6 & 3.8 \\
\hline
\end{tabular}

Source: Authors' calculations from VHLSS 2006

The largest disparities between rural and urban areas can be found with respect to the domains of child work, water and sanitation and shelter. Deprivation in these dimensions is at least three times more prevalent in rural areas than it is in urban areas. Climate and environmental conditions might play a role with respect to water and sanitation and shelter as well as cultural and traditional beliefs. A more equal distribution over rural and urban areas can be found with respect to education and health. A lack of infrastructure or limited access to these services might be more prevalent in rural areas but not to a large degree. The domain of social inclusion and protection indicates a reversed distribution of deprivation with higher prevalence rates in urban rather than rural areas. The specific indicator refers to children living in households headed by individuals who cannot work due age or disability. Such types of households might be more prevalent in urban rather than rural areas, reversing the rural-urban divide in favour of the rural areas. Discrepancies between urban and rural areas are thus widespread across all domains but its degree and sign depends on the specific domain under consideration. Efforts to close the gap between the living conditions of children in these two different areas and reduce inequality should thus also be guided accordingly.

Table 4.4 presents poverty estimates for groups of children decomposed by characteristics of the household head and household, providing insight into the distribution of monetary and multidimensional child poverty over these characteristics.

Table 4.4 Unconditional child poverty profile for household characteristics

\begin{tabular}{l|c|c}
\hline Indicator & Monetary poverty rate & $\begin{array}{c}\text { Multi dimensional } \\
\text { poverty rate }\end{array}$ \\
\hline Total & 22.6 & 30.7 \\
\hline Gender of hh head & $* * *$ & $* * *$ \\
\hline Household head male & 24.2 & 31.6 \\
Household head female & 16.2 & 26.9 \\
\hline Age hh. head & $* * *$ & $* * *$ \\
\hline Age hh head 18-29 & 37.4 & 43.0 \\
Age hh head 30-39 & 24.4 & 30.6 \\
Age hh head 40-49 & 19.7 & 27.4 \\
Age hh head 50-59 & 19.9 & 27.4 \\
Age hh head 60-69 & 26.1 & 34.8 \\
Age hh head 70-79 & 19.4 & 42.5 \\
Age hh head 80-99 & 20.7 & 41.5 \\
\hline Education hh. head & $* * *$ & $* * *$ \\
\hline
\end{tabular}




\begin{tabular}{l|c|c}
\hline hh head has no education & 39.8 & 51.8 \\
hh. head has primary education & 25.2 & 34.3 \\
hh. head has secondary education & 13.2 & 18.0 \\
hh. head has post sec education & 3.3 & 9.3 \\
\hline Occupation hh. head & $* * *$ & $* * *$ \\
\hline hh head is unemployed/retired & 18.1 & 45.3 \\
hh head is gov/defense staff & 6.4 & 16.5 \\
hh head is skilled professional & 9.0 & 16.0 \\
hh head is unskilled worker & 28.4 & 34.0 \\
\hline Presence children in specific age groups & $* * *$ & $* * *$ \\
\hline At least 1 child $<5$ in hh & 19.5 & 28.5 \\
At least 1 child $5-11$ in hh & 24.2 & 29.7 \\
At least 1 child $>11$ in hh & 22.4 & $* 1.5$ \\
\hline Proportion of hh members that are & $* * *$ & \\
children & & 23.6 \\
\hline$<25 \%$ of hh members are children & 10.3 & 29.0 \\
25-39\% of hh members are children & 16.3 & 31.4 \\
40-49\% of hh members are children & 23.9 & 33.0 \\
\hline $49 \%$ of hh members are children & 28.3 & \\
\hline Source: Authors calculations from VHLSS & & \\
\hline
\end{tabular}

Source: Authors' calculations from VHLSS 2006

Notes: ${ }^{* * *}<0.001$, significance level chi-squared equality of means

Female-headed households display lower poverty rates than households headed by men, which is in contrast to previous research findings. Female-headed households are generally associated with higher poverty levels, especially in terms of monetary poverty. This contrasting result when compared to previous research might be due to the fact that we are specifically considering child poverty. Women are known to distribute household resources differently than men and typically spend a higher proportion on children's nutrition, education and healthcare (Quisumbing et al. 2001). Referring to the age of the household head, child poverty is highest amongst children with the youngest household heads, except in the case of urban multidimensional child poverty. Overall, poverty incidence decreases with age of the household head. Higher levels of educational attainment of the household head relate to lower poverty incidence across the board. Regardless of the poverty measure used and the area under consideration, higher levels of educational attainment are associated with significantly lower levels of child poverty. Education effects are thus found to be stronger in the case of child poverty than expenditure-based household poverty as found by Minot and Baulch (2004). Considering the occupational status of the household head, children living in households headed by unemployed and unskilled staff face the highest poverty incidence. However, whilst children living in households headed by unemployed or retired heads face the highest risk to multidimensional poverty, monetary poverty is most prevalent amongst children living in households headed by unskilled workers. Children living in households headed by government/defence staff or a skilled professional are least like to be monetary or multidimensionally poor. With respect to the number of children present in the household, the findings partly confirm previous research conclusions. Increasing numbers of children in the household go hand in hand with significant increases in child poverty incidence. 


\subsection{Conditional poverty profile}

The conditional poverty profile extends the distributional analysis of child poverty and considers the explanatory power of the individual and household characteristics in determining child poverty by using logistic regression modelling. The multidimensional and monetary models include all factors from the unconditional poverty profile as explanatory variables. Further, we include quadratic terms for age of the child and age of the household head (Luzzi et al. 2008, Silva 2008). Considering the large urban-rural disparities, we estimate the model separately for the urban and rural samples. Performing separate estimations and analyses is useful when model effects are not the same for two populations (see e.g. Alexandrova 2006, Grootaert 1997, Ravallion and Wodon 2004, Wodon 2000). We used a counterpart of the Chow test to estimate whether the model parameters of the rural group are significantly different from the urban group ${ }^{34}$. This test strongly rejects the hypothesis that the factor effects are the same for the rural and urban samples (multidimensional poverty: 241.13, $\mathrm{p}<0.000$; monetary poverty: chi-squared=100.23, $\mathrm{p}<0.000$ ), indicating that the model should be estimated for the two groups separately. In distributive terms, this implies that children in rural areas are disproportionately affected by poverty than children in urban areas. Estimating the model for the separate samples allows for the distributional analysis of demographic and socioeconomic groups within urban and rural areas.

Table 4.5 reports the marginal effects and standard errors for the four different models. They provide an indication of the sign, size and significance of effects on multidimensional and monetary child poverty in comparison to the reference category and thereby the most important distributional factors. A robustness check indicates that the results of the alternative poverty lines are largely in line with those of the original model, indicating the model's robustness.

${ }^{34}$ A regular Chow test can only be used in linear regression models. See Greene (2002, p. 681) on the equivalent of a Chow test for discrete choice models. 


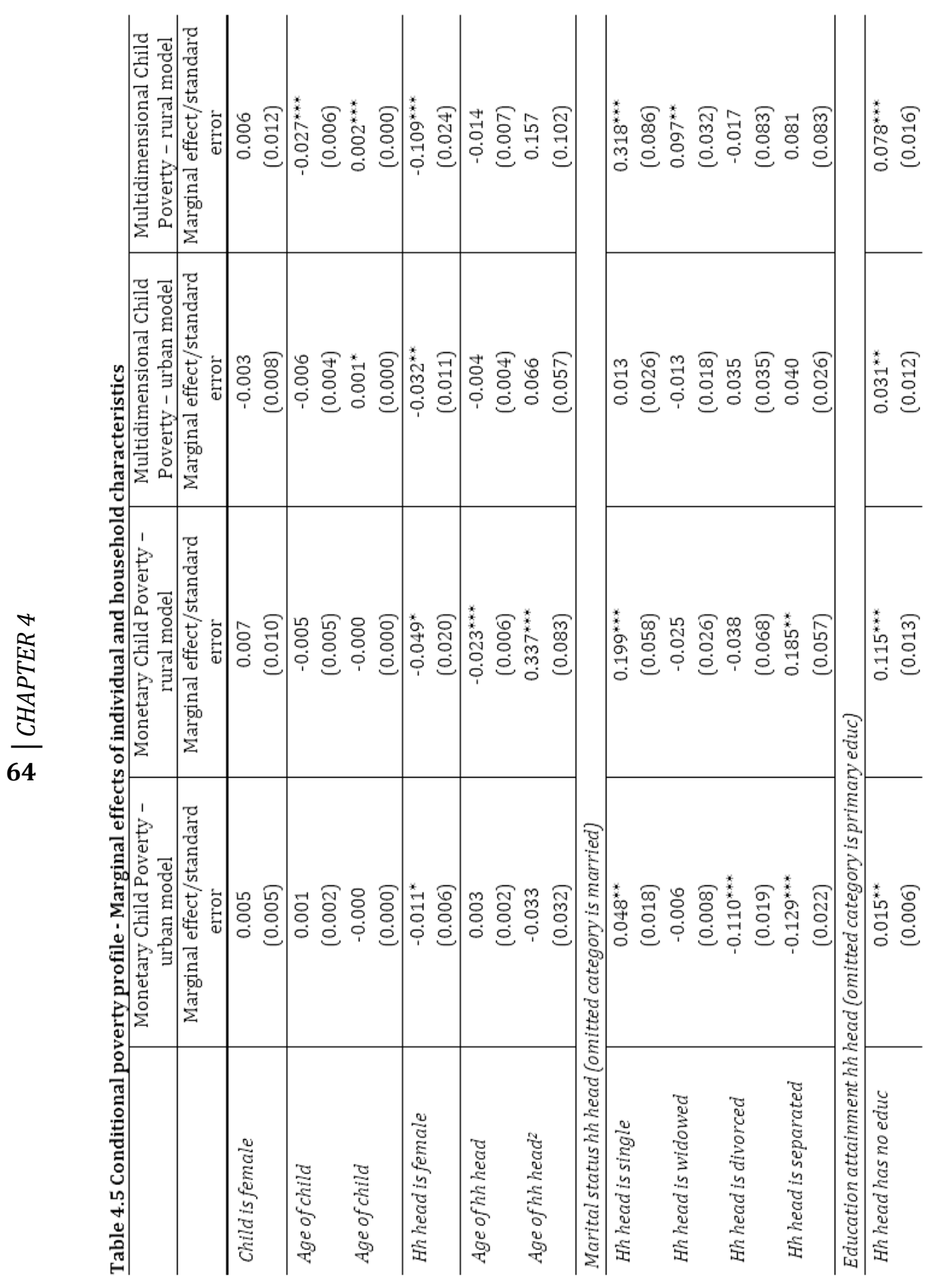




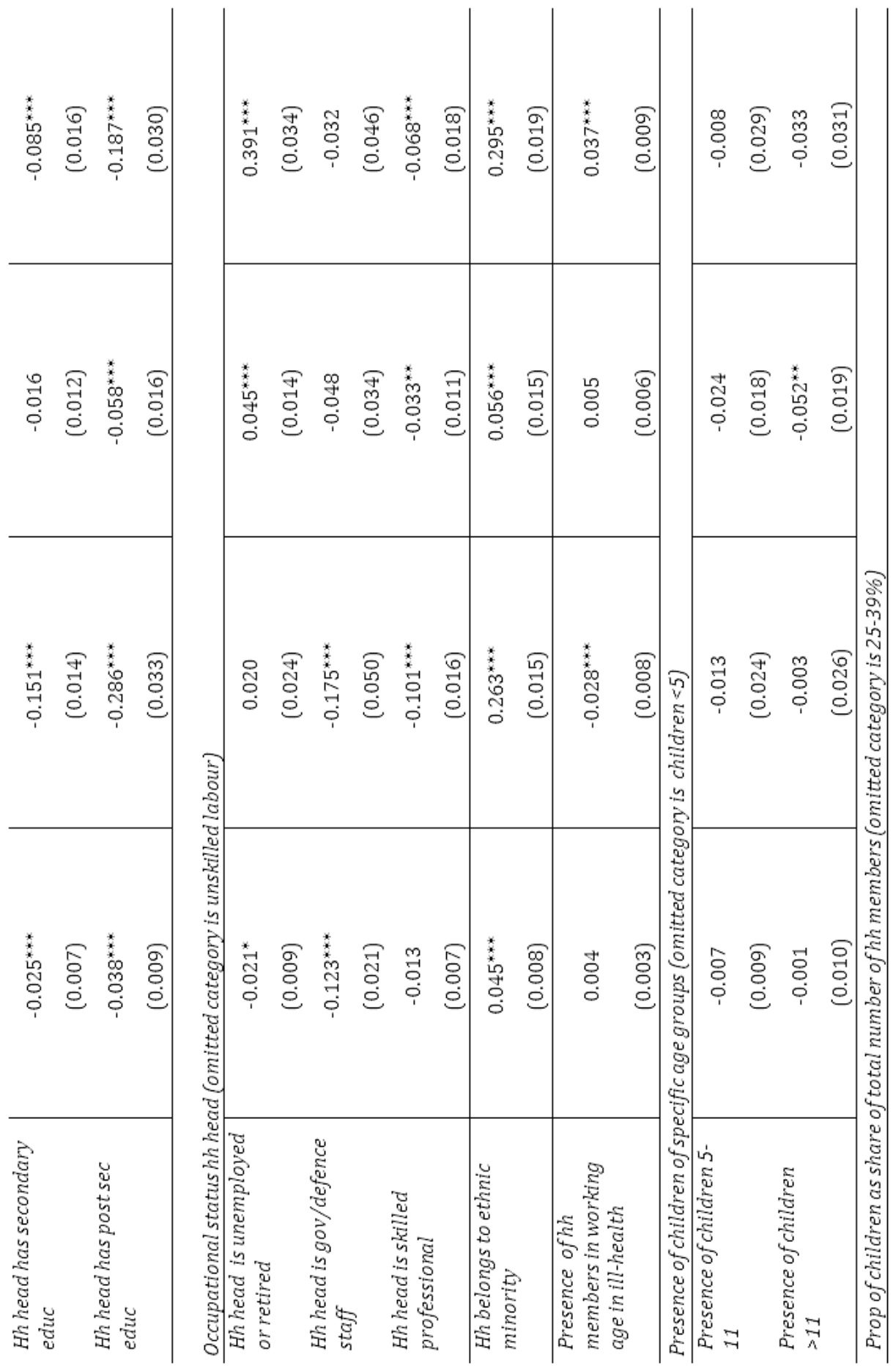




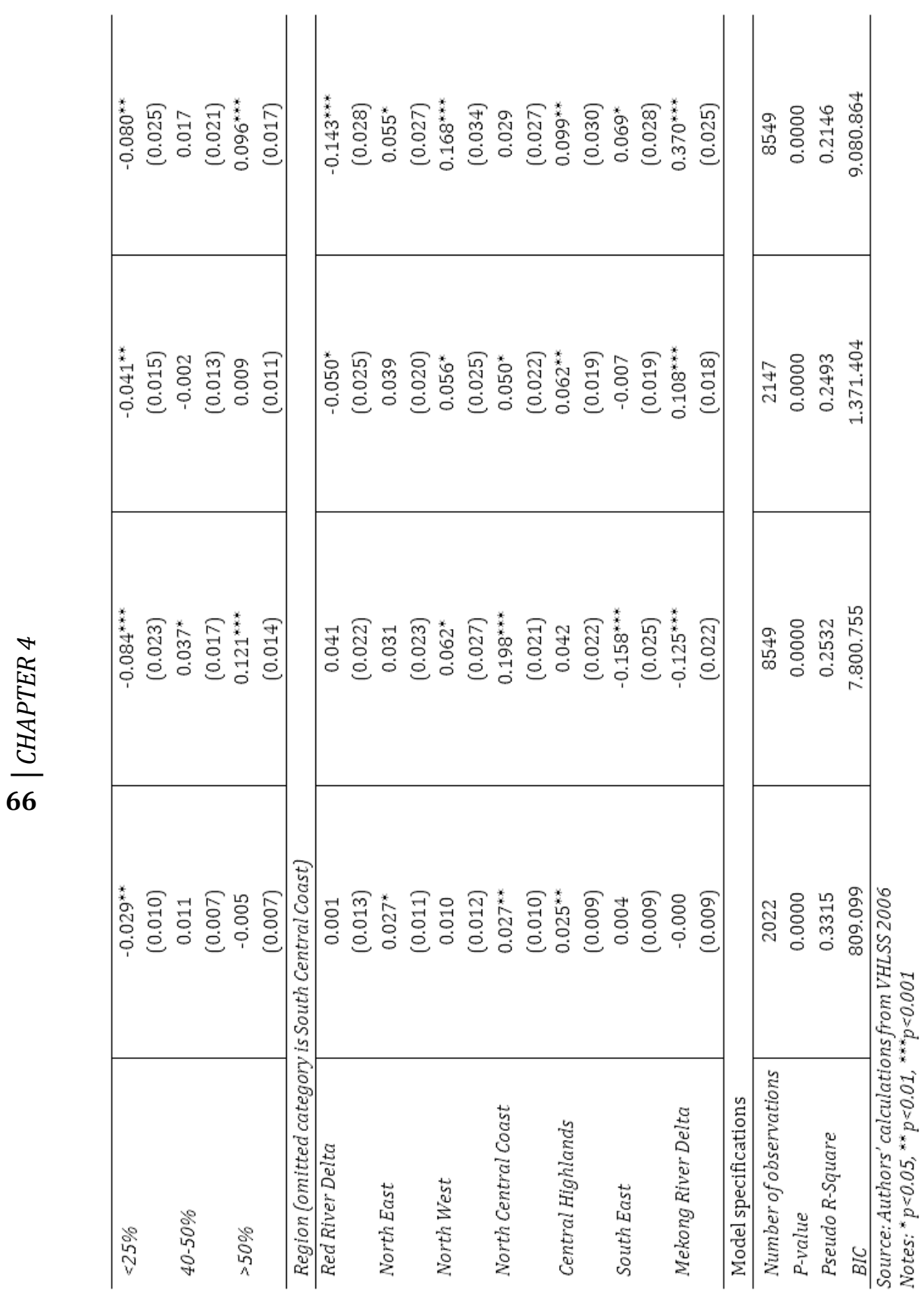




\section{False Positives or Hidden Dimensions $\mid 67$}

The findings in Table 4.5 in part confirm the hypothesized effects from previous research and the unconditional poverty profile but also provide some interesting insights into the different conclusions that can be drawn about the distribution of child poverty based on either multidimensional or monetary poverty measurement.

The existence of gender equality from the unconditional poverty profile is further confirmed. There is no significant effect on multidimensional or monetary child poverty when being a girl compared to being a boy. The age of the child only has a significant impact in the case of rural multidimensional poverty, albeit quite small. All else equal, one extra year of age for children decreases the multidimensional poverty risk by 3 percentage points. The effect of the quadratic term of the child's age has a small poverty increasing impact, which is line with the findings from the unconditional profile. In the specific case of multidimensional poverty, the domain of child work might be a strong attribute.

The distributional effect of the gender of the household head is also more pronounced with respect to multidimensional poverty. Children living in a femaleheaded household face a significantly lower risk to multidimensional poverty in both urban and rural areas. The age of the household head only has a significant impact in the case of rural monetary poverty, with a poverty decreasing effect of age and increasing effect of the quadratic term for age. The quadratic term for age incorporates the generally observed inverse U-shaped effect of age, indicating that the age of the household head has a poverty reducing impact only up to a certain point. Whilst older heads of households might initially add positively to household income in combination with low educational and care costs, this effect might be reversed beyond a certain age due to retirement, loss of income and high care requirements. Marginal effects of the marital status of the household head clearly suggest that children living in households with single heads are in a disadvantaged position, especially in rural areas. The effects of other categories of marital status on the poverty risk of children are inconclusive. The distributional impact of the educational attainment of the household head is highly significant across the board with a decreased poverty risk for higher levels of educational attainment. Effects are larger in terms of rural monetary poverty than rural multidimensional poverty, suggesting that the importance of educational attainment of the household head for reducing the poverty risk is more pronounced with respect to monetary poverty. Nevertheless, it can be concluded that children living in households with lower educated household heads are generally disproportionately affected by child poverty. The distribution of child poverty along the lines of the occupational status of the household head provides different results for the monetary and multidimensional poverty models. In line with the findings of the unconditional poverty profile, findings suggest that children living in households headed by unemployed or retired workers are more likely to be poor in exclusively multidimensional terms. Children living in households headed by government or defence staff face a significantly smaller risk to monetary poverty only. Effects of occupational status are generally larger in rural areas than urban areas. Multidimensional and monetary poverty approaches both provide the same picture with respect to ethnicity. Minot and Baulch (2004) found similar effects when relating ethnicity to per capita expenditures, indicating that ethnic groups other than Kinh or Chinese are more prone to poverty when living in rural areas. The effect of the proportion of children in the household on poverty is in line with previous research and the unconditional poverty profile. Small proportions of children in the household 
are associated with lower poverty risks, regardless of the area and poverty indicator under consideration. Large proportions of children in the household significantly increase the risk to monetary and multidimensional poverty in rural areas.

Spatial disparities are pronounced in monetary as well as multidimensional poverty terms but do not consistently display the same sign of effect. Children living in the South East and Mekong River Delta regions experience a decreased risk to monetary poverty in comparison to children living in the reference region of South Central Coast. Their risk with respect to multidimensional poverty, however, is higher. In other words, children living in these two regions would be considered relatively well off in monetary poverty terms but be considered a disadvantaged group with respect to multidimensional poverty. An analysis at the domain level might provide a better understanding of these opposing signs.

The conditional poverty profile and its analysis clearly indicate that certain socioeconomic and demographic groups of children in Vietnam are more disadvantaged in terms of child poverty than others, confirming the existence of horizontal inequalities. However, results from the monetary and multidimensional poverty models are not always consistent. Older children face a higher risk with respect to multidimensional poverty but not concerning monetary poverty. The reduction in the probability to be poor for children living in female-headed households is larger in the case of multidimensional poverty than monetary poverty. Next, the effects of occupational status of the household head on the child's poverty risk are different in the monetary and multidimensional models. Living in a household headed by a disabled or retired worker significantly increases the risk to multidimensional poverty whilst living in a household with government or defence staff significantly decreases the risk to monetary poverty. Finally, children living in the South East and Mekong River Delta regions have a decreased risk to monetary poverty but an increased risk to multidimensional poverty. Considering the domain poverty rates underlying the aggregate multidimensional poverty indicator can help to gain a more in-depth understanding of the inequality between specific groups and differences in outcomes. Table 4.6 presents domain poverty rates for groups formed by the child individual characteristic of age of the child and household characteristics of gender and occupational status of the household head and region of residence. 


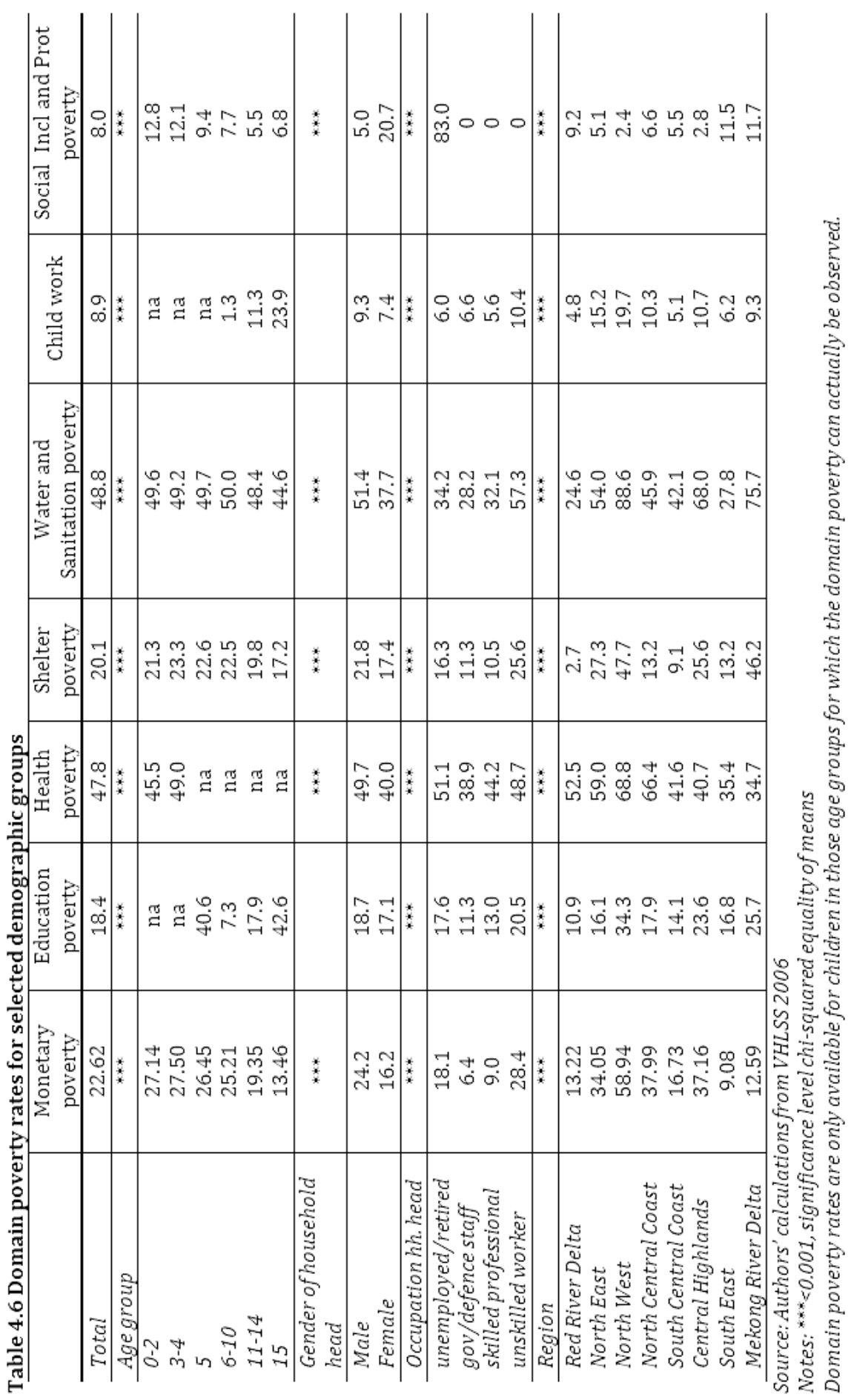


The unconditional and conditional profile in this study indicated that older children were particularly more vulnerable to multidimensional poverty. Child work was suggested to be a possible driver of the increased risk to multidimensional poverty for this age group. Domain poverty rates in Table 4.6 partly confirm this hypothesis. Almost one out of four children aged 15 are considered poor in the child work domain. However, we can not only attribute the high multidimensional poverty rate for this age group to child work. It can also be observed that 43 percent of all children aged 15 are poor with respect to education, which is the highest incidence rate of all age groups. In other words, the underlying factors of high rates of multidimensional poverty and increased poverty risk for 15-year olds that are not captured by the monetary poverty rate can be found in the areas of education and child work.

Furthermore, the unconditional and conditional profile indicated that children living in female-headed households have a lower probability to be poor than those living in male-headed households. In terms of multidimensional poverty, domain poverty rates indicate that this is largely driven by poverty in the area of water and sanitation and health. There is relatively little inequality between children in maleheaded and female-headed households with respect to the area of education, shelter and child labour. However, the disaggregation by domain poverty also indicates that the overall figures mask a reversed disparity with respect to social inclusion and protection. Poverty in this domain is four times higher for children living in femaleheaded households than in male-headed households. Considering domain poverty rates by level of occupational status of the household head clearly indicates that the increased risk to multidimensional poverty for children living in households headed by retired or disablement can be largely attributed to poverty in the social inclusion and protection domain. The indicator in this domain refers to children living in households headed by individuals who do not work due to retirement or disablement. By definition, there is no poverty in this domain for the other categories of occupational status. In terms of the other domains, children living in households headed by unskilled workers are most disadvantaged.

Finally, domain poverty rates by region indicate that the diverging results with respect to monetary and multidimensional poverty risks in the Mekong River Delta region are largely driven by the water and sanitation and shelter domain. Poverty incidence in these domains is amongst the highest for the Mekong River Delta, despite the low poverty incidence in monetary terms. In other words, children living in the Mekong River Delta might find themselves in relatively fortunate position with respect to monetary poverty, they are disproportionately affected concerning the issues of shelter and water and sanitation.

\subsection{Conclusion}

This paper provides insight into the distribution of child poverty over a variety of demographic and socio-economic groups from a monetary and multidimensional perspective. On the one hand, the paper aimed to investigate the existence of horizontal inequalities with respect to child poverty in Vietnam and on the other hand, it assessed whether the use of multiple poverty indicators leads to a more in-depth understanding of the distribution of child poverty. For these purposes, the most 
widely used household-level monetary method for poverty measurement is complemented by multidimensional, child-focused and country-specific approach for the analysis of child poverty. Unconditional and conditional poverty profiles were used to draw conclusions on the distribution of child poverty and consider whether some groups face higher poverty risks than others in terms of either poverty measures.

The distributional analysis of child poverty based on both poverty measures enables us to draw a number of general conclusions about the existence of horizontal inequalities. Firstly, there is a large urban-rural divide suggesting that children living in rural areas disproportionately carry the burden of child poverty in Vietnam. This holds in terms of multidimensional as well as monetary poverty and confirms previous findings in research about spatial distribution in Vietnam. Secondly, large discrepancies can be found in child poverty incidence rates for groups decomposed along the lines of educational attainment of the household head and the child's ethnicity. These results are also in line with conclusions from other studies and indicate that child poverty monotonically decreases with increases in educational attainment and that children of ethnic minority are a highly disadvantaged group. Furthermore, gender of the child is not found to have an impact on the poverty risk suggesting that boys and girls have equal opportunities in Vietnam.

The unconditional and conditional poverty profiles also clearly outline that the use of a set of complementary poverty indicators can provide a more detailed picture of the distribution of child poverty and underlying drivers. In particular, domain level information underlying the multidimensional poverty indicator can increase the understanding of different outcomes in terms of monetary and multidimensional poverty and guide targeted interventions aimed to reduce horizontal inequalities. Using this type of information, we learned that the urban-rural divide is most pronounced with respect to the domains of child work, water and sanitation and shelter. Furthermore, older children might do relatively well in terms of monetary poverty but are disproportionately disadvantaged in multidimensional terms due to the issues of education and child work. Children living in male-headed households face an especially high risk to be deprived in the areas of health and water and sanitation and children living in the Mekong River Delta are particularly deprived with respect to shelter and water and sanitation, despite their relatively small risk to monetary poverty. This detailed level of information can guide efforts towards the reduction of inequality. In closing the gaps between different socio-economic and demographic groups of children in Vietnam, this type of analysis can support the identification of priority intervention areas.

The findings of this study add value to the academic and policy debate with respect to the use of a set of poverty indicators for a distributional analysis. In particular, it fills a knowledge gap in terms of the distribution of child poverty over various demographic and socio-economic groups in Vietnam and extends previous work on distribution and inequality by taking a monetary and multidimensional perspective. Furthermore, the study clearly illustrates that a set of multiple indicators does not only provide more detailed information with respect to inequality but can also guide the prioritization and formulation of policy initiatives. 


\subsection{Annexes}

\subsubsection{Annex 1 Domains and indicators multidimensional child poverty approach as based on VHLSS}

Table A4.1 Exact definitions selected indicators based on VHLSS data

\begin{tabular}{|c|c|c|c|}
\hline Domain & Indicators & Definition of indicator & $\begin{array}{l}\text { Definition of threshold and } \\
\text { remarks on indicator definition }\end{array}$ \\
\hline \multirow[t]{4}{*}{$\begin{array}{l}\text { Education } \\
\text { poverty }\end{array}$} & \multirow[t]{3}{*}{$\begin{array}{l}\text { Enrolment } \\
\text { poverty rate }\end{array}$} & $\begin{array}{l}\text { children in age } 5 \text { not } \\
\text { attending pre-school as a } \\
\text { percentage of all children } \\
\text { in age } 5\end{array}$ & \multirow{3}{*}{$\begin{array}{l}\text { Age definition used for } \\
\text { calculating net enrolment rate } \\
\text { per level of schooling: taking into } \\
\text { account birth date and start of } \\
\text { school year, including over- } \\
\text { achieving children that are in a } \\
\text { higher grade than appropriate for } \\
\text { their age }\end{array}$} \\
\hline & & $\begin{array}{l}\text { children in age } 6-10 \text { not } \\
\text { attending primary school } \\
\text { as a percentage of all } \\
\text { children in age } 6-10\end{array}$ & \\
\hline & & $\begin{array}{l}\text { children in age } 11-15 \text { not } \\
\text { attending lower primary } \\
\text { school as a percentage of } \\
\text { all children in age } 11-15\end{array}$ & \\
\hline & $\begin{array}{l}\text { Completion } \\
\text { poverty rate }\end{array}$ & $\begin{array}{l}\text { children in age } 11-15 \text { that } \\
\text { have not completed } \\
\text { primary education as a } \\
\text { percentage of all children } \\
11-15\end{array}$ & $\begin{array}{l}\text { All children aged } 11-15 \text { at the } \\
\text { time of interview are considered } \\
\text { vulnerable when they have not } \\
\text { completed primary school }\end{array}$ \\
\hline $\begin{array}{l}\text { Health } \\
\text { poverty }\end{array}$ & $\begin{array}{l}\text { Health visit } \\
\text { poverty rate }\end{array}$ & $\begin{array}{l}\text { Children in age } 2-4 \text { not } \\
\text { having visited a } \\
\text { professional health facility } \\
\text { in the last } 12 \text { months as a } \\
\text { percentage of all children } \\
\text { aged } 2-4\end{array}$ & $\begin{array}{l}\text { Professional health facilities } \\
\text { include village health centre, } \\
\text { commune health centre, regional } \\
\text { general clinics, district hospital, } \\
\text { provincial hospital, central } \\
\text { hospital, other state-owned } \\
\text { hospital, private hospital, other } \\
\text { hospital and private clinics. } \\
\text { Traditional herb doctors and } \\
\text { other health centres are excluded }\end{array}$ \\
\hline \multirow[t]{2}{*}{$\begin{array}{l}\text { Shelter } \\
\text { poverty }\end{array}$} & $\begin{array}{l}\text { Electricity } \\
\text { poverty rate }\end{array}$ & $\begin{array}{l}\text { children living in a } \\
\text { dwelling without } \\
\text { electricity as a percentage } \\
\text { of all children in age } 0-15\end{array}$ & - \\
\hline & $\begin{array}{l}\text { Housing } \\
\text { poverty rate }\end{array}$ & $\begin{array}{l}\text { children not living in } \\
\text { proper housing as a } \\
\text { percentage of all children } \\
\text { in age } 0-15\end{array}$ & $\begin{array}{l}\text { Proper dwellings include villas, } \\
\text { strong houses with private and } \\
\text { shared facilities and semi- } \\
\text { permanent houses. Shift-made or } \\
\text { other houses are considered } \\
\text { improper dwellings }\end{array}$ \\
\hline \multirow[t]{2}{*}{$\begin{array}{l}\text { Water and } \\
\text { Sanitation } \\
\text { poverty }\end{array}$} & $\begin{array}{l}\text { Sanitation } \\
\text { poverty rate }\end{array}$ & $\begin{array}{l}\text { children living in a } \\
\text { dwelling without a } \\
\text { hygienic sanitation facility } \\
\text { as a percentage of all } \\
\text { children in age } 0-15\end{array}$ & $\begin{array}{l}\text { Hygienic sanitation includes flush } \\
\text { toilet, suilabh and double vault } \\
\text { compost latrine. Toilets directly } \\
\text { over water, other facilities or no } \\
\text { toilet are considered unhygienic. }\end{array}$ \\
\hline & Water & children not drinking safe & Safe drinking water sources \\
\hline
\end{tabular}




\begin{tabular}{l|l|l|l}
\hline & poverty rate & $\begin{array}{l}\text { drinking water as a } \\
\text { percentage of all children } \\
\text { in age 0-15 }\end{array}$ & $\begin{array}{l}\text { include private tap water from } \\
\text { inside and outside the house, } \\
\text { deep drill wells, hand-dug and } \\
\text { reinforced wells, hand-dug, non- } \\
\text { reinforced and covered wells, } \\
\text { protected springs, rain water and } \\
\text { bought water } \\
\text { Unsafe drinking water includes } \\
\text { unprotected springs, small water } \\
\text { tank, water tank, rivers, lakes and } \\
\text { ponds and others }\end{array}$ \\
& $\begin{array}{ll}\text { Child work } \\
\text { rate }\end{array}$ & $\begin{array}{l}\text { children age 6-15 that } \\
\text { have worked for an } \\
\text { employer or in household } \\
\text { production in the last 12 } \\
\text { months as a percentage of } \\
\text { all children in age 6-15 }\end{array}$ & $\begin{array}{l}\text { Child work includes having } \\
\text { horked for wage/salary, } \\
\text { household production or trading } \\
\text { or business for the household } \\
\text { regardless of the number of hours } \\
\text { or days worked }\end{array}$ \\
\hline $\begin{array}{l}\text { Social } \\
\text { Inclusion } \\
\text { and } \\
\begin{array}{l}\text { Protection } \\
\text { poverty }\end{array}\end{array}$ & $\begin{array}{l}\text { Caregiver } \\
\text { poverty rate }\end{array}$ & $\begin{array}{l}\text { children in age 0-15 living } \\
\text { in households with heads } \\
\text { that do not work due to } \\
\text { disablement or old age, } \\
\text { age 0-4 }\end{array}$ & $\begin{array}{l}\text { Includes heads of household that } \\
\text { can not work due to disablement, } \\
\text { old age/retirement. }\end{array}$ \\
\hline
\end{tabular}


$\frac{⿱ 亠}{2}$ 


\section{Chapter 5}

\section{MAKING POVERTY ANALYSES RICHER - MULTIDIMENSIONAL POVERTY RESEARCH FOR POLICY $\operatorname{DESIGN}_{35}$}

35 Published as:

Neubourg, Chris de, Keetie Roelen and Franziska Gassmann (2009) Making Poverty Analyses Richer - Multidimensional poverty research for policy design. In Boyser, K., C. Dewilde, D. Dierckx and J. Friedrichs (Eds) Between the Social and the Spatial - Exploring Multiple Dimensions of Poverty and Social Exclusion, Ashgate Publishing, pp. 35-56 


\subsection{Introduction}

The information revealed by poverty estimates relying on multidimensional indicators on the number and the characteristics of poor people overlaps only partially with the information provided by poverty estimates based on money-metric indicators. The differences in outcomes between multidimensional and monetary approaches are substantial and guide social policy in different ways and along different alleys. This holds for nearly all countries but is especially true for poverty in low- and middle income countries, as is illustrated in this paper for Vietnam and Congo.

Poverty estimates based on a monetary indicator basically identify everybody as poor whose income/resources (or expenditures) are lower than a pre-set income/expenditure level. These types of poverty estimates are most widely used for poverty analyses worldwide (Redmond 2008; Laderchi et al 2003; Leyte et al. 2001) and are usually preferred for several reasons:

- There is a long tradition of poverty analyses based on money-metric indicators. This long tradition is, in turn, further reinforced by the use of cash transfers in social policy;

- because of its long tradition, data on incomes and/or expenditures are largely available for many countries;

- monetary values of wealth (and poverty) are believed to be easily comparable across the income distribution, across time and across countries ${ }^{36}$;

- money-metric poverty estimates usually lead to single indicators that lend itself easily for advocacy purposes and are easy to quote on front pages of newspapers and in the political debate;

Monetary poverty indicators implicitly assume that individuals/households having enough money can buy everything that they need for the fulfilment of their basic needs (Thorbecke 2008; Tsui 2002). This implicit assumption is most widely criticised. The consumer sovereignty of individuals that forms the basis for this assumption is often not observed in the daily life of many and especially of poor households. The underlying rationale implies that all attributes can be purchased on markets and can be expressed in monetary terms. Markets for basic goods, however, often do not exist, are incomplete or function imperfectly (Thorbecke 2008; Bourguignon and Chakravarty 2003; Tsui 2002). Goods and services related to basic needs such as clean water, accessible healthcare and education are semi-public or public goods in many countries, thus making households dependent on the production of these goods and services by public authorities. The availability of purchasing power among households will not suffice to gain access to these goods since households may

36 This is only partially true. Monetary values use a cardinal scale thus assuming equal distance between each consecutive unit of measurement $(€, \$, \ldots)$ for the individuals/households involved; this disregards differences in the marginal utility of money along the income distribution and gave rise to an important literature on subjective poverty/wealth measures. Monetary values have to be corrected for price differences over time and over place; while there is extensive experience with corrections for inflation and international differences in price levels (PPP's), the problems associated with the corrections often introduce measurement errors which are difficult to understand even if the same methodologies are used to define poverty lines (e.g. see Notten, de Neubourg, 2007a and 2007b for details). 


\section{False Positives or Hidden Dimensions $\mid 77$}

be restricted in their consumption by supply constraints ${ }^{37}$. In other specific circumstances some private goods, such as food, are not available due to extreme situations (draught, famine, natural disasters, displacement). Again a higher disposable income will be of some help to households but will not guarantee access to the basic goods and services due to rationed supply on private markets. Supply constraints are not very important in developed economies but are in many cases significant in low- and middle-income countries.

Equally important for questioning the consumer sovereignty assumption is the fact that income and resources are usually measured at the household level disregarding the intra-household distribution 38 (Hulme and McKay 2008). Assuming that households with enough resources to cover their basic needs actually cover the basic needs of all their members implies assuming that either all household members have equal power (or at least enough power to secure the fulfilment of their own basic needs) or that there is perfect solidarity amongst the household members. The latter assumption is violated when the preferences of one household member dominate the consumption pattern of the household. This is, for example, the case if one the household members is a substance abuser. In the latter case, the other household members are possibly deprived from the fulfilment of their basic needs and can thus be considered as poor despite the fact total household resources theoretically would be sufficient to cover the basic needs of all household members.

In this context, children are particularly vulnerable to deprivation of their specific needs. They cannot be regarded as full economic agents exercising consumer sovereignty: they are not able to secure their own income/resources until a certain age, and they are not sovereign in taking consumption decisions (White, Leavy and Masters 2002). Children are usually the weaker parties in the household. Moreover, for the fulfilment of their basic needs they have to rely more than adults on the production of goods and services by public authorities (especially in education and health, but also in water and sanitation). The discrimination of girls compared to boys in some countries adds a specific gender dimension to the deprivation of children.

The specific position of children justifies a careful poverty analysis based on alternative approaches. Following Sen's seminal work on the capability approach (Sen 1985), the field of multidimensional poverty measurement has seen a wide expansion including basic needs approaches (Streeten 1981, 1984) or social exclusion methods (Marlier, Atkinson, Cantillon and Nolan 2007). Recent child poverty studies have also focused on more multidimensional aspects of poverty (see Gordon et al. 2003; Bradshaw et al. 2006). The comparison between monetary and multidimensional concepts has been the subject of previous research. Whilst some scholars have focused on the underlying conceptual and theoretical foundations of poverty measures (see e.g. Sen 1976, 1982, 1985, 1993, Nussbaum 1992, 2000, Ravallion 1994, Laderchi, Saith and Stewart 2003, Thorbecke 2008), others have analyzed poverty measurement from an empirical or applied perspective largely focusing on

37 Moreover, it is difficult assign a monetary value to specific attributes (especially those related to aspects of social inclusion) deemed important to consider people as non-poor such as literacy, numeracy, life expectancy, social participation and access to information (Hulme and McKay, 2008; Thorbecke, 2008).

${ }^{38} \mathrm{In}$ fact, it is not entirely disregarded; it is taken into account by relying on equivalence scales to estimate the resources obtained by each household member. 
the investigation of similarities or differences of poverty outcomes using different types of poverty measurement (see e.g. Klasen 2000, Perry 2002, Bourguignon and Chakravarty 2003, Baulch and Masset 2003, Bradshaw and Finch 2003, Bastos, Fernandes and Passos 2004, Wagle 2009). Findings in these studies generally suggest that the use of monetary and multidimensional poverty measures results in different pictures of poverty, pointing towards modest, if not very limited, overlap in results (see Klasen 2000, Perry 2002, Baulch and Masset 2003, Bastos, Fernandes and Passos 2004, Whelan, Layte and Maitre 2004, Wagle 2009).The development of a multidimensional poverty measure requires decisions to be made, each subject to their own advantages and disadvantages. Inherent to the construction of a multidimensional poverty measurement are choices related to domains and indicators (Klasen 2000; Alkire and Foster 2008; Roelen et al. 2009a), which are often based on value judgments and context-specificity, making multidimensional poverty estimates susceptible to misinterpretation (Roelen et al., 2009a) and controversy (Klasen, 2000). Other contentious issues that need to be tackled when constructing a multidimensional poverty measure include the weighting scheme for domains and indicators as well as the construction of an aggregate poverty index (see Klasen, 2000; Nolan and Whelan, 2007; Alkire and Foster, 2008).

In this paper we choose to avoid most of the problems related to multidimensional poverty measurement by focusing the analysis on the comparison of a monetary indicator with the specific dimensions ${ }^{39}$ of (child) poverty rather than with a composite indicator of (child) poverty based on a combination of dimensions. The latter analysis is made in Roelen et al. (2009c) studying the properties and results of an aggregated multidimensional child poverty indicator approach with a monetary indicator.

\subsection{Concepts and methodologies}

The measure of monetary poverty refers to those living in households with an income or consumption aggregate below the monetary poverty line. In the case of Vietnam, poverty is calculated on the basis of the poverty line as used by the General Statistical Office (GSO) of Vietnam and is generally referred to as the official poverty line. The monetary poverty line captures the cost of a food and non-food consumption basket, with the cost component of the food basket being based on a daily intake of 2100 calories per person per day (VDR 2008). The poverty measure is based on per capita consumption expenditures as welfare measure. Finally, as monetary poverty is based on household poverty, monetary child poverty incidence is based on the percentage of children living in households that are monetary poor. A similar method for the measurement of monetary poverty is used for the analysis of poverty in Congo.

The multidimensional poverty method used in this paper for the case of Vietnam was developed to identify poverty among children in Vietnam. It is a child-specific, outcome-focused and country-specific approach that considers non-monetary aspects of deprivation that are especially relevant for children. Included items consist of education, health, child labour and water and sanitation, among others. A total of nine indicators distributed over six domains are chosen on the basis of stakeholder

39 The concepts dimensions and domains are used interchangeably in this chapter. 
discussions, previous research and data availability, and are considered to appropriately reflect the poverty status of children in Vietnam (Roelen et al., 2006, 2009a, 2009b). ${ }^{40}$ Domain deprivation is constituted by not meeting the threshold of at least one of the indicators within the specific domain, also known as the union approach (Atkinson, 2003). The overall poverty headcount is determined by deprivation in at least two domains, also known as the dual cut-off identification strategy (Alkire and Foster 2008). A country-specific approach to the measurement of multidimensional poverty was also developed for the case of Congo along the same lines (Notten, 2008).

The paper compares the outcomes of dimensions in poverty with the outcome of monetary poverty for children in Vietnam and for adults in Congo. We also use the data to seek pockets of concentrated deprivations by investigating how many children (adults) are simultaneously poor along different dimensions. Moreover, it is possible to investigate the drivers and determinants of various compositions of the different groups of poor. It is argued that monetary poverty counts cannot be regarded as good substitutes for poverty as measured by the non-monetary dimensions in the case of children in Vietnam and adults in Congo. Hence, the results and the analyses based on multidimensional poverty definitions provide richer information than simple monetary poverty estimates; they make it easier to identify policy priorities and to guide the design and composition of social policy measures.

\subsection{Monetary poverty and domain poverty rates for children in Vietnam}

Table 5.1 provides the simple poverty rates as calculated for each domain separately and for the traditional monetary poverty rate for the case of Vietnam. It can be seen that the poverty rates are of the same magnitude with respect to education, shelter and monetary poverty. A much larger proportion of children are deprived in health and water and sanitation, while the share of children deprived in the child labour and social inclusion dimensions is much smaller.

Table 5.1 Monetary and domain child poverty rates for Vietnam

\begin{tabular}{l|c|c}
\hline Domain poverty rate & $\begin{array}{c}\% \text { of } \\
\text { children }\end{array}$ & $\begin{array}{c}\text { \% of children that are also monetary } \\
\text { poor }\end{array}$ \\
\hline Monetary poverty rate & 22.6 & 22.6 \\
\hline Education poverty rate & 18.4 & 34.5 \\
\hline Health poverty rate & 47.8 & 33.6 \\
\hline Shelter poverty rate & 21.0 & 41.7 \\
\hline $\begin{array}{l}\text { Water and sanitation poverty } \\
\text { rate }\end{array}$ & 48.8 & 37.1 \\
\hline Child labour poverty rate & 8.9 & 36.1 \\
\hline Social inclusion poverty rate & 8.0 & 18.9 \\
\hline
\end{tabular}

Source: Authors' calculations based on VHLSS 2006

${ }^{40}$ Section 4.4.1 provides the details with respect to the data whilst Annex 1 in section 4.8.1 discusses the indicators and domains that are used for the estimation of the poverty rates in the various dimensions 
The main question to be answered in this paper is to what extent the information provided by monetary poverty estimates can be used as a proxy for the other six domain poverty rates. A first indication is provided by the third column in Table 5.1; it is obvious that in many cases the overlap is limited ranging from 33.6 percent of overlap in the case of health-poverty and monetary poverty to 41.7 percent of overlap in the case between shelter-poverty and monetary poverty. It is even as low as 18.9 percent in the case of social inclusion-poverty. All in all, the overlap of children being deprived in one of the domains and those being monetary poor does not exceed 50 percent. This implies that if social and economic policy is targeted to the children being monetary poor, it misses out a significant number of children who are not identified as poor using a monetary indicator while nevertheless being deprived in at least one of the domains. However, the analysis can even be taken further.

As an example, Figure 5.1 compares the density distribution of the normalised per capita expenditures for all children and the same density function for the children deprived in the health domain. From the graph it can be seen that the distributions have the same shape with a bias for the health deprived children towards the left (lower income groups). However, despite the fact that the bias indicates that relative more health deprived children are found among the lower income groups, the displacement of the two distributions is in fact very modest ${ }^{41}$.

${ }^{41}$ The graphs of the other domains show very similar pictures; they are not presented here for convenience's sake. 
Figure 5.1 Normalized per capita expenditures for all children and children deprived in the health domain, Vietnam 2006

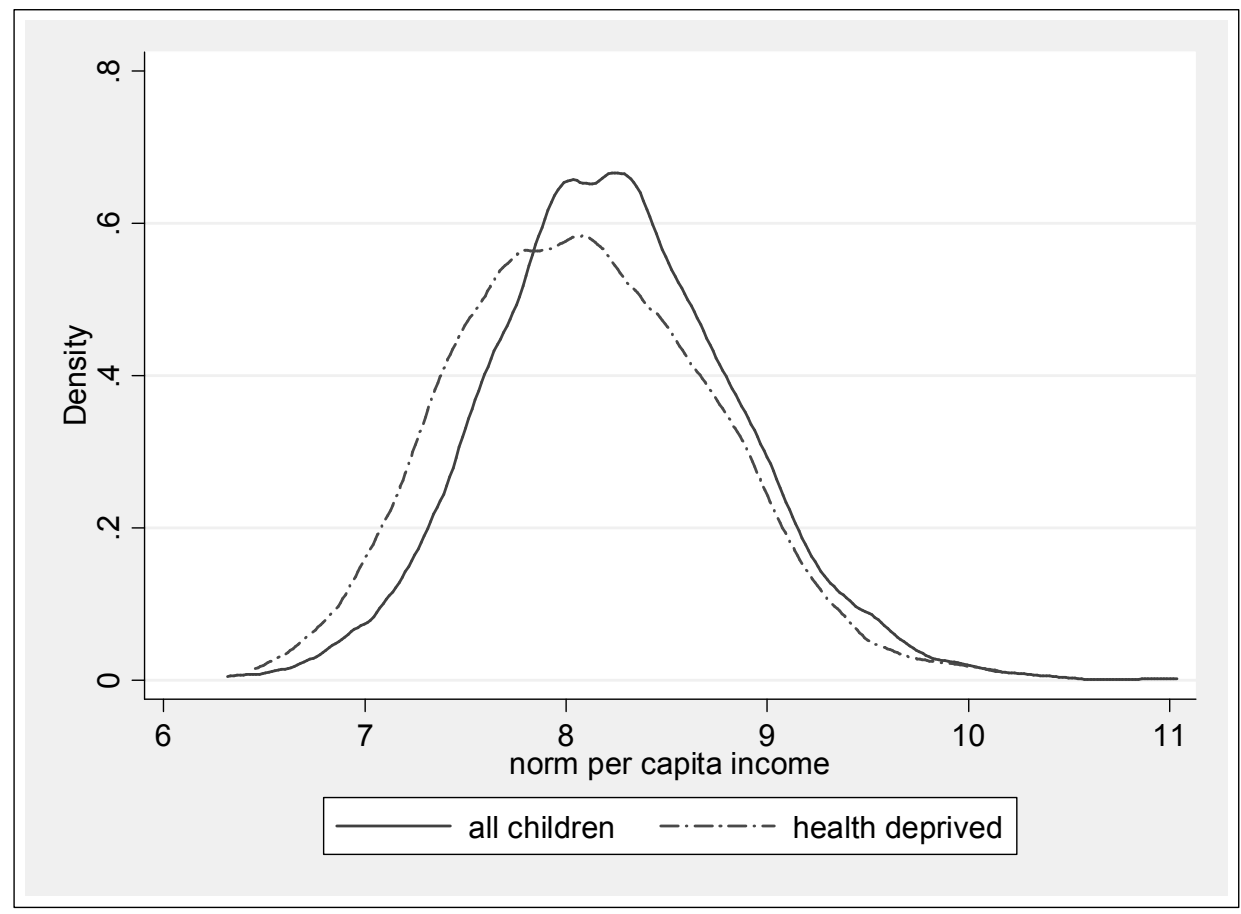

Source: Authors' calculations based on VHLSS 2006

This is further illustrated by Figure 5.2 wherein the same density function for the health deprived children as in Figure 5.1 is compared to the density distribution for the monetary poor children only ${ }^{42}$. The density function of the normalised per capita expenditures for the children that are monetary poor is by construction of a very different shape; it is truncated at the right hand side at the expenditure level of the poverty line and it has a sharp peak actually before the poverty line. From Figure 5.2 it can be seen that both graphs are not good representations for each other. More specifically, it can be seen that relatively there are almost as many children deprived in the health domain among the higher income groups as among the lower. This is further illustrated in Figure 5.3 depicting the proportion of children deprived in the health domain by income (expenditure) quintile. This graph (3) clearly illustrates that as much as between 43 and 60 percent of the children are deprived (poor) in the health domain in $4^{\text {th }}$ and the $5^{\text {th }}$ quintile with the proportion in the $4^{\text {th }}$ even higher than in the third quintile.

42 Please note that the seeming difference in the shape of the density function for the health deprived children between Figures 5.1 and 5.2 is due to scaling differences between the two graphs. 
Figure 5.2: Normalized per capita expenditures for monetary poor children and children deprived in the health domain, Vietnam 2006

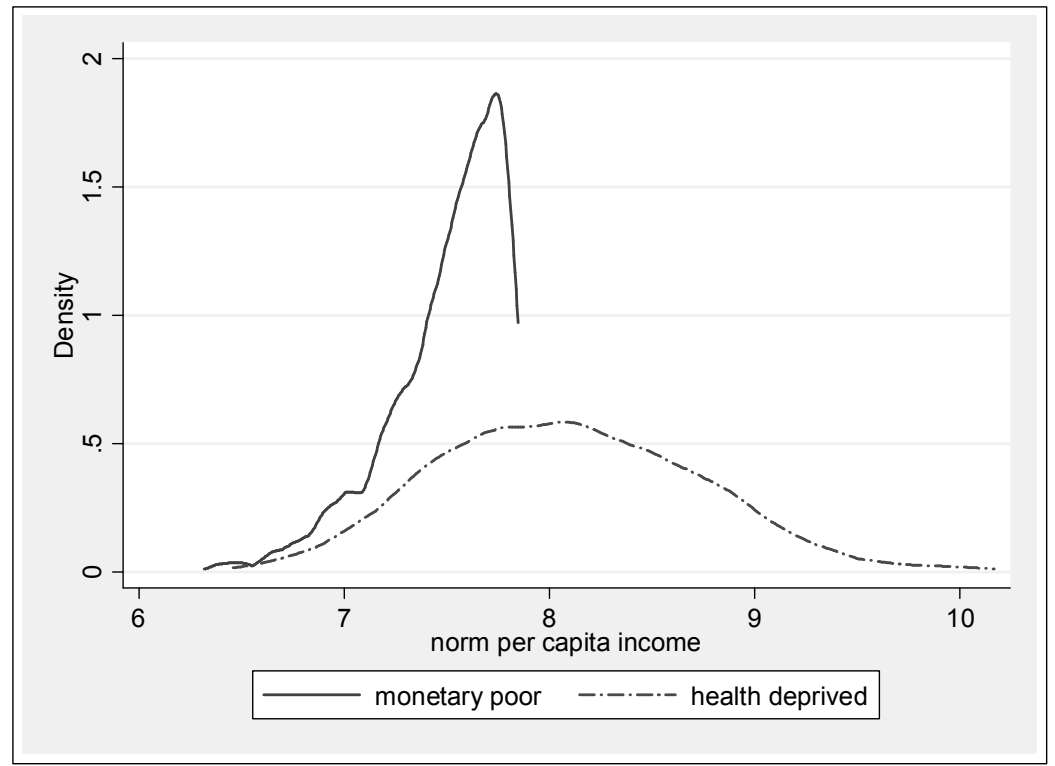

Source: Authors' calculations from VHLSS 2006

Figure 5.3 Proportion of health deprived children by income quintile, Vietnam 2006

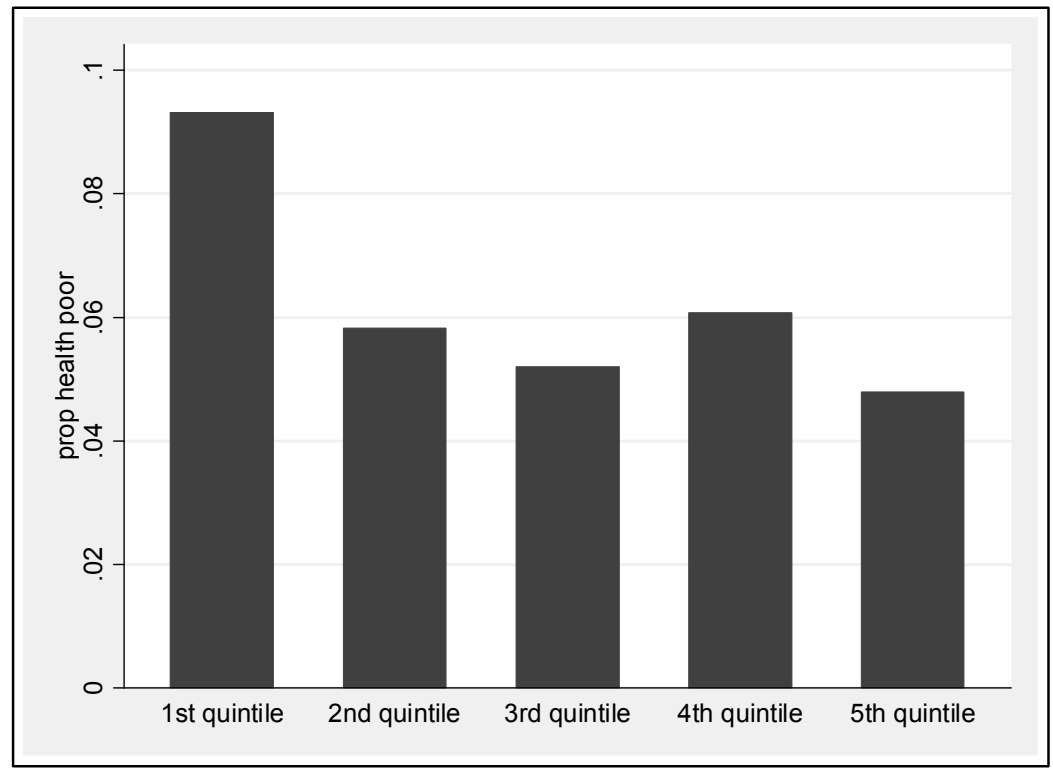

Source: Authors' calculations from VHLSS 2006 
Table 5.2 Correlation between monetary and multidimensional poverty, Vietnam 2006

\begin{tabular}{l|c}
\hline & Monetary poverty \\
\hline Education poverty & $0.169^{*}$ \\
Health poverty & $0.133^{*}$ \\
Shelter poverty & $0.269^{*}$ \\
Water and Sanitation poverty & $0.361^{*}$ \\
Labour poverty & $0.133^{*}$ \\
Social Inclusion and Protection poverty & $-0.032^{*}$ \\
\hline
\end{tabular}

Source: Authors' calculations based on VHLSS 2006

Note: correlation coefficients referring to domain poverty are calculated for the sample of children for which the specific domain poverty is observable

* indicates that the correlation coefficients are significant at the 1 percent level.

Obviously, the deprivation in the health domain is almost 100 percent in the lowest income group, but still monetary poverty is not a good predictor of the deprivation in the health domain for children in Vietnam as is further demonstrated in Table 5.2. Considering the association between monetary poverty status and poverty in specific domains, the correlations are very low. The association is strongest between monetary poverty and deprivation in the water and sanitation and shelter domains. However, with coefficients between 0.269 and 0.361 , even these correlations have to be considered to be very modest. The limited degree of correlation between monetary and (multi)dimensional poverty indicators is in line with evidence presented for other countries by other researchers. Klasen (2000) finds limited correlation between income and deprivation measures in South Africa. Furthermore, in a review of different poverty studies in OECD countries, Perry (2002) as well as Layte et al. (2001) conclude that the association between monetary poverty and other measures of deprivation is much looser than often assumed.

\subsection{Monetary poverty and domain poverty rates for adults in Congo}

We argued above that domain poverty rates are especially important for children since they have a special position within households and as (non-) sovereign consumers. Whether that is also true for adults is an empirical question to be answered. The analysis for Vietnam did not address that issue but research based on a similar definition of domains and a similar way of measuring poverty within the domains in Congo (Brazzaville) included adults as well. The main results are summarized in Tables 5.3 and $5.4^{43}$.

${ }^{43}$ For details of the Congo study, see Notten et al., 2008 and Notten, 2008. 
Table 5.3 Poverty incidence per domain: Congo 2005.

\begin{tabular}{l|c|c|c|c}
\hline & \multicolumn{4}{|c}{ Incidence (percentages) } \\
\hline & Total population & Children & Adult women & Adult men \\
\hline Monetary & 50.1 & 53.7 & 47.8 & 46.2 \\
Education & 37.9 & 52.51 & 36.7 & 21.9 \\
Nutrition & 42.9 & 43.7 & 43.6 & 40.8 \\
Health & 44.52 & 44.0 & 46.0 & 44.0 \\
Labour & 21.0 & 5.63 & 28.3 & 24.5 \\
Water and Sanitation & 67.5 & 69.9 & 66.1 & 64.9 \\
Shelter & 58.7 & 61.6 & 57.4 & 54.8 \\
Social inclusion & 32.1 & 33.8 & 34.6 & 26.4 \\
\hline Population shares (\%) & 100 & 46.2 & 28.6 & 25.2 \\
\hline
\end{tabular}

1 Only children aged $6-17$; incidence for boys $53.7 \%$; for girls $51.2 \%$;

$238 \%$ of individuals in the sample only namely those who had been ill during the last 4 weeks ;

${ }^{3}$ Children aged 10 - 14 only; incidence boys $4.9 \%$; for girls $6.3 \%$.

Source: Notten et al., 2008; estimates based on ECOM 2005.

Table 5.4: Adult women and men simultaneously monetary poor and deprived in one of six domains, Congo 2005

\begin{tabular}{l|c|c}
\hline & Adult women & Adult men \\
\hline Education & $19 \%$ & $11 \%$ \\
\hline Nutrition & $25 \%$ & $22 \%$ \\
\hline Health & $24 \%$ & $23 \%$ \\
\hline Labour & $13 \%$ & $12 \%$ \\
\hline Water and Sanitation & $35 \%$ & $33 \%$ \\
\hline Shelter & $31 \%$ & $28 \%$ \\
\hline Social inclusion & $21 \%$ & $16 \%$ \\
\hline
\end{tabular}

Source: Notten et al., 2008.

From Table 5.3 it can be concluded that adults (both men and women) show high monetary poverty rates in Congo (respectively 46.2 and 47.8). The poverty rates are also high for nearly all the domains considered with the highest figures for the water and sanitation domain and lower figures for the labour and the social inclusion domains. As was the case for children in Vietnam, the overlap between adults in Congo being simultaneously monetary poor and deprived in one of the domains is extremely limited (Table 5.4). Percentages of overlap are consistently higher for women than for men but still very limited and nowhere higher than one third, indicating that monetary poverty is only a poor predictor of deprivation in the other domains for adults in Congo (as was the case for children in Vietnam).

\subsection{Making poverty analyses richer by providing more detailed information to policy designers}

The conclusions above have serious implications for the design and the successful implementation of social policy. Focussing social policy on the individuals (children and adults) who live in poor households according to a money-metric poverty measure may mean missing out on people who are seriously deprived in important domains such as health, education and access to clean water. According to our estimates presented here, and previous studies by other authors for other countries 
(see above), there are a lot of people who are not poor in the monetary sense, but nevertheless do not have access to basic goods such as basic health care, clean water and education. Given this conclusion we plea for enriching poverty analyses by taking into consideration the additional and complementary information provided by multidimensional poverty analyses (as we plead elsewhere for using relative and absolute poverty lines alongside when considering monetary poverty - Notten and de Neubourg, 2007a, 2007b). Obviously, it requires more data and more analyses and evidently, the analyses may look less streamlined and be less fit for newspapers headlines; but it can be safely argued that social policy can gain in quality when the information from multidimensional poverty studies is taken into account.

Multidimensional poverty rates allow going beyond simple monetary poverty headcounts. In the remainder of this paper we elaborate on the search for overlap between the dimensions and on understanding the poverty profile that stems from a more detailed analysis of the dimensions.

While the headcount of people being poor along one of the dimensions tell you something on the severity ${ }^{44}$ of deprivation in these domains, the analysis can be taken a step further by studying the number of people that are simultaneously poor in more dimensions. Estimates of children in Vietnam being deprived in two dimensions simultaneously are given in Table 5.5 (the overlap between the six dimensions and the monetary poverty rate is already given in Table 5.1).

Table 5.5 Proportions of children experiencing poverty in two domains, Vietnam 2006

\begin{tabular}{|c|c|c|c|c|c|}
\hline & $\begin{array}{c}\text { health } \\
2-4\end{array}$ & $\begin{array}{c}\text { shelter } \\
0-15\end{array}$ & $\begin{array}{c}\text { water and } \\
\text { sanitation } \\
0-15 \\
\end{array}$ & $\begin{array}{l}\text { Child work } \\
\quad 6-15\end{array}$ & $\begin{array}{c}\text { social inclusion } \\
\text { and protection } \\
0-15\end{array}$ \\
\hline education & $\mathrm{X}^{1}$ & $\begin{array}{c}5-15, \\
n=8326 \\
3.22\end{array}$ & $\begin{array}{c}5-15, n=8326 \\
12.58\end{array}$ & $\begin{array}{c}6-15 \\
\mathrm{n}=7800 \\
5.10\end{array}$ & $\begin{array}{c}5-15, n=8326 \\
1.25\end{array}$ \\
\hline health & & $\begin{array}{c}2-4, \\
n=1428 \\
11.55\end{array}$ & $\begin{array}{c}2-4, n=1428 \\
23.93\end{array}$ & $\mathrm{X}^{1}$ & $\begin{array}{c}2-4, n=1428 \\
6.27\end{array}$ \\
\hline shelter & & & $\begin{array}{c}0-15 \\
\mathrm{n}=10696 \\
18.72\end{array}$ & $\begin{array}{c}\begin{array}{c}6-15 \\
\mathrm{n}=7800 \\
3.08\end{array} \\
\end{array}$ & $\begin{array}{c}0-15, \mathrm{n}=10696 \\
1.34\end{array}$ \\
\hline $\begin{array}{l}\text { water and } \\
\text { sanitation }\end{array}$ & & & & $\begin{array}{c}6-15 \\
n=7800 \\
6.51\end{array}$ & $\begin{array}{c}0-15, \mathrm{n}=10696 \\
2.99\end{array}$ \\
\hline child work & & & & & $\begin{array}{c}6-15, \mathrm{n}=7800 \\
0.40\end{array}$ \\
\hline
\end{tabular}

1 This figure cannot be calculated since the health variable in the case of Vietnam is based on children aged 0 - 4; these children, however, do not go to school or cannot be active on the labour market and for that reason the overlap is zero.

Source: Authors' calculations based on VHLSS 2006

44 This is different from a poverty severity index for the domains, although it is possible to calculate that figure as well as is done, see Roelen et al. $2009 \mathrm{~b}$. 
From Table 5.5 it can be seen that for Vietnam the overlap between the domains water and sanitation and shelter on the one hand, and health and education on the other hand is largest. This tells something about the physical living conditions of the children and their ability to gain access to health and educational services. The overlap between the child labour variable with the deprivation in education is amazingly low: it seems that at least part of the children with activities on the labour market still go to school suggesting that for those children child labour is an addition rather than a substitute for being in full time education.

Studying the same overlap for children in Congo in Table 5.6 basically reveals the same picture, only with much higher values and percentages reflecting the fact that Congo is a poorer economy compared to Vietnam. Also in the Congolese case the overlap with the monetary indicator is limited to less than one third (except for water and sanitation and shelter). But also the overlap of children being poor in any pair of two domains is limited, indicating that each dimension brings substantially new information to the analysis. As in the Vietnamese case, the overlap between child labour and children deprived in the education domain is small; clearly, being engaged in child labour is also in Congo for at least part of the children a supplement rather than a substitute to full time education. This is not to say that most of the children in Congo do attend school: more than 52 percent of the Congolese children are not attending school adequately as can be seen from Table 5.3. However, in most cases this is not due to the fact that the children are active on the labour market.

Table 5.6 Proportions of children experiencing poverty in two domains, Congo 2005

\begin{tabular}{l|c|c|c|c|c|c|c}
\hline & Monetary & Education & Nutrition & Health & Labour & $\begin{array}{c}\text { Water and } \\
\text { sanitation }\end{array}$ & Shelter \\
\hline $\begin{array}{l}\text { Monetary } \\
\text { Education }\end{array}$ & - & & & & & & \\
Nutrition & 27 & - & - & & & & \\
Health & 26 & 28 & 26 & - & & & \\
Labour & 4 & 5 & 2 & 3 & - & & \\
Water and & 42 & 40 & 33 & 34 & 5 & & \\
Sanitation & & 37 & 31 & 31 & 5 & 54 & - \\
Shelter & 37 & 20 & 19 & 18 & 2 & 28 & 26 \\
$\begin{array}{l}\text { Social } \\
\text { inclusion }\end{array}$ & 24 & & & & & & \\
Source:
\end{tabular}

Source: Notten et al., 2008, estimates based on ECOM 2005

Note: All children except for education (only children aged between 6 - 17) and for labour (only children aged between 10 - 14).

Tables 5.7 and 5.8 provide the same information for adult men and women in Congo. Striking are the small differences between men and women in general. However, when the differences are more outspoken, they reveal new information. The gender bias to the detriment of women is particularly outspoken for women who are deprived in the education domain; women who had not followed a formal education are much more often found among the adults that are monetary poor, suffer significantly more from malnutrition and have far less access to health services. The effect of having less education is far less outspoken for men in these domains. Since malnutrition, limited access to health care and less money for mothers usually also means malnutrition, limited access to health care and less money for their children, the observed gender bias is especially detrimental for children. 
Table 5.7 Proportions of adult women experiencing poverty in two domains: Congo 2005

\begin{tabular}{l|c|c|c|c|c|c|c}
\hline & Monetary & Education & Nutrition & Health & Labour ${ }^{1}$ & $\begin{array}{c}\text { Water and } \\
\text { sanitation }\end{array}$ & Shelter \\
\hline $\begin{array}{l}\text { Monetary } \\
\text { Education }\end{array}$ & - & - & & & & & \\
Nutrition & 25 & 19 & - & & & & \\
Health & 24 & 21 & 24 & - & & & \\
Labour & 13 & 5 & 13 & 13 & - & & \\
Water and & 35 & 28 & 32 & 32 & 17 & - & \\
$\begin{array}{l}\text { Sanitation } \\
\text { Shelter }\end{array}$ & 31 & 27 & 29 & 29 & 13 & 49 & - \\
Social \\
inclusion
\end{tabular}

${ }_{1}^{1}$ women aged 18 - 54 only.

Source: Notten et al., 2008; estimates based on ECOM 2005.

Table 5.8 Proportions of adult men experiencing poverty in two domains: Congo 2005

\begin{tabular}{l|c|c|c|c|c|c|c}
\hline & Monetary & Education & Nutrition & Health & Labour ${ }^{1}$ & $\begin{array}{c}\text { Water and } \\
\text { sanitation }\end{array}$ & Shelter \\
\hline $\begin{array}{l}\text { Monetary } \\
\text { Education }\end{array}$ & - & - & & & & & \\
Nutrition & 22 & 11 & - & & & & \\
Health & 23 & 13 & 24 & - & & & \\
Labour & 12 & 4 & 11 & 13 & - & & \\
Water and & 33 & 16 & 29 & 32 & 15 & - & \\
Sanitation & 28 & 14 & 25 & 29 & 12 & 46 & - \\
Shelter & 16 & 8 & 14 & 16 & 7 & 21 & 20 \\
Social \\
inclusion
\end{tabular}

${ }^{1}$ men aged $18-54$ only.

Source: Notten et al., 2008; estimates based on ECOM 2005.

For policy design purposes the analysis can be taken some steps further. Poverty profiles using the various dimensions can be constructed. The first step is the decomposition of the poverty incidence in the various dimensions for several subgroups in the population sample. This is illustrated for Vietnam in Table 5.9 wherein the poverty incidences in the six dimensions are broken down by gender, rural-urban settlement, by region and by age. This table reveals policy information which can guide social policy to target specific subgroups among the children or to abstain from targeting along a certain line. The difference between boys and girls is not very important in none of the dimensions. The differences between urban and rural areas, however, are striking with children living in rural areas being much worse off except in the social inclusion domain. The differences are big in all other domains but especially big with respect to water and sanitation and shelter; still, the differences in the education and the health domains are substantial and should attract the attention of the policy makers.

When disaggregating by regional level, the picture becomes more detailed. The North-West is the most problematic region in Vietnam in the sense that for all dimensions (except social inclusion) children in that region are much worse off than their peers in the other regions: almost 90 percent of the children in that region do not have access to clean water; almost 70 percent do not have access to decent health facilities, and more than one third of the children are not at school or are lagging 
behind significantly. This is in contrast with the more prosperous parts of the country: the Red River Delta and the South East. In these regions relatively fewer children are deprived in the six domains. It should be noted, however, that this does not mean that child-poverty is not a problem: even in the 'best' region of the country a quarter of the children do not have access to clean water, and more than 1 out of 10 children is not at school. The North East, the North West and the North Central Coast need special policy attention when it comes to health facilities: a large proportion (60 percent or more) of the children do not dispose of accessible health facilities.

Looking at ethnicity, it is obvious that the conditions for children among Kinh and the Chinese are better than for the other ethnicities, while the age of the children does not have a big influence on the poverty incidence in the six dimensions. School dropout is a problem at very young age and at older age, while child labour increases with age.

While the information in Table 5.9 provides already plausible focus points for social and infrastructural policy, the analysis can be further refined. The basis for refinement is given in Figure 5.4. The Venn diagram depicts the overlap between three domains for Congolese children: monetary poverty, education poverty and child labour poverty. 25 percent of the children in Congo are not deprived in any of these 3 domains; 3 percent is deprived in all the three domains simultaneously; 31 percent are simultaneously monetary poor and education poor and 18 percent are only educational poor without being poor in one of the two other dimensions. Of course, this kind of diagrams can be constructed for all combinations of 2, 3, 4 and more dimensions; Figure 5.4 is given for illustrative purposes indicating what possibilities a multidimensional poverty analysis provides. The following step is trying to understand the drivers behind the multidimensional poverty rates. This can be studied by estimating probit (logit) functions on some of the groups reflected in percentages in the Venn diagram; first, the determinants for children who are not deprived in any of the domains are estimated; what makes them so different from the others? Subsequently, any of the groups can be studied: for example the group of children that suffer both from monetary and education poverty versus the group of children that are only education poor: what makes them special? How is it possible that children who do not live in monetary poor households are never the less deprived in the education domain? Some of these analyses are made in Roelen et al., 2009c and in Notten et al., 2008. 
Figure 5.4 Overlap between the monetary, education and child labour poverty, children Congo 2005

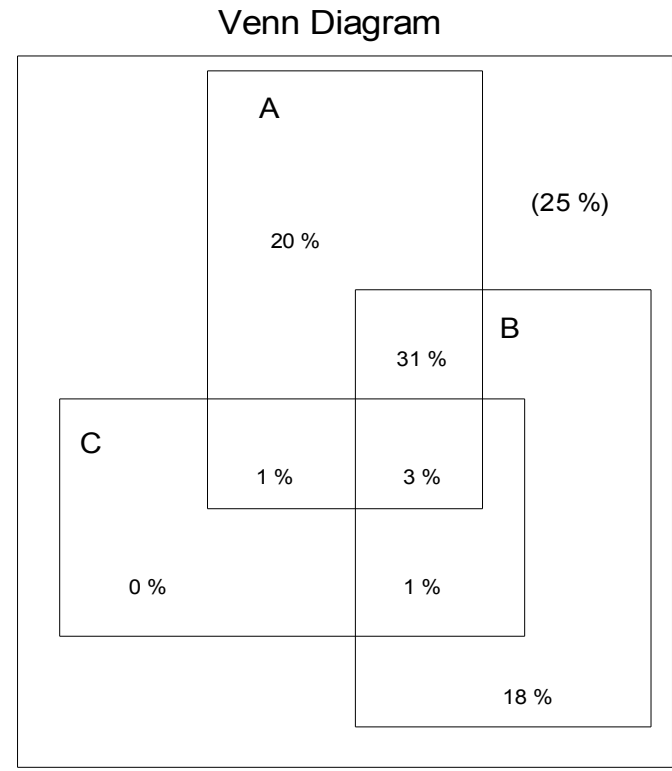

$$
N=45239
$$

A Monetaire

B Education

C Travail

Source: Notten et al., 2008; estimates based on ECOM 2005. 


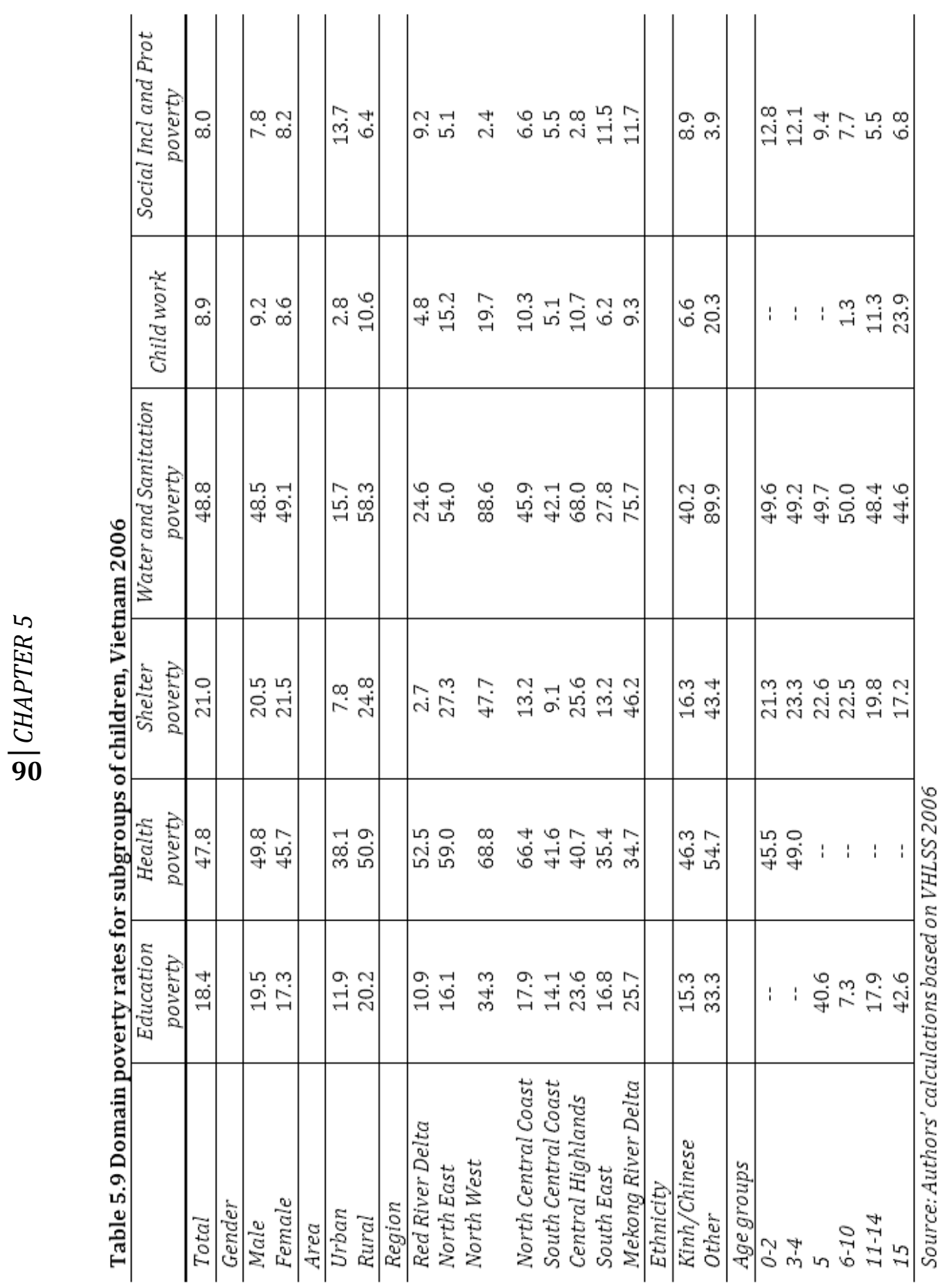




\subsection{Conclusion}

Money-metric poverty measures provide useful information on the number of monetary poor people as well as on their profile. However, the information is limited because the headcount implicitly assumes that people living in households above the defined poverty line are able to afford the fulfilment of the basic needs for all its members. It has been argued that this may not be the case especially for children and adults living in low and middle income countries. Reasons are found in limited consumer sovereignty, supply constraints in basic (semi-) public goods and supply rationing on private markets.

In order to overcome the drawbacks of money-metric poverty measures, multidimensional poverty estimates are developed. They take into account the deprivation in various domains to estimate the number of poor. Most multidimensional poverty estimates construct a composite index which can then be used as an alternative to money-metric measures. Composite indices have their own disadvantages related to weighting and construction. In this paper we avoided most of these problems by focusing on the various dimensions separately.

The overall conclusions confirm the findings of previous studies that found that the overlap between monetary poverty measures on the one hand and poverty estimates based on one or more dimensions is surprisingly limited in the case of children in Vietnam and adults in Congo. Clearly, deprivation in one or several dimensions does coincide relatively little with being identified as monetary poor.

The analysis of the separate dimensions provides very useful policy information as to where to find the people that lack access to basic goods and services. The profile of people being deprived in several dimensions simultaneously also reveals where to focus policy attention when designing social policy.

In order to make these analyses possible, detailed data are needed as well as the calculation (estimation) of many tables, cross tabulations, figures and diagrams. There is a trade-off between the richness of the analysis and inputs needed to produce this richness. It could be even questioned whether social policy should engage in this type of detail when designing new initiatives. Even when the full richness of the analysis cannot be used in designing policy, they can still be useful for policy monitoring and evaluation. 


$$
\frac{2}{92}
$$




\section{Chapter 6}

\section{FALSE POSITIVES OR HIDDEN DIMENSIONS - WHAT CAN MONETARY AND MULTIDIMENSIONAL MEASUREMENT TELL US ABOUT CHILD POVERTY? ${ }_{45}$}

A widely used division between poverty measures is that of monetary versus multidimensional measures. This division is based on conceptual and ideological underpinnings as well as empirical and analytical outcomes. Comparisons of the use and outcomes of these methods have shown that they predominantly provide different pictures of poverty in terms of figures of overall levels of poverty as well as groups of poor individuals. This paper adds value to the longstanding and ongoing debate on poverty measurement by comparing the use of a monetary and multidimensional poverty measurement with a special focus on children and extending the empirical analysis beyond conventional methods. In addition to investigating whether overall poverty outcomes or groups of identified poor children differ when using two different poverty measures, we also investigate the drivers underlying these differences. Findings confirm a considerable degree of misidentification when using monetary and multidimensional poverty measurement. Correlation between monetary and multidimensional child poverty is limited and both poverty measures prove to be inadequate to predict poverty in terms of the other poverty measure. An analysis of the groups of poverty suggest that certain demographic groups of children are captured disproportionately by monetary and multidimensional poverty measures and that there are underlying factors that in- or decrease a child's probability to belong to a specific poverty group.

${ }^{45}$ Submitted to:

International Journal of Social Welfare, February 2010 


\subsection{Introduction}

The debate on the definition of poverty and the approaches to conceptualize and measure it is longstanding and remains on-going. What is poverty? How does it manifest itself? And how can it be measured? These are questions that have engaged and still occupy scholars since Rowntree's seminal work in the beginning of the $20^{\text {th }}$ century (Alcock 2006). A division of poverty approaches that is often made within this debate is that of monetary versus multidimensional approaches, each with their own advantages and shortcomings. While some scholars focus the discussion on the theoretical and ideological underpinnings of the approaches, others have investigated the use of different poverty approaches in more empirical or analytical terms. As a result, it is widely established that different approaches do not only differ in terms of their conceptual foundations (see e.g. Laderchi 1997, Laderchi, Saith and Stewart 2003) but also with respect to empirical outcomes (see e.g. Klasen 2000 Perry 2002, Baulch and Masset 2003, Bradshaw and Finch 2003, Maltzahn and Durrheim 2007, Wagle 2009). Despite the range of evidence on the topic, the majority of empirical studies do not move beyond the notion that the degree of overlap in poverty outcomes is limited and biased towards different groups in society. Little analysis has been undertaken to assess the factors and dynamics underlying this limited degree of overlap.

The issue of child poverty remains a hidden element and under-prioritized despite the wide acknowledgment that child-focused policy analyses are crucial to account for a number of issues (see Ben-Arieh 2000, Minujin et al. 2005, Roelen et al. 2009a). Children hold a special position within the household structure due to their high dependency on others for the distribution of basic needs (e.g. White, Leavy and Masters 2003), which are in turn different from the basic needs of adults (e.g. Waddington 2004). Moreover, poverty often manifests itself as a vicious circle, causing children to be trapped in poverty from birth onwards (e.g. Corak 2006). Despite the wide acknowledgment of the importance of child-focused poverty measurement and analysis and the existing range of literature on the measurement of child poverty using monetary and multidimensional methods, an in-depth analysis of whether and how the use of such two measures leads to different results with respect to child poverty is, to our knowledge, limited ${ }^{46}$.

This paper analyzes the use of two distinct poverty approaches with respect to specifically children. We use the Vietnam Household Living Standards Survey (VHLSS) 2006 to investigate the outcomes for child poverty when measuring poverty using a monetary versus multidimensional approach on the basis of a broad set of methods. In addition to considering the degree of overlap or mismatch, we also investigate underlying dynamics that could explain potential differences in outcomes. The remainder of the paper is structured as follows: firstly, we discuss previous comparative research on monetary and multidimensional poverty measures and outline the monetary and multidimensional approaches used in this study. Next, the data and methodology are described in detail. Thirdly, we compare the use of the

\footnotetext{
46 Bastos, Fernandes and Passos (2004) find differences in outcomes when using an income or deprivation perspective for the measurement of child poverty in Portugal but do not draw any conclusions with respect to the implications for the academic or policy debate.
} 


\section{False Positives or Hidden Dimensions | 95}

monetary and multidimensional approaches in terms of child poverty. This is followed by a more in-depth analysis to gain an understanding of the extent to which one poverty measure could serve as a proxy for the other. In the fifth section, we investigate characteristics and micro-determinants associated with a child's risk to be identified as exclusively monetary or multidimensionally poor or as both. Finally, we draw conclusions on the basis of our findings.

\subsection{Monetary and Multidimensional Child Poverty}

The division between monetary and multidimensional concepts is commonly made within the area of poverty measurement and the analysis of one or both types of approaches has been the subject of numerous previous studies. Whilst some scholars have focused their research on the underlying conceptual and theoretical foundations of poverty measures (see e.g. Sen 1976, 1982, 1985, 1993, Nussbaum 1992, 2000, Ravallion 1994, Laderchi 1997, Laderchi, Saith and Stewart 2003, Thorbecke 2008), others have analyzed poverty measurement from an empirical or applied perspective (see e.g. Klasen 2000, Perry 2002, Bourguignon and Chakravarty 2003, Baulch and Masset 2003, Bradshaw and Finch 2003, Bastos, Fernandes and Passos 2004, Wagle 2009), largely focusing on the investigation of similarities or differences of poverty outcomes using different types of poverty measurement. Findings in these studies generally suggest that the use of monetary and multidimensional poverty measures results in different pictures of poverty, pointing towards modest, if not limited, overlap of results (see Laderchi 1997, Klasen 2000, Perry 2002, Baulch and Masset 2003, Sahn and Stifel 2003, Bastos, Fernandes and Passos 2004, Whelan, Layte and Maitre 2004, Wagle 2009). A short account of conceptual and theoretical considerations underlying both approaches is provided below.

Whilst monetary definitions refer to the measurement of poverty on the basis of income or expenditures, multidimensional measurement incorporate a broad base of attributes that are assumed to reflect the state of poverty ${ }^{47}$. Money-metric poverty measurement was and remains the most widely used method for poverty analysis world-wide (Redmond 2008, Laderchi et al. 2003, Layte et al. 2001) and is based on the rationale that individuals with a certain degree of purchasing power are able to fulfil their basic needs (Thorbecke 2008, Tsui 2002). However, there are a number of drawbacks of the monetary approach, especially in terms of the measurement of child poverty. Its underlying rationale assumes that all attributes for the fulfilment of basic needs can be purchased on markets and expressed in monetary terms. However, in many instances those markets do not exist or function imperfectly (Thorbecke 2008, Bourguignon and Chakravarty 2003, Tsui 2002) and monetary values can not be assigned to specific attributes ${ }^{48}$ (Thorbecke 2008, Hulme and McKay 2008). Furthermore, when individuals or households have sufficient income for the purchase of a basic basket of goods, it does not directly imply that it is also spent on this basket of goods (Thorbecke 2008). Also, income or consumption is predominantly measured

47 This paragraph shows overlap with section 5.1; readers having read that section are advised to continue with the next paragraph.

48 Consider attributes such as literacy, numeracy, life expectancy, social participation and information. 
at one point in time, masking seasonal variability (Sahn and Stifel 2003) or at the household level, not capturing intra-household distribution (Hulme and McKay 2008). Hence, one has to rely on equivalence scale methods to infer conclusions for individuals within the households, including children. Finally, children are not economic actors themselves and therefore not able to generate income to sustain their own livelihood. Monetary indicators would thus not adequately reflect children's state of poverty (White, Leavy and Masters 2003). As a response to these conceptual and technical drawbacks, alternative general poverty approaches have been developed in a multidimensional sphere (Maltzahn and Durrheim 2007). Amartya Sen was one of the first scholars to propose an approach including other aspects than (merely) income that were considered to better reflect the state of poverty (Sen 1985). Consequently, the field of multidimensional poverty measurement has seen a wide expansion, including Sen's capability approach, basic needs approaches (Streeten 1981, 1984) or social exclusion methods (Marlier, Atkinson, Cantillon and Nolan 2007). Recent child poverty studies have also focused on more multidimensional aspects of poverty (see Gordon et al. 2003, Bradshaw et al. 2006, Noble et al. 2006). Although the development of multidimensional poverty measurement largely resulted from the conceptual and theoretical drawbacks inherent to the monetary poverty approach (Maltzahn and Durrheim 2007), the multidimensional poverty measurement also holds a number of disadvantages. Inherent to the construction of a multidimensional poverty measurement is the translation of concept into an operational measure (Wagle 2009) and thereby choices related to the conceptual framework, domains and indicators (Laderchi 1997, Klasen 2000, Alkire and Foster 2008, Roelen et al. 2009a). These choices are often subject to value judgments and context-specific and implicit choices make multidimensional poverty estimates susceptible to misinterpretation (Roelen et al. 2009a) and controversy (Klasen 2000). Other contentious issues that need to be tackled when constructing a multidimensional poverty measure include the weighting scheme for domains and indicators as well as the construction of an aggregate poverty index (see Klasen 2000, Nolan and Whelan 2007, Alkire and Foster 2008).

Following the seminal work in the 1970's and 1980's by Sen $(1976,1985)$, the poverty debate has seen a "general move [...] away from the view of income as the sole measure of poverty [...] (Maltzahn and Durrheim 2007). Given a few exceptions (e.g. Maltzahn and Durrheim 2007), previous studies have indicated that monetary poverty is weakly correlated with alternative dimensions of poverty and thus not an appropriate proxy for poverty in multidimensional terms (De Neubourg et al. 2009). Research in empirical terms has focused primarily on the analysis of size and group differences using different poverty approaches. A few examples highlight the main line of findings. Wagle (2009) finds that monetary poverty versus capability approaches point towards differences with respect to the magnitude and demographic profile of poverty in the United States. Findings by Baulch and Masset (2003) suggest that chronic poverty in Vietnam is more persistent in terms of deprivation with respect to malnutrition and education than in terms of monetary poverty. An exploration of poverty and deprivation in South Africa by Klasen (2000), suggests that expenditure versus deprivation-based poverty measures capture different groups in society despite a strong overall correlation between expenditures and deprivation levels. Findings from Bradshaw and Finch (2003) for Britain underscore the limited overlap in poverty groups by concluding that "[...] the people who are defined as living in 


\section{False Positives or Hidden Dimensions $\mid 97$}

poverty by different measures of poverty are different". Its far-reaching policy implication is an important reason that this research topic has been the subject of a range of previous work and remains to be of utmost interest and importance. If different approaches to poverty indeed draw different pictures of poverty and capture different groups of poor, the policy response to poverty is highly respondent to the poverty measure used (Laderchi 1997, Bradshaw and Finch 2003, Sahn and Stifel 2003, De Neubourg et al. 2009). This paper adds value to the debate in two ways. Firstly, it presents a thorough analysis of the overlap and mismatch of monetary and multidimensional child poverty applied to the case of Vietnam, validating previous research and providing new insights. Secondly, this paper takes the analysis one step further and investigates the drivers of the mismatch between monetary and multidimensional child poverty.

\subsection{Data and Methodology}

\subsubsection{VHLSS $2006^{49}$}

The data used for this study is the Vietnam Households Living Standards Survey (VHLSS) from 2006. This household survey is based on the former Vietnam Living Standards Survey (VLSS) but employs a bigger sample size and is to be conducted every other year. The VLSS was conducted in 1993 and 1998 and the VHLSS from 2002 onwards every second year by the Government Statistical Office (GSO), following the World Bank's Living Standards Measurement Survey (LSMS) methodology. The VHLSS survey samples from 2002 to 2010 are drawn from a master sample, which is a random sample of the 1999 Population Census enumeration areas. The VHLSS 2006 contains 9.189 households with 39.071 individuals, including 10.696 children under the age of 16 .

Household surveys like the VHLSS provide micro-data at the level of the household and their individual members on a range of issues related to children's well-being and poverty as well as social protection. A number of limitations are also inherent to the use of the VHLSS and similar household surveys. The most notable one is that the sampling method causes a substantial group in the society to be omitted from the sample and subsequent data (Evans and Harkness 2008). The sample for the survey is constructed on the basis of the official lists of registered households in communes and urban wards in Vietnam that have lived in the enumeration area for at least six months (Pincus and Sender 2006, 2008). This implies that households or individuals that have recently migrated are not included in the sampling frame (Edmond and Turk 2004). Further, due to the strict the household registration system, or ho khau system, many households and individuals do not satisfy the necessary criteria to newly register and stay unregistered (Pincus and Sender 2006, 2008). But also migrants that have temporary forms of registration appear to be under represented in the sampling frame (VDR 2008). The omission of these groups in society is not only an important issue to point out because of its suspected significant size but even more so because of the denial of social and public services they experience due to their status. The

49 This section shows overlap with section 4.4.1; readers having read that section are advised to continue with the next section. 
structural exclusion of the unregistered migrant group from the data will most likely present us with underestimations for (child) poverty.

\subsubsection{Methods of Analysis}

As a clear understanding of the child poverty approaches at hand is crucial for a sound and solid poverty analysis and interpretation of results (Ravallion 2004, Roelen et al. 2009a), we clearly outline the poverty measures used in this paper for the case of Vietnam. The monetary poverty method builds on per capita expenditures ${ }^{50}$ as underlying welfare measure. The monetary poverty line in 2006 lies at 2559 VND per day, capturing the cost of a food and non-food basket (VDR 2008) ${ }^{51}$. This poverty line was established by the General Statistical Office (GSO) and the World Bank (WB) and is generally referred to as the official poverty line. The incidence of monetary child poverty is based on the share of children with a per capita income below the poverty line, which is provided by the poverty headcount or incidence rate. The depth of poverty is measured by the average shortfall of income to the poverty line as a percentage of the poverty line, which is represented by the poverty gap ratio. Both measures are part of the FGT-class of poverty measures and can be denoted as follows:

$$
P=\frac{1}{N} \sum_{i=1}^{q}\left[\frac{\left(z-y_{i}\right)}{z}\right]^{\alpha}
$$

where $N$ represents the total population, $q$ represents the population below the poverty line, $z$ denotes the poverty line and $y_{i}$ is the individual's income. If $\alpha$ is 0 , the equation denotes the poverty headcount ratio and if $\alpha$ is 1 , the equation represents the poverty gap ratio (Ravallion 1994) ${ }^{52}$.

The multidimensional poverty method used in this paper is a child-specific, outcome-focused and country-specific approach that considers non-monetary aspects of deprivation that are especially relevant for children. It was especially developed to identify poverty amongst children in Vietnam. Included items consist of education, health, child labour and water and sanitation, among others. A total of six domains and nine indicators within these domains are selected on the basis of stakeholder discussions, previous research and data availability and they are considered to appropriately reflect the poverty status of children in Vietnam (Roelen et al. 2006, $2009 a, 2009 b)$. The aggregation of the indicator and domain poverty rates to arrive at the overall child poverty rate follows a combination of the union and dual cut-off

50 Per capita expenditures have been calculated on the basis of equal weights for each household member, making no assumptions about economics of scale.

51 The cost component of the food basket is based on a daily intake of 2100 calories per person per day (VDR 2008).

52 The FGT-class of poverty measures also includes the poverty severity index, which is calculated by assuming $\alpha$ is 2 and thereby giving greater weight to larger shortfalls of income (Ravallion 1994). We do not use this measure in this chapter. 
identification strategy (see Roelen et al. 2009b). A child is domain deprived if he/she does not meet the threshold of at least one of the indicators within the specific domain, also known as the union approach (Atkinson 2003). The overall poverty headcount is determined by deprivation in at least two domains, also known as the dual cut-off identification strategy (Alkire and Foster 2008). Depth of poverty is measured by the normalized deprivation score, dividing the total number of observed deprivations by the maximum number of observable deprivations per individual child (Roelen et al. 2009b). The poverty gap ratio is represented as a percentage of the maximum number of observable deprivations. The calculation of the child poverty depth in this manner is in line with the calculation of the monetary poverty indicators and can thus be used parallel in a comprehensive poverty analysis (Roelen et al. $2009 \mathrm{~b}$ ). However, instead of taking the distance to the poverty line as underlying measure, we count the total number of observed indicator deprivations per individual child. The formal notation of the multidimensional child poverty measures are as follows (see also Roelen et al. 2009b):

The percentage of children falling below the specified threshold per indicator is denoted as the indicator poverty rate.

$$
I V=\frac{\sum_{i=1}^{n} I_{i}}{n}
$$

where $n$ stands for all children for which the indicator is observable and $I_{i}$ represents a dichotomous variable with value 1 if the child is below the indicator threshold and thus vulnerable and value 0 if the child meets the threshold and is not vulnerable. The domain poverty rate reflects the rate of children experiencing deprivation within a specific domain as a percentage of children for whom the indicators within that domain are observable. The domain poverty rate is given by

$$
D V=\frac{\sum_{i=1}^{n} D_{i}}{n}
$$

where $n$ represents all children for which the indicators are observable and $D_{i}$ stands for domain poverty, a dichotomous variable with value 1 if the child suffers deprivation within the specific domain and value 0 if the child does not suffer deprivation. A child is considered to suffer domain poor if it experiences indicator poverty for at least one indicator within that domain:

$$
D_{i}=1 \quad \text { if } \sum_{i=1}^{d} I_{i} \geq 1
$$

where $d$ stands for the total number of indicators identified per domain. The rates for child poverty can be written as follows: 


$$
\text { ChildPov }=\frac{\sum_{i=1}^{N} \text { Pov }_{i}}{N}
$$

where $N$ represents the full sample size of children aged 0-15 and Povi represents a dichotomous variable with value 1 if a child suffers child poverty:

$$
\operatorname{Pov}_{i}=1 \quad \text { if } \sum_{i=1}^{D} D_{i} \geq 2
$$

where $D$ stands for the total number of domains within the specific approach. The depth of child poverty is consequently calculated by dividing the number of observed indicator poverty by the maximum of observable indicators for each individual child:

$$
\operatorname{Gap}_{i}=\frac{\sum_{i=1}^{p} I_{i}}{\sum_{i=1}^{P} I_{i}} x 100
$$

where $p$ stands for the total number of indicators for which the child is considered to be poor and $P$ represents to the maximum of number of observable indicators for the individual child. The aggregate child poverty gap ratio can be written as follows:

$$
\text { ChildGap }=\frac{\sum_{i=1}^{N} G_{a p}}{N}
$$

A set of different methods is used in this paper to investigate the main research questions. Cross tabulations and correlation coefficients have previously been used in other comparative studies of poverty measures (see e.g. Klasen 2000) and will also be employed in this study. ROC curves prove a useful tool to further assess the degree to which one approach is capable of predicting poverty in terms of the other poverty measure and as such can serve as a proxy measure. A Receiver Operator Characteristics (ROC) curve is a method to visualize the performance of a test to discriminate between two populations (Minot and Baulch 2004). In terms of our study, it allows for the assessment of targeting efficiency when using the monetary poverty measure to identify children that are multidimensionally poor. The outcomes provide an indication of the extent to which the monetary poverty method would be suitable as a proxy for multidimensional poverty. The application of ROC curves for poverty analysis to date has been fairly limited. Wodon (1997) and Minot and Baulch 
(2004) are among the few scholars that have used this specific method to assess targeting performance of different poverty indicators. Cross tabulations and Venn diagrams are used to assess and visualize the degree of overlap of children identified as monetary and/or multidimensionally poor. Although cross-tabulations are fairly common for the analysis of overlap or mismatch of poverty measures (see e.g. Klasen 2000, Baulch and Masset 2003, Bastos et al. 2004, Whelan et al. 2004), the use of Venn diagrams is limited. Finally, multinomial regression enables the investigation of underlying drivers or dynamics that cause children to be identified as multidimensional and/or monetary poor. The identification of child poverty using two distinct poverty measures leads to four mutually exclusive groups in the population, making multinomial regression the appropriate method for analysis (see also Whelan et al. 2004).

\subsection{Comparing Monetary and Multidimensional Poverty Measurement}

A comparative analysis of poverty measurement using monetary and multidimensional approaches consists of two different aspects, namely differences in the magnitude of poverty and differences in groups of poverty. The first refers to overall poverty figures, indicating the size of poverty for different groups in society. The second, however, refers to the question whether the same or different children are captured by the two poverty approaches.

A comparison of the magnitude of child poverty in Vietnam is presented in Table 6.1. It can be observed that 23 percent of all children below 16 years of age are monetary poor, compared to a poverty incidence rate of 31 percent for multidimensional poverty. These size differences are considerable but can also be considered as largely arbitrary due to their dependence on the level of the poverty line. Although the setting of the poverty line is often the result of a long and thorough process, it remains subjective and open to debate. Rather than the discrepancies in magnitude, possible differences between groups of children captured by the monetary and multidimensional poverty approaches are of greater interest.

Table 6.1 Monetary and multidimensional poverty

\begin{tabular}{l|c|c}
\hline & \multicolumn{2}{|c}{ VHLSS, $\mathrm{n}=10696$} \\
\hline & $\begin{array}{c}\text { Monetary Child } \\
\text { Poverty Rate }\end{array}$ & $\begin{array}{c}\text { Multidimensional } \\
\text { Child Poverty Rate }\end{array}$ \\
\hline Total & 22.62 & 30.72 \\
\hline
\end{tabular}

Source: Authors' calculations from VHLSS 2006

In order to focus the remainder of our analysis and discussion on differences arising with respect to the demographic profile and groups of poor children, we remove size differences in poverty by artificially equalizing the monetary and multidimensional poverty rates. The monetary poverty line is raised to such a level of 
per capita income ${ }^{53}$ so that the monetary approach captures the same proportion of poor children as the multidimensional approach. Table 6.2 presents an unconditional poverty profile for various demographic groups.

Table 6.2 Adjusted monetary and multidimensional poverty by demographic groups

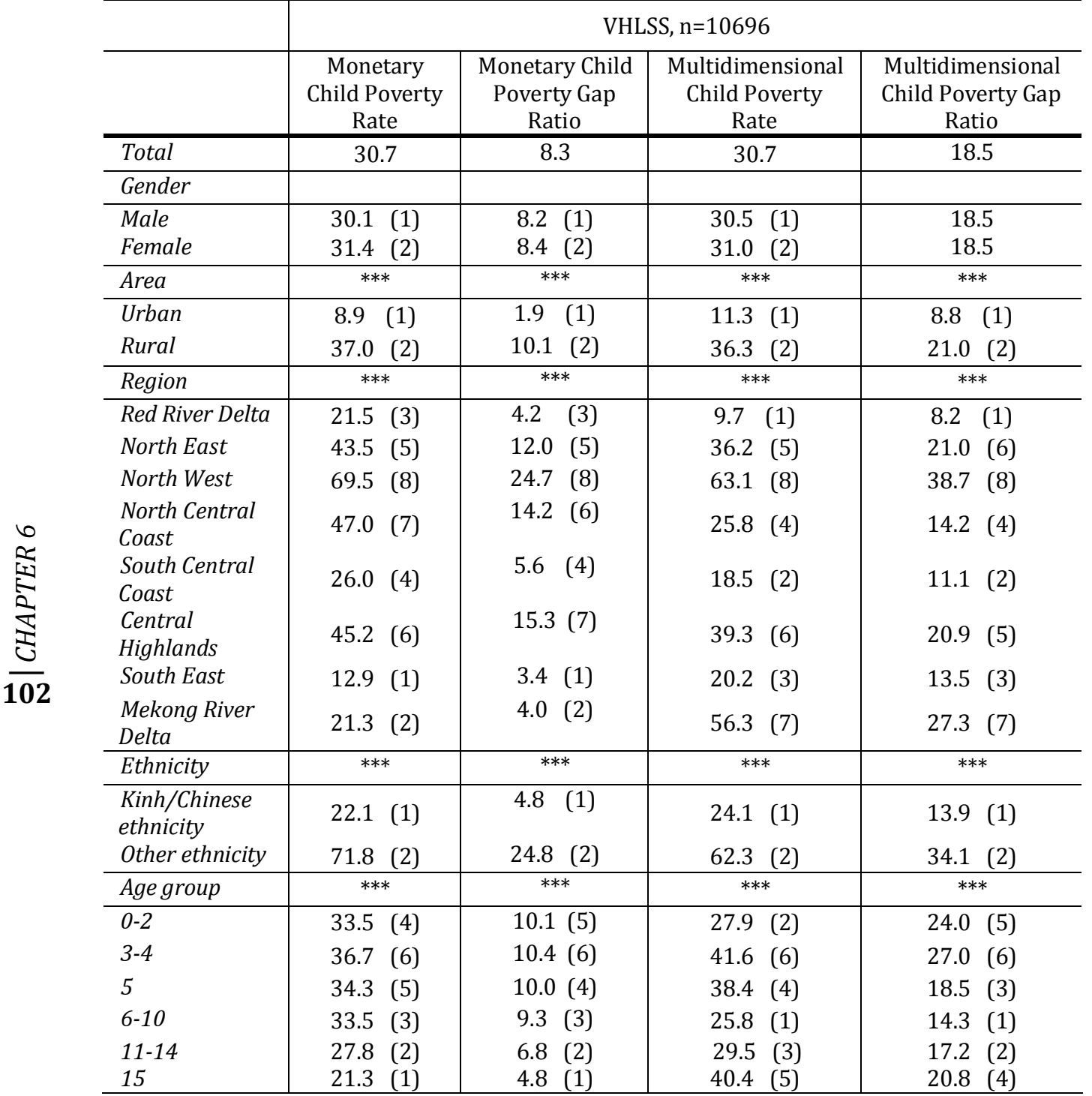

Source: Authors' calculations from VHLSS 2006

Note: ${ }^{* *}<0.001$, significance level chi-squared group equality of means

53 The original level of the monetary poverty line was 2,559.850 VND; the adjusted monetary poverty line is $2,905.000 \mathrm{VND}$. 
Demographic decomposition shows that both monetary and multidimensional poverty figures do not display a significant degree of gender inequality. Incidence rates and depth ratios do diverge for different areas, regions and age groups in Vietnam. A considerably smaller proportion of children living in urban areas are poor in comparison to rural areas in terms of both monetary and multidimensional poverty. However, the multidimensional method disproportionately captures the urban population compared to the monetary method; the discrepancy between poverty estimates for the urban and rural areas is smaller in case of multidimensional poverty than monetary poverty. Regional poverty estimates indicate that the monetary and multidimensional approaches rank regions differently. Both methods identify the North West region as the region with the highest incidence and depth of child poverty. However, regional rankings differ greatly when considering the other regions. Most notable is the Mekong River Delta, which has the one but lowest poverty incidence in terms of monetary poverty but one but highest poverty incidence and depth in terms of multidimensional poverty. Decomposition of poverty by ethnicity indicates that the ethnic minorities are greatly disadvantaged in terms of both monetary and multidimensional poverty, although the discrepancy is more outspoken with respect to monetary poverty. Poverty figures by age group indicate that children in the oldest age bracket experience least incidence and depth in terms of monetary poverty. The picture with respect to multidimensional poverty is almost reversed, indicating that children in the oldest age bracket are amongst the most deprived. Note that the monetary poverty is purely based on data at the household level while the multidimensional poverty method in part captures individual children's situation. The underlying indicators and the different age groups they capture, form an explanation for these different poverty rates by age groups.

The poverty estimates in Table 6.2 point towards differences in the demographic profiles of the poor children using a monetary and multidimensional poverty approach. Further comparative analysis of both child poverty approaches analyses the extent to which one approach is able to differentiate poverty in terms of the other approach. Clearly, if the theoretical and conceptual differences between both approaches would not translate in different outcomes, we could simply use one poverty approach (Laderchi 1997). However, previous research leads to the suspicion that this is not the case. Figure 6.1 displays the distribution of income for children being identified as multidimensionally poor as well as children who are not identified as such. 
Figure 6.1 Distribution of normalized income for multidimensionally poor and non-poor

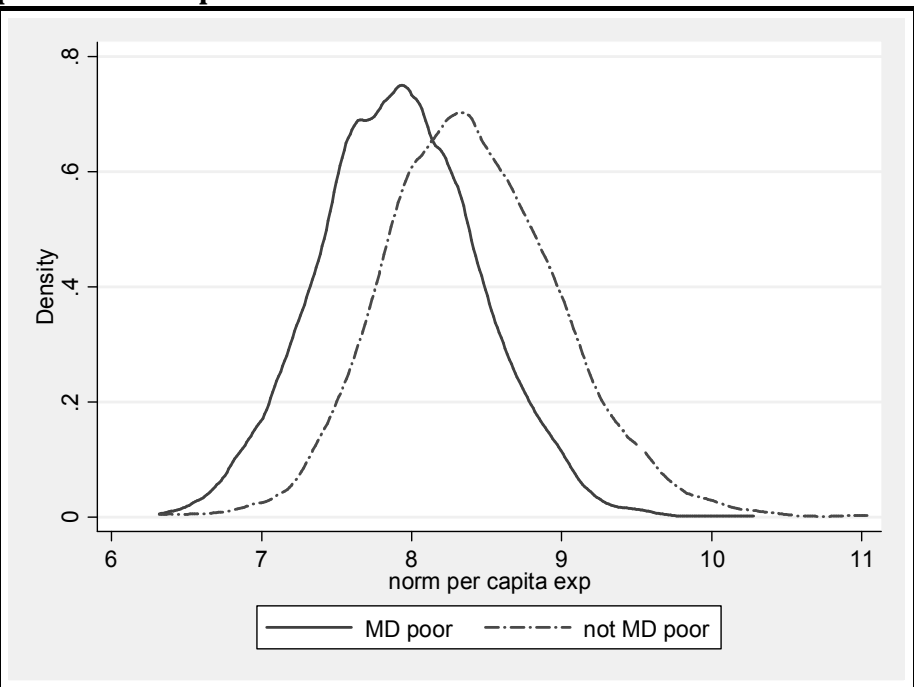

Source: Authors' calculations from VHLSS 2006

Both groups face a normal distribution with respect to their normalized income but at a lower level of income for children that are multidimensionally poor. On the basis of this figure, it is tempting to report that the difference between multidimensionally poor and non-poor can be captured by income and to assume that both measures are highly correlated. Further analysis, however, points towards a more diversified picture. The proportion of multidimensionally poor children by income quintile is presented in Figure 6.2.

Figure 6.2 Proportion of multidimensionally poor children by income quintile

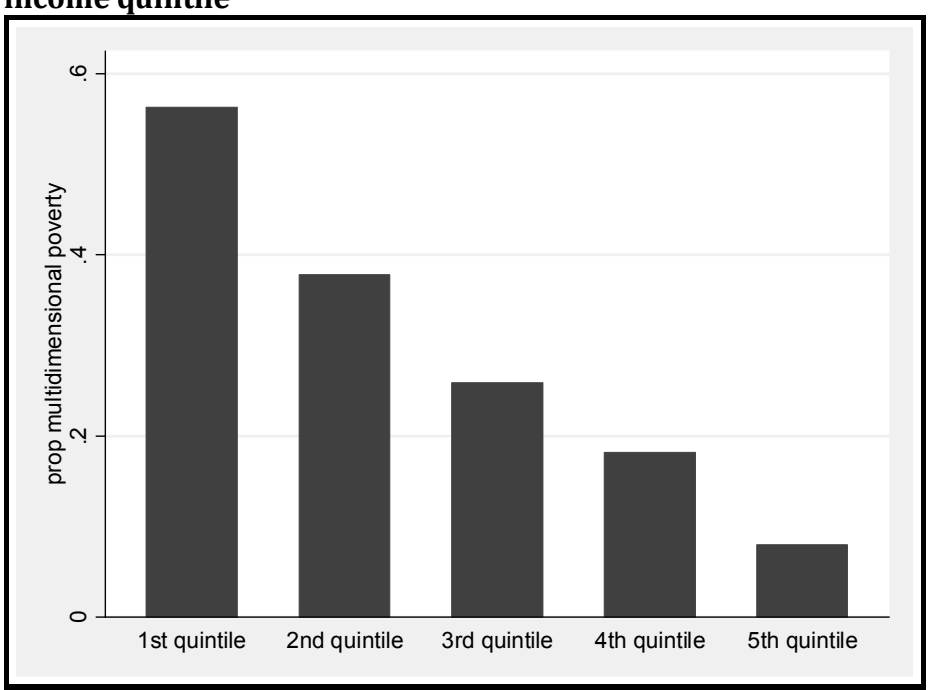

Source: Authors' calculations from VHLSS 2006 
Although the first quintile holds the largest proportion of children that are multidimensionally poor, we can also observe that 8 and 17 percent of all children in the top two income quintiles are multidimensionally poor. In other words, income is not able to fully differentiate between children being multidimensionally poor or not. Correlation coefficients in Table 6.3 underline these findings by displaying a limited degree of association between monetary and multidimensional poverty.

Table 6.3 Correlation monetary and multidimensional poverty

\begin{tabular}{l|c|c}
\hline & Monetary poverty & $\begin{array}{c}\text { Per capita } \\
\text { expenditures }\end{array}$ \\
\hline $\begin{array}{l}\text { Multidimensional poverty } \\
\text { Multidimensional normalized } \\
\text { poverty score }\end{array}$ & $0.316^{*}$ & $-0.362^{*}$ \\
\hline Education poverty & & \\
Health poverty & $0.169^{*}$ & \\
Shelter poverty & $0.134^{*}$ & \\
Water and Sanitation poverty & $0.269^{*}$ & \\
Labour poverty & $0.361^{*}$ & \\
Social Inclusion and Protection & $0.142^{*}$ & \\
poverty & $0.032^{*}$ & \\
\hline
\end{tabular}

Source: Authors' calculations from VHLSS 2006

Notes: The correlation between per capita expenditures and multidimensional poverty score is calculated by means of the Pearson correlation coefficient; the correlation between monetary poverty and multidimensional poverty as well as domain poverty is calculated using the Phi correlation coefficient. Correlation coefficients referring to domain poverty are calculated for the sample of children for which the specific domain poverty was also observable.

Correlation coefficients between various indicators of monetary and multidimensional poverty are all significant but at fairly low levels of correlation. The correlation between monetary and multidimensional poverty status and size of poverty measures display similar levels with coefficients between 0.316 and 0.362 (as the multidimensional normalized poverty score is an inverse poverty indicator compared to per capita expenditures, the correlation coefficients holds a negative sign). Considering the correlation between monetary poverty status and poverty in specific domains, the association is strongest between poverty in the water and sanitation and shelter domains. However, with coefficients between 0.269 and 0.361 , this is rather modest. The limited degree of correlation between monetary and multidimensional poverty indicators has also become evident from previous studies. Klasen (2000) finds limited correlation between income and deprivation measures in South Africa. Furthermore, in a review of different poverty studies in OECD countries, Perry (2002) as well as Layte et al. (2001) also conclude that the association between poverty and another measure of deprivation is much looser than is often assumed.

In addition to these non-parametric tools, we explore the explanatory power of the monetary poverty method to assess multidimensional poverty through ROC curves. ROC curves graphically depict the performance of a test to discriminate between two populations (Minot and Baulch 2004). The X-axis of an ROC graph depicts the "false positives" (1-specificity) or the inclusion error (Wodon 1997). In this specific case, this refers to the identification of children that are not multidimensionally poor as 
monetary poor. The Y-axis depicts the "true positives" (sensitivity) or correct identification (Wodon 1997), this referring to multidimensionally poor children also being identified as monetary poor. The false positives and true positives are depicted along a continuum of probability cut-offs, which refers to poverty risks or the probability to be poor in this case. An ROC curve that is depicted by a 45 degree line indicates a model with no explanatory power, i.e. the chances of being identified or not as monetary poor are equal regardless of the actual probability to be multidimensionally poor. An ROC curve bowed towards the upper left corner of the graph indicates a model with larger predictive power as the rate of true positives increases at a relatively higher rate than the rate of false positives. The area under the ROC curve indicates the efficiency of the diagnostic test An area with value 1 indicates a perfect test, while an area of 0.5 points to a model without any predictive value (the 45 degree line). Figure 6.3 presents an ROC curve for the use of the monetary poverty measure to explain multidimensional child poverty.

\section{Figure 6.3 ROC curve for monetary poverty as a test for multidimensional poverty}

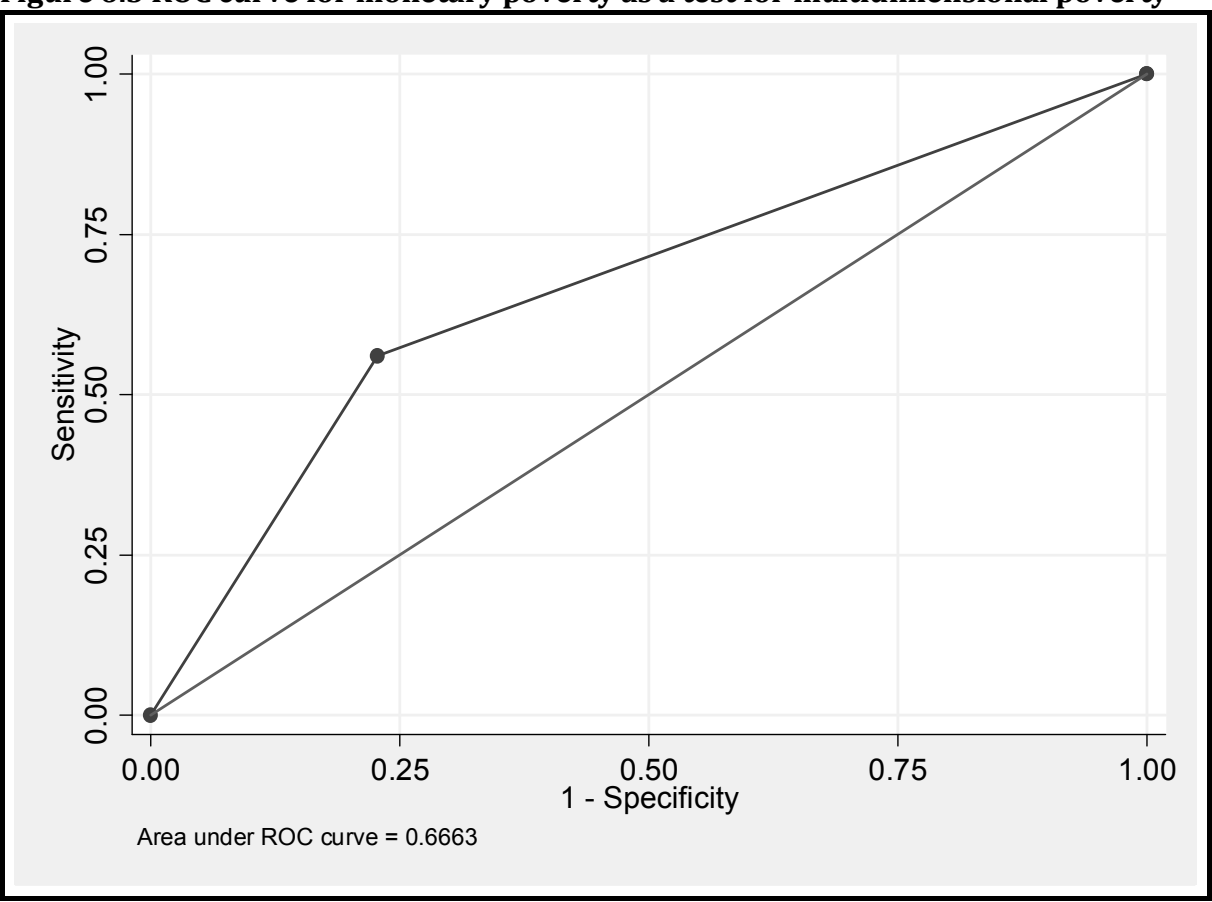

Source: Authors' calculations from VHLSS 2006

The ROC curve in Figure 6.3 points towards limited power of the monetary poverty measure to predict or proxy multidimensional poverty. The area under the ROC curve is 0.67 , suggesting little explanatory power. The bowed ROC curve is split up into two segments, the lower part capturing the children that are identified by monetary poverty and the upper segment representing all others. Considering the values of the X- and Y-axes at the point where the curvature changes, it can be observed that monetary poverty captures approximately 20 percent false positives and 55 percent true positives. In other words, if the monetary poverty measure was 
used to predict multidimensional child poverty, the probability to be rightly identified as such by the monetary approach would be around 55 percent. By the same token, there is a chance of approximately 20 percent to be identified as poor by the monetary poverty approach when not multidimensionally poor. Results are similar when testing the use of the multidimensional poverty measure as a proxy for monetary poverty. The area under the ROC curve is also 0.67, indicating that the multidimensional poverty measure is not well able to differentiate between children that are monetary poor or not. Less than half of all children that are monetary poor are identified as poor using the multidimensional poverty measure while a considerable proportion of children that are not monetary poor would be identified as poor. Based on the results from the ROC analysis as well as the findings above, it is evident that monetary and multidimensional child poverty is not closely related and one poverty measure is not adequately able to differentiate child poverty in terms of the other measure.

\subsection{Groups of Poverty}

An analysis of the groups of children identified to be poor by the monetary and multidimensional poverty approach provides insight into the extent to which the poverty measures capture the same or different groups of children. Table 6.4 presents the percentages of children identified by the monetary and/or multidimensional poverty approach for different levels of the monetary poverty line. Figure 6.4 presents a Venn diagram that displays the figures from Table 6.4 in a graphical manner. Such an analysis of the overlap of monetary and multidimensional child poverty identifies four so-called "poverty groups". Group A consists of those children only identified as poor by multidimensional poverty, group B contains those children that are only monetary poor, group $\mathrm{AB}$ are those children that are identified as being poor by both approaches and group $\mathrm{C}$ are the non-poor children.

Table 6.4 Cross tabulations of multidimensional and monetary poverty

\begin{tabular}{l|c|c|c}
\hline & & \multicolumn{2}{|c}{ Monetary poor } \\
\hline & & $Y e s$ & No \\
\hline $\begin{array}{l}\text { Multi- } \\
\text { dimensional } \\
\text { poor }\end{array}$ & $Y e s$ & $16(A B)$ & $15(A)$ \\
\cline { 2 - 4 } & No & $15(B)$ & $55(\mathrm{C})$ \\
\hline
\end{tabular}

Source: Authors' calculations from VHLSS 2006 


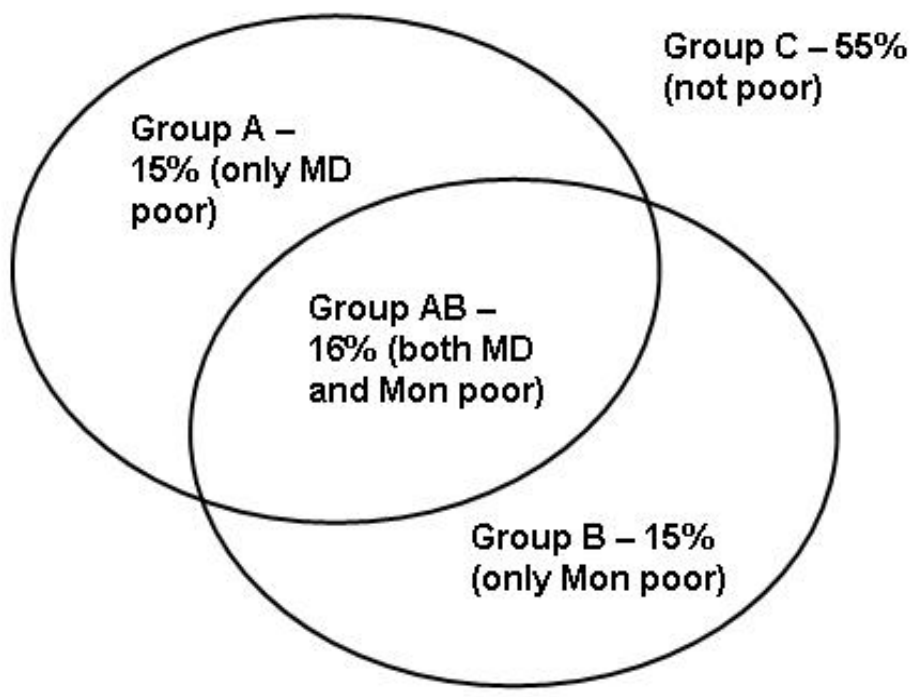

Source: Authors' calculations from VHLSS 2006

Results in Table 6.4 and Figure 6.4 indicate that the degree of overlap between children identified as poor in monetary and multidimensional terms is limited. It can be observed that more than 40 percent of all children have been identified as poor by the multidimensional and/or the monetary poverty approach but only 13 percent of all children is captured by both approaches. Whilst 18 percent of all children are only identified as multidimensionally poor, 10 percent is considered only to be poor according to the monetary approach Similar analyses in previous studies have reached conclusions along the same lines. Bastos et al. (2004) find that there is limited overlap between quartiles of children identified as poor using a monetary child poverty index and multidimensional child deprivation index. Similarly, Klasen (2000) finds a large degree of misidentification of the poor, with considerable groups of people that are only identified by either the monetary or multidimensional poverty measures.

Table 6.5 provides information about the demographic composition of these poverty groups. The unconditional poverty profile in Table 6.2 indicated rankings of sub-groups of poor children on the basis of monetary and multidimensional poverty are similar (except for decomposition by region and age), suggesting that findings of both poverty measures are mutually supporting (Perry 2002). However, previous research has indicated that there is a considerable degree of mismatch at the level of the individual when both measures are used for the identification of poverty (see Klasen 2000, Perry 2002). Estimates in Table 6.5 examine which demographic subgroups are particularly affected by the misidentification of the monetary and multidimensional poverty. 


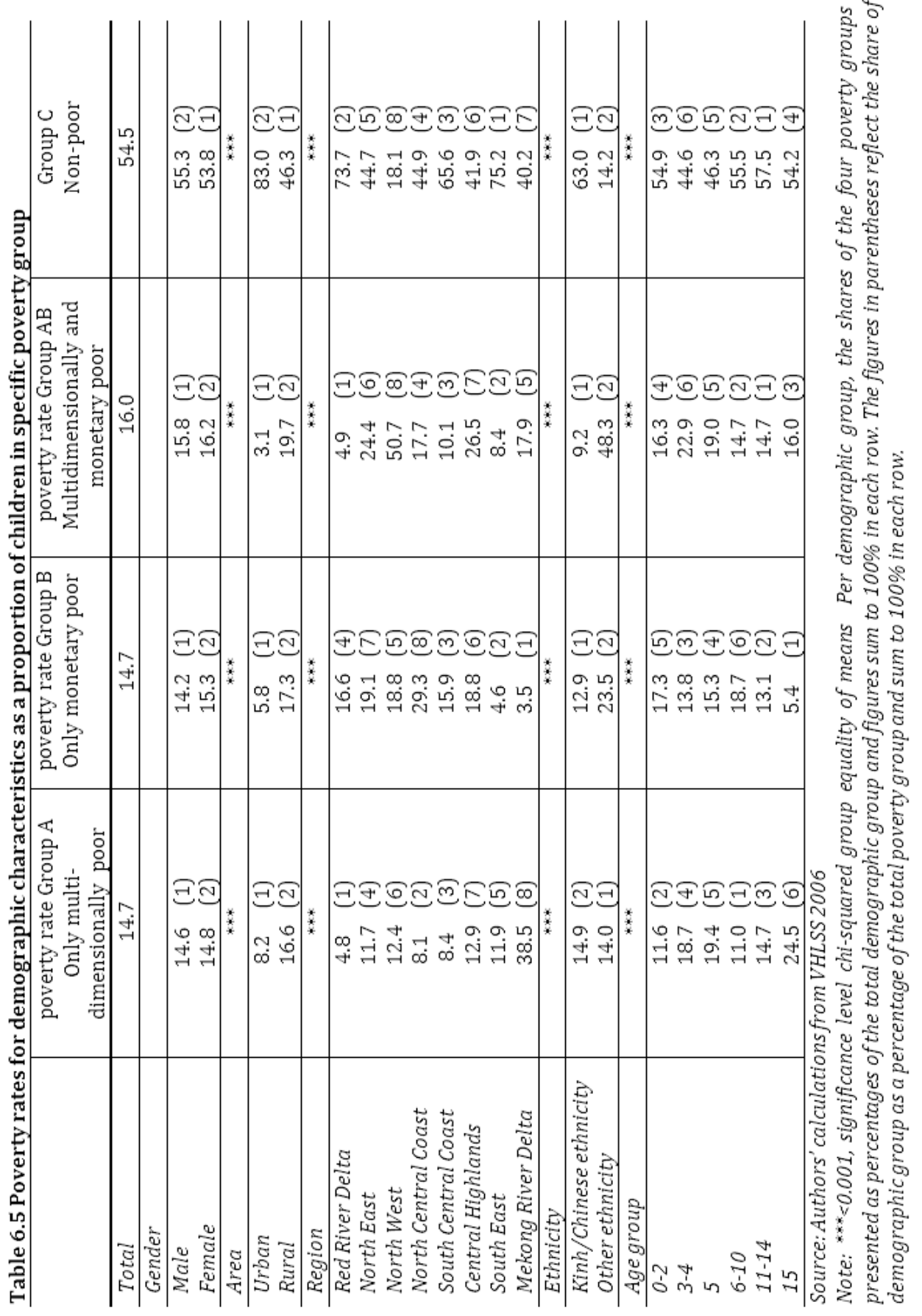


The demographic figures show that the participation in the poverty groups is not biased towards either boys or girls. The proportions of boys and girls over the various poverty groups do not display significant differences, regardless of the poverty method used. However, the decomposition by area shows that children living in rural areas are disproportionately poorer than children living in urban areas in all poverty groups. Whilst 83 percent of all children in urban areas are not poor (group C), more than half of those in rural areas belong to one of the poverty groups. The overlap of poverty in rural areas in limited; one out of five children in rural areas are both multidimensionally and monetary poor (group $\mathrm{AB}$ ) but 17 percent of all rural children are only multidimensionally poor (group A) and another 17 percent is only monetary poor (group B). The equal shares of rural children in groups A and B does not suggest that either the monetary or multidimensional approach is more prone to capture children in rural areas. The regional decomposition of the shares of children in the various poverty groups does, however, point towards a certain bias of the poverty approaches. The Mekong River Delta and North Central Coast regions are appropriate examples to illustrate that the monetary and multidimensional approaches capture different groups of children. Only 8 percent of all children in the North Central Coast are exclusively multidimensionally poor (group A) , ranking second best of all regions, but 29 percent of all children in this region are exclusively monetary poor (group B), ranking lowest of all regions. At the other end of the scale, children in the Mekong River Delta are faring well with respect to monetary poverty; only 4 percent of all children are exclusively monetary poor (group B). However, they seem extremely prone to multidimensional poverty as 39 percent of all children are exclusively multidimensionally poor (group A). A large degree of misidentification can also be observed with respect to ethnicity. The large majority of children of ethnic minority belong to one of the poverty groups A, B or AB. However, the shares of children exclusively multidimensionally poor (group A) are similar for both ethnic groups, whilst there are great discrepancies with respect to the other poverty groups. At 48 percent, the share of children of ethnic minority that are poor with respect to both poverty approaches (group $\mathrm{AB}$ ) is 5 times higher than the share of children of Kinh/Chinese majority, suggesting that almost half of all children of ethnic minority are highly impoverished. Decomposition of poverty groups by age brackets indicates that the children in the oldest age bracket are prone to be captured by the multidimensional approach but not so by the monetary approach

The notion that monetary and multidimensional poverty measurement capture different groups of the population in a disproportionate manner is important in both academic as well as policy terms. In terms of the academic debate, it becomes evident that the different theoretical underpinnings of poverty approaches also result in different outcomes of poverty. The way in which poverty is understood and conceptualized also translates in the identification of different groups of people in society as being poor (Laderchi 1997), also in terms of child poverty. In other words, the conceptual debate about poverty is not only a theoretical exercise but one with far-reaching empirical implications. With respect to policy, the misidentification of the poor is especially relevant in terms of targeting (e.g. Klasen 2000, Sahn and Stifel 2003) as well as design (Laderchi 1997). If either a monetary or multidimensional poverty measure is used for the targeting of policies, a considerable group in society would be excluded despite its poverty status in terms of the other poverty measure. Furthermore, specific demographic groups in society would be more prone to be 
identified as poor and be targeted while others run a greater risk of not being identified as such and to be excluded from the policy under consideration. The design of policy measures to respond to the issue of poverty will also differ when using different poverty approaches. Whilst the creation of employment opportunities for adults to increase income might appear most relevant in case of a lack of monetary means, the improvement of access and/or quality of basic services might be more appropriate in case of deprivation in alternative dimensions of poverty (Laderchi 1997).

\subsection{Drivers of Poverty Mismatch}

Although these notions on the basis of the findings and analysis above provide a valuable contribution to the ongoing debate on poverty measurement, especially in terms of child poverty, the findings also give rise to another question. Namely, what are the drivers for these differences? Can we consider those groups of children that are captured by only one of the poverty measures to be "false positives"? Or do they have specific characteristics and represent a vulnerable group in society that requires careful attention? Furthermore, can the children identified to be poor by both measure considered to be the "ultra-poor" or are their characteristics too divergent to make any such inferences about this group? In this section, we attempt to gain a more detailed insight of the specific situation of the poverty groups and the underlying dynamics that drive them.

In order to gain further insight into the characteristics of the specific poverty groups, we consider the differences in underlying poverty indicators. Table 6.6 presents the proportion of children in each poverty group that suffer poverty in each domain ${ }^{54}$.

54 Note that the percentages in the column for Group B add up to $100 \%$ as children in this group can theoretically only suffer deprivation in one domain or no domain; if they suffered deprivation in more domains, they would have been identified as multidimensionally poor. The percentages in the columns for group $A$ and $A B$ do not add up to $100 \%$ as children in these groups can suffer deprivation in multiple domains. 
Table 6.6 Domain poverty rates by poverty group

\begin{tabular}{l|c|c|c|c}
\hline & $\begin{array}{c}\text { Group A - } \\
\text { Only multi- } \\
\text { dimensionally poor }\end{array}$ & $\begin{array}{c}\text { Group B - } \\
\text { Only monetary } \\
\text { poor }\end{array}$ & $\begin{array}{c}\text { Group AB - } \\
\text { Multidimensionally } \\
\text { and monetary poor }\end{array}$ & $\begin{array}{c}\text { Group C - } \\
\text { Non-poor }\end{array}$ \\
\hline Domain Poverty rate & $\begin{array}{c}\text { Domain Poverty } \\
\text { rate }\end{array}$ & Domain Poverty rate & non-poor \\
\hline Total & 14.7 & 14.7 & 16.0 & 54.5 \\
\hline Domains & & & & na \\
\hline Education & 35.9 & 4.1 & 36.7 & na \\
$\begin{array}{l}\text { Health } \\
\text { Shelter }\end{array}$ & 12.1 & 3.6 & 13.6 & na \\
$\begin{array}{l}\text { Water and } \\
\text { sanitation } \\
\text { Child labour } \\
\text { Social Inclusion } \\
\text { and Protection }\end{array}$ & 58.5 & 3.1 & 67.2 & na \\
\hline $\begin{array}{l}\text { No domain } \\
\text { (only monetary }\end{array}$ & 18.1 & 55.9 & 18.7 & na \\
poor) & 16.9 & 0.9 & 10.6 & na \\
\hline
\end{tabular}

Source: Authors' calculations from VHLSS 2006

Estimates for group B reveals that more than 70 percent of all children in this group suffer poverty in one domain in addition to being monetary poor. Poverty in the water and sanitation domain is most prevalent for all poverty groups. The large majority of group A and group $A B$ children suffer poverty in this domain while this amounts to 56 percent for children in group $B$. The domain with the second largest incidence rates in groups $A$ and $A B$ is shelter with incidence rates between 59 and 67 percent. Remarkably, estimates indicate that only a small proportion of group B children, 3 percent, suffer from poverty with respect to shelter. Poverty incidence rates for other domains hover around the same percentage with the exception of child labour, which amounts to only 1 percent. This relatively low percentage of children suffering child labour in group B is intuitively appealing as child labour might be a source of income and inversely related to monetary poverty. The proportions of domain poverty incidence for groups $\mathrm{A}$ and $\mathrm{AB}$ do not display diverging trends that can be thought to specifically "drive" the group's poverty status, although incidence rates are generally at a higher level for group $\mathrm{AB}$.

In addition to considering the degree of domain poverty by poverty group, we also assess their distributions of income. Figure 6.5 presents the distribution of normalized income for poverty group A. Children in group A are identified as poor by the multidimensional approach but have a level of income that is above the monetary poverty line. 
Figure 6.5 Income distribution poverty groups $A$ and $C$

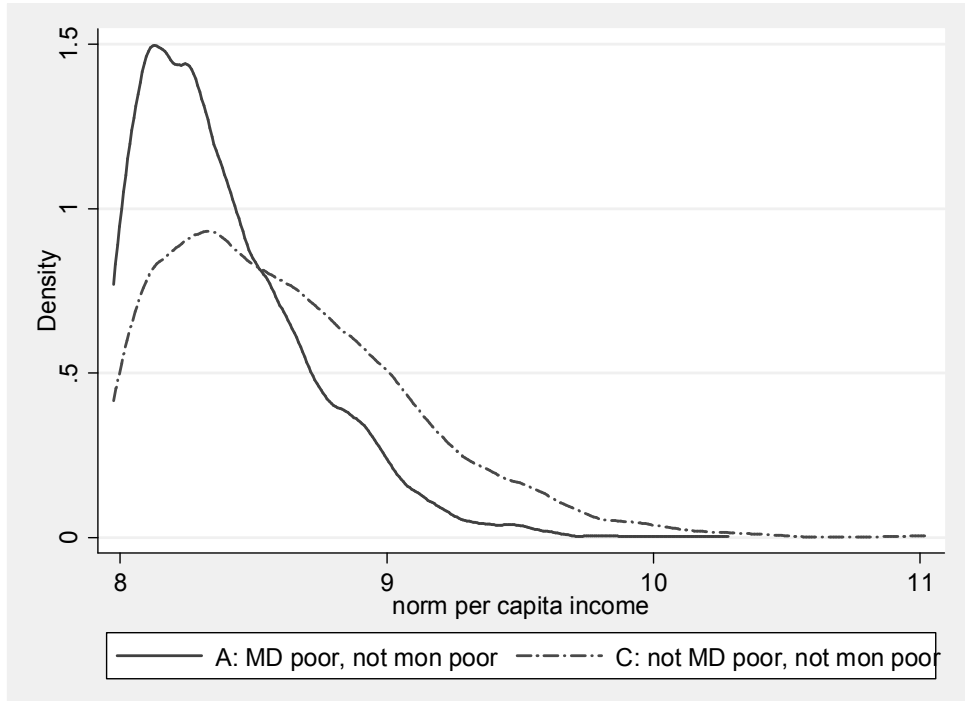

Source: Authors' calculations from VHLSS 2006

Figure 6.5 indicates that normalized per capita income is skewed towards the poverty line for group A children, especially in comparison to the non-poor C. This finding is also in line with the bar graph in Figure 6.2, which indicated that the majority of the children in the lowest poverty quintiles are multidimensionally poor. This result bears the question of the specific factors at play that weaken the "power" or ability to provide for multidimensional issues, despite a level of income above the poverty line. Such factors could include low educated or low-skilled parents.

Similarly, the income distributions of normalized per capita income for groups B and $\mathrm{AB}$ are presented in Figure 6.6. This allows for the comparison between income distributions between those children that are only identified to be monetary poor but not multidimensionally poor and those children that have been identified as poor by both approaches. 


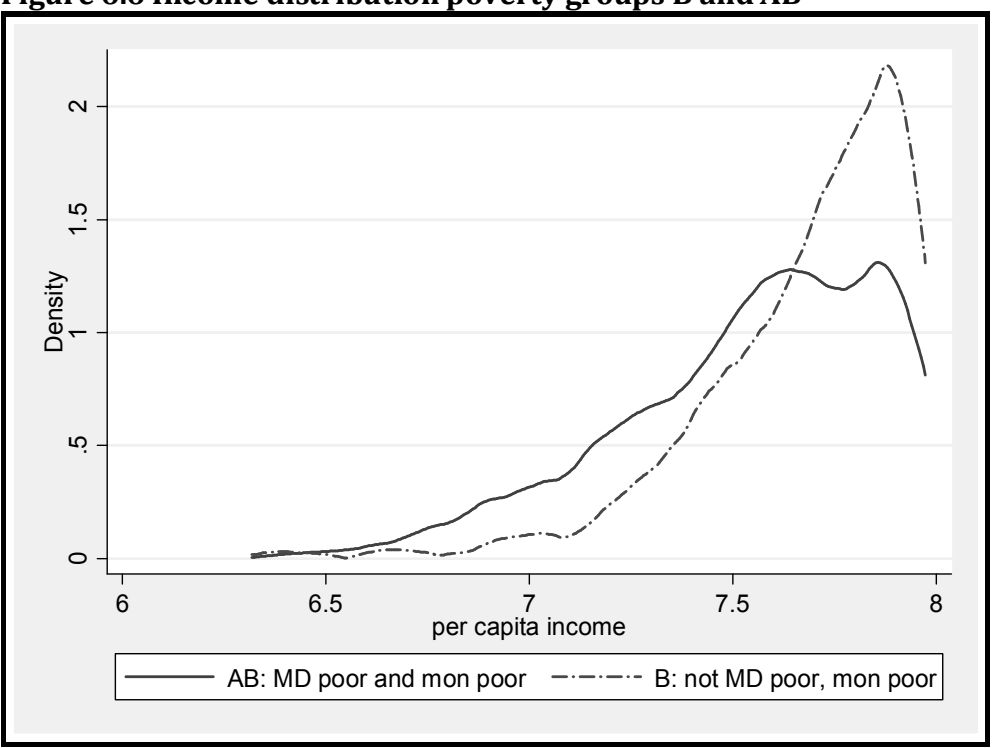

Source: Authors' calculations from VHLSS 2006

The distribution plots in Figure 6.6 display that the income of group B children is skewed towards the poverty line in comparison to those children that are in group AB. Hence, the level of income of children identified as poor by both approaches is generally lower than that of children in group B, who are captured by the monetary poverty but not multidimensional poverty. This finding suggests that children in group B have some sort of mechanism to cushion the effects of low income to be able to prevent themselves from falling into multidimensional terms. Factors contributing to such mechanisms might include the head of household to be female or welleducated.

After having established that children in groups A and B have incomes skewed towards the monetary poverty line, suggesting that there might be specific factors in place that prevent or cause children to be multidimensionally poor despite or in spite their level of income, we also consider the poverty situation of group AB. Children in this group are captured by both poverty measures and estimates in Table 6.5 and Figure 6.6 also indicated that domain poverty incidence is higher while income is generally lower than in respectively poverty groups A and B. For a more detailed insight into the degree of poverty of group $A B$, we consider the depth of poverty. Figure 6.7 compares the depth of multidimensional poverty for groups $A$ and $A B$ as well as monetary poverty for groups $\mathrm{B}$ and $\mathrm{AB}$. 
Figure 6.7 Monetary and multidimensional poverty depth by poverty group

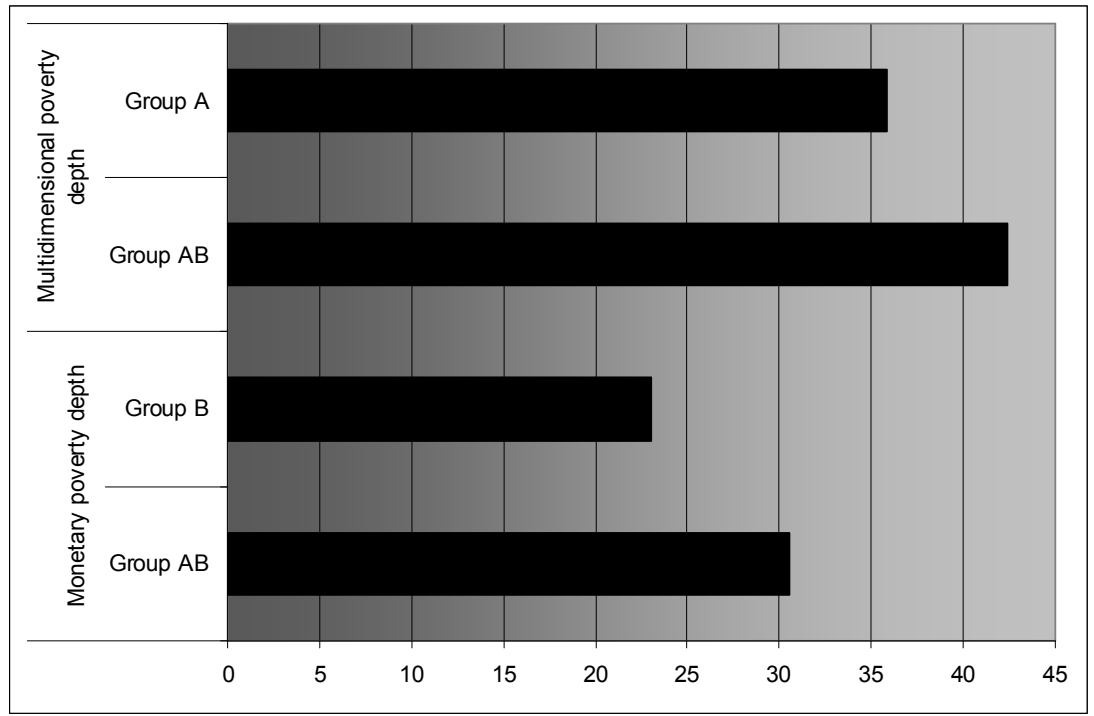

Source: Authors' calculations from VHLSS 2006

The bar graph clearly indicates that children in group $\mathrm{AB}$ are poorer in monetary as well multidimensional terms than children that are identified as poor by only one poverty measure. As such, these children can be considered as "ultra-poor". They have little means to cope and experience more as well as deeper poverty in terms of both income and domain poverty.

The question of specific factors in- or decreasing children's chances to be identified as poor by none, one or both poverty measures remains. What are the underlying drivers that cause children with levels of income just above the poverty line to fall into multidimensional poverty and, by the same token, children with an income just below the monetary poverty line to prevent themselves from falling into multidimensional poverty? Furthermore, what are determinants causing children to be ultra-poor? Characteristics of the household head or household that the child lives in may result in a specific family life strategy that is able to either mitigate the effects of low income on children and prevent a child from being multidimensionally poor despite being monetary poor (Bastos et al. 2004). By the same token, specific living conditions of the child might increase his or her risk to be poor in multidimensional terms despite not being identified as monetary poor or cause him or her to be ultrapoor. Multinomial regression is used to further analyze the impact of characteristics of the individual child, household head, household and locations on the probability for a child to belong to either one of these poverty groups, controlling for the other characteristics. Table 6.7 reports the relative risks of belonging the either poverty groups $\mathrm{AB}$, $\mathrm{A}$ or $\mathrm{B}$ in reference to group $\mathrm{C}$ (non-poor). If the reported relative risk for a certain poverty group is larger than one, the specific characteristic increases the probability for a child to belong to that poverty group rather than to be non-poor and belong to reference group $\mathrm{C}$. 


\begin{tabular}{|c|c|c|c|}
\hline & \multicolumn{3}{|c|}{ Multinomial Model } \\
\hline & $\begin{array}{c}\mathrm{AB} \\
\mathrm{b} / \mathrm{se}\end{array}$ & $\begin{array}{c}\mathrm{A} \\
\mathrm{b} / \mathrm{se}\end{array}$ & $\begin{array}{c}\mathrm{B} \\
\mathrm{b} / \mathrm{se} \\
\end{array}$ \\
\hline \multicolumn{4}{|c|}{ Child Characteristics } \\
\hline $\begin{array}{l}\text { Child is female } \\
\text { Age of child }\end{array}$ & $\begin{array}{c}1.1045 \\
(0.0730) \\
0.9867 \\
(0.0095)\end{array}$ & $\begin{array}{c}1.0156 \\
(0.0640) \\
1.0476^{* * *} \\
(0.0105)\end{array}$ & $\begin{array}{c}1.0636 \\
(0.0677) \\
0.9424^{* * *} \\
(0.0086)\end{array}$ \\
\hline \multicolumn{4}{|c|}{ Household Head Characteristics } \\
\hline Hh head is female & $\begin{array}{c}0.4800^{* * *} \\
(0.0637)\end{array}$ & $\begin{array}{c}0.5803^{* * *} \\
(0.0667)\end{array}$ & $\begin{array}{c}0.5845^{* * *} \\
(0.0738)\end{array}$ \\
\hline Age of hh head & $\begin{array}{c}0.9961 \\
(0.0037)\end{array}$ & $\begin{array}{c}0.9930 \\
(0.0036)\end{array}$ & $\begin{array}{c}10.071 \\
(0.0038)\end{array}$ \\
\hline Hh head is single & $\begin{array}{c}6.8513^{* * *} \\
-23.625\end{array}$ & $\begin{array}{l}2.6343^{* *} \\
(0.9754)\end{array}$ & $\begin{array}{c}3.5046^{* * *} \\
-11.904\end{array}$ \\
\hline Hh head is widowed & $\begin{array}{c}13.233 \\
(0.2203)\end{array}$ & $\begin{array}{l}1.4449^{*} \\
(0.2145)\end{array}$ & $\begin{array}{c}0.9978 \\
(0.1684)\end{array}$ \\
\hline Hh head is divorced & $\begin{array}{c}2.1841^{*} \\
(0.7613)\end{array}$ & $\begin{array}{c}0.6391 \\
(0.2813)\end{array}$ & $\begin{array}{c}0.7080 \\
(0.3117)\end{array}$ \\
\hline Hh head is separated & $\begin{array}{c}12.818 \\
(0.7473)\end{array}$ & $\begin{array}{c}3.2453^{* *} \\
-12.680\end{array}$ & $\begin{array}{c}4.2990^{* * *} \\
-16.828\end{array}$ \\
\hline Hh head has no educ & $\begin{array}{c}2.4341^{* * *} \\
(0.2100)\end{array}$ & $\begin{array}{c}1.2053^{*} \\
(0.1041)\end{array}$ & $\begin{array}{c}1.6026^{* * *} \\
(0.1453)\end{array}$ \\
\hline $\begin{array}{l}\text { Hh head has secondary } \\
\text { educ }\end{array}$ & $\begin{array}{c}0.4256^{* * *} \\
(0.0403)\end{array}$ & $\begin{array}{c}0.6931^{* * *} \\
(0.0581)\end{array}$ & $\begin{array}{c}0.4812^{* * *} \\
(0.0387)\end{array}$ \\
\hline $\begin{array}{l}\text { Hh head has post sec } \\
\text { educ }\end{array}$ & $\begin{array}{c}0.1229^{* * *} \\
(0.0273)\end{array}$ & $\begin{array}{c}0.4873^{* * *} \\
(0.0629)\end{array}$ & $\begin{array}{c}0.1154^{* * *} \\
(0.0224)\end{array}$ \\
\hline $\begin{array}{l}\text { Hh head is unemployed } \\
\text { or retired }\end{array}$ & $\begin{array}{c}2.8740^{* * *} \\
(0.4170)\end{array}$ & $\begin{array}{c}4.0829^{* * *} \\
(0.5301)\end{array}$ & $\begin{array}{l}0.6134^{* *} \\
(0.1061)\end{array}$ \\
\hline $\begin{array}{l}\text { Hh head is gov/defence } \\
\text { staff }\end{array}$ & $\begin{array}{l}0.3505^{* *} \\
(0.1135)\end{array}$ & $\begin{array}{c}0.6977 \\
(0.1674)\end{array}$ & $\begin{array}{c}0.2409^{* * *} \\
(0.0869)\end{array}$ \\
\hline $\begin{array}{l}\text { Hh head is skilled } \\
\text { professional }\end{array}$ & $\begin{array}{c}0.3912^{* * *} \\
(0.0453)\end{array}$ & $\begin{array}{c}0.8406^{*} \\
(0.0708)\end{array}$ & $\begin{array}{c}0.6434^{* * *} \\
(0.0561)\end{array}$ \\
\hline \multicolumn{4}{|c|}{ Household Characteristics } \\
\hline $\begin{array}{l}\text { Hh belongs to ethnic } \\
\text { minority } \\
\text { Presence of hh members } \\
\text { in ill-health in working } \\
\text { age (16-59) }\end{array}$ & $\begin{array}{c}0.0784^{* * *} \\
(0.0082)\end{array}$ & $\begin{array}{c}0.2721^{* * *} \\
(0.0299)\end{array}$ & $\begin{array}{c}0.1700^{* * *} \\
(0.0184)\end{array}$ \\
\hline
\end{tabular}




\begin{tabular}{|c|c|c|c|}
\hline & & & \\
\hline & $(0.0508)$ & $(0.0547)$ & $(0.0477)$ \\
\hline $\begin{array}{l}11 \text { years } \\
1 \text { resence of chilaren } 5-\end{array}$ & & $0.7322^{*}$ & 11.788 \\
\hline & $(0.1051)$ & $(0.0998)$ & $(0.1705)$ \\
\hline $\begin{array}{l}\text { Presence of children }>11 \\
\text { years }\end{array}$ & 0.7947 & $0.6627^{* *}$ & 13.077 \\
\hline & $(0.1267)$ & $(0.1027)$ & $(0.2050)$ \\
\hline$<25 \%$ & $0.6261^{* *}$ & $0.6906^{* *}$ & $0.6953^{*}$ \\
\hline & $(0.0897)$ & $(0.0799)$ & $(0.0987)$ \\
\hline $40-50 \%$ & $1.5260^{* * *}$ & 10.188 & $1.4788^{* * *}$ \\
\hline & $(0.1743)$ & $(0.1080)$ & $(0.1642)$ \\
\hline$>50 \%$ & $2.4724^{* * *}$ & $1.2840^{* *}$ & $1.8754^{* * *}$ \\
\hline & $(0.2303)$ & $(0.1075)$ & $(0.1711)$ \\
\hline & Locationa & istics & \\
\hline $\begin{array}{l}\text { Household is located in } \\
\text { rural area }\end{array}$ & $\begin{array}{l}5.5023^{* * *} \\
(0.7301)\end{array}$ & $\begin{array}{c}3.0361^{* * *} \\
(0.2816)\end{array}$ & $\begin{array}{c}2.3204^{* * *} \\
(0.2465)\end{array}$ \\
\hline Red River Delta & $\begin{array}{c}0.7408 \\
(0.1279)\end{array}$ & $\begin{array}{c}0.5401^{* * *} \\
(0.0891)\end{array}$ & $\begin{array}{l}1.4598^{* *} \\
(0.1761)\end{array}$ \\
\hline North East & $\begin{array}{c}1.4187^{*} \\
(0.2243)\end{array}$ & $\begin{array}{l}1.5871^{* *} \\
(0.2488)\end{array}$ & $\begin{array}{c}10.958 \\
(0.1506)\end{array}$ \\
\hline North West & $\begin{array}{c}3.5652^{* * *} \\
(0.7379)\end{array}$ & $\begin{array}{c}2.8400^{* * *} \\
(0.6247)\end{array}$ & $\begin{array}{c}14.012 \\
(0.2872)\end{array}$ \\
\hline North Central Coast & $\begin{array}{c}2.4682^{* * *} \\
(0.3804)\end{array}$ & $\begin{array}{c}12.128 \\
(0.1965)\end{array}$ & $\begin{array}{c}2.6514^{* * *} \\
(0.3260)\end{array}$ \\
\hline Central Highlands & $\begin{array}{c}1.8978^{* * *} \\
(0.3091)\end{array}$ & $\begin{array}{c}1.9933^{* * *} \\
(0.3212)\end{array}$ & $\begin{array}{c}12.180 \\
(0.1736)\end{array}$ \\
\hline South East & $\begin{array}{c}0.7919 \\
(0.1292)\end{array}$ & $\begin{array}{c}1.4535^{*} \\
(0.2143)\end{array}$ & $\begin{array}{c}0.2881^{* * *} \\
(0.0464)\end{array}$ \\
\hline Mekong River Delta & $\begin{array}{c}2.5359^{* * *} \\
(0.3660)\end{array}$ & $\begin{array}{c}6.6252^{* * *} \\
(0.8730)\end{array}$ & $\begin{array}{c}0.3079 * * * \\
(0.0500)\end{array}$ \\
\hline $\begin{array}{l}\text { Pseudo R-Square } \\
\text { chi2 } \\
\text { p }\end{array}$ & $\begin{array}{c}0.2508 \\
6.6 \mathrm{e}+03 \\
0.0000\end{array}$ & & \\
\hline
\end{tabular}

Source: Authors' calculations from VHLSS 2006

Note: reference categories are: Hh head is married, Hh head has primary education, Hh head is unskilled worker, 25-39\% proportion of children in household, region is South Central Coast

Regression results point towards a few important factors that impact a child's probability to belong to a specific poverty group. Firstly, the age of the child increases the relative risk to be exclusively multidimensionally poor (and belong to group A) rather than non-poor (group C) but decreases the chance to be exclusively monetary poor (belong to group B) rather than group C, all else equal. The age of the child appears to have a positive effect on children's well-being in monetary terms but negatively impacts multidimensional aspects of well-being. Children living in femaleheaded households are less likely to be poor, regardless of the poverty measure used. 
If the household head is female, children in that household have a smaller risk to belong to belong to groups $\mathrm{A}, \mathrm{AB}$ or $\mathrm{B}$ than to group C. Marital status of the household head has a more specific impact on a child's probability to belong to one of the specific poverty groups. Children living in households with single heads have a higher poverty risk than those living with married heads of household. Furthermore, they have a relatively higher chance to belong to group $\mathrm{AB}$ and be identified as "ultra-poor". By the same token, children living with a widowed head of household are more likely to be identified as only multidimensionally poor and to be part of group A. Children in households with separated heads face a disproportionately higher risk to be exclusively monetary poor and be part of group B. Educational attainment of the household head also plays an important role in the determination of poverty risks and poverty group participation. In comparison to children living in households with heads having attained primary education, those living with uneducated household heads have a higher chance to be poor and face a disproportionate risk to be ultrapoor. Higher levels of educational attainment of the household head monotonically decrease the poverty risk for children, in specific the risk to face combined poverty or monetary poverty. Higher levels of employment of the household head, in comparison to having unskilled work, also decrease a child's poverty risk. Living in a household headed by an unemployed or retired worker interestingly increases a child's risk to belong to the ultra-poor group $\mathrm{AB}$ or group $\mathrm{A}$ (multidimensionally poor) but decreases his or her risk to belong to group B (monetary poor). Ethnicity has a large impact on poverty risks for children. Children of ethnic majority have a decreased relative risk to belong to one of the poverty groups than to reference non-poor group C. Their poverty risk is smallest with respect to ultra-poverty and largest with respect to multidimensional poverty. Next, larger households imply greater poverty risks. In case more than half of all household members consist of children, the risk to belong to poverty groups $\mathrm{A}, \mathrm{AB}$ or $\mathrm{B}$ is approximately twice as large as the risk to belong to group C. Children in large households have the largest relative risk to face combined monetary and multidimensional poverty. Finally, locational characteristics indicate that children living in different areas and regions of Vietnam have a different probability to belong to either one of the poverty groups. The multinomial regression results confirm the findings of previous cross-tabulations. Children living in rural areas experience an increased risk to belong to any of the poverty groups in comparison to reference group C. However, they are especially vulnerable to facing combined monetary and multidimensional poverty. Their risk of being ultra-poor instead of not being poor at all is seven times higher than for children living in urban areas. Regional relative risks are along the findings of the descriptive statistics, indicating that children living in the Mekong River Delta experience an increased risk to belong to group $\mathrm{A}$ (multidimensionally poor) or $\mathrm{AB}$ (ultra-poor) but not to group $\mathrm{B}$ (monetary poor).

The association found between a number of micro-determinants and their impact on a child's risk to belong to a specific poverty group can provide an indication of the underlying drivers for participation in the specific poverty groups. Children that face the highest risk to be both monetary and multidimensionally poor are those living in households headed by single or uneducated individuals, living in households with a large proportion of children, rural areas and mountainous regions. As children characterized by these factors are identified as poor by both poverty measures, they could be considered to be the "ultra-poor" and the most vulnerable group of society. 
Their situation provides them with little options for mitigating the effects of poverty and could be considered a special focus group in terms of targeting of poverty reduction policies. Findings also point towards factors that increase a child's risk to be identified as multidimensionally poor but do not impact or even decrease the probability to be identified as monetary poor and vice versa. Whilst children in households with widowed heads are especially prone to experience only multidimensional poverty, children in households with separated heads have a relatively higher risk of being only monetary poor. Widowed heads of households seem thus to be better equipped to protect their child from monetary poverty rather than multidimensional poverty. An underlying explanation for this difference could be monetary social welfare schemes that provide benefits to widows that make children in households headed by widows less vulnerable to poverty in monetary terms but not with respect to other areas of well-being. But also cultural attitudes towards loneparent households resulting from widowhood or separation and the degree of social acceptance of these situations might play a role. Specific monetary welfare schemes might also explain the relatively higher multidimensional poverty risk for children living in households headed by unemployed or retired workers, whilst they experience a smaller chance to be monetary poor. Findings also have implications in terms of regional identification of poverty, especially with respect to the Mekong River Delta. Results clearly show that children living in this region have lower risk to be only monetary poor than not to be poor at all. However, the risk to being only multidimensionally poor is 6 times higher than not being poor. Clearly, geographical issues are an important factor causing children to be prone to experience multidimensional poverty despite income levels above the monetary poverty line.

\subsection{Conclusion}

This paper aimed to investigate whether the use of monetary and multidimensional poverty measures results in different outcomes with respect to child poverty in Vietnam. We compared the magnitude of poverty as well as groups of poverty when using two poverty measures that each has a distinct conceptual and theoretical foundation. Furthermore, we attempted to investigate the factors and underlying drivers that cause children to be captured by none, one or both of the poverty measures. The study's findings have implications for the academic field of poverty measurement as well as policy arena. Generally, findings suggest that monetary and multidimensional poverty methods geared towards the measurement of child poverty draw a different picture, leading to diverging conclusions about the situation of children in Vietnam and appropriate policies to respond. The notion that monetary and multidimensional poverty measures provide different outcomes in terms of the size as well as groups of poverty is not new and has been established in previous research. Nevertheless, such an analysis has not yet been conducted with a special reference to children and with the current set of methods used. Nor have previous studies attempted to move beyond the finding that there is a mismatch of poverty and to extend the analysis to gain an understanding of underlying factors that drive this mismatch.

The analysis in this paper clearly points towards differences in poverty outcomes when using a monetary versus multidimensional approach. The case study of Vietnam 
reveals that demographic profiles on the basis of either one of the poverty measures is different. Various tests of the capability of one poverty approach to differentiate poverty in terms of the other approach lead to the conclusion that the monetary poverty approach can not serve as a proxy for multidimensional poverty and vice versa. The degree of correlation between monetary and multidimensional poverty as well as monetary poverty and poverty in separate domains proves to be limited. An ROC analysis underlines these findings and indicates that the monetary child poverty measure is a poor predictor of multidimensional child poverty and conversely. Furthermore, we find that the mismatch in the identification of child poverty using both approaches is considerable with the existence of a large group of children exclusively identified as multidimensionally poor and a group of children that is only captured by the monetary measure.

The attempt to gain an understanding of the underlying drivers of the mismatch of poverty is what moves the current analysis beyond existing research. We find that, despite low levels of correlation, the income of children that are identified as poor by only one poverty measure is skewed towards the poverty line. The majority of children that are only monetary poor suffer poverty in one domain of the multidimensional poverty measure and have an income just below the monetary poverty line. By the same token, children that are only multidimensionally poor have the highest domain poverty incidence rates and have levels of income skewed towards the poverty line. Children that are identified as both monetary and multidimensionally poor can be considered to be the ultra-poor as their depth of monetary and multidimensional poverty is larger than the poverty depth of children identified by only one of the poverty measures. Specific factors that increase a child's risk to be identified as exclusively multidimensionally poor and unable to meet their basic multidimensional needs despite an income level above the monetary poverty line include the age of the child, the household being headed by a widow, the presence of a member of the household in working age being of ill-health and living in the Mekong River Delta. By the same token, factors were identified that increase the probability of a child to be only monetary poor and thus having a specific mechanism in place to be able to meet the basic needs despite levels of income below the poverty line. These factors include living in a household with a separated head or in households with large proportions of children. Children living in households with single, uneducated or unemployed or retired heads, in urban areas and mountainous regions appear to be most vulnerable groups in society and are most likely to be identified as poor by both approaches and thus as ultra-poor.

The general finding that there is a considerable mismatch of poverty and that different groups of society are affected differently by this mismatch has important implications for the academic and policy debate. With respect to academia, this paper illustrates that the underlying conceptual and theoretical differences between poverty approaches are matched by diverging empirical outcomes, also in the case of child poverty. The use of a specific poverty measure for any type of analysis referring to children requires careful consideration with awareness that outcomes are likely to diverge when a different measure is applied. The value of this paper with respect to the policy debate is two-fold. On the one hand, findings suggest that policy monitoring and evaluation efforts can provide different pictures when based on just one of the child poverty measures. The choice of a specific poverty measure could be used to the advantage of a specific policy and bias results in favor of the policy under 
consideration and vice versa. On the other hand, the analysis points out that targeting on the basis of one poverty measure has perverse effects for those identified as poor by the other poverty measure and vice versa. Targeting on the basis of a single poverty measure automatically implies that those individuals only identified as poor by another measure are excluded. Furthermore, findings suggest that specific demographic groups in society are more or less prone to be identified as poor by only one or both of the approaches, implying that policies targeted on a single measure of poverty are biased towards specific demographic groups of children. This paper's attempt to gain a deeper understanding of the factors underlying the risks to be more or less likely to belong to a specific poverty group indicated that there are indeed a number of underlying characteristics that influence poverty group participation. Knowledge and awareness of these underlying factors is another important issue in terms of policy design as it might prevent unintended consequences of targeting on the basis of a specific poverty measure. An in-depth analysis of the characteristics impacting the probability to be identified by either one or more poverty measures provides a more detailed understanding of the demographic groups at risk and underlying processes contributing to that risk. Further research is necessary to investigate these underlying processes and their effect on the most vulnerable groups in society. Moreover, further research efforts should be directed towards the consolidation of monetary and multidimensional approaches in such a way that they provide consistent and coherent outcomes. 
$\frac{6}{122}$ 


\section{Chapter 7}

\section{SOCIAL WELFARE IN VIETNAM - A CURSE OR BLESSING FOR POOR CHILDREN? ${ }_{55}$}

Despite a rapid increase in economic growth accompanied by the rise of living standards over the last two decades in Vietnam, there is still a considerable proportion of the population that lives in poor and vulnerable conditions. Especially children are disproportionately affected by poverty. The country employs a broad range of social protection programs that tend to be regressive in impact rather than supportive of the poor. The paper evaluates the social welfare scheme in Vietnam in terms of child poverty. We use the Vietnam Household Living Standards Survey (VHLSS) 2006 and identify and quantify child poverty in monetary as well as multidimensional terms. We consider the link between social welfare receipt and poverty and evaluate coverage, exclusion and inclusion errors. Furthermore, we use benefit incidence analysis to evaluate the impact of social welfare on monetary child poverty. Findings suggest that coverage of the social welfare scheme is limited and that the scheme suffers from considerable exclusion and inclusion errors. Furthermore, we find that social welfare only slightly reduces the incidence and depth of monetary poverty.

55 Published as:

Roelen, Keetie (2010) Social Welfare in Vietnam - a curse or blessing for poor children?, Asian Social Work and Policy Review, forthcoming 


\subsection{Introduction}

In the late 1980's, Vietnam experienced rapid economic growth as a result of far reaching economic reforms, the so-called Doi Moi policies, which were accompanied by a steep decrease in poverty rates (Balisacan et al. 2004). Average economic growth rates amounted to 6.9 percent from 1988 to 1994 and 7.4 percent from 1994 to 2000 (Glewwe 2004). Central planning was replaced by free-market oriented economic policies, bringing about great changes in the agricultural sector, private business and employment development, foreign trade and social sector policies and creating business and entrepreneurial opportunities for Vietnamese as well as foreigners (Glewwe 2004). Further, it resulted in a sharp decrease in poverty with monetary rates dropping from 29 percent in 2002 to 20 percent in 2004 (VASS 2006). However, there is ample research suggesting that the economic success and the drop in poverty was not shared by all groups in society (Taylor 2004) and that Vietnam struggles to ensure ongoing reduction in the levels of poverty and promote equality (Evans and Harkness 2008). Especially children in Vietnam are disproportionately affected by poverty.

Vietnam employs a wide range of social policy and protection programs, which are in part the result from the country's post-colonial war and post-war social government (Evans and Harkness 2008, Van de Walle 2004a). Vietnam's social protection scheme consists of social insurance and social welfare schemes, the latter including targeted benefit programs and special schemes for war veterans and invalids among others (Justino 2005). However, the system does not include a specific program that is targeted towards children. Several studies have investigated the impact of social protection on the poor or specific groups in society (e.g. Cuong and Van den Berg 2009) Evans et al. 2007a, 2007b, UNDP 2004, Van de Walle 2004a, $2004 \mathrm{~b}$ ) and evidence suggests that these are widely regressive in nature (Evans and Harkness 2008) and thus can not be considered to be pro-poor (Van de Walle 2004a, 2004b). The issue of child poverty remains a hidden element and under-prioritized. The need for a child focused perspective in the development and poverty reduction process has been widely recognized over the last decade (e.g. Gordon et al. 2003a, 2003b, Minujin et al. 2005, Roelen et al. 2009a) for a number of reasons. Children hold a special position within the household structure due to their high dependency on others for the distribution of basic needs (e.g. White, Leavy and Masters 2003), which are in turn different from the basic needs of adults (e.g. Waddington 2004). Moreover, poverty often manifests itself as a vicious circle, causing children to be trapped in poverty from birth onwards (e.g. Corak 2006). Child-focused policy analyses are crucial to account for these issues. To our knowledge, no evaluation has been undertaken to assess Vietnam's social protection system or specific programs with respect to children. This study examines the performance and impact of social welfare with respect to child poverty, using both a monetary and multidimensional poverty approach.

The remainder of the paper is structured as follows: first, we describe social transfers in Vietnam and social welfare in particular. Second, we briefly outline the data and methods of analysis employed for this study, including an overview of the poverty methods. This is followed by the empirical discussion, in which we analyze child poverty in Vietnam, the targeting performance of social welfare and the impact 
of social welfare on child poverty. The paper concludes with a discussion of the main findings.

\subsection{Social transfers in Vietnam}

Despite the increase in living standards in the last decade, the country still employs an extensive social protection and safety net system. This broad system is considered a heritage of the socialist period and strong commitment to the combat of poverty and inequality (Evans and Harkness 2008, Van de Walle 2004a). Formal social protection in Vietnam can be subdivided into two different pillars, namely social insurance and social welfare. Social insurance schemes in Vietnam primarily consist of social insurance pensions on a pay-as-you-go basis but also include short-term sickness benefits, unemployment allowances, maternity and disability benefits (Evans and Harkness 2008). The social insurance schemes primarily covered workers in the public sector but was expanded to the private sector in 1995 (Van de Walle 2004a). Participation in these schemes is biased towards those in formal employment and the public sector. As a result, Evans and Harkness (2008) show that three-quarters of the pensions are distributed to the two richest percentiles rather than to the poor. Social welfare includes schemes for veterans and war invalids and targeted benefit programs that have cash and in-kind components (Justino 2005). More detailed information about social welfare will be provided in the next section. Although the range of formal social protection measures in Vietnam is of considerable size, it represents a modest share in aggregate household income (Cox 2004). Evans and Harkness (2008) estimated that the share of formal social security income in overall household income is 4 percent. Notwithstanding the existing range of programs in Vietnam, there are no special provisions for children.

In addition to the formal schemes, many households are supported by informal transfers, including a steady flow of remittances as well as one-time cash or in-kind gifts, from those living outside of the household. This flow of remittances is caused by international and booming domestic migration after organized migration moved to more spontaneous migration in the mid 90's (Niimi, Pham and Reilly 2008)56. Informal transfers are considerably more substantial in size than the flow of formal transfers. Data from 2004 on internal remittances shows that more than half of the internal migrants sent a transfer home with an average amount that reflects 17 percent of the migrant's earnings (Niimi et al. 2008). Cox (2004) also finds that there is high prevalence of informal transfers with higher incidence and value than formal social security. Whilst public transfers are often considered to crowd out private transfers, previous research shows that in Vietnam shows that the receipts of public transfers is strongly associated with private transfers (Cuong and Van den Berg 2009, Evans and Harkness 2008).

Social welfare in Vietnam includes a variety of non-contributory cash and in-kind schemes such as targeted benefits, benefits for war veterans and invalids but also

$56 \mathrm{Niimi}$ et al. (2008) find that the three main ways in which the reforms affected internal migration in Vietnam are 1) decollectivization of land in the agricultural sector, 2) the marketization of the economy and 3) the inflow of Foreign Direct Investment (FDI) focused on specific industries and regions. 
relief for homeless elderly, orphans and disabled and disaster relief (Justino 2005). Benefits for Veterans and War Invalids are paid by the Social Guarantee Fund for Veterans and War Invalids, which distributes transfers to those who have contributed in the war or suffered consequences resulting from the war (including family members) (Van de Walle 2004a). As the program is politically motivated rather than poverty focused, it is less likely to function progressively (Evans and Harkness 2008). Homeless elderly, orphans and seriously disabled poor receive benefits from the Social Guarantee Fund for Regular Relief. Street children are also covered through this fund. Resulting from scarce local resources (Van de Walle 2004a, 2004b), coverage is generally low (Van de Walle 2004a, Justino 2005) and the amount of welfare is generally too low to have any substantial impact on poverty (Evans and Harkness 2008). Short-term welfare for disaster-struck areas is provided through the Contingency Fund for Pre-Harvest Starvation and Disaster Relief (Justino 2005). The program is considered to suffer serious shortcomings with a diversion of funds to those not suffering from disaster, leaving those in need when a disaster does occur (Justino 2005). The objectives of the various social welfare schemes are thus different and range from poverty reduction to support of those that have suffered during the war ${ }^{57}$. In this paper, we will analyze the impact of these different benefits on child poverty despite the fact that this might not be their primary purpose. However, the small size of the different individual schemes as well as the structure of the data does not allow for a detailed decomposition.

\subsection{Data and Methods of Analysis}

\subsubsection{VHLSS $2006^{58}$}

The data source used for this study is the Vietnam Households Living Standards Survey (VHLSS) from 2006. This household survey is based on the former Vietnam Living Standards Survey (VLSS) but employs a bigger sample size and is to be conducted every other year. The VLSS was conducted in 1993 and 1998 and the VHLSS from 2002 onwards bi-annually by the Government Statistical Office (GSO), following the World Bank's Living Standards Measurement Survey (LSMS) methodology. The VHLSS survey samples from 2002 to 2010 are drawn from a master sample, which is a random sample of the 1999 Population Census enumeration areas. The VHLSS 2006 contains 9.189 households with 39.071 individuals, including 10.696 children under the age of 16.

Household surveys like the VHLSS provide micro-data at the level of the household and their individual members on a range of issues related to children's well-being and poverty as well as social protection. They also suffer from a substantial limitation that one has to keep in mind. The sampling method causes a substantial group in the

57 The exact targeting methods for the various transfers and benefit schemes will not be discussed in this paper. Information on targeting is scarce and the data does not hold information on specific reasons for entitlement such as war injury, invalidity or the occurrence of a disaster (see also Evans and Harkness 2008).

58 This section shows overlap with section 4.4.1; readers having read that section are advised to continue with the next section. 
society to be omitted from the sample and subsequent data (Evans and Harkness 2008). The sample for the survey is constructed on the basis of the official lists of registered households in communes and urban wards in Vietnam that have lived in the enumeration area for at least six months (Pincus and Sender 2006, 2008). This implies that households or individuals that have recently migrated are not included in the sampling frame (Edmond and Turk 2004). Further, due to the strict the household registration system, or ho khau system, many households and individuals do not satisfy the necessary criteria to newly register and stay unregistered (Pincus and Sender 2006, 2008). But also migrants that have temporary forms of registration appear to be under represented in the sampling frame (VDR 2008). The omission of these groups in society is not only an important issue to point out because of its suspected significant size but even more so because of the denial of social and public services they experience due to their status. The structural exclusion of the unregistered migrant group from the data will most likely present us with underestimations for (child) poverty.

\subsubsection{Methods of Analysis}

As a clear understanding of the poverty approaches at hand is crucial for a sound and solid poverty analysis and interpretation of results (Ravallion, 2004; Roelen et al., 2009a), this section outlines the poverty methods used in this paper. We will use a monetary as well as multidimensional approach to the measurement of child poverty. Previous research has indicated that monetary and multidimensional poverty approaches do not capture the same groups of children in Vietnam, justifying the use of two parallel poverty measures (Roelen et al., 2009c). The importance using different approaches as complements to each other due to their degree of mismatch in terms of outcomes has been acknowledged and emphasized by many scholars (see e.g. Klasen 2000, Sahn and Stifel 2003, Laderchi 2007, Neubourg et al. 2009). Furthermore, the use of the different poverty approaches allows for a different perspective in the impact analysis of social welfare.

The monetary poverty method refers to poverty calculated on the basis of the poverty line as used by the General Statistical Office (GSO) and generally referred to as the official poverty line. The monetary poverty line captures the cost of a food and non-food consumption basket, while the food poverty line only captures the cost of the food basket. The cost component of the food basket is based on a daily intake of 2100 calories per person per day (VDR 2008). Both poverty measures are based on per capita consumption expenditures as welfare measure. The poverty headcount presents the share of the population living in households not meeting the poverty line while the poverty gap indicates the average distance from the poverty line as a percentage of that poverty line.

The multidimensional method can only be used for the identification of child poverty and not for the measurement of overall poverty. The approach is especially developed to be a child-specific and outcome-focused approach that considers nonmonetary aspects of deprivation that are especially relevant for children in Vietnam. Included items consist of education, health, child labour and water and sanitation, among others. A total of seven domains and twelve indicators within domains are chosen on the basis of stakeholder discussions, previous research and data availability 
and are considered to appropriately reflect the poverty status of children in Vietnam (Roelen et al. 2009a). The overall poverty headcount is determined by deprivation in at least two domains, also known as the dual cut-off identification strategy (Alkire and Foster 2008). Domain deprivation is constituted by not meeting the threshold of at least one of the indicators within the specific domain, also known as the union approach (Atkinson 2003). The use of both the monetary and multidimensional child poverty measure as complements to each other allows for a comprehensive analysis of social welfare.

A number of methods are used to analyze the performance and impact of social welfare on child poverty. We use cross-tabulations to assess and multinomial regression to understand inclusion of non-poor children in the social welfare program and exclusion of those children that are either monetary or multidimensionally poor. The impact of social welfare on monetary poverty is analyzed using a benefit incidence analysis. The scheme's impact on multidimensional poverty can not be assessed as it is not possible to establish a counterfactual on the basis of crosssectional data.

A limitation of the data and methods used in this study refer to the fact that we only incorporate micro-determinants into the analysis. In other words, we only consider characteristics of individuals within the household or the household itself and whether these have an impact on poverty or the probability to be in- or excluded from receiving targeted social welfare. Especially with respect to the latter issue, this limits the analysis. It is widely acknowledged in the literature that coverage, exclusion or inclusion is also influenced by macro-determinants related to the supply and availability of social welfare (see Van de Walle 2004a, VDR 2008), including public expenditures. However, little information and data is available to assess and incorporate this issue into more detail. Further research efforts are required to take these macro-aspects into consideration and provide a more holistic picture of poverty in association with social protection. Despite this limitation, the current study with its available data and methods at hand provides valuable insights into the relationship between and impact of social welfare benefits on child poverty.

\subsection{Child poverty in Vietnam}

In this section, we discuss the situation with respect to child poverty. Findings in Table 7.1 suggest that children are disproportionately affected by poverty.

Table 7.1 Poverty in Vietnam

\begin{tabular}{l|c|c|c|c|c|c}
\hline & \multicolumn{2}{|c|}{ Monetary poverty } & \multicolumn{2}{c|}{ Food poverty } & \multicolumn{2}{c}{ Multidimensional poverty } \\
\hline & headcount & gap & headcount & gap & headcount & gap \\
\hline total & 15.8 & 3.8 & 6.6 & 1.3 & na & na \\
\hline $\begin{array}{l}\text { children } \\
(0<16)\end{array}$ & 22.6 & 5.8 & 10.3 & 2.3 & 30.7 & 18.5 \\
\hline
\end{tabular}

Source: Authors' calculations from VHLSS 2006

Poverty estimates indicate that 16 percent of the population is identified to be monetary poor while 7 percent does not meet the food poverty threshold. The average poverty gap for all individuals is 6 percent of the poverty line. Children face the 
highest poverty risk and depth in terms of monetary and food poverty. The prevalence of poverty is higher compared to the total population with 23 percent of all children being monetary poor and 10 percent living in food poverty. The depth of monetary and food poverty is also more pronounced for children in comparison to the overall population. Multidimensional child poverty figures underline the disadvantaged position of children in Vietnam with almost one out of three children below 16 years of age suffering deprivation with respect to at least two non-monetary aspects. Multidimensional poverty incidence among children is 8 percentage points higher than monetary poverty incidence. An analysis of the overlap of poverty indicates that the two poverty measures do not only point to a different size of poverty but that they also capture different groups of children as being poor (see Roelen et al. 2009c).

Table 7.2 Child poverty in Vietnam

\begin{tabular}{|c|c|c|c|c|}
\hline & $\begin{array}{c}\text { Monetary } \\
\text { Child Poverty } \\
\text { Rate }\end{array}$ & $\begin{array}{c}\text { Monetary } \\
\text { Child Poverty } \\
\text { Gap }\end{array}$ & $\begin{array}{c}\text { Multi - } \\
\text { dimensional Child } \\
\text { Poverty Rate }\end{array}$ & $\begin{array}{c}\text { Multi- } \\
\text { dimensional } \\
\text { Child Poverty } \\
\text { Gap }\end{array}$ \\
\hline Total & 22.62 & 5.8 & 30.72 & 18.5 \\
\hline Male & 22.40 & 5.8 & 30.47 & 18.5 \\
\hline \multirow[t]{2}{*}{ Female } & 22.85 & 5.9 & 30.99 & 18.5 \\
\hline & $* * *$ & $* * *$ & $* * *$ & $* * *$ \\
\hline Urban & 5.42 & 1.2 & 11.25 & 8.8 \\
\hline \multirow[t]{2}{*}{ Rural } & 27.58 & 7.2 & 36.33 & 21.0 \\
\hline & $* * *$ & $* * *$ & $* * *$ & $* * *$ \\
\hline Red River Delta & 13.22 & 2.5 & 9.66 & 8.2 \\
\hline North East & 34.05 & 8.4 & 36.16 & 21.0 \\
\hline North West & 58.94 & 19.3 & 63.12 & 38.7 \\
\hline $\begin{array}{l}\text { North Central } \\
\text { Coast }\end{array}$ & 37.99 & 10.4 & 25.75 & 14.2 \\
\hline $\begin{array}{l}\text { South Central } \\
\text { Coast }\end{array}$ & 16.73 & 3.5 & 18.50 & 11.1 \\
\hline Central Highlands & 37.16 & 11.9 & 39.33 & 20.9 \\
\hline South East & 9.08 & 2.4 & 20.24 & 13.5 \\
\hline \multirow[t]{2}{*}{$\begin{array}{l}\text { Mekong River } \\
\text { Delta }\end{array}$} & 12.59 & 2.3 & 56.31 & 27.3 \\
\hline & $* * *$ & $* * *$ & $* * *$ & $* * *$ \\
\hline $\begin{array}{l}\text { Kinh/Chinese } \\
\text { ethnicity }\end{array}$ & 14.50 & 3.0 & 24.08 & 13.9 \\
\hline Other ethnicity & 61.25 & 19.2 & 62.34 & 34.1 \\
\hline
\end{tabular}

Source: Authors' calculations from VHLSS 2006

Note: ${ }^{* * *}<0.001$, significance level chi-squared group equality of means

Poverty incidence and depth estimates for children in Table 7.2 suggest that there are large discrepancies between demographic groups in Vietnam. There is no evidence for the existence of any gender inequality, regardless of the poverty method or measure used. However, we do observe a large urban-rural divide, large regional differences and a highly disadvantaged position of ethnic minorities. Monetary and 
multidimensional poverty incidence is more prevalent amongst children living in rural areas and they also experience deeper poverty. The ranking of regions on the basis of poverty incidence and depth differs depending on the poverty method under consideration. Whilst the Mekong River Delta is amongst the regions with lowest monetary poverty incidence and depth, it is one of the worst performers in terms of multidimensional poverty. Regardless of the poverty method chosen, the Red River Delta region has the lowest poverty incidence and depth and the North West region has the highest poverty incidence and depth. Children belonging to ethnic minorities are highly disadvantaged in terms of both monetary and multidimensional poverty.

\subsection{Coverage and inclusion errors of social welfare}

The first step in considering the performance of social welfare in Vietnam with respect to child poverty is to consider the degree of coverage, comparing social welfare to informal transfers and social insurance. The data does not allow for an exact breakdown of types of transfers as it conflates a number of benefits. Given these constraints, we include domestic and overseas remittances in informal transfers. Pensions, sickness allowances, job loss allowances and lump-sum retirement allowances are categorized under social insurance. Social welfare includes war invalid benefits, survivor benefits, disaster relief allowances and social welfare allowances. As pointed out previously, the scheme is assessed with respect to its performance on child poverty, despite that not being its prime purpose. Table 7.3 displays the coverage rates of the different types of transfers.

\section{Table 7.3 Coverage of informal transfers, social insurance and social welfare ${ }^{59}$}

\begin{tabular}{l|c|c|c|c|c}
\hline & $\begin{array}{c}\text { Proportion } \\
\text { of total } \\
\text { population }\end{array}$ & $\begin{array}{c}\text { Proportion of } \\
\text { monetary } \\
\text { poor } \\
\text { population }\end{array}$ & $\begin{array}{c}\text { Proportion } \\
\text { of children }\end{array}$ & $\begin{array}{c}\text { Proportion of } \\
\text { monetary } \\
\text { poor children }\end{array}$ & $\begin{array}{c}\text { Proportion of } \\
\text { multi- } \\
\text { dimensionally } \\
\text { poor children }\end{array}$ \\
\hline $\begin{array}{l}\text { Informal } \\
\text { transfers }\end{array}$ & 89.7 & 87.0 & 89.1 & 85.9 & 87.3 \\
\hline Social insurance & 9.1 & 2.3 & 4.8 & 1.8 & 2.6 \\
\hline Social welfare & 10.5 & 14.7 & 9.0 & 15.1 & 13.0 \\
\hline
\end{tabular}

Source: Authors' calculations from VHLSS 2006

Figures indicate that informal transfers are an important source of income for the whole population as well as the poor. The role of formal transfers is considerably smaller with a large degree of exclusion. Social insurance covers 9 percent of the total population but only 2 percent of the poor population. Furthermore, children benefit proportionately less from social insurance in comparison to the overall population. Social welfare disproportionately covers the poor population (the proportion of the poor population receiving social welfare is larger than the proportion of total population receiving social welfare) and especially poor children in comparison to the overall population, underlining the finding that social welfare is a more poverty targeted program.

${ }^{59}$ Coverage of total population and children respectively refers to those individuals living in a household where anyone has received a transfer in the last 12 months. 
Although social welfare can generally be considered biased towards the poor, it is also biased towards specific demographic groups. Ideally, demographic groups that hold a greater share in poverty also receive a greater share of social welfare. However, coverage rates for specific demographic groups might not reflect the share of these demographic groups in poverty, pointing towards under- or over-coverage in reference to poverty. Table 7.4 presents the distribution of social welfare beneficiaries over different demographic groups as a ratio to the share of these different groups in monetary and multidimensional child poverty. If the number of poor children is equal to the number of children receiving social welfare in a specific demographic group, the ratio is 1 . A ratio higher than 1 indicates that the specific demographic group holds more children that receive social welfare than that are poor, and are thus "overcovered" and vice versa.

Table 7.4 Distribution of social welfare and poverty over demographic groups of children

\begin{tabular}{l|c|c}
\hline & $\begin{array}{c}\text { Ratio - share in social } \\
\text { welfare/share in monetary } \\
\text { poverty }\end{array}$ & $\begin{array}{c}\text { Ratio-share in social } \\
\text { welfare/share in } \\
\text { multidimensional poverty }\end{array}$ \\
\hline Total & 0.39 & 0.29 \\
\hline Gender & 1.03 & 1.03 \\
\hline Male & 0.97 & 0.97 \\
\hline Aremale & & 1.76 \\
\hline Urban & 2.67 & 0.94 \\
Rural & 0.90 & \\
\hline Region & & 2.82 \\
\hline Red River Delta & 1.52 & 0.89 \\
North East & 0.69 & 0.26 \\
North West & 0.20 & 1.88 \\
North Central Coast & 0.94 & 1.96 \\
South Central Coast & 1.61 & 1.26 \\
Central Highlands & 0.98 & 0.94 \\
South East & 1.53 & 0.37 \\
Mekong River Delta & 1.22 & \\
\hline Ethnicity & & 1.04 \\
\hline Kinh/Chinese & 1.27 & 0.93 \\
Other & 0.69 & 1.31 \\
\hline Age groups & & 0.7 \\
\hline O-2 & 1.00 & 0.79 \\
3-4 & 0.78 & 1.17 \\
5 & 0.84 & 0.64 \\
6-10 & 0.88 & 0.83 \\
11-14 & 1.08 & \\
15 & 1.86 & \\
\hline Source:Authors'calcuting & \\
\hline
\end{tabular}

Source: Authors' calculations from VHLSS 2006

The ratios in Table 7.4 clearly indicate that the share of children receiving social welfare is not proportional to the share of poor children for specific demographic groups, especially with respect to area and region of residence. In case of monetary poverty, the share of children in urban areas receiving social welfare is 2.7 larger than their share in poverty. By the same token, the share of children in rural areas 
receiving social welfare is smaller than the share in poverty. Regional ratios also point towards large disparities. Whilst the Red River Delta, South Central Coast, South East and Mekong River Delta regions hold more children benefiting from social welfare than children in monetary poverty, the North West region only has one child receiving social welfare for five monetary poor children. Interestingly, this picture is not the same with respect to multidimensional poverty. In contrast to the case of monetary poverty, the share of children receiving social welfare is higher than their share in poverty in the North Central Coast and Central Highlands regions but lower in the South East and Mekong River Delta regions. Finally, the ratios in Table 7.4 clearly point out that despite the fact that coverage rates of the ethnic minority groups are considerably larger than for the Kinh/Chinese ethnicity, it is still not sufficient to reflect their share in poverty. In sum, social welfare benefits can not be considered to be supportive of the poorest groups in society to an extent that reflects these groups' share in poverty.

In addition to the coverage of all children and poor children by social welfare, we also consider its inclusion error. The inclusion error refers to the non-poor population and children that are covered by social welfare.

Table 7.5 Inclusion error of social welfare

\begin{tabular}{l|c|c|c}
\hline & $\begin{array}{c}\text { Proportion of non- } \\
\text { monetary poor } \\
\text { population }\end{array}$ & $\begin{array}{c}\text { Proportion of non- } \\
\text { monetary poor } \\
\text { children }\end{array}$ & $\begin{array}{c}\text { Proportion of non multi- } \\
\text { dimensionally poor } \\
\text { children }\end{array}$ \\
\hline Social welfare & 9.7 & 7.2 & 7.2 \\
\hline
\end{tabular}

Source: Authors' calculations from VHLSS 2006

The estimates in Table 7.5 show that 1 out of 10 non-poor individuals receive social welfare and that this inclusion error is smaller for children, amounting to 7 percent in case of both monetary and multidimensional poverty. Social benefit schemes with such a modest inclusion error are generally perceived to perform fairly well with respect to targeting. However, we have to keep in mind that social welfare is only a small scheme with limited outreach. Considering the distribution of social welfare over the poor and non-poor population in Table 7.6 shows that the targeting performance of social welfare can not be considered to be good.

Table 7.6 Distribution of social welfare

\begin{tabular}{l|c|c|c}
\hline & $\begin{array}{c}\text { Share of poor in social } \\
\text { welfare beneficiaries }\end{array}$ & $\begin{array}{c}\text { Share of non-poor in } \\
\text { social welfare } \\
\text { beneficiaries }\end{array}$ & Total \\
\hline Monetary poverty & 22.1 & 77.9 & 100 \\
\hline Total population & 38.0 & 62.0 & 100 \\
\hline Children & \multicolumn{3}{|c}{} \\
\hline Multidimensional poverty & 55.6 & 100 \\
\hline Children & 44.4 &
\end{tabular}

Source: Authors' calculations from VHLSS 2006

The distribution of social welfare beneficiaries indicates that the poor represent a smaller share of the social welfare recipients than the non-poor. This difference is most outspoken in case of monetary poverty. However, even with respect to multidimensional poverty we find that less than half of all children that receive social 
welfare are poor. These estimates underline the finding in previous research (see Evans and Harkness 2008, Van de Walle 2004a, 2004b) that social protection in Vietnam, and social welfare in specific, can not be considered to be pro-poor.

To gain a more in-depth understanding of those groups of children that are covered by social welfare in relation to their poverty status, we use Venn diagrams. Four different mutually exclusive groups can be identified in the overall child population, based on their poverty status and whether or not they receive social welfare benefits. Group AB represents the group of children that are poor ánd covered by the program and the share of this group in the overall population. The share of children in group A captures the share of children that are poor but not covered by the program. Group B represents those children that are covered by the program but not poor. Group $\mathrm{C}$ are those not poor and not in the program and will not be further considered in this analysis The combined shares of groups $A B$ and $B$ represent the coverage rate of the total population as they capture all children receiving social welfare. The exclusion and inclusion errors, however, can not directly be deduced from the Venn diagrams as we consider the share of total child population rather than the poor or non-poor population ${ }^{60}$. Nevertheless, we can interpret children in group $\mathrm{A}$ as children wrongfully omitted from the social welfare scheme as they are poor. Children in group $\mathrm{B}$ can be considered to wrongfully receive social welfare as they are not poor. Children in group $\mathrm{AB}$ are then the rightful recipients as they are poor. Figure 7.1 illustrates the situation with respect to monetary poverty whilst Figure 7.2 depicts the case of multidimensional poverty.

${ }^{60}$ Note that the percentages in the Venn diagrams are different from the coverage rates and inclusion errors provided above. The percentages in the Venn diagrams refer to coverage and wrongfully included as a share of the whole population rather than the poor or non-poor population. 
Figure 7.1 Coverage, exclusion and inclusion of social welfare in terms of monetary poverty

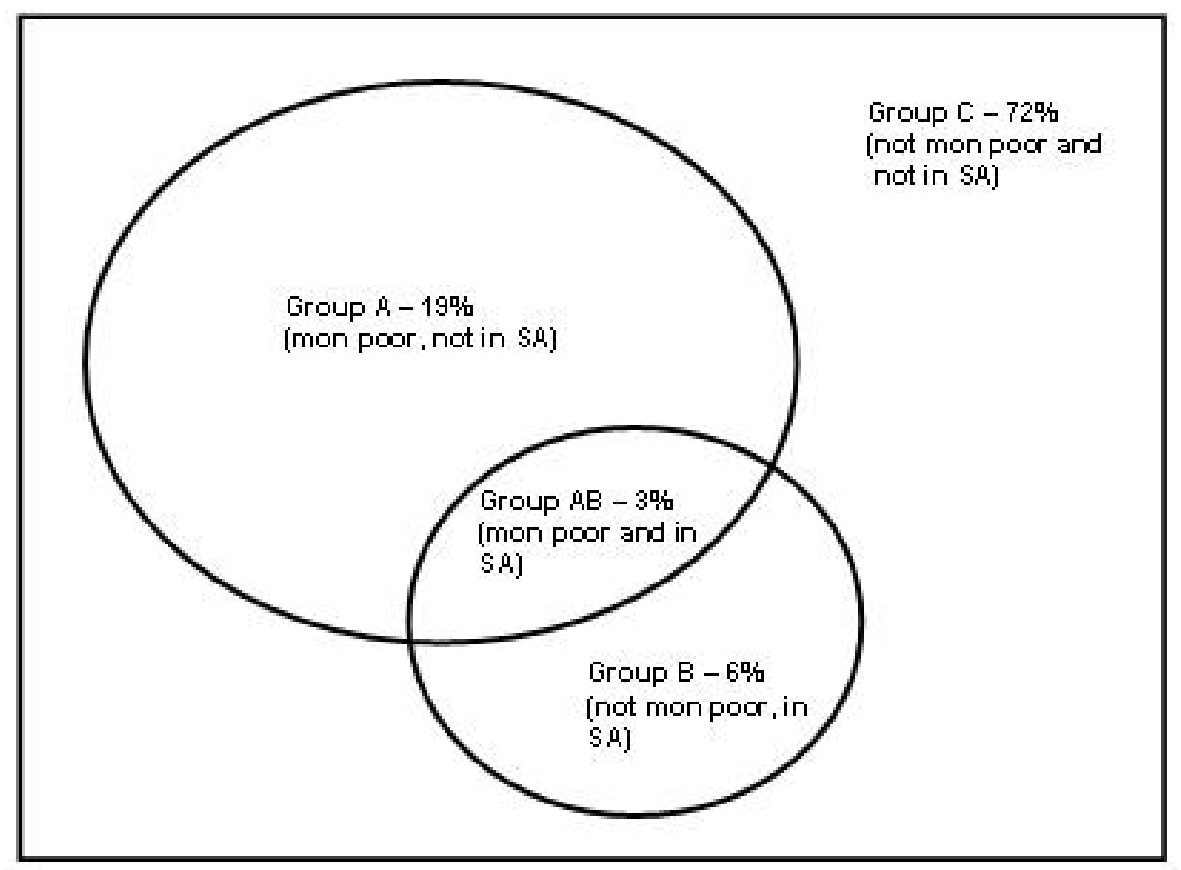

Source: Authors' calculations from VHLSS 2006

The Venn diagram in Figure 7.1.indicates that merely 3 percent of all children in 134 Vietnam belongs to group $\mathrm{AB}$ and thus are both monetary poor and covered by social welfare. The group of monetary poor children but excluded from social welfare, group A, is considerably larger at 19 percent. The diagram also illustrates that the share of children wrongfully receiving social welfare (group B) is twice as high as the share of children that are rightful recipients of social welfare (group $\mathrm{AB}$ ). 
Figure 7.2 Coverage, exclusion and inclusion of social welfare in terms of multidimensional poverty

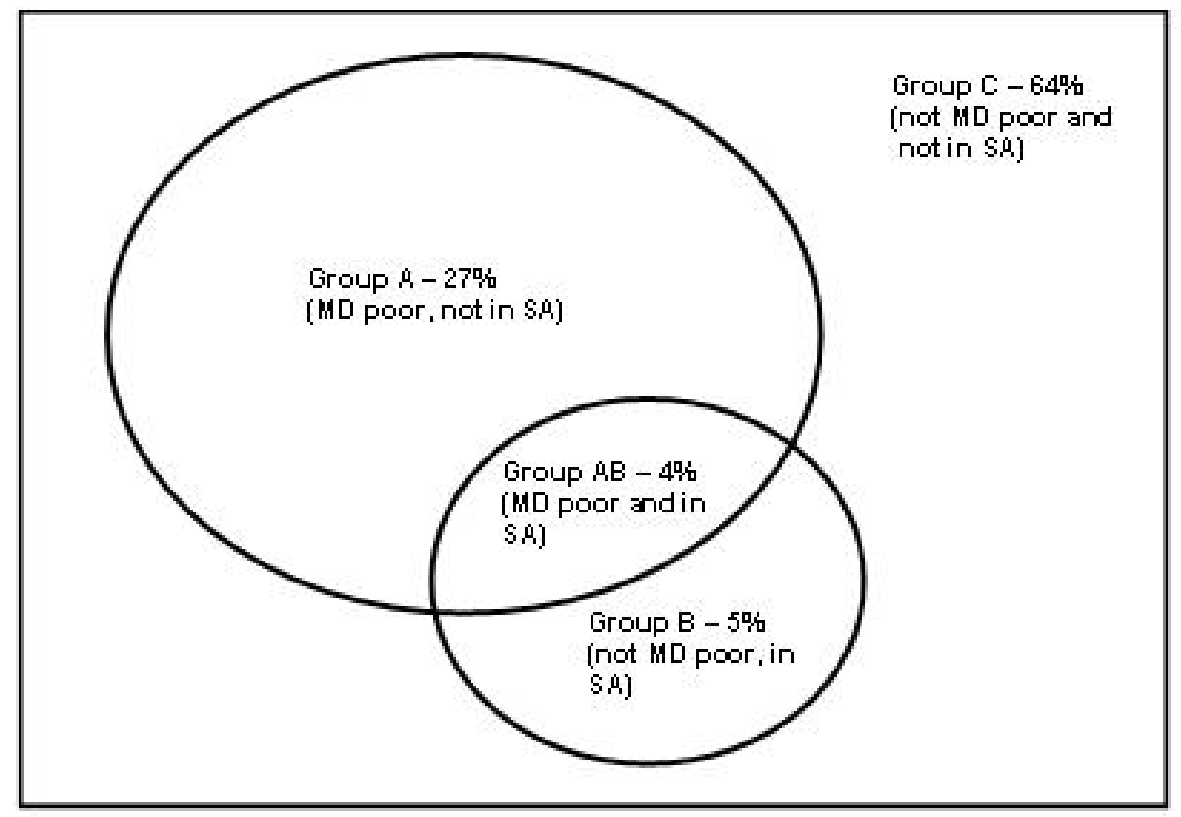

Source: Authors' calculations from VHLSS 2006

Results with respect to multidimensional poverty in Figure 7.2 suggest that the share of wrongful recipients of social welfare (group B) is less pronounced in the case of multidimensional poverty. Nevertheless, one out of four children in Vietnam does not receive social welfare despite being multidimensionally poor.

The groups identified on the basis of social welfare receipt and poverty status are mutually exclusive (each child can only belong to one group), which allows us to use multinomial logistic regression to investigate whether there are factors that in- or decrease the probabilities of belonging to a specific poverty group. As these different poverty groups can be interpreted to be the wrongfully excluded group (A) and wrongful recipient group (B), it enables the identification of factors contributing to a child's probability to receive social welfare although he or she is not poor or to be omitted from the social welfare scheme despite being poor. The multinomial regression results in Table 7.7 present the relative risks and standard errors. If the relative risk is greater than 1 , the probability for a child to belong to the specific group is higher than to belong to the reference group. The assessment of relative risks of belonging to group B rather than reference group C provides us with factors for receiving social welfare but not being poor. The assessment of relative risks of belonging to group $\mathrm{A}$ rather than reference group $\mathrm{AB}$ refers to factors leading to omission from the scheme despite being poor ${ }^{61}$.

61 The reason for reporting results with a different reference group is to facilitate the interpretation of findings. Assessing the probability of belonging to group B (receiving social welfare but not poor) with reference to group C (not receiving social welfare and not poor) 
Table 7.7 Multinomial regression results child poverty and social welfare

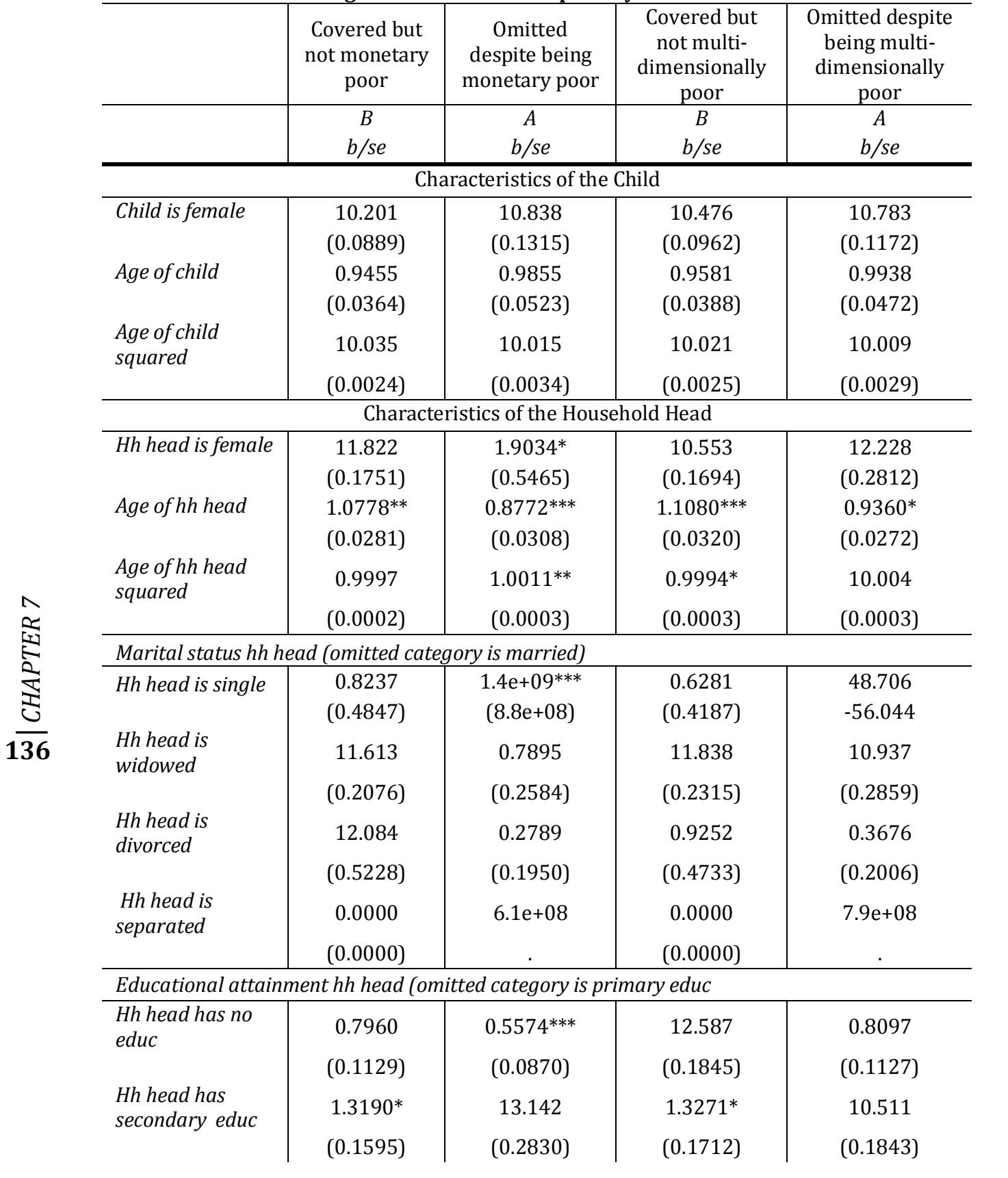

can help to explain inclusion errors. The assessment of the risk of belonging to group A (poor but not receiving social welfare) in reference to group $A B$ (poor and receiving social welfare) is useful to consider the exclusion error. Assessing the probability to belong to group $A B$ in reference to group $\mathrm{C}$, for example, would not allow for such intuitive interpretation of results. 
False Positives or Hidden Dimensions | 137

\begin{tabular}{|c|c|c|c|c|}
\hline $\begin{array}{l}\text { Hh head has post } \\
\text { sec educ }\end{array}$ & $\begin{array}{l}1.4846^{*} \\
(0.2335) \\
\end{array}$ & $\begin{array}{r}54.929 \\
-60.736 \\
\end{array}$ & $\begin{array}{l}1.4729^{*} \\
(0.2490) \\
\end{array}$ & $\begin{array}{r}0.7359 \\
(0.2338) \\
\end{array}$ \\
\hline \multicolumn{5}{|c|}{ Occupational status hh head (omitted category is unskilled labour) } \\
\hline $\begin{array}{l}\text { Hh head is } \\
\text { unemployed or } \\
\text { retired }\end{array}$ & $\begin{array}{c}0.8375 \\
(0.1339)\end{array}$ & $\begin{array}{c}0.4218^{* * *} \\
(0.1072)\end{array}$ & $\begin{array}{l}0.6770^{*} \\
(0.1303)\end{array}$ & $\begin{array}{l}0.6591 * \\
(0.1337)\end{array}$ \\
\hline \multirow[t]{2}{*}{$\begin{array}{l}\text { Hh head is } \\
\text { gov/defence staff }\end{array}$} & 13.338 & $0.2490^{*}$ & 13.377 & 0.5487 \\
\hline & $(0.3242)$ & $(0.1352)$ & $(0.3444)$ & $(0.2243)$ \\
\hline \multirow{2}{*}{$\begin{array}{l}\text { Hh head is skilled } \\
\text { professional }\end{array}$} & 0.9640 & $2.8590^{* *}$ & 0.9184 & 15.803 \\
\hline & $(0.1115)$ & -10.300 & $(0.1118)$ & $(0.3724)$ \\
\hline \multicolumn{5}{|c|}{ Characteristics of Household } \\
\hline \multirow{2}{*}{$\begin{array}{l}\text { Hh belongs to } \\
\text { ethnic minority } \\
\\
\text { Presence of hh } \\
\text { members in ill- } \\
\text { health in working } \\
\text { age (16-59) }\end{array}$} & $\begin{array}{l}0.6090^{* *} \\
(0.0988)\end{array}$ & $\begin{array}{l}3.2161^{* * *} \\
(0.5101)\end{array}$ & $\begin{array}{l}0.4416^{* * *} \\
(0.0677)\end{array}$ & $\begin{array}{l}2.9164^{* * *} \\
(0.4118)\end{array}$ \\
\hline & $\begin{array}{l}1.1915^{* *} \\
(0.0719)\end{array}$ & $\begin{array}{l}0.7211^{* * *} \\
(0.0562)\end{array}$ & $\begin{array}{l}1.2074 * * \\
(0.0797)\end{array}$ & $(0.0525)$ \\
\hline
\end{tabular}

\begin{tabular}{|c|c|c|c|c|}
\hline \multicolumn{5}{|c|}{ Prop of children as share of total number of hh members (omitted category is 25-39\%) } \\
\hline$<25 \%$ & 0.9188 & 0.7498 & 10.700 & 13.558 \\
\hline & $(0.1239)$ & $(0.2377)$ & $(0.1537)$ & $(0.3386)$ \\
\hline \multirow[t]{2}{*}{$40-50 \%$} & $1.3334^{*}$ & $0.5631^{* *}$ & 10.895 & $0.4709 * * *$ \\
\hline & $(0.1637)$ & $(0.1156)$ & $(0.1501)$ & $(0.0770)$ \\
\hline \multirow[t]{2}{*}{$>50 \%$} & $0.6947^{* *}$ & $0.6465^{*}$ & 0.8152 & 0.8752 \\
\hline & $(0.0843)$ & $(0.1208)$ & $(0.1028)$ & $(0.1348)$ \\
\hline \multicolumn{5}{|c|}{ Locational characteristics } \\
\hline \multirow{3}{*}{$\begin{array}{l}\text { Household is } \\
\text { located in rural } \\
\text { area }\end{array}$} & $1.7731^{* * *}$ & 11711 & $17509^{* * *}$ & 13434 \\
\hline & & & & \\
\hline & $(0.2127)$ & $(0.3108)$ & $(0.2260)$ & $(0.2661)$ \\
\hline \multicolumn{5}{|c|}{ Region (omitted category is South Central Coast) } \\
\hline \multirow[t]{2}{*}{ Red River Delta } & $0.6602^{* *}$ & 0.6248 & $0.6576^{* *}$ & 0.6372 \\
\hline & $(0.1010)$ & $(0.2252)$ & $(0.1017)$ & $(0.2138)$ \\
\hline \multirow[t]{2}{*}{ North East } & $0.5815^{* *}$ & 12.191 & $0.5395^{* *}$ & 13.484 \\
\hline & $(0.1124)$ & $(0.3825)$ & $(0.1050)$ & $(0.4046)$ \\
\hline \multirow[t]{2}{*}{ North West } & $0.3739^{*}$ & $4.8000^{* * *}$ & $0.0845^{* * *}$ & $3.1388^{* *}$ \\
\hline & $(0.1453)$ & -19.710 & $(0.0539)$ & -11.368 \\
\hline \multirow{2}{*}{$\begin{array}{l}\text { North Central } \\
\text { Coast }\end{array}$} & 0.9564 & $0.4501^{* *}$ & 0.7995 & $0.3627^{* * *}$ \\
\hline & $(0.1534)$ & $(0.1335)$ & $(0.1282)$ & $(0.1013)$ \\
\hline $\begin{array}{l}\text { Central } \\
\text { Highlands }\end{array}$ & $0.4244^{* * *}$ & $0.4856^{*}$ & $0.6553^{*}$ & 0.6205 \\
\hline
\end{tabular}




\begin{tabular}{l|c|c|c|c} 
& $(0.0996)$ & $(0.1471)$ & $(0.1350)$ & $(0.1795)$ \\
South East & $0.3653^{* * *}$ & 0.6725 & $0.3483^{* * *}$ & 10.145 \\
Mekong River & $(0.0660)$ & $(0.2347)$ & $(0.0666)$ & $(0.3116)$ \\
Delta & $0.4568^{* * *}$ & 15.105 & $0.3716^{* * *}$ & 15.600 \\
& $(0.0732)$ & $(0.5402)$ & $(0.0745)$ & $(0.4341)$ \\
\hline \multicolumn{5}{|c}{ Model Specifications } \\
\hline Pseudo R-Square & 0.2321 & 0.2321 & 0.2036 & 0.2036 \\
chi2 & $4.1 \mathrm{e}+03$ & $4.1 \mathrm{e}+03$ & $4.0 \mathrm{e}+03$ & $4.0 \mathrm{e}+03$ \\
$p$ & 0.0000 & 0.0000 & 0.0000 & 0.0000 \\
\hline
\end{tabular}

Source: Authors' calculations from VHLSS 2006

Relative risk estimates for participation in group B for both the monetary and multidimensional poverty models point towards a number of factors that increase a child's probability to be included in the social welfare scheme without being poor. Living in households with older household heads as well as higher levels of education of the heads of household increase the child's probability to benefit from social welfare without being poor. Belonging to the ethnic majority, the presence of household members in working age of ill-health and living in rural areas also increase the probability to belong to group B rather than the non-poor group C. These factors for inclusion might be a reflection of the eligibility criteria for the various schemes listed under social welfare or issues relating to access and take-up. The age of the household head and presence of ill household members in working age is likely to be related to the eligibility for war invalids, veterans and survivor benefits. Heads of household having received more education might be better informed about how to apply for social welfare. Belonging to the ethnic majority might also make access to the social welfare programs easier. The probability to be included in the social welfare scheme without being poor is larger for children living in rural areas, which can be attributed to the fact that social subsidy benefits are larger in rural areas (Van de Walle 2004a). Regional results indicate that living in any other region than the reference region of South Central Coast decreases the probability to be included in the social welfare scheme without being poor.

Factors increasing the risk to be excluded from social welfare despite being poor are less pronounced. The risk to belong to group A rather than group AB increases when the household head is female or a skilled professional. The first exclusion factor might again reflect the eligibility for war invalids and veteran benefits, which is more likely to be biased towards men. Factors of exclusion that hold in the case of both monetary and multidimensional poverty include belonging to an ethnic minority and living in the North West region. The first finding underlines the disadvantaged position of ethnic minorities. The second finding confirms previous conclusions by Van de Walle (2004a) that poorer areas are less capable of reaching the poor or implementing the programme or both. 


\subsection{Social welfare and its impact on child poverty}

To measure the impact of social welfare on child poverty, we use benefit-incidence analysis to look into the case of monetary poverty. Given the available data, we were not able to perform an impact analysis for the case of multidimensional poverty

The effect of social welfare on monetary poverty is simulated without and with substitution effects. In the first case, we simply deduct the amount of social welfare received from income to establish the counterfactual. This assumes no replacement of income by means of changes in labour supply or other behavioural responses (Van de Walle 2003). However, households and individuals are likely to substitute and increase their income without social welfare through other means (Van de Walle 2003). As a result, the actual increase of income by social welfare is less than the amount transferred (Cuong and Van den Berg 2009). To account for this behavioral change, we also calculate the impact of social welfare on poverty including a substitution effect of 40 percent $^{62}$.

Table 7.8 Monetary poverty with and without social welfare

\begin{tabular}{l|c|c|c|c}
\hline & $\begin{array}{c}\text { Total } \\
\text { poverty }\end{array}$ & $\begin{array}{c}\text { Total poverty } \\
\text { gap }\end{array}$ & $\begin{array}{c}\text { Child } \\
\text { poverty }\end{array}$ & $\begin{array}{c}\text { Child poverty } \\
\text { gap }\end{array}$ \\
\hline Without substitution effect \\
\hline With social welfare & 15.8 & 3.8 & 22.6 & 5.8 \\
\hline Without social welfare & 17.4 & 4.7 & 23.7 & 6.6 \\
\hline With substitution effect & 15.8 & 3.8 & 22.6 & 5.8 \\
\hline With social welfare & 16.4 & 4.0 & 23.0 & 6.1 \\
\hline Without social welfare &
\end{tabular}

Source: Authors' calculations from VHLSS 2006

Estimations in Table 7.8 suggest that social welfare has a limited impact on poverty incidence and depth for the total population as well as children in specific. Using the counterfactual situation without the assumption of substitution effects indicates that the poverty incidence for the total population drops by 1.6 percentage points and the poverty gap drops by 0.9 percentage points when households receive social welfare. These changes are smaller in the case of child poverty, despite their more disadvantaged position. Child poverty incidence respectively drops by 1.1 percentage points and the child poverty gap by 0.8 percentage points. Effects are even smaller when we consider the counterfactual situation assuming a substitution effect. Poverty incidence for the total population only drops by 0.8 percentage points and for children by 0.6 percentage points when employing the social welfare scheme. The effect on poverty depth is also considerably smaller when assuming substitution

62 To account for the substitution effect and behavioral responses, we calculate the marginal propensity to consume out of social welfare income (see also Van de Walle, 2003, 2004a 2004 b and Cuong \& Berg, 2009). By regressing per capita expenditures against the per capita receipt of social transfers and individual and household characteristics, we find a marginal propensity to consume of 0.4 , which is in line with previous findings by Van de Walle (2003, 2004a, 2004b) and Cuong \& Berg (2009). This finding implies that a household would substitute a foregone transfer of 100 VND with 40 VND with income from other sources and per capita expenditures are reduced by 60 VND rather than 100 VND. 
effects. Generally, we can conclude that social welfare benefits have very little impact on monetary child poverty, which is in line with the previous findings of low coverage and considerable exclusion of poor children.

\subsection{Conclusion}

This study assessed the performance and the impact of social welfare benefits on child poverty in Vietnam, using both monetary and multidimensional poverty approaches. Although previous studies have shown that social protection in Vietnam is largely regressive in nature, no such study had been undertaken to assess the performance of specific programmes with respect to children. Findings in this study indicate that children are a disadvantaged group in society in terms of overall poverty as well as in relation to the receipt of social welfare. Furthermore, estimates suggest that social welfare has to little to no impact in terms of monetary child poverty.

Estimates indicate that monetary and food poverty is more prevalent amongst children in comparison to the total population and that this is accompanied by a slightly larger poverty gap. Child poverty is especially prevalent in rural areas, amongst ethnic minorities and in specific regions. The large regional disparities are captured differently by the monetary and multidimensional poverty approaches. Whilst the Mekong River Delta is amongst the regions with lowest monetary poverty incidence, it ranks amongst the regions with the highest incidence when considering multidimensional poverty.

An assessment of the targeting performance of social welfare indicates that the programme has limited coverage with considerable inclusion and exclusion errors in terms of both monetary and multidimensional poverty. Only a very small share of the total child population as well as the poor child population is covered, also in comparison to the size of informal transfers and social insurance benefits. In relation to the small coverage of the social welfare scheme, the inclusion error is considerable, being over half the size of the coverage rate. The receipt of social welfare is biased towards specific demographic groups that do not necessarily have the largest prevalence of poverty. Especially rural areas, the North West region and ethnic minorities hold a share of children receiving social welfare that is smaller than their share in poverty. Multinomial regression was used to identify factors contributing to the probability to be in- or excluded from the receipt of social welfare when poor or not poor. The risk to be excluded from the social welfare scheme despite being monetary poor increases when the head of household is female or a skilled professional. Being of ethnic minority or living in the North West region increases the exclusion risk for both monetary and multidimensionally poor children. The probability for a child to be a recipient of social welfare without being poor tends to increase when the heads of household are older or have higher levels of educational attainment or when he/she belongs to the ethnic majority. These strong factors contributing to the probability or risk of a child to be wrongfully covered or omitted from the social welfare scheme on the basis of their poverty status is in part a reflection of eligibility criteria as well as issues of access and take-up but also confirms that the scheme can not be considered to be pro-poor.

An impact analysis of the social welfare scheme suggests that it has limited effect on monetary child poverty, in terms of both incidence and depth. Poverty incidence 
and depth are only reduced by a few percentage points when comparing the situation with social welfare to the situation without social welfare. It is important to note, however, that the social welfare scheme under consideration here includes a number of programmes that are not designed to support the poor or targeted towards the poor. Hence, in terms of policy recommendations, this paper does not argue for the abolishment or re-design of the current social welfare scheme. However, it does point out that it is by no means a blessing for poor children in Vietnam and that the reduction of child poverty through any type of social scheme requires alternative policy options. 


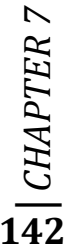


False Positives or Hidden Dimensions 143

Chapter 8

CONCLUSION 
This book addressed a number of issues related to the definition and measurement of child poverty and its implications for policy analysis. It contributes to both the academic and policy debate by filling specific conceptual and empirical gaps and by extending the debate beyond its current state of affairs. Chapter 2 addressed the need for child-focused approaches for poverty measurement that are developed in an explicit and transparent manner. This was practically illustrated by the development of a child poverty approach geared to the case of Vietnam. Chapter 3 provided an indepth empirical investigation into child poverty in Vietnam, exploring the use of a country-specific and multidimensional approach to the measurement of child poverty and providing extensive information about the situation of child poverty in Vietnam. The empirical analysis was extended in Chapter 4 by moving beyond a child poverty profile and investigating the distribution of child poverty and the existence of horizontal inequalities on the basis of monetary and multidimensional child poverty approaches. The tension between monetary and multidimensional approaches to poverty was elaborated upon in Chapter 5 by exploring the mismatch between the identification of poverty on the basis of these approaches in Vietnam and Congo and discussing the implications for policy design. Chapter 6 consequently provided an indepth investigation into differences in outcomes for child poverty on the basis of monetary and multidimensional child poverty approaches from different angles. Finally, both approaches were used to evaluate the performance of the social welfare in Vietnam in Chapter 7, thereby illustrating the implications of the use of different child poverty approaches for policy evaluation.

In sum, the contribution of the collection of chapters in this book lies in investigating three research issues put forward in the introduction of this book:

\section{1) The importance of choice and definition for the measurement of child poverty.}

2) Child poverty in Vietnam: who and where are the poor?

3) To what extent do monetary and multidimensional approaches of child poverty differ with respect to conceptual and empirical outcomes?

All three issues were discussed from both a conceptual and empirical viewpoint. Moreover, although this book is first and foremost an academic piece of writing, all chapters also have a strong policy component. The contributions of this book should move beyond the mere scientific debate and be relevant and of value added to those designing, monitoring and evaluating policies. Only through the inclusion of such a policy focus can we attempt to make this research relevant for its main subject; poor children. The book's main findings and contributions with respect to the three questions are discussed in greater detail in the following sections. We conclude this chapter by elaborating on needs and options for future research. 


\subsection{Under what conditions can child poverty approaches be developed and used?}

Despite worldwide acknowledgement that children deserve special attention in the poverty and development debate, they still remain an under-prioritized group when considering academic debates on poverty issues or the formulation of poverty reduction policies. The purpose of an approach especially geared to capture child poverty can be considered a knife that cuts both ways. On the one hand, it provides insight into and understanding of the specific situation of children, taking into account the dependence on their direct environment for the provision of basic needs, their specific basic needs requirements and the long-term adverse effects of a lack of basic needs. On the other hand, it facilitates the formulation of policy options to address exactly those issues that are relevant for children in the fight against child poverty.

The use of a generic construction process as a guide for the development of a child poverty approach facilitates and creates the enabling conditions for an explicit and transparent decision-making process with respect to the underlying conceptual framework, choice of domain(s) and indicator(s) and output measures. It should avoid the fallacy of many existent child poverty approaches that have been developed in an implicit and unclear manner. A lack of transparency and clarity makes a child poverty approach highly susceptible to misinterpretation and misunderstanding as choices made at each step in the process are subject to a degree of arbitrariness, normative decision-making and value judgments. A clear and transparent discussion of the choices at hand assists scholars, practitioners and policy makers in choosing the appropriate approach for their objectives and to adequately interpret the results and findings based on the specific approach. Empirical estimates of child poverty in Vietnam underline these findings by illustrating that choices with respect to definition of indicators, indicator thresholds and methodology have far-reaching implications for the concurrent poverty estimates. Sensitivity analyses suggest that a specific choice for indicator, threshold or methodology has the potential to in- or deflate the child poverty estimates at different levels of aggregation.

In sum, to be able to gain an insight into the issue of child poverty, one requires estimates and analysis based on an approach with a specific child focus. Consequently, to fully understand and rightfully interpret the estimates produced by a child poverty approach, one has to have transparent and full insight into its conceptual framework and technical foundation. The generic construction process guides an explicit development procedure and creates the enabling conditions to build transparent and child poverty approaches.

\subsection{What is the state of child poverty in Vietnam?}

The contributions in this book with respect to child poverty in Vietnam are both conceptual and empirical in nature and considered from a monetary and multidimensional perspective. It comprises the development of a country-specific and multidimensional child poverty approach, an extensive child poverty profile based on 
both monetary and multidimensional approaches, a distributional analysis and an analysis of the link between child poverty and social welfare. The analysis of Vietnam is also relevant beyond the country case as it touches upon fundamental issues with respect to the development and use of child poverty approaches for poverty analysis. As such, it is also extends the answer to the first research question as it illustrates the use of the generic construction process for the development a child poverty approach.

The generic construction process served as a guide for the development of the multidimensional and Vietnam-specific child poverty approach and ensured that the underlying rationale and purpose were made explicit, thereby leading to careful choices with respect to the concept, domains and indicators and outcome products. In addition to the commonly developed poverty headcount measure, the multidimensional child poverty approach also encompassed a measure for child poverty depth and severity at the level of the individual child. The correspondence of this set of poverty measures with the set of poverty measures widely used within the monetary approach enables the use of both approaches as a complement to or alternative of monetary child poverty estimates. Moreover, the careful development process of the specific approach for Vietnam as well as certain elements of the conceptual framework and output measures might be relevant beyond the countryspecific context and serve as a blueprint for similar exercises in other countries or contexts.

Empirical findings in this book highlighted a number of relevant issues with respect to child poverty in Vietnam, relating to groups of poor children, their characteristics and their degree and forms of poverty. The broad range of empirical findings will not be repeated here but limited to general conclusions. Firstly, one can observe large disparities between different demographic groups of children in Vietnam. Children living in the northern, mountainous regions and those belonging to an ethnic minority are most prone to poverty. Secondly, specific characteristics of the individual child, household or household head contribute to a child's monetary or multidimensional poverty risk. These risks are different depending on the poverty approach under consideration or whether a child lives in a rural or urban area. Notable is the importance of the educational attainment and employment status of the parents in reducing the risk towards poverty. The large disparities between demographic groups and the existence of factors significantly in- or decreasing a child's poverty risk suggest a large degree of horizontal inequality in Vietnam. Findings with respect to poverty at domain-level also point towards areas of wellbeing that are extremely pressing for children in Vietnam. Considerable progress remains to be made with respect to water, sanitation and leisure. Finally, the social welfare system in Vietnam appears to have little to no impact on child poverty.

To conclude, the combination of empirical evidence on child poverty in Vietnam on the basis of household survey data provides a new and wide range of information on the topic that was not available up to this point. The development of a multidimensional child poverty approach for the specific case of Vietnam and its use for poverty profiling and analysis can be considered a conceptual and methodological contribution beyond the country context. Specific elements of the child poverty approach developed for Vietnam, such as the extension of the poverty headcount measure to the poverty gap and severity measures, also have the potential to be introduced in similar exercises. 


\subsection{To what extent do monetary and multidimensional approaches of child poverty differ with respect to conceptual and empirical outcomes?}

A central theme throughout the majority of the longstanding debate on poverty measurement, and thus the chapters in this book, is the tension between monetary and multidimensional approaches towards the measurement of poverty. Conceptual drawbacks of the monetary approach have been widely documented in the existing literature, primarily as a justification for the development of a multidimensional approach to (child) poverty. Research on multidimensional child poverty measurement is still fairly novel but the existing range of studies, this book inclusive, also reveal a set of conceptual and methodological hurdles in the development and use of the multidimensional approaches. In addition to fundamental differences in conceptual and methodological underpinnings, empirical outcomes reveal that these two types of child poverty approaches are not always in agreement with each other. Concluding remarks on the book's main findings with respect to the use of monetary versus multidimensional approaches to child poverty measurement can be subdivided in two subjects: 1) implications of the use of one or both approaches for poverty analysis and 2) the way in which their outcomes feed into the processes of policy design, analysis, monitoring and evaluation.

\subsubsection{Monetary versus multidimensional child poverty - implications for poverty analysis}

The discussion in this book contributes to the debate on options and limitations of the monetary and multidimensional approaches with respect to child poverty analysis. Limitations of the monetary approach are primarily conceptual and methodological in nature but the data is widely available and its use widespread. The multidimensional approach is in part a response to the conceptual shortcomings of the monetary approach but faces limitations with respect to data availability and intuitive use of methods and poverty measures. Given the underlying possibilities and limitations inherent to the monetary and multidimensional approaches, a poverty analysis on the basis of a combination of both approaches ensures that conceptual shortcomings of one approach can be overcome by the use of the other. Such a combined analysis can prevent a child poverty analysis to be rejected purely on conceptual grounds and appeals to all users' theoretical ideas of child poverty.

Empirical findings illustrate that the underlying conceptual and theoretical differences between poverty approaches are matched by diverging empirical outcomes. This holds in the case of child as well as adult poverty. Deprivation with respect to monetary poverty is weakly correlated with deprivation in other domains of multidimensional poverty as well as composite multidimensional poverty. Findings suggest that one poverty approach cannot serve as a proxy for another poverty approach. The use of a specific poverty measure for any type of analysis requires careful consideration with awareness that outcomes are likely to diverge when a different measure is applied. A poverty analysis based on a combination of approaches can overcome the risk that a poverty analysis hinges on a one-sided conception of 
poverty. It provides a diversified picture of poverty, revealing that poverty outcomes are in part dependent on the underlying conceptual and theoretical assumptions about poverty. It also allows for the identification of the groups of poor captured by either one or both of the poverty approaches and an analysis of their specific characteristics. Children that are captured by both the multidimensional and monetary approaches can be considered ultra-poor as their poverty is most severe in terms of both approaches. An investigation of the characteristics and microdeterminants of the ultra-poor as well as those that are captured by only one of the poverty approaches extends the poverty analysis beyond a standard poverty profile and distributional analysis. Questions remain with respect to the underlying causality between different forms of poverty.

\subsubsection{Monetary versus multidimensional child poverty - what does it mean for policy analysis?}

The general finding of considerable poverty mismatch and the fact that different groups of society are affected differently by this mismatch has important implications for the policy debate. The value of this book with respect to the policy debate is twofold. First of all, findings suggest that policy monitoring and evaluation efforts can lead to different conclusions when based on a single poverty approach. The choice of a specific poverty approach could be used to the advantage of a specific policy and bias results in favour of the policy under consideration and vice versa. This could hold at the general level or at the level of specific demographic groups. Secondly, the analysis points out that targeting of policies on the basis of monetary poverty potentially has perverse effects for those identified as multidimensionally poor and vice versa. Targeting purely based on the identification of a single poverty measure automatically implies that those individuals only identified as poor by another measure are excluded. Findings suggest that specific demographic groups in society are more or less prone to be identified as poor by only one or both of the approaches, implying that policies targeted on a single measure of poverty are biased towards specific demographic groups of children. The awareness that different child poverty approaches have the potential to identify different groups of children as poor is important for conscious and sound policy design as well as transparent policy monitoring and evaluation. A combined use of approaches for poverty analysis, explicitly including an investigation into the overlap of poverty according to different models, reduces the potential bias resulting from the use of a single poverty approach.

Furthermore, findings suggest that there are a number of underlying characteristics of children that influence their probability to be identified by either one or both of the poverty approaches. Knowledge and awareness of these underlying factors is another important issue in terms of policy design. An in-depth analysis of the characteristics impacting the probability to be identified by either one or more poverty measures provides a more detailed understanding of the demographic groups at risk and underlying processes contributing to that risk.

In sum, the contributions in this book referring to the tension between monetary and multidimensional approaches to poverty culminate in a plea for child poverty analysis on the basis of a combination of approaches. Any attempt to simplify a 
complex issue such as child poverty by basing the analysis on a single approach only will result in a conceptual and empirical bias. The picture of child poverty itself as well as the policy outcomes will be skewed towards underlying conceptual and methodological foundations. Poverty and policy analysis on the basis of combined approaches will be more diversified, less partial and better able to identify different groups of poor children in society.

\subsection{Future research}

Although this book holds a number of contributions within the field of child poverty, it also reveals needs and options for future research. Firstly, additional studies aimed towards the development of child poverty approaches should test the use of the generic construction process. It proved to be a useful tool for the development of the child poverty approach for Vietnam, thereby giving it scope to serve as a guide for similar exercises. Nevertheless, further investigation is required to test its usability in other contexts. The applicability of the generic construction process within the general field of poverty definition and measurement should also be considered. Secondly, the extent to which the child poverty approach developed for Vietnam can provide a useful example for other child poverty approaches requires further research. Specific elements of the Vietnam-specific approach, such as the conceptual framework, methodology or poverty measures might prove relevant for other approaches, notwithstanding their specific context. The degree to which such elements can be transferred to other approaches without undermining their contextual elements should be studied further. Thirdly, further and more in-depth research is needed to gain greater insight and understanding of the underlying dynamics resulting in variation between different child poverty approaches. Additional research efforts should be directed towards the consolidation of monetary and multidimensional approaches to ensure that they provide consistent and coherent outcomes. Another issue of specific interest is the causality of poverty. With respect to those children that are captured by both the monetary and multidimensional poverty approaches, for example, the question arises whether there is a causal link between multiple forms of poverty and if so, what the direction of this causal link is. Longitudinal research will also improve the understanding of this issue.

In sum, whilst the contributions this book fills previous knowledge gaps and provides valuable information in the field of child poverty; it also presents a plea for more information and additional analysis. The collection of more information and pursuit of additional analysis should go beyond the mere satisfaction of academic interests but also address the needs of those in the policy field. Child poverty research can only be a serious attempt to address the issue of child poverty if it provides valuable input and tools for those designing, implementing and monitoring interventions. 


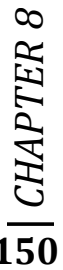




\section{$9 \quad$ References}

Alexandrova, A., Hamilton, E., \& Kuznetsova, P. (2006). What can be learned from introducing settlement typology into urban poverty analysis: the case of the Tomsk region, Russia. Urban Studies, 43(7), 1177-1189.

Alkire, S. (2002). Dimensions of Human Development. World Development, 30(2), 181205.

Alkire, S. (2007). Multidimensional Poverty: How to choose dimensions. Maitreyee, Human Development and Capability Association, Number 7.

Alkire, S. (2008). Choosing Dimensions: the Capability Approach and Multidimensional Poverty. In N. Kakwani \& J. Silber (Eds.), The Many Dimensions of Poverty. New York: Palgrave-Macmillan.

Alkire, S., \& Foster, J. (2008). Counting and Multidimensional Poverty Measurement: Oxford Poverty \& Human Development Initiative, OPHI Working Paper 7, OPHI.

Asselin, L.-M., \& Vu Tuan, A. (2005). Dynamic Poverty Analysis in Vietnam 1992-2002. Paper presented at the Many Dimensions of Poverty International Conference, Brasilia, 29-31 August 2005

Asselin, L.-M., \& Vu Tuan, A. (2005). Multidimensional Poverty Monitoring: a methodology and implementation in Vietnam (No. 2005-06): PEP.

Atkinson, A. B. (2003). Multidimensional deprivation: contrasting social welfare and counting approaches. Journal of Economic Inequality, 1, 51-65.

Atkinson, A. B., Marlier, E., \& Nolan, B. (2004). Indicators and Targets for Social Inclusion in the European Union. Journal of Common Market Studies, 42(1), 47-75.

Balisacan, A., Pernia, E., \& Estrada, G. (2004). Economic Growth and Poverty Reduction in Vietnam. In E. Pernia \& A. Deolalikar (Eds.), Poverty, Growth and Institutions in Developing Asia: Palgrave Macmillan.

Barnes, H., Wright, G., Noble, M., \& Dawes, A. (2007). The South African Index of Multiple Deprivation for Children: Census 2001. Cape Town: HSRC Press

Bastos, A., Fernandes, G., \& Passos, J. (2004). Child income poverty and child deprivation: an essay on measurement. International Journal of Social Economics, 31(11/12), 1050-1060.

Baulch, B., Chuyen, T. T. K., Haughton, D., \& Haughton, J. (2004). Ethnic Minority Development in Vietnam: A Socioeconomic Perspective. In P. Glewwe, N. Agrawal \& D. Dollar (Eds.), Economic Growth, Poverty and Household Welfare in Vietnam. Washington DC: World Bank

Baulch, B., Chuyen, T. T. K., Haughton, D., \& Haughton, J. (2007). Ethnic minority development in Vietnam. Journal of Development Studies, 43(7), 1151-1176.

Baulch, B., \& Masset, E. (2003). Do Monetary and Nonmonetary Indicators Tell the Same Story About Chronic Poverty? A Study of Vietnam in the 1990s. World Development, 31(3), 441-453.

Baulch, B., \& McCulloch, N. (2002). Being Poor and Becoming Poor: Poverty Status and Poverty Transitions in Rural Pakistan. Journal of Asian and African Studies, 37(2), 168-185. 
Ben-Arieh, A. (2000). Beyond Welfare: measuring and monitoring the state of children - new trends and domains. Social Indicators Research, 52(3), 235-257.

Biggeri, M. (2007). Choosing dimensions in the case of children's wellbeing. Maitreyee, Human Development and Capability Association, Number 7.

Blank, R. (2007). Analyzing Poverty and Anti-Poverty Policies in the US and Other Higher-Income Nations. Maastricht Graduate School of Governance, PhD lecture. Maastricht.

Bourguignon, F., \& Chakravarty, S. (2003). The measurement of multidimensional poverty. Journal of Economic Inequality, 1(1), 25-49.

Bourguignon, F., \& Pereira de Silva, L. (2003). The impact of economic policies on poverty and income distribution: Oxford University Press.

Boyden, J. (2006). Young Lives Project. Concepts and Analytical Framework. Young Lives Research Project

Bradbury, B., \& Jantti, M. (2001). Child poverty across industrialised world: evidence from the Luxembourg income study. In K. Vleminckx \& T. Smeeding (Eds.), Child Well-being: Child Poverty and Child Policy in Modern Nations: What Do We Know?. Bristol: The Policy Press.

Bradshaw, J. (2000). Child poverty in comparative perspective. In D. Gordon \& P. Townsend (Eds.), Breadline Europe. Bristol: Policy Press.

Bradshaw, J. (2008). Child Poverty and Well-Being. Social \& Public Policy Review, 1(1), 1-11.

Bradshaw, J., \& Finch, N. (2003). Overlaps in Dimensions of Poverty. Journal of Social Policy, 32, 513-525

Bradshaw, J., Hoelscher, P., \& Richardson, D. (2006). An Index of Child Well-being in the European Union. Social Indicators Research, 80(1), 133-177.

Bradshaw, J., \& Richardson, D. (2009). An Index of Child Well-Being in Europe. Child Indicators Research, 2(3), 319-351

Brooks-Gunn, J., \& Duncan, G. (1997). The Effects of Poverty on Children. The Future of Children, 7(2), 55-71.

Buvinic, M., \& Gupta, G. R. (1997). Female-Headed Households and Female-Maintained Families: Are They Worth Targeting to Reduce Poverty in Developing Countries. Economic Development and Cultural Change, 45(2), 259-280.

Cappelari, L., \& Jenkins, S. (2006). Summarizing Multiple Deprivation Indicators: ISER, University of Essex.

Centre for International Economics. (2002). Vietnam poverty analysis. Canberra and Sydney.

Chakravarty, S. (2006). An Axiomatic Approach to Multidimensional Poverty Measurement via Fuzzy Sets. In A. Lemmi \& G. Betti (Eds.), Fuzzy Set Approach to Multidimensional Poverty Measurement (Vol. 3): Springer US.

CHIP. (2004). Children and Poverty - some questions answered. CHIP Briefing No. 1. London

Corak, M. (2005). Principles and practicalities for measuring child poverty. Innocenti Working Paper No. 2005-01: UNICEF

Corak, M. (2006a). Do Poor Children become Poor Adults? Lessons from a Cross Country Comparison of Generational Earnings Mobility: IZA Discussion Paper No. 1993. Bonn: Institute for the Study of Labour (IZA).

Corak, M. (2006b). Principles and practicalities for measuring child poverty. International Social Security Review, 59(2), 3-36. 
Cox, D. (2004). Private interhousehold transfers in Vietnam. In P. Glewwe, N. Agrawal \& D. Dollar (Eds.), Economic Growth, Poverty and Household Welfare in Vietnam. Washington DC: World Bank.

Cuong, N. V., \& Van den Berg, M. (2009). Impact of Public and Private Transfers on Poverty and Inequality: Evidence from Vietnam: Mansholt Graduate School of Social Sciences

Delamonica, E. E. (2007). Poverty and Children: Policies to break the vicious cycle. Paper presented at the CROP/Childwatch Conference Rethinking Poverty and Children in the New Millennium: Linking Research and Policy, September 2007, Oslo, Norway.

Delamonica, E. E., \& Minujin, A. (2007). Incidence, Depth and Severity of Children in Poverty. Social Indicators Research, 82(2), 361-374.

Diekmann, A., \& Jann, B. (2008). Regression Models for Categorical Dependent Variables (Logit, Probit and Related Techniques). Paper presented at the ZA Spring Seminar 2008, Cologne.

Duncan, G., \& Brooks-Gunn, J. (1997). Consequences of Growing Up Poor. New York: Russell Sage Foundation.

DWP. (2002). Measuring Child Poverty, a Consultation Document. UK: Department for Work and Pensions (DWP).

Edmonds, E., \& Turk, C. (2004). Child labour in transition in Vietnam. In P. Glewwe, N. Agrawal \& D. Dollar (Eds.), Economic Growth, Poverty and Household Welfare in Vietnam: Washington DC. World Bank.

Esping-Andersen, G., \& Sarasa, S. (2002). The generational conflict reconsidered. Journal of European Social Policy, 12(1), 5-21.

Evans, M., Gough, I., Harkness, S., McKay, A., Thanh, H. D., \& Thu, N. D. L. (2007a). How Progressive is Social Security in Vietnam: Hanoi. UNDP

Evans, M., Gough, I., Harkness, S., McKay, A., Thanh, H. D., \& Thu, N. D. L. (2007b). The Relationship between Old Age and Poverty in Vietnam: Hanoi. UNDP

Evans, M., \& Harkness, S. (2008). Social Protection in Vietnam and Obstacles to Progressivity. Asian Social Work and Policy Review, 2(1), 30-52.

Glewwe, P. (2004a). An Investigation of the Determinants of School Progress. In P. Glewwe, N. Agrawal \& D. Dollar (Eds.), Economic Growth, Poverty and Household Welfare in Vietnam: Washington DC: World Bank

Glewwe, P. (2004b). An Overview of Economic Growth and Household Welfare in Vietnam in the 1990's. In P. Glewwe, N. Agrawal \& D. Dollar (Eds.), Economic Growth, Poverty and Household Welfare in Vietnam. Washington DC: World Bank

Gordon, D., Nandy, S., Pantazis, C., Pemberton, S., \& Townsend, P. (2003a). The Distribution of Child Poverty in the Developing World. Bristol, UK: Centre for International Poverty Research.

Gordon, D., Nandy, S., Pantazis, C., Pemberton, S., \& Townsend, P. (2003b). Child Poverty in the Developing World. Bristol: Policy Press.

Greene, W. (2002). Econometric Analysis (5th ed.): Prentice Hall.

Grootaert, C. (1997). The Determinants of Poverty in Côte d'Ivoire in the 1980's. Journal of African Economies, 6(2), 169-196.

GSO. (2007). Findings from the Viet Nam Multiple Indicator Cluster Survey 2006: Hanoi. GSO 
Hagerty, M., \& Land, K. (2007). Constructing Summary Indices of Quality of Life: A Model for the Effect of Heterogeneous Importance Weights. Sociological Methods Research, 35(4), 455-496.

Haughton, D., Haughton, J., \& Nguyen, P. (2001). Living Standards during an Economic Boom - the case of Vietnam. Hanoi: Statistical Publishing House Hanoi.

Haveman, R., \& Wolfe, B. (1995). The Determinants of Children's Attainments: A Review of Methods and Findings. Journal of Economic Literature, 33(4), 18291878.

Hulme, D., \& McKay, A. (2008). Identifying and Measuring Chronic Poverty: Beyond Monetary Measures? In N. Kakwani \& J. Silber (Eds.), The Many Dimensions of Poverty: New York. Palgrave Macmillan.

Justino, P. (2005). Beyond HEPR: A framework for an integrated national system of social insurance in Vietnam. Hanoi: UNDP.

Klasen, S. (2000). Measuring Poverty and Deprivation in South Africa. Review of Income and Wealth, 46(1), 33-58.

Kruijk, H. d., \& Rutten, M. (2007). Weighting Dimensions of Poverty Based on People's Priorities: Constructing a Composite Poverty Index for the Maldives: Q-Squared Working Paper No. 35

Laderchi, C. R. (1997). Poverty and its many dimensions: The role of income as an indicator. Oxford Development Studies, 25(3), 345-360.

Laderchi, C. R., Saith, R., \& Steward, F. (2003). Does it Matter that we do not Agree on the Definition of Poverty? A Comparison of Four Approaches. Oxford Development Studies, 31(3), 243-274.

Land, K. (2005). The Foundation for Child Development Index of Child Well-Being (CWI), 1975-2003 with Projections for 2004: Duke University, Durham, North Carolina.

Land, K., Lamb, V., \& Mustillo, S. K. (2001). Child and Youth Well-Being in the United States, 1975-1998: some findings from a new index. Social Indicators Research, 56(3), 241-320.

Lanjouw, P., \& Ravallion, M. (1995). Poverty and Household Size. The Economic Journal, 105(433), 1415-1434.

Layte, R., Nolan, B., \& Whelan, C. (2001). Reassessing Income and Deprivation Approaches to the Measurement of Poverty in the Republic of Ireland. The Economic and Social Review, 32(3), 239-261.

Long, S. (1997). Regression Models for Categorical and Limited Dependent Variables: Thousand Oaks, Sage.

Luzzi, G., Flückiger, Y., \& Weber, S. (2008). Multidimensional poverty: Factor and cluster analysis. In N. Kakwani \& J. Silber (Eds.), Quantitative Approaches to Multidimensional Poverty Measurement. London: Palgrave MacMillan.

Maltzahn, R. v., \& Durrheim, K. (2007). Is poverty multidimensional? A comparison of income and asset based measures in five Southern African countries. Social Indicators Research, 86(1), 149-162.

Marlier, E., Atkinson, A. B., Cantillon, B., \& Nolan, B. (2007). The EU and Social Inclusion: Facing the challenges. Bristol The Policy Press.

Micklewright, J. (2001). Should the UK government measure poverty and social exclusion with a composite index?: Florence. Innocenti Research Centre (IRC).

Minh Nguyen, T., \& Popkin, B. (2003). Income and Health Dynamics in Vietnam: Poverty Reduction, Increased Health Inequality. Population, 58(2), 253-264. 
Minot, N. (2000). Generating Disaggregated Poverty Maps: An Application to Vietnam. World Development, 28(2), 319-331.

Minot, N., \& Baulch, B. (2004). The Spatial Distribution of Poverty in Vietnam and the Potential for Targeting. In P. Glewwe, N. Agrawal \& D. Dollar (Eds.), Economic Growth, Poverty, and Household Welfare in Vietnam: Washington DC. World Bank.

Minujin, A., Delamonica, E., Gonzalez, E. and Al Davidziuk. (2005). Children Living in Poverty: a review of child poverty definitions, measurements and policies. Paper presented at the Unicef Conference Children and Poverty: Global Context, Local Solutions, New York, April 25-27, 2005.

Moore, K. A., Lippman, L., \& Brown, B. (2004). Indicators for Child-Well-Being: the Promise for Positive Youth Development. The ANNALS of the American Academy of Political and Social Science, 591(1), 125-145.

Moore, K. A., Vandivere, S., Lippman, L., McPhee, C., \& Bloch, M. (2007). An Index of the Condition of Children: The Ideal and a Less-than Ideal US Example. Social Indicators Research, 84(3), 291-331.

Nardo, M., Saisana, M., Saltelli, A., Tarantola, S., Hoffman, A., \& Giovannini, E. (2005). Handbook on Constructing Composite Indicators: Methodology and User Guide. OECD Statistics Working Papers (2005/3). OECD

Nguyen, B., Albrecht, J., Vroman, S., \& Westbrook, D. (2007). A quantile regression decomposition of urban-rural inequality in Vietnam. Journal of Development Economics, 83(2), 466-490.

Nguyen, H. (2003). Monitoring and Evaluation of the Comprehensive Poverty Reduction and Growth Strategy (C-PRGS) and the National Target Programme on Poverty Reduction and Employment. (HEPR: program 143): Hanoi. Ministry of Labour, Invalids and Social Affairs.

Niimi, Y., Pham, T. H., \& Reilly, B. (2008). Determinants of Remittances: Recent Evidence Using Data on Internal Migrants in Vietnam. World Bank Policy Review Paper No. 4586. World Bank

Noble, M., Wright, G., \& Cluver, L. (2006). Developing a Child-Focused and Multidimensional Model of Child Poverty for South Africa. Journal of Children and Poverty, 12(1), 39-53.

Nolan, B., \& Whelan, C. (2007). On the multidimensionality of poverty and social exclusion. In S. Jenkins \& J. Micklewright (Eds.), Inequality and Poverty Reexamined (pp. 146-165). Oxford: Oxford University Press.

Notten G. and C. de Neubourg (2007a), Relative or absolute poverty in the US and the EU? The battle of the rates. Maastricht: Maastricht Graduate School of Governance, MGSoG Working Paper 2007/001.

Notten G. and C. de Neubourg (2007b), Poverty in Europe and the USA, exchanging official measurement methods. Maastricht: Maastricht Graduate School of Governance, MGSoG Working Paper 2007/005.

Notten, G., B. Makosso and A. Mpoue (2008), La pauvreté multidimensionelle des enfants et des femmes en Républic du Congo, Brazzaville UNICEF Congo

Notten, G. (2008), Multidimensional Poverty in the Republic of Congo: Being Poor Simultaneously in Many Ways. Manchester: Brooks World Poverty Institute. BWPI Working Paper 65.

Nussbaum, M. (1992). Human Functioning and Social Justice. Politicial Theory, 20(2), 202-246. 
Nussbaum, M. (2000). Women and Human Development: The capabilities approach. New York: Cambridge University Press.

Perry, B. (2002). The Mismatch between Income Measures and Direct Outcome Measures of Poverty. Social Policy Journal of New Zealand, 19, 101-127.

Phung, D. T. (2004). Poverty line, poverty measurement, monitoring and assessment of $M D G$ in Vietnam: Hanoi. GSO.

Pincus, J., \& Sender, J. (2006). Quantifying Poverty in Vietnam: Hanoi, UNDP, School of Oriental and African Studies.

Pincus, J., \& Sender, J. (2008). Quantifying Poverty in Viet Nam: Who Counts? Journal of Vietnamese Studies, 3(1), 108-150.

Poverty Task Force. (2002a). Achieving the Vietnam Development Goals: An overview of progress and challenges. Hanoi: World Bank.

Poverty Task Force. (2002b). Eradicating Poverty and Hunger. Hanoi.

Quisumbing, A., Brown, L., Feldstein, H. S., Haddad, L., \& Pena, C. (1995). Women: they key to food security: Washington DC. The International Food Policy Research Institute

Quisumbing, A., Haddad, L., \& Pena, C. (2001). Are women overrepresented among the poor? An analysis of poverty in 10 developing countries. Journal of Development Economics, 66(1), 225-269.

Qvortrup, J. (1997). Indicators of childhood and intergenerational dimension. In A. Ben-Arieh \& H. Wintersberger (Eds.), Monitoring and Measuring the State of Children - Beyond Survival (pp. 101-112). Vienna: European Centre for Social Welfare Policy and Research.

Qvortrup, J. (1999). The Meaning of Child's Standard of Living. In A. Bowers Andrews \& N. Hevener Kaufman (Eds.), Implementing the UN Convention on the Rights of the Child: A standard of living adequate for development: Praeger Publishers.

Ravallion, M. (1994). Poverty Comparisons: Harwood Academic Publishers.

156 Ravallion, M., \& Wodon, Q. (1999). Poor Areas, or only Poor People? Journal of Regional Science, 39(4), 689-711.

Redmond, G. (2008). Child poverty and child rights: Edging towards a definition. Journal of Children and Poverty, 14(1), 63-82.

Richardson, D., Hoelscher, P., \& Bradshaw, J. (2008). Child well-being in the CEE and the CIS. Child Indicators Research, 1(3), 211-250.

Robeyns, I. (2003). The Capability Approach: An Interdisciplinary Introduction: University of Amsterdam, Amsterdam.

Robeyns, I. (2005). Selecting Capabilities for Quality of Life Measurement. Social Indicators Research, 74(1), 191-215.

Robeyns, I. (2006). The Capability Approach in Practice The Journal of Political Philosophy, 14(3), 351-376.

Roelen, K., Gassmann, F., \& Neubourg, C. d. (2006). Discussion Paper Child Vulnerability to Poverty Indices for Vietnam. Hanoi: UNICEF Vietnam, Maastricht Graduate School of Governance.

Roelen, Keetie and Franziska Gassmann (2008) Measuring Child Poverty and WellBeing: a literature review. Maastricht: Maastricht Graduate School of Governance Working Paper, MGSoG WP 2008/001.

Roelen, K., Gassmann, F., \& Neubourg, C. d. (2009a). The Importance of Choice and Definition for the Measurement of Child Poverty- the case of Vietnam. Child Indicators Research, 2(3), 245-263. 
Roelen, Keetie, Franziska Gassmann and Chris de Neubourg (2009b) Child Poverty in Vietnam - providing insights using a country-specific and multidimensional model, Social Indicators Research, DOI: 10.1007/s11205-009-9522-X

Roelen, K., Gassmann F. \& Neubourg, C. de (2009c) False Positives and Hidden Dimensions - what can monetary and multidimensional measurement tell us about child poverty? Maastricht: Maastricht Graduate School of Governance, mimeo

Sahn, D., \& Stifel, D. (2003). Exploring Alternative Measures of Welfare in the Absence of Expenditure Data. Review of Income and Wealth, 49(4), 463-489.

Save the Children. (2008). The Child Development Index: Save the Children UK.

Schreiner, M. (2007). A Simple Poverty Scorecard for the Philippines: Center for Social Development, Washington University.

Sen, A. (1976). Poverty: an ordinal approach to measurement. Econometrica, 44(2), 219-231.

Sen, A. (1979). Issues in the Measurement of Poverty. The Scandinavian Journal of Economics, 81(2), 285-307.

Sen, A. (1982). Poverty and Famines: An Essay on Entitlement and Deprivation. Oxford, UK: Oxford University Press.

Sen, A. (1985). Commodities and Capabilities. Oxford, UK: Oxford University Press.

Sen, A. (1993). Capability and Well-Being. In M. Nussbaum \& A. Sen (Eds.), The Quality of Life. Oxford: Oxford University Press.

Sen, A. (1999). Development as Freedom. Oxford: Oxford University Press.

Silva, I. D. (2008). Micro-level determinants of poverty reduction in Sri Lanka: a multivariate approach. International Journal of Social Economics, 35(3), 140158.

Socialist Republic of Vietnam (2004) Law on Protection, Care and Education of Children, Socialist Republic of Vietnam, No. 14/2004/L-CTN

Stewart, F. (2002). Horizontal Inequalities: A Neglected Dimension of Development. Paper presented at the WIDER Annual Lectures 5, Helsinki

Streeten, P. (1981). First Things First: Meeting Basic Human Needs in Developing Countries. New York: Oxford University Press.

Streeten, P. (1984). Basic Needs: Some Unsettled Questions. World Development 12(9), 973-978.

Tanton, R., Harding, A., Daly, A., McNamara, J., \& Yap, M. (2006). Children at risk of Social Exclusion. Methodology and Overview. Paper presented at the International Geographic Union Conference, Brisbane, 3-7 July 2006.

Taylor, P. (2004). Social Inequality in Vietnam and the Challenges to Reform: Institute of South East Asian Studies.

Thorbecke, E. (2005). Multi-dimensional Poverty: Conceptual and Measurement Issues. Paper presented at the Many Dimensions of Poverty International Conference, Brasilia, 29-31 August 2005

Thorbecke, E. (2008). Multidimensional Poverty: Conceptual and Measurement Issues. In N. Kakwani \& J. Silber (Eds.), The Many Dimensions of Poverty. New York: Palgrave Macmillan.

Tsui, K.-y. (2002). Multidimensional Poverty Indices. Social Choice and Welfare, 19(1), 69-93.

United Nations. (2007). UN Millennium Development Goals. Retrieved 15-12, 2007, from http://www.un.org/millenniumgoals/\# 
UNDP. (2007). Human Development Report. Retrieved 18-01-2008, 2008, from http://hdr.undp.org/en/

UNDP, \& MOLISA. (2004). Taking Stock, Planning Ahead: Evaluation of the National Targeted Programme on Hunger Eradication and Poverty Reducation and Programme 135: Hanoi. UNDP. MOLISA

UNHCHR. (1989). Convention on the Rights of the Child (Vol. General Assembly resolution 44/25): UNHCHR.

UNICEF. (2005). Child Poverty in Rich Countries Report Card No. 6: Florence. Innocenti Research Centre

Van de Walle, D. (2004a). The Static and Dynamic Incidence of Vietnam's Public Safety Net. In P. Glewwe, N. Agrawal \& D. Dollar (Eds.), Economic Growth, Poverty, and Household Welfare in Vietnam. Washington DC: World Bank.

Van de Walle, D. (2004b). Testing Vietnam's Public Safety Net. Journal of Comparative Economics, 32(4), 661-679.

Vandivere, S., \& McPhee, C. (2008). Methods for Tabulating Indices of Child Well-Being and Context: An Illustration and Comparison of Performance in 13 American States. Child Indicators Research, doi: 10.1007/s12187-008-9009-3.

VASS. (2006). Vietnam Poverty Update Report: Poverty and Poverty Reduction in Vietnam 1993-2004: Hanoi. Vietnamese Academy of Social Sciences.

VDR. (2008). Vietnam Development Report 2008: Social Protection. Hanoi: Joint Donor Report to the Consultative Group Meeting.

Waddington, H. (2004). Linking Economic Policy to Childhood Poverty: a review of the evidence on growth, trade reform and macroeconomic policy. CHIP Report No. 7. CHIP

Wagle, U. (2002). Rethinking Poverty: definition and measurement. International Social Science Journal, 54(171), 155-165.

Wagle, U. (2009). Capability Deprivation and Income Poverty in the United States, 1994 and 2004: Measurement Outcomes and Demographic Profiles. Social Indicators Research, 94(3), 509-533.

Watson, V., Sutton, M., Dibben, C., \& Ryan, M. (2008). Deriving weights for the Index of Multiple Deprivation based on societal preferences: The application of a discrete choice experiment: OPHI Working Paper No. 23. OPHI.

Whelan, C., Layte, R., \& Maitre, B. (2004). Understanding the Mismatch Between Income Poverty and Deprivation: A Dynamic Comparative Analysis. European Sociological Review, 20(4), 287-302.

White, H., Leavy, J., \& Masters, A. (2003). Comparative Perspectives on Child Poverty: A review of poverty measures Journal of Human Development, 4(3), 379-396.

White, H., \& Masset, E. (2002a). Child Poverty in Vietnam: Using Adult Equivalence Scales to Estimate Income-Poverty for Different Age Groups (No. 6).

White, H., \& Masset, E. (2002b). Constructing the Poverty Profile: An Illustration of the Importance of Allowing for Household Size and Composition in the Case of Vietnam, Young Lives Working Paper No. 3, Young Lives Research Project.

White, S. (2002). Being, Becoming and Relationship: conceptual challenges of a child rights approach in development. Journal of International Development, 14(8),1095-1104.

Wodon, Q. (1997). Targeting the Poor Using ROC Curves. World Development, 25(12), 2083-2092. 
False Positives or Hidden Dimensions | 159

Wodon, Q. (2000). Micro determinants of consumption, poverty, growth and inequality in Bangladesh. Applied Economics 32(10), 1337-1352.

Young Lives. (2001). Summary of the Young Lives Conceptual Framework. Retrieved 06-11, 2006, from www.younglives.org.uk 


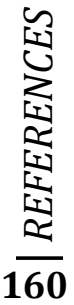




\section{Samenvatting}

Kinderarmoede is een ongewenst, en voor velen, onaanvaardbaar fenomeen. De redenen hiervoor zijn enerzijds gerelateerd aan het intrinsieke belang van welzijn voor kinderen in het hier en nu en anderzijds aan de toekomstige gevolgen van het opgroeien in armoede. Ieder kind, zoals ieder mens, heeft het recht op een minimaal niveau van welzijn en standaard van leven. Daarnaast weten we dat een gebrek aan welzijn tijdens de kinderjaren verregaande negatieve gevolgen kan hebben voor de ontwikkeling van het kind en standaard van leven als volwassene. Metingen van de situatie van kinderarmoede zijn cruciaal om een inzicht te krijgen in de verschillende facetten van het probleem en om mogelijke oplossingen te kunnen formuleren in de vorm van beleid. De erkenning van dit belang heeft in het afgelopen decennium geleid tot een groeiend aantal studies naar kinderarmoede en de meting ervan. Dit proefschrift behandelt drie verschillende onderwerpen met betrekking tot kinderarmoede en de meting en bestrijding ervan. Het bouwt daarbij op bestaande studies en draagt bij aan het onderzoeksspectrum door nieuwe inzichten toe te voegen aan de academische en beleidsdiscussie. Ten eerste bespreekt het proefschrift het belang van definitie en een duidelijk keuzeproces in de ontwikkeling van maatstaven voor kinderarmoede en wordt er een generiek constructie proces voorgesteld. Ten tweede wordt het generieke constructie proces getoetst doormiddel van een toepassing op data van Vietnam en wordt er een uitgebreide empirische analyse van de kinderarmoede in Vietnam gegeven. Deze empirische studie biedt een gedetailleerd inzicht in de specifieke situatie in Vietnam zowel als een voorbeeld voor soortgelijke analyses. Als laatste worden de verschillen in uitkomsten van het gebruik van monetaire versus multidimensionele maatstaven van kinderarmoede onderzocht en besproken vanuit een onderzoeks- zowel als beleidsperspectief.

Een overzicht van bestaande studies naar kinderarmoede maakt duidelijk dat veel van de gebruikte methoden en maatstaven op een impliciete en onduidelijke manier zijn ontwikkeld. En dat terwijl er veel keuzes gemaakt dienen te worden in de constructie van een methode om kinderarmoede te meten, zoals over het concept, welvaartsaggregaat en gebruik van armoedelijnen. Een gebrek aan inzicht in de processen die de uiteindelijke keuzes tot stand brengen kan tot een onjuist begrip en interpretatie van de situatie met betrekking tot kinderarmoede leiden. Inzicht in de keuze processen die ten grondslag liggen aan de constructie van armoede methoden en maatstaven zowel als duidelijkheid over de argumenten voor het maken van bepaalde beslissingen kan deze problemen voorkomen en een juist begrip van de situatie bevorderen. In dit proefschrift wordt een generiek constructie proces voorgesteld dat dient als een richtlijn voor degenen die een methode voor de meting van kinderarmoede ontwikkelen. Dit generieke constructie proces is afgeleid van een analyse van bestaande studies en de impliciete keuze processen gemaakt in deze studies. Het volgen van het generieke constructie proces als richtlijn leidt tot een expliciete discussie rond de keuzes die gemaakt moeten worden met betrekking tot de verschillende stappen in het proces. Deze stappen omvatten de identificatie van het doel en de reden voor de specifieke meting en studie van kinderarmoede, de 
formulering van een conceptueel kader van kinderarmoede, de selectie van domeinen en indicatoren die het conceptuele kader vertegenwoordigen en de constructie van armoede cijfers. De keuze in ieder van deze stappen is afhankelijk van de keuze die gemaakt is in de voorgaande stappen, vandaar dat het van belang is iedere stap in de voorgestelde volgorde gedetailleerd te overwegen. Het voorgestelde generieke constructie proces in dit proefschrift vormt een bijdrage aan het onderzoeks- zowel als beleidsdebat met betrekking tot kinderarmoede.

Naast een theoretische discussie over het generieke constructie proces, wordt deze ook toegepast op de situatie in Vietnam. Vervolgens wordt nationale enquête data over, onder andere, huishoudinkomen, onderwijs, gezondheidszorgen en levensomstandigheden gebruikt om de ontwikkelde multidimensionele methode te testen en een uitgebreid armoede profiel van Vietnamese kinderen te verkrijgen. Dit armoede profiel bevat naast informatie over multidimensionele armoede ook cijfers over monetaire kinderarmoede, onderverdeeld naar geslacht, regio, landelijke versus stedelijke gebieden, etniciteit en leeftijdgroep. Ook bevat dit proefschrift een onderzoek naar de distributie van kinderarmoede over de verschillende bevolkingsgroepen in Vietnam en een analyse van de relatie tussen het sociale bijstandssysteem en kinderarmoede in het land. Daarmee draagt het bij aan de conceptuele zowel als empirische discussie over kinderarmoede in de specifieke context van Vietnam. Bovendien zijn een aantal aspecten ook relevant in buiten deze context en van meer algemene waarde.

De toepassing van het generieke constructie proces heeft geleid tot de ontwikkeling van een transparante en weloverwogen methode voor de meting van kinderarmoede in Vietnam. De multidimensionele maatstaf is contextspecifiek (in tegenstelling tot generiek en toepasbaar in andere landen of regio's), gericht op uitkomsten (in tegenstelling tot "input" zoals beleidsfinanciering of aanwezige infrastructuur) en gericht op de situatie van kinderen zelf (in tegenstelling tot een focus op huishoudniveau). De geïdentificeerde dimensies binnen de maatstaf zijn onderwijs, gezondheid, onderdak, water en sanitaire voorzieningen, kinderarbeid, vrije tijdsbesteding en sociale integratie en bescherming. Binnen deze dimensies zijn vervolgens indicatoren geïdentificeerd op basis van discussies met beleidsmakers, achtergrondliteratuur, publieke consensus documenten (zoals de Millennium Development Goals en het Kinderrechtenverdrag) en de beschikbare enquête data. Aggregatie van de informatie op indicator en dimensie niveau wordt vervolgens geaggregeerd om de armoede situatie voor alle kinderen in Vietnam te schatten. Doormiddel van de expliciete discussie rondom de ontwikkeling van de armoedemaatstaf zullen de uitkomsten beter te begrijpen en te interpreteren zijn. De wijze waarop de Vietnam-specieke maatstaf voor kinderarmoede is ontwikkeld kan bovendien dienen als voorbeeld voor andere studies. De constructie van geaggregeerde armoede schattingen heeft naast een meting van de frequentie van armoede bovendien geleid tot een meting van de diepte en sterkte van armoede. De specifieke methoden voor de meting van de diepte en sterkte van kinderarmoede verschillen van eerder voorgestelde methoden in andere studies en zijn ook toepasbaar in contexten buiten de Vietnamese context.

De empirische uitkomsten van de analyse in dit proefschrift leiden tot een aantal interessante conclusies met betrekking tot kinderarmoede in Vietnam, de specifieke bevolkingsgroepen die getroffen worden, hun karakteristieken en mate en 
vorm van armoede. Er is weinig tot geen bewijs voor ongelijkheid tussen jongen en meisjes maar er bestaan grote verschillen tussen kinderen die in stedelijke of landelijke gebieden of verschillende regio's wonen en tussen groepen met verschillende etniciteit. Kinderen die in landelijke gebieden of in de noordelijke, bergachtige regio's wonen zowel als de kinderen van een etnische minderheidsgroep hebben een grotere kans getroffen te worden door armoede in zowel multidimensionele en monetaire zin. De specifieke karakteristieken van het individuele kind, het huishouden of hoofd van het huishouden kunnen bijdragen aan een vermindering of vergroting van het risico voor een kind om arm te zijn maar dit is sterk afhankelijk van de specifieke armoede maatstaf (multidimensioneel of monetair) en of een kind in een landelijk of stedelijk gebied woont. Het belang van het onderwijsniveau en de positie in de arbeidsmarkt van het hoofd van het huishouden blijkt echter van groot belang voor de verkleining van het armoede risico in alle gevallen. De grootste problemen die kinderen in Vietnam ondervinden betreffen de dimensies van onderdak, water en sanitair en vrije tijdsbesteding. Uit de analyse van het sociale bijstandssysteem in Vietnam blijkt dat dit weinig tot geen invloed heeft op de situatie van kinderarmoede in Vietnam.

Een centraal thema in het gevestigde debat over de meting van armoede is de spanning tussen monetaire en multidimensionele armoede maatstaven. De monetaire meting van armoede gebeurt al ruim een eeuw maar heeft een aantal conceptuele en technische tekortkomingen en nadelen. Veelal als gevolg van deze tekortkomingen is men in de jaren tachtig van de vorige eeuw begonnen met de ontwikkeling van multidimensionele armoede maatstaven. Hoewel onderzoek op dit gebied dus nog redelijk nieuw is in vergelijking met die van monetaire armoede, stuiten de bestaande studies ook op conceptuele en technische hindernissen in de meting van multidimensionele armoede. Naast de fundamentele verschillen in concept en methode die de monetaire en multidimensionele armoede maatstaven van elkaar onderscheiden, leiden empirische resultaten ook tot verschillende conclusies met betrekking tot kinderarmoede. De verschillen in conclusies als gevolg van het gebruik van monetaire versus multidimensionele maatstaven is van belang voor zowel het onderzoeks- als beleidsveld.

Zoals gezegd kent de monetaire manier van armoedemeting conceptuele en methodologische bezwaren en is de ontwikkeling van multidimensionele maatstaven van armoede veelal een reactie op deze bezwaren. Multidimensionele methoden worden op hun beurt echter weer geplaagd door een gebrek aan data en het intuïtieve gebruik van metingen en maatstaven. Gegeven dat beide methoden stuiten op problemen die conceptueel en methodologisch van aard zijn, kan het gebruik van een combinatie van methoden voor de meting van kinderarmoede de tekortkomingen van de andere methode compenseren. Het gecombineerde gebruik van methoden voor de meting van kinderarmoede kan vervolgens voorkomen dat studies, of hun resultaten, worden afgewezen puur op basis van conceptuele en methodieke bezwaren. Empirische resultaten onderschrijven het belang van een gecombineerd gebruik van kinderarmoede maatstaven. Monetaire armoede blijkt zwak gecorreleerd met multidimensionele armoede en zijn beiden armoedemaatstaven slechte "proxies" voor elkaar. De groep kinderen die wordt geïdentificeerd als arm in monetaire zin is slechts gedeeltelijk hetzelfde als de groep kinderen die wordt geïdentificeerd in multidimensionele zin, suggererende dat beide methoden verschillende vormen van 
armoede identificeren. De kinderen die arm worden bevonden in monetaire zowel als multidimensionele zin kunnen als "ultra-arm" beschouwd worden aangezien hun diepte en sterkte in monetaire en multidimensionele zin het grootste is. Het simultane gebruik van armoede maatstaven leidt dus tot een zorgvuldigere analyse van de situatie van kinderarmoede vanuit een conceptueel en theoretisch zowel als empirisch oogpunt.

De bevinding dat het gebruik van verschillende armoedemaatstaven kan leiden tot de identificatie van verschillende groepen kinderen en dus tot uiteenlopende conclusies is niet alleen van belang voor de onderzoekswereld maar zeker ook voor de beleidswereld. Het belang van deze resultaten in een beleidscontext heeft twee kanten. Ten eerste leiden deze resultaten tot het inzicht dat conclusies van beleidsevaluaties op basis van slechts één armoedemaatstaf sterk afhankelijk zijn van de gekozen armoedemaatstaf. Men kan dus een specifieke armoedemaatstaf kiezen voor de evaluatie van beleid die ten gunste is van het specifieke beleid en daarbij minder gunstige uitkomsten negeren. Dit kan gelden op een landelijk of algemeen niveau of voor specifieke bevolkingsgroepen. Het gecombineerde gebruik van armoedemaatstaven kan deze potentiële vertekening van beleidsresultaten gedeeltelijk wegnemen en een zuiverder beeld van de daadwerkelijke uitkomsten schetsen. Ten tweede wijzen de resultaten in dit proefschrift erop dat het richten van beleidsinitiatieven of toekennen van uitkeringen op basis van slechts één armoedemaatstaf leidt tot de uitsluiting van groepen kinderen met een bepaalde mate van armoede of kwetsbaarheid die niet door de specifieke armoedemaatstaf wordt onderkend. Aangezien kinderen van specifieke bevolkingsgroepen of wonende in bepaalde gebieden een grotere kans hebben om door slechts één van de armoedemaatstaven als arm te worden aangemerkt, hebben zij een grotere kans op marginalisatie en uitsluiting van beleidsinitiatieven. Het gebruik van complementaire armoedemaatstaven kan leiden tot een coherenter beleid met minder uitsluiting van kwetsbare groepen kinderen van beleidsinitiatieven als gevolg. In andere woorden, doormiddel van de verbetering van beleidsevaluaties zowel als de identificatie van arme en kwetsbare groepen kan er beter vorm gegeven worden aan beleid dat erop is gericht kinderarmoede uit de wereld te helpen. 


\section{Biography}

Keetie Roelen was born in 1981 and grew up in the Netherlands. She started her studies in International Economic Studies (IES) at the Faculty of Economics and Business Administration (now School of Business and Economics) of Maastricht University in 1999. After pursuing a specialization in development economics and a student exchange at the Charles University in Prague, she obtained her MSc. in August 2003. Her Master thesis was entitled "The Relationship between Poverty and Growth in Sub-Saharan Africa".

After her studies, Keetie pursued an internship at the Poverty Unit in UNDP Namibia and worked for Gassmann Consulting on social assistance in the Netherlands. She started working as a researcher, lecturer and course coordinator at the Faculty of Economics and Business Administration of Maastricht University in September 2004. In August 2005, Keetie joined the Maastricht Graduate School of Governance (MGSoG), where she carried different responsibilities. She was coordinator for the Master programme in Public Policy and Human Development (MPP) from August 2005 to August 2007 and acted as coordinator and lecturer for various Master courses. In addition, she worked on numerous research and training projects for the World Bank and UNICEF, amongst others, in Albania, Moldova, Kosovo, Bosnia Herzegovina, Vietnam, Myanmar and Senegal. Keetie's expertise lies in the field of child poverty, poverty measurement and social policy evaluation.

Keetie started the pursuit of her PhD in September 2006 with a research project commissioned by UNICEF Vietnam. Her PhD specifically focuses on the definition and measurement of child poverty and their relevance for policy-making and evaluation. Keetie has published her research in international peer-reviewed journals and book volumes and has presented her research at numerous international conferences. 


\section{MGSoG Dissertation Series}

Denisa Maria Sologon

Earning Dynamics in Europe

MGSoG Dissertation Series, nr. 7 (2010)

Melissa Siegel

Money and Mobility: Migration and Remittances

MGSoG Dissertation Series, nr. 6 (2010)

Jessica S. Hagen-Zanker

Modest Expectations: Causes and effects of migration on migrant households in source countries

MGSoG Dissertation Series, nr. 5 (2010)

Mirtha R. Muniz Castillo

Human Development and Autonomy in Project Aid: Experiences from four bilateral projects in Nigaragua and El Salvador

MGSoG Dissertation Series, nr. 4 (2009)

Christiane Arndt

166 Governance Indicators

MGSoG Dissertation Series, nr. 3 (2009)

Britta Augsburg

Microfinance - Greater Good or Lesser Evil?

MGSoG Dissertation Series, nr. 2 (2009)

Geranda Notten

Measuring and Managing Poverty Risks

MGSoG Dissertation Series, nr. 1 (2008) 